Universidad de Lima

Facultad de Economía

Carrera de Economía

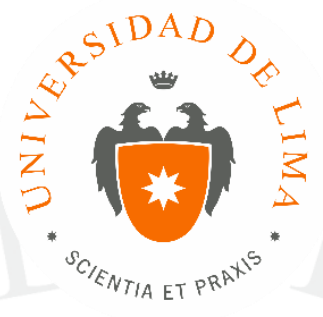

\title{
PRUEBA DE ESTRÉS DE RIESGO DE CRÉDITO, MERCADO Y LIQUIDEZ EN LA BANCA MÚLTIPLE DEL PERÚ
}

Trabajo de investigación para optar el título profesional en Economía

\author{
Alan Richard Rodríguez Manrique \\ Código 20100965 \\ Asesor \\ Jorge Amadeo Medicina Di Paolo \\ Juan Antonio Ramírez Andueza
}

Lima - Perú

Abril de 2016 


\section{PRUEBA DE ESTRÉS DE RIESGO DE CRÉDITO, MERCADO Y LIQUIDEZ EN LA BANCA MÚLTIPLE DEL PERÚ}




\section{TABLA DE CONTENIDO}

CAPÍTULO I: BASILEA Y LAS PRUEBAS DE ESTRÉS 12

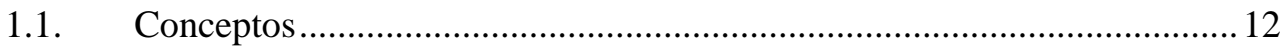

1.1.1. Comité de Supervisión Bancaria de Basilea ............................................17

1.1.1.1. Antecedentes a Basilea III......................................................................... 19

1.1.1.2. Basilea I: Acuerdo de Capital de Basilea ................................................... 19

1.1.1.3. Basilea II: Nuevo Marco de Capital ........................................................20

1.1.1.4. Hacia Basilea III............................................................................... 21

1.1.2. Normas de regulación de Basilea III .....................................................21

1.1.3. Regulación vigente en el Perú ...............................................................24

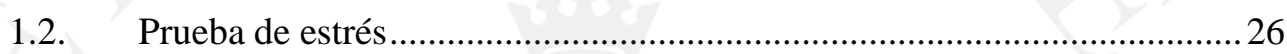

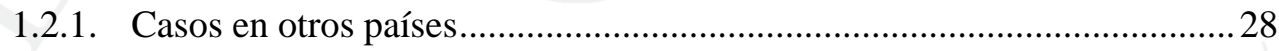

1.3. Literatura correspondiente a las Pruebas de Estrés ...................................29

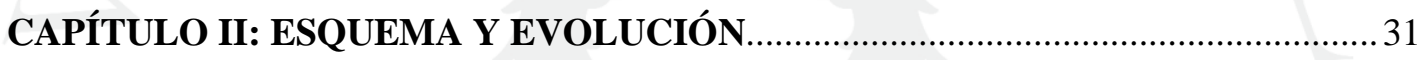

2.1. Descripción de los agentes económicos ..................................................... 31

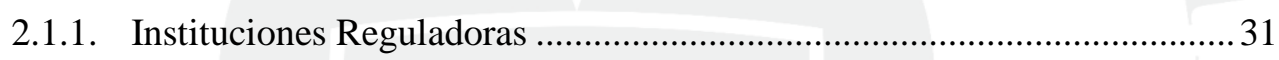

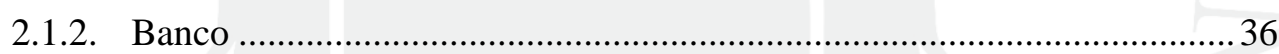

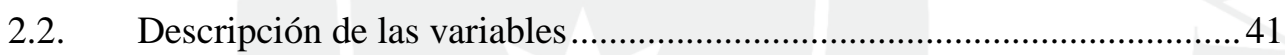

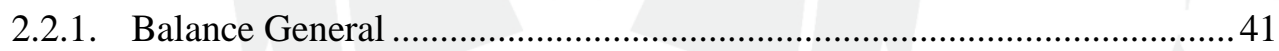

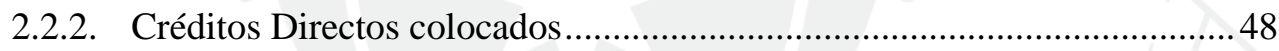

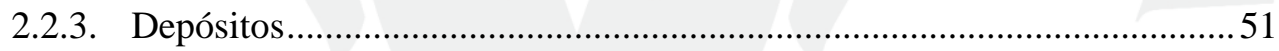

2.2.4. Adeudos y obligaciones con entidades nacionales y del exterior...............53

2.2.5. Indicadores de Morosidad y Calidad de Cartera .........................................56

2.2.6. Estado de Resultados (Estado de Ganancias y Pérdidas) ...........................61

2.2.7. Producto Bruto Interno..........................................................................66

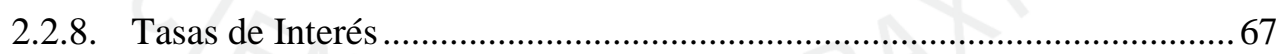

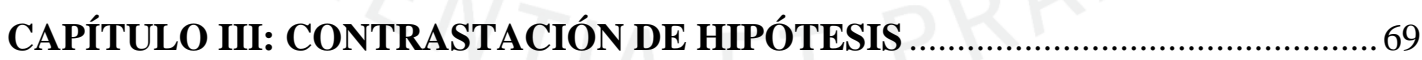

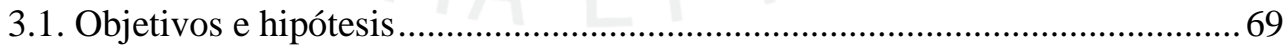

3.2. Prueba de Estrés de Riesgo de Crédito ............................................................ 71

3.2.1. Metodología del Modelo de Riesgo Crédito.................................................73

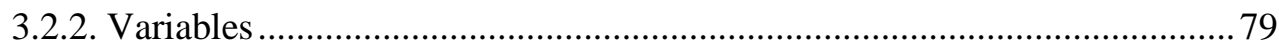

3.2.3. Aplicación de la metodología .................................................................. 81

3.2.3.1. Ecuación 3.1 Modelo de Tasa de Deterioro.............................................. 81

3.2.3.2. Ecuación 3.2 Modelo de Provisiones en relación a la Cartera .................. 96 
3.2.4. Aplicación de la Prueba de Estrés: Simulación VAR Impulso-Respuesta .. 103

3.3. Prueba de Estrés de Riesgo Mercado...............................................................114

3.3.1. Metodología del Modelo de Riesgo Mercado.............................................. 1

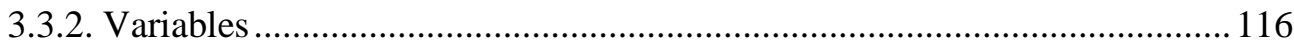

3.3.3. Aplicación de la Prueba de Estrés- Simulación VAR Impulso-Respuesta... 126

3.4. Prueba de Estrés de Riesgo de Liquidez ...........................................................132

3.4.1. Metodología del Modelo de Riesgo Liquidez................................................ 133

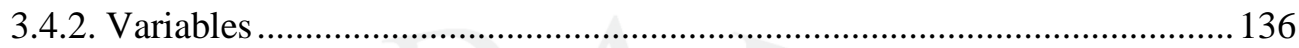

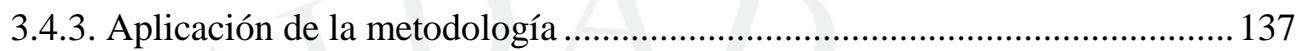

3.4.4. Aplicación de la Prueba de Estrés...................................................................... 141

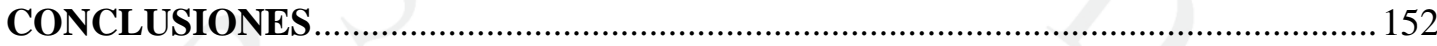

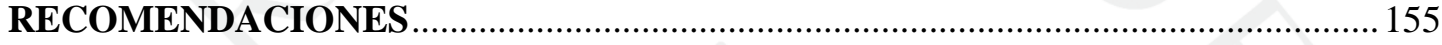

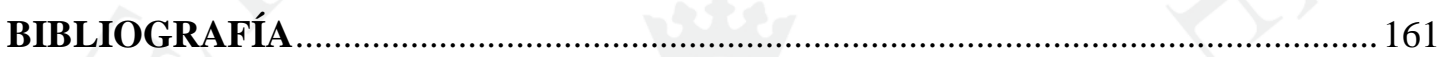

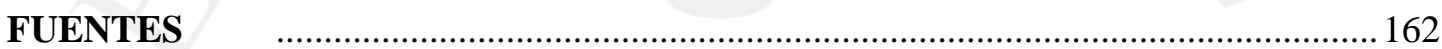




\section{ÍNDICE DE TABLAS}

Tabla 1.1. Construcción de Escenarios

Tabla 1.2 Resumen de las Reformas de Basilea- III ....

Tabla 2.1 Balance General de los 5 Bancos de Operaciones Múltiple.

Tabla 2.2 Indicadores de Riesgo Crediticio.

Tabla 2.3 Estado de Ganancias y Pérdidas de los 5 Bancos de Operaciones Múltiples

Tabla 3.1 Variables del Modelo de Riesgo Crédito ............................. 80

Tabla 3.1.1. Análisis de Correlograma...................................... 82

Tabla 3.1.2 Prueba de Raíz Unitaria........................................ 83

Tabla 3.1.3 Prueba de ensayo de la ecuación 3.1 en su versión original.............. 87

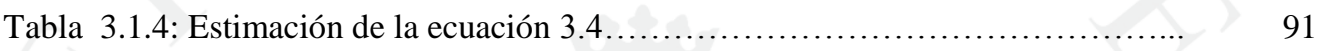

Tabla 3.1.5 Diagnostico de Residuos - Histograma de prueba de Normalidad.......... 92

Tabla 3.1.6 Diagnostico de Residuos - Prueba de correlación serial LM............. 93

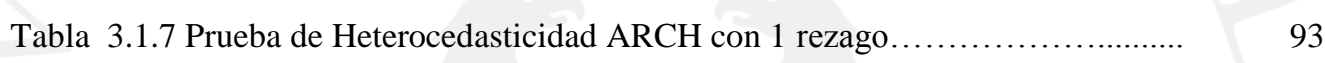

Tabla 3.1.8 Diagnostico de Estabilidad - Prueba RESET de Ramsey.................. 94

Tabla 3.1.9 Prueba de Raíz Unitaria para Provisiones ............................ 97

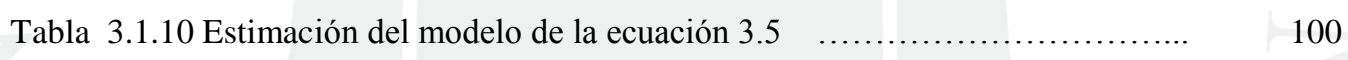

Tabla 3.1.11 Diagnostico de Residuos -Histograma de Prueba de Normalidad........... 101

Tabla 3.1.12 Prueba de Heterocedasticidad ARCH LM .......................... 102

Tabla 3.1.13 Estimación de Vectores Auto regresivos........................... 107

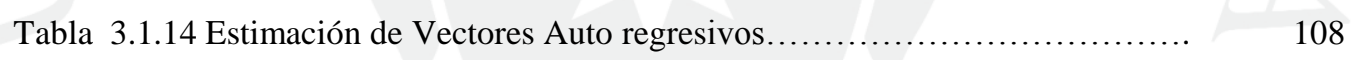

Tabla 3.1.15 Resultados medidos en desviaciones acumuladas ......................... 108

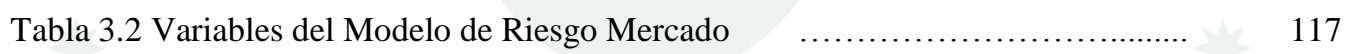

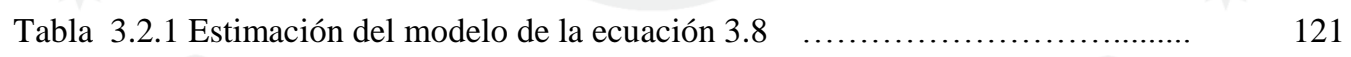

Tabla 3.2.2 Diagnostico de Residuos -Histograma de Prueba de Normalidad............. 121

Tabla 3.2.3 Diagnostico de Residuos - Prueba de correlación serial LM.............. 122

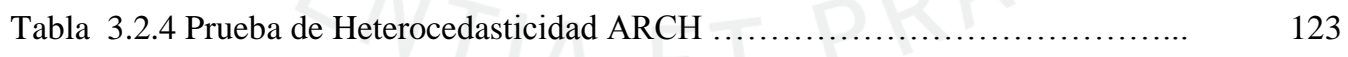

Tabla 3.2.5 Prueba de Heterocedasticidad White ............................. 124

Tabla 3.2.6 Diagnostico de Estabilidad - Prueba RESET de Ramsey ................... 125

Tabla 3.2.7. Resultados medidos en desviaciones acumulada..................... 127

Tabla 3.3 Variables del Modelo de Riesgo Liquidez............................... 136

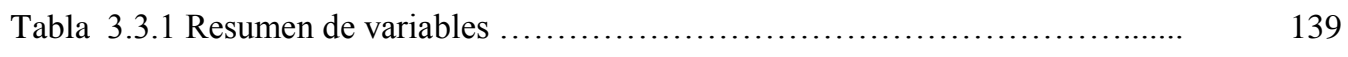

Tabla 3.3.2 Estadísticos Descriptivos.................................... 139

Tabla 3.3.3 Resultados medidos en desviaciones acumuladas .................... 149 


\section{ÍNDICE DE FIGURAS}

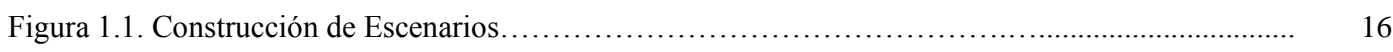

Figura 1.1. Resumen de las Reformas del Comité de Supervisión Bancaria de Basilea- Basilea III ....... 23

Figura 2.1 Créditos Directos por Banco y participación .......................................................................... 40

Figura 2.2 Evolución de los Activos de los 5 Principales Bancos de Operaciones Múltiples ............ 43

Figura 2.3 Composición de los Activos de los 5 Principales Bancos de Operaciones Múltiples .......... 45

Figura 2.4 Evolución de los Activos de los 5 Principales Bancos de Operaciones Múltiples............ 45

Figura 2.5 Evolución del Pasivo y del Patrimonio de los 5 Principales Bancos de Operaciones Múltiple 46

Figura 2.6 Composición de los Pasivos de los 5 Principales Bancos de Operaciones Múltiples .............. 47

Figura 2.7 Evolución de los Pasivos de los 5 Principales Bancos de Operaciones Múltiples ............. 47

Figura 2.8 Evolución por Tipo de Crédito Directo de los 5 Principales Bancos de Operaciones Múltiples 49

Figura 2.9 Evolución de los saldos en Créditos Directos de los 5 Principales Bancos de Operaciones Múltiples

Figura 2.10 Evolución de los saldos de Créditos Directos vigentes de los 5 Principales Bancos de Operaciones

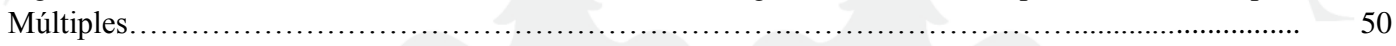

Figura 2.11 Evolución de los Depósitos de los 5 Principales Bancos de Operaciones Múltiples .......... 52

Figura 2.12 Composición de los Depósitos de los 5 Principales Bancos de Operaciones Múltiples....... 52

Figura 2.13 Evolución de los Adeudos y Obligaciones Financieras de los 5 Principales Bancos de Operaciones Múltiples............................................................................... 55

Figura 2.14 Composición de los Adeudos y Obligaciones Financieras de los 5 Principales Bancos de Operaciones

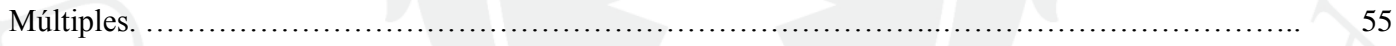

Figura $2.15 \%$ Variación anual de los Créditos Directos según situación........................... 58

Figura 2.16 Indicadores de Riesgo Crédito Agregado de los 5 Principales Bancos de Operaciones Múltiples 59

Figura 2.17 Indicadores de Riesgo Crédito Agregado de los 5 Principales Bancos de Operaciones Múltiples 59

Figura 2.18 Tasa de Deterioro (\% Cartera Deteriorada) Agregada de los 5 Principales Bancos de Operaciones Múltiples

Figura 2.19 Tasa de Deterioro (\% Cartera Deteriorada) Agregada de los 5 Principales Bancos de Operaciones Múltiples

Figura 2.20 Evolución del Estado de Resultados (G y P) Agregado de los 5 Principales Bancos de Operaciones Múltiples...

Figura 2.21 Evolución de los Ingresos Financieros de los 5 Principales Bancos de Operaciones Múltiples 64

Figura 2.22 Evolución de los Márgenes de Rentabilidad de los 5 Principales Bancos de Operaciones Múltiples

Figura 2.23 Gasto de Provisión anualizado de los 5 Principales Bancos de Operaciones Múltiples....... 65

Figura $2.24 \%$ Variación de 12 meses del PBI Real. ......................................... 66

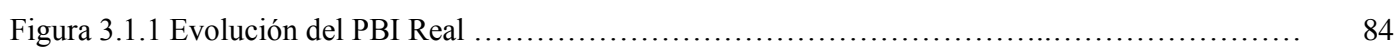

Figura 3.1.2 Análisis Bivariable............................................................. 84

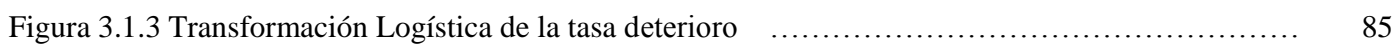


Figura 3.1.4 Estimación del modelo de la ecuación 3.4.

Figura 3.1.5 Estimación de la Bondad de ajuste del modelo de la ecuación 3.4 .................... 92

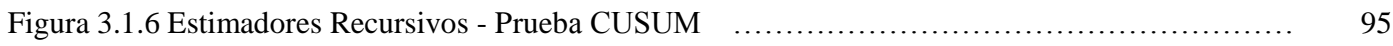

Figura 3.1.7 Estimadores Recursivos- Prueba de cuadrados CUSUM/ ............................ 95

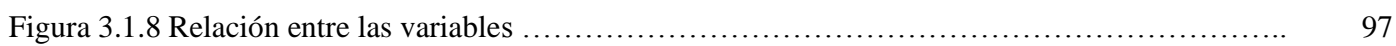

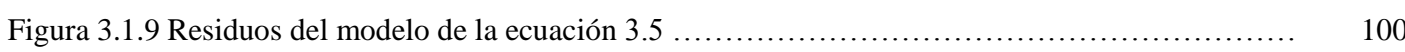

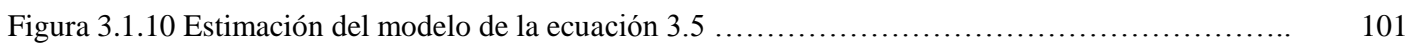

Figura 3.1.11 Estimación de la variable endógena en el modelo de la ecuación 3.5 ................... 102

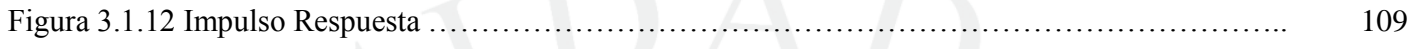

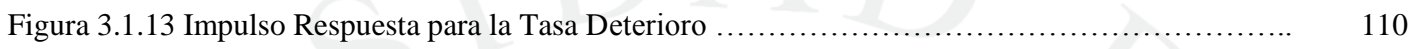

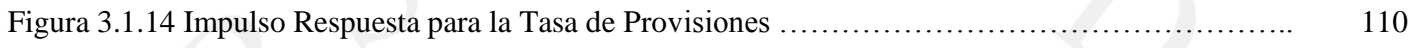

Figura 3.1.15 Distribución de las desviaciones de la variable endógena de la ecuación 3.4 ............. 111

Figura 3.1.16 Distribución de las desviaciones de la variable endógena de la ecuación 3.5 .............. 111

Figura 3.1.17 Detalle del Impacto en la distribución para la Tasa Deterioro ......................... 112

Figura 3.1.18 Detalle del Impacto en la distribución para la Tasa Provisiones .......................... 113

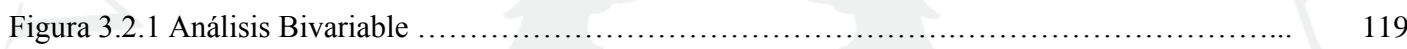

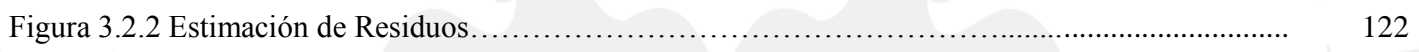

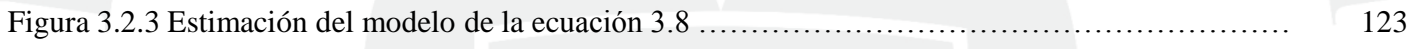

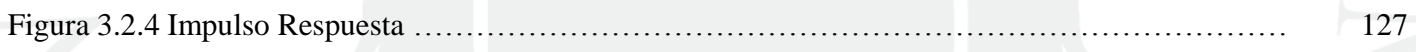

Figura 3.2.5 Distribución de las desviaciones de la variable endógena de la ecuación 3.8 .............. 128

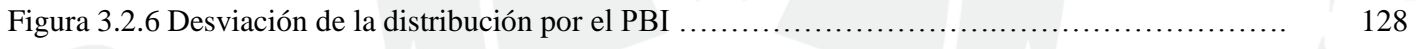

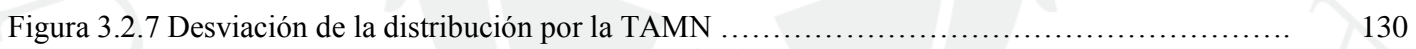

Figura 3.2.8 Desviación de la distribución por la TAMEX .......................................... 130

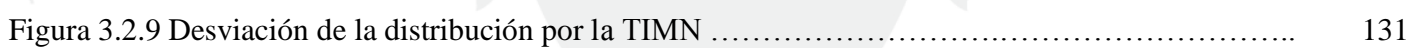

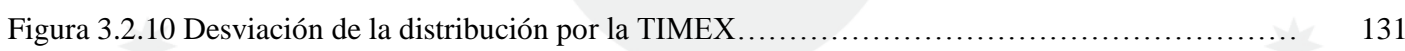

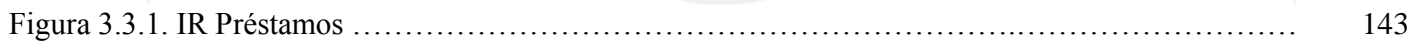

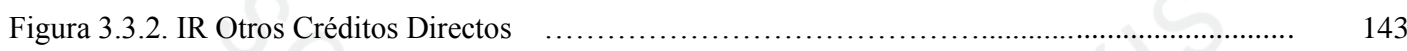

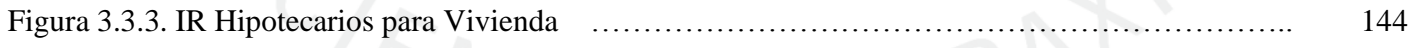

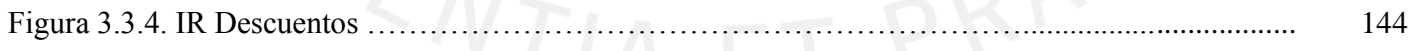

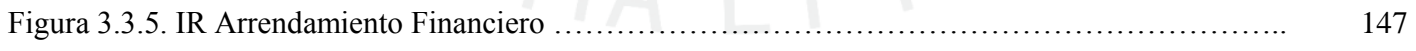

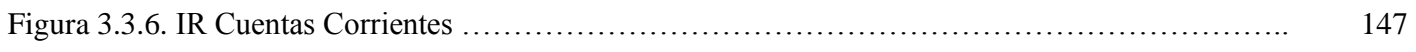

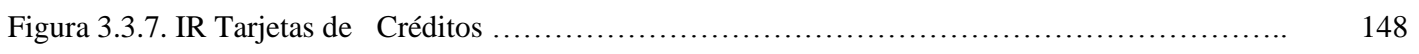

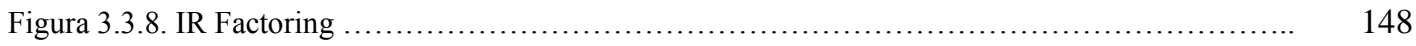




\section{INTRODUCCIÓN}

"La crisis de 2008-2009 demostró que el principal desafío macroeconómico que enfrenta una economía como la peruana es el manejo de choques macroeconómicos adversos...” (Dancourt, 2013)

La crisis financiera en el mercado de créditos e hipotecas estadounidense impactó de manera distinta en América Latina a comparación de otras regiones, debido principalmente a su capacidad de solvencia. Esto fue producto de las reformas llevadas a cabo en la última década (a partir de inicios del año 2000), como lo fueron: coeficientes de capital superiores a los requeridos, financiación interna estable, adecuada gestión del riesgo de liquidez de divisivas y escaza exposición directas de bonos hipotecarios privados (Sanahuja, 2012). También, uno de los motivos por los cuales América Latina pudo enfrentar mejor la crisis fue por la falta de exposición ante activos tóxicos como los créditos hipotecarios subprime y los fondos de inversión libre conocidos como Hedge Funds.

A raíz de que la crisis financiera impacto en el sector real; el Banco de Pagos Internacionales diseño una nueva serie de regulaciones que llevarían el nombre de Basilea III. Dentro de este nuevo marco regulatorio estarían nuevas indicaciones como: promover la resiliencia bancaria, una mejor absorción de los choques de estrés económico financieros y aumentar el capital y la cobertura de los activos. Esto repercutiría en tasas de préstamo más altas y una desaceleración del crecimiento de los créditos, presionando a una recuperación más lenta.

En los últimos años se han hecho tres importantes Pruebas de Estrés, también conocidas como Pruebas de Resistencia, nivel mundial. En el 2009 las autoridades el gobierno estadounidense publicaron sus pruebas de resistencia conocida como la U.S. Supervisory Capital Asssesment Program (SCAP). En el 
año 2011 en Europa, la European Committe for Bank Supervision (ECBS) público un ejercicio de estrés a nivel bancario. Después, la nueva European Banking Authority (EBA) publicó los resultados de una prueba de estrés ejecutada a 91 Bancos de Europa en un intento de solventar las dudas acerca de la validez de la prueba anterior de la ECBS y para así mostrar una señal de mayor transparencia en el mercado.

En la actualidad, las autoridades europeas han reforzado los procedimientos a seguir en la ejecución de las pruebas de solvencia. Esto a través de más consistencia en la información y más transparencia en las metodologías aplicadas para así promover el aumento de la calidad de la capitalización de los Bancos. Sin embargo, aún quedan pendientes cuestiones controversiales; pero la evidencia histórica indica que los beneficios del nuevo marco regulatorio superarán los riesgos inherentes a enfrentar en la región de europea.

La crisis financiera de los años 2008-2009 implicó el nacimiento de nuevos paradigmas en las ramas de la economía y las finanzas. A su vez, reveló que a pesar del crecimiento del sistema bancario, existían vulnerabilidades perjudiciales para el mercado y la economía en conjunto. Los distintos agentes privados a escala global toman decisiones en búsqueda de maximizar su rentabilidad y asegurar su solvencia; pero no en base a una sostenibilidad en conjunto. A causa de ello, es necesario conocer las vulnerabilidades del sector bancario en el Perú y determinar en qué medida sus respuestas se hallan condicionadas.

Actualmente, en relación a las pruebas de estrés aplicadas, no existen suficientes estudios disponibles al público ya que las conclusiones y opiniones desarrolladas pueden afectar el comportamiento de los agentes del mercado y llegar a representar una situación inconveniente si es que se revelan vulnerabilidades en las instituciones bancarias. Las pruebas de resistencia no deben responder solo a un acontecimiento o contexto del momento sino deben 
de repetirse con periodicidad y siempre en búsqueda de afinar las metodologías y abarcar mayor información relevante; ya que al igual que los negocios evolucionan, los riesgos adyacentes también.

Una prueba de estrés no puede encerrarse en sí sola, ya que no apela a la idiosincrasia del contexto que la rodea. Esta debe ser una herramienta adaptable antes los diversos escenarios posibles y que no se limite a valorar la capacidad de solvencia de una entidad, sino en exponer el comportamiento sistemático del sector. Por ello, la prueba de estrés posee un lugar relevante en el catálogo de herramientas supervisoras y resulta ser un excelente ejemplo para medir si las políticas implementadas surtieron efecto en los agentes o brindaron resultados sólidos. Siendo así, el estudio se justifica en la necesidad de prevenir cualquier efecto negativo sobre la banca múltiple y suavizar futuras distorsiones del mercado a razón de no afectar el desarrollo y crecimiento del sector. La regulación no es un trabajo que solo compete a las entidades públicas; sino es un deber de todos los participantes.

El presente trabajo apunta a cuantificar los impactos en los indicadores de riesgo producidos en un escenario de estrés. El primer capítulo se enfoca en la explicación de los conceptos pertinentes, en las normas de regulación de Basilea y en la definición de la Prueba de Estrés. El segundo capítulo se centra en la descripción de los agentes económicos y en el análisis de las variables económicas y financieras a utilizar en la contrastación de la hipótesis. El tercer capítulo se divide en tres Pruebas de estrés ligadas a un tipo de riesgo en específico: riesgo de crédito, riego de mercado y riesgo de liquidez. En cada Prueba de estrés se introduce y aplica un modelo y luego se simulan los distintos escenarios (variaciones en variables) para cuantificar los impactos producidos en los indicadores de riesgo. Finalmente están las conclusiones y recomendaciones ligadas a los resultados del estudio. El trabajo se limita a analizar el conjunto agregado de los 5 principales bancos de operaciones múltiple en el Perú en un umbral de tiempo del año 2001 al año 2014. 
Al final se concluye, salvo el caso de la prueba de estrés ligada al nivel de la tasa de provisiones, que el impacto por una variación de las variables exógenas a la economía local en la evolución y tendencia de los indicadores de riesgo de la baca múltiple no es tan significativo como el impacto producido por las variables endógenas a la economía del país. 


\section{CAPÍtulo I: BASILEA Y LAS PRUEBAS DE ESTRÉS}

En este capítulo se hace un a introducción con respecto al esquema de construcción de escenarios para las Pruebas de Estrés. Después se explica el motivo y el proceso de creación del Comité de Supervisión Bancaria de Basilea y, a su vez, la evolución de sus regulaciones propuestas. Seguido, se detalla la aplicación de estas regulaciones en el Perú y su desarrollo en los últimos años. Se explica y define el concepto de Prueba de Estrés, mencionando casos de Programas de aplicación en otros países y literatura acerca del tema. Finalmente, se describe la situación actual del Perú, analizando los distintos agentes que participan en el funcionamiento de mercado financiero nacional.

\subsection{Conceptos}

Las pruebas de estrés constituyen una herramienta previsora que los organismos reguladores de los sistemas financieros emplean para determinar los efectos de escenarios negativos adversos en los resultados de las empresas financieras. Esta prueba emplea un número de estadísticos que generan un valor esperado del impacto dado la información disponible en el periodo de aplicación de la prueba. Las pruebas de estrés permiten al supervisor evaluar la necesidad de medidas de regulación para asegurar la estabilidad del sistema financiero en caso de que se presentase choques adversos drásticos.

Pero, para ello es necesario contar con lineamientos que regulen el manejo de los programas de estrés que incorporan las distintas pruebas a hacer. De acuerdo a los principios establecidos por el Comité de supervisión bancaria de Basilea (BCBS, 2009): 
La ejecución de programas de pruebas de estrés debe formar parte integral de la cultura de la administración global del riesgo en el banco. La prueba de estrés debe ser accionable, es decir, los análisis de los resultados deben impactar en los resultados de las decisiones del negocio. El envolvimiento de la alta administración o directorio en el programa de estrés es esencial para una gestión efectiva.

El Banco debe operar un Programa de estrés que promueva la identificación de riesgos y refuerce la gestión del capital y la liquidez. El Programa de estrés debe tomar en cuenta las posiciones a lo largo de la organización y ha de cubrir un rango de técnicas y perspectivas.

La entidad financiera debe tener por escrito las políticas y procedimientos de manejo del Programa de estrés. Las operaciones deben de ser registradas y documentadas. Se debe poseer la infraestructura adecuada de información. El esquema metodológico de las pruebas de estrés se debe mantener actualizado. La efectividad como la robustez de los componentes individuales debe de ser evaluado regularmente e independientemente.

El Banco debe ser capaz de integrar las distintas áreas administrativas para presentar una imagen completa del riesgo global en la entidad. El programa debe de cubrir una serie de escenario incluyendo los "forward looking", es decir, proyecciones. Tomando en consideración las interaccione sistémicas y los efectos retroalimentación.

Se tiene que incluir una serie de niveles de resistencia, incluyendo los evento que provocarían daños sea por la magnitud de la pérdida o la pérdida de reputación. También se debe determinar qué escenarios afectarían la viabilidad del banco e identificar los riesgos escondidos y las interacciones entre los mismos. Se tiene que tomar en cuenta las presiones en simultáneo del mercado de activos y de fondos de financiamiento. La efectividad de las técnicas de 
mitigación del riesgo deben cubrir todos los riesgos independientes de su probabilidad de ocurrencia.

Los supervisores requerirán que se tome acciones correctivas si se identifican deficiencias o si los resultados de las pruebas no son implementados en la adecuada toma de decisiones. Es necesario el uso conjunto de herramientas de estadística que permitan cuantificar las pérdidas esperadas ante choques y obtener estimadores confiables.

El riesgo de crédito es un análisis estático y dinámico a la vez. Incorpora varios niveles como el riesgo de contraparte, de sector, de exposición y recupero, de concentración y correlación. El enfoque de una prueba de estrés de riesgo crédito puede clasificarse como:

Hacia arriba (Bottom Up): el análisis es realizado por los propios modelos de la institución pero empleando un escenario macroeconómico provisto por el ente supervisor. Al final se agregan los efectos individuales en la composición del portafolio para cuantificar el efecto por institución y de ahí el efecto final sobre el sistema.

Hacia abajo (Top Down): el análisis es realizado por el propio entre supervisor, empleando un modelo agregado para todo el sistema financiero en función a factores macro y luego se usan los parámetros del modelo para obtener los impactos en cada institución. Este enfoque es el más común y se utilizara en las pruebas a desarrollarse en el capítulo 3.

Existen dos tipos de básicos de análisis en el marco de la prueba de estrés: Primero, los análisis de sensibilidad que buscan evaluar el impacto en una variable específica. Segundo, los análisis de escenarios que pretenden cuantificar el efecto generado por el cambio conjunto de una serie de variables 
correlacionadas. El segundo resulta ser un análisis más complejo, pero a su vez más completo que el anterior.

La construcción de un escenario es la creación de un modelo que provea la consistencia interna y permita pronosticar correctamente (forward looking) sobre la relación entre el sistema financiero y el sector real de la economía. El escenario puede ser basado en un evento en específico independiente de las características del portafolio o uno que incorpore las caracterizas relevantes de un evento pasado y los identifica en los parámetros del riesgo. Un escenario basado en proyecciones macroeconómicas emplea modelos econométricos o estimaciones expertas que predicen el comportamiento de la actividad económica ante choques.

Por ejemplo, el análisis de riesgo de crédito estudia el impacto por las variaciones de las cuentas del estado financiero y su efecto transmisión en la hoja de balance. Esto repercutirá en las proyecciones de morosidad, que son la base con la cual se calculan las provisiones. Con los datos anteriores se obtendrá el impacto en la utilidad y en los ratios de capital.

Los choques agregados provocan fluctuaciones en la tasa de morosidad del sistema financiero. Un choque adverso en la actividad económica conduce a que el nivel de provisiones aumente y se reduzca la utilidad de la empresa bancaria. De ello parte la necesidad de incrementos de capital por parte de las entidades.

Los intermediarios financieros son regulados como un resguardo contra la interrupción de los servicios especiales brindados por ellos y los costos que esto impondría sobre la economía y la sociedad en su conjunto. Las quiebras bancarias destruyen el ahorro de los hogares y restringen el acceso al crédito de las empresas. Además puede causar pánico y contagio generalizado en instituciones sólidas. 
La regulación es socialmente beneficiosa pero impone costos privados sobre los propietarios y directivos de los intermediarios financieros. Por lo tanto resulta útil comparar los beneficios sociales que se obtendrán con los costos privados para los productores de servicios financieros. La fragilidad de los mercados financieros proviene directamente de las fallas de mercado. Los mercados financieros tienden a comportamientos extremos si no son controlados, son vulnerables a actos deshonestos, están afectos al poder monopólico y tiene una limitada capacidad de autorregulación.

Figura 1.1.

Construcción de Escenarios de Portafolio de Créditos en la Banca Múltiple. Elaboración propia.

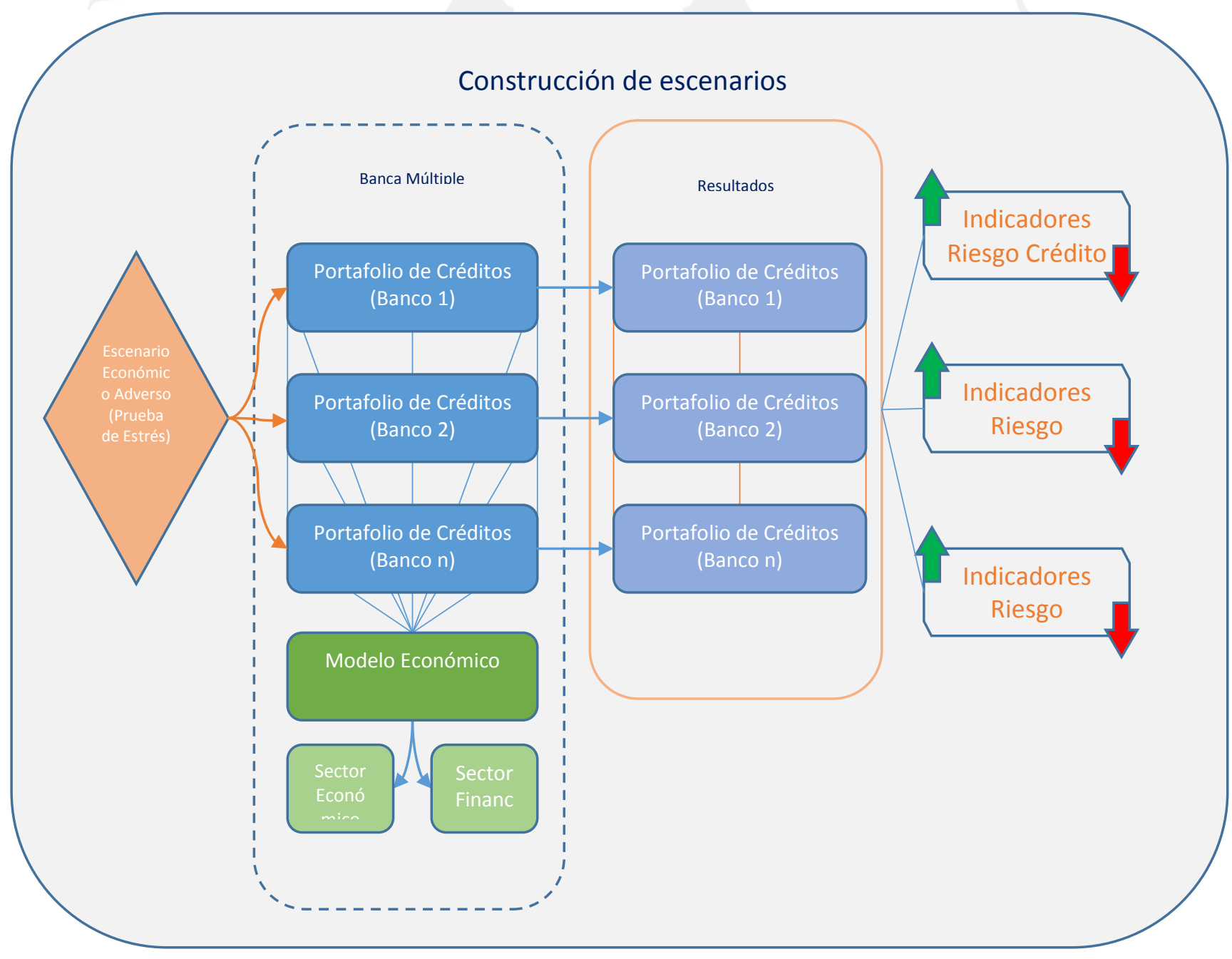


Incluso cuando la regulación es bien intencionada, esta impone costos directos e indirectos a los intermediarios financieros. Una reacción común es la formación de mercados informales y paralelos. El ciclo regulatorio tiene típicamente tres fases: las crisis que son producidas por pánicos, colapsos o escándalos; la regulaciones que son las nuevas leyes enfocadas en solucionar los problemas que originaron la crisis; la innovación donde la entidades afectadas buscan salidas y las no reguladas aprovechan para entrar en el mercado; y el regreso a la crisis anterior o nace una nueva.

\subsubsection{Comité de Supervisión Bancaria de Basilea y Reglamentación}

\section{Basilea III}

El Comité de Supervisión Bancaría de Basilea (BCBS) es el principal organismo normativo internacional para la regulación de los bancos. Integrado por los Miembros de Comité de distintos países, su misión es fortalecer la regulación, la supervisión y las metodologías aplicadas a los bancos a nivel internacional para alcanzar la estabilidad financiera uniforme en el mundo.

Dentro de las tareas a realizar por la BCBS se encuentra: canalizar y publicar la información correspondiente a la evolución de los bancos y los mercados financieros, detectar y analizar los futuros riesgos, publicar nuevas estrategias para reforzar la supervisión bancaria, promover nuevas normas de regulación, criticar los puntos ambiguos de la regulación y brindar soluciones ante ello, hacer seguimiento a la implementación de las Normas aprobadas por el Comité en los países miembros e interactuar y coordinar con otras entidades internacionales para promover el resguardo de la estabilidad financiera

Es necesario que los miembros de la BCBS estén comprometidos con los lineamientos para que esta pueda ejecutar sus normas y mandatos. Por lo tanto 
los miembros de la BCBS deben: resguardar la estabilidad financiera, aplicar las normas emitidas por la BCBS antes del vencimiento del plazo estipulado, ampliar y fortalecer su esquema de normas, brindar mayor importancia a la estabilidad financiera mundial antes que los interés nacionales y trabajar activamente en las tareas del BCBS.

La BCBS alienta la aplicación oportuna y coherente de sus normas por parte de los miembros y recién en el año 2012 comenzó a monitorear la implementación de las normas para mejorar la resistencia del sistema bancario mundial, para llegar a fomentar la igualdad de condiciones de regulación para los bancos con transacciones internacionales.

Las decisiones de la BCBS se toman en consenso con los miembros del comité que son representados por una autoridad en regulación de cada país. El BCBS se dedica a establecer normas para la supervisión y regulación prudencial de los bancos. Sin embargo, estas mismas normas representan los requisitos mínimos a aplicar en cada país y sus miembros pueden elegir si desean ser más estrictos en la aplicación. A su vez todas las normas están sujetas a una consulta pública donde se invita a las partes interesadas presentar sus observaciones $\mathrm{u}$ críticas.

A parte de las normas, el comité también se sirvió de otras herramientas para reforzar la regulación en los países miembros: las directrices publicadas buscan resumir y adaptar las normas dentro de ámbitos donde es necesaria la regulación financiera de los mismo bancos; complementando la labor originalmente de las normas. La publicación de Buenas Prácticas sirve para ampliar su entendimiento y alentar al juicio crítico interno de los miembros del comité para ubicar mejoras internas en los procesos. 


\subsubsection{Antecedentes a Basilea III}

El origen del Comité se remonta a las turbulencias del mercado financiero producidas por el colapso del sistema de Bretton-Woods de tipos de cambio en el año 1973. En respuesta a ello y otros hechos contemporáneos, las autoridades de los Bancos Centrales de los países del G-10 establecieron un Comité de Reglamentación y Supervisión Bancaria a finales de 1974, el cual más tarde llevaría el nombre de Basilea.

En 1975 se publicó un trabajo que luego se llamaría el Acuerdo (“Concordat") que establecía los principios para compartir las responsabilidades de supervisión entre los Bancos y las Autoridades Supervisoras. En abril de 1990, se publicó el trabajo "Intercambio de Información entre los supervisores de los mercados financieros", un suplemento al acuerdo de 1975 que busco mejorar el flujo de información entre los supervisores bancarios de distintos países. En octubre de 1996, la Comisión publicó un informe llamado la "Supervisión bancaria internacional". El documento presentó propuestas para la superación de obstáculos a la supervisión de las operaciones bancarias internacionales.

\subsubsection{Basilea I: Acuerdo de Capital de Basilea}

Con las bases establecidas para la supervisión de los bancos de operaciones internacionales, la suficiencia de capital pronto se convirtió en el foco principal de discusión del Comité. A principios de la década de los 80`s, la crisis de la deuda latinoamericana intensifico las preocupaciones del Comité con respecto a los ratios de capital de los principales bancos se iban deteriorado a la vez que el riesgo internacional aumentaba.

Con el respaldado del G-10, los miembros del Comité decidieron detener la erosión de los estándares de capital en los bancos y comenzaron a trabajar en 
uniformizar las metodologías de medición de la suficiencia de capital. Esto dio lugar a un consenso por el enfoque de medición de riesgos ponderado, tanto dentro como fuera de los balances de los bancos.

Hubo una profunda preocupación dentro de la Comité por la necesidad de imponer un acuerdo multinacional para reforzar la estabilidad del sistema bancario internacional y eliminar las causas de la desigualdad de competitividad producida por las diferencias en los requisitos de capital de cada país.

En julio de 1988 se publicó un documento por los miembros del G-10 llamado el "Acuerdo de Capital de Basilea", el cual establecía un sistema de medición de capital. El documento de 1988 exigía un ratio de capital mínimo de $8 \%$ en relación a los activos ponderados por riesgo.

\subsubsection{Basilea II: Nuevo Marco de Capital}

En junio de 1999, la Comisión presentó una nueva propuesta de esquema de gestión del capital para reemplazar el Acuerdo de 1988. Esto condujo a la publicación del Esquema de Gestión del Capital Revisado en el año 2004, que luego sería conocido como Basilea II.

El documento estaba conformado por tres pilares: Primero, los requisitos mínimos de capital que ampliaron las normas establecidas en el Acuerdo de 1988; segundo, la supervisión de la gestión adecuada del capital y el proceso de evaluación interna; y tercero, el uso eficaz de la divulgación de información como un instrumento para fortalecer la disciplina del mercado y alentar a mejores prácticas bancarias. El nuevo Esquema fue diseñado para enfrentar la innovación financiera que se había producido en los últimos años. Los cambios buscaban fortalecer los procesos de medición y control de riesgos continuos. 
Los países miembros del Comité y varios países no miembros acordaron adoptar las nuevas normas, aunque en diferentes escalas de tiempo. A partir de entonces, la aplicación del nuevo esquema a través de los países se convirtió en la tarea más difícil para el Comité.

Uno de los retos que los supervisores enfrentan dentro del esquema de Basilea II fue la necesidad de aprobar el uso de métodos de medición del riesgo en múltiples jurisdicciones. Si bien esto no es un concepto nuevo para la comunidad de entidades supervisoras, Basilea II amplió el alcance de dichas homologaciones y exigió un mayor grado de cooperación entre los supervisores.

\subsubsection{Hacia Basilea III}

Incluso antes de que el Banco de inversión Lehman Brothers quebrara en septiembre de 2008, la necesidad de un fortalecimiento fundamental del esquema de Basilea II se había hecho evidente. El sector bancario había entrado en la crisis financiera con demasiado apalancamiento de fondeo e inadecuados amortiguadores de liquidez. Estos defectos fueron acompañados por el mal gobierno y gestión de riesgos; así como, la inapropiada estructura de incentivos. La peligrosa combinación de estos dos factores produjo el exceso de crecimiento de los créditos.

\subsubsection{Normas de regulación de Basilea III}

En septiembre de 2010, se anunciaron los estándares mínimos de capital para los bancos comerciales. Esto siguió al acuerdo que ahora se conoce como "Basilea III". En noviembre de 2010, las nuevas normas de capital y liquidez fueron aprobadas en la Cumbre de Líderes del G-20 en Seúl y posteriormente acordaron en la reunión del Comité de Basilea diciembre de 2010. 
Las normas propuestas fueron emitidas por el Comité, con los nombres de "Basilea III: Marco para la medición del riesgo de liquidez, normas y supervisión internacional" y "Basilea III: un esquema para la regulación del sistema bancario global”. El marco de Basilea III revisa y fortalece los tres pilares establecidos por Basilea II. También una serie de nuevas regulaciones como:

Una capa adicional de Participación de Capital común (el amortiguador para la conservación de capital) que, cuando se ve afectado, desactiva el pagos por concepto de utilidades para así llegar a proteger el requisito mínimo de capital.

Un amortiguador de capital anti cíclico, que impone restricciones a los Bancos en los auges de crédito en el sistema con el objetivo de reducir sus pérdidas en el escenario que ocurran caídas en el mercado de créditos.

Un ratio de apalancamiento, es decir, una cantidad mínima de pérdida por absorción de capital en relación con todos los activos del banco independientemente de su ponderación por riesgo.

Requerimientos de liquidez, es decir, un coeficiente de cobertura de liquidez (LCR) destinado a estimar el dinero necesario para cubrir las necesidades de financiamiento durante un período de estrés de 30 días.

Propuestas adicionales para los bancos correspondientes al riesgo sistémico que incluye los requisitos para el capital complementario y el capital contingente. Estas definiciones de capital más estricto y la aplicación de coeficientes mínimos represento una modificación fundamental de lo que significaba la regulación bancaria. Al mismo tiempo, el Comité de Basilea, explico que las normas se implementarían de manera que no impidieran la recuperación de la economía real. 
Figura 1.2

Resumen de las Reformas del Comité de Supervisión Bancaria de Basilea- Basilea III.
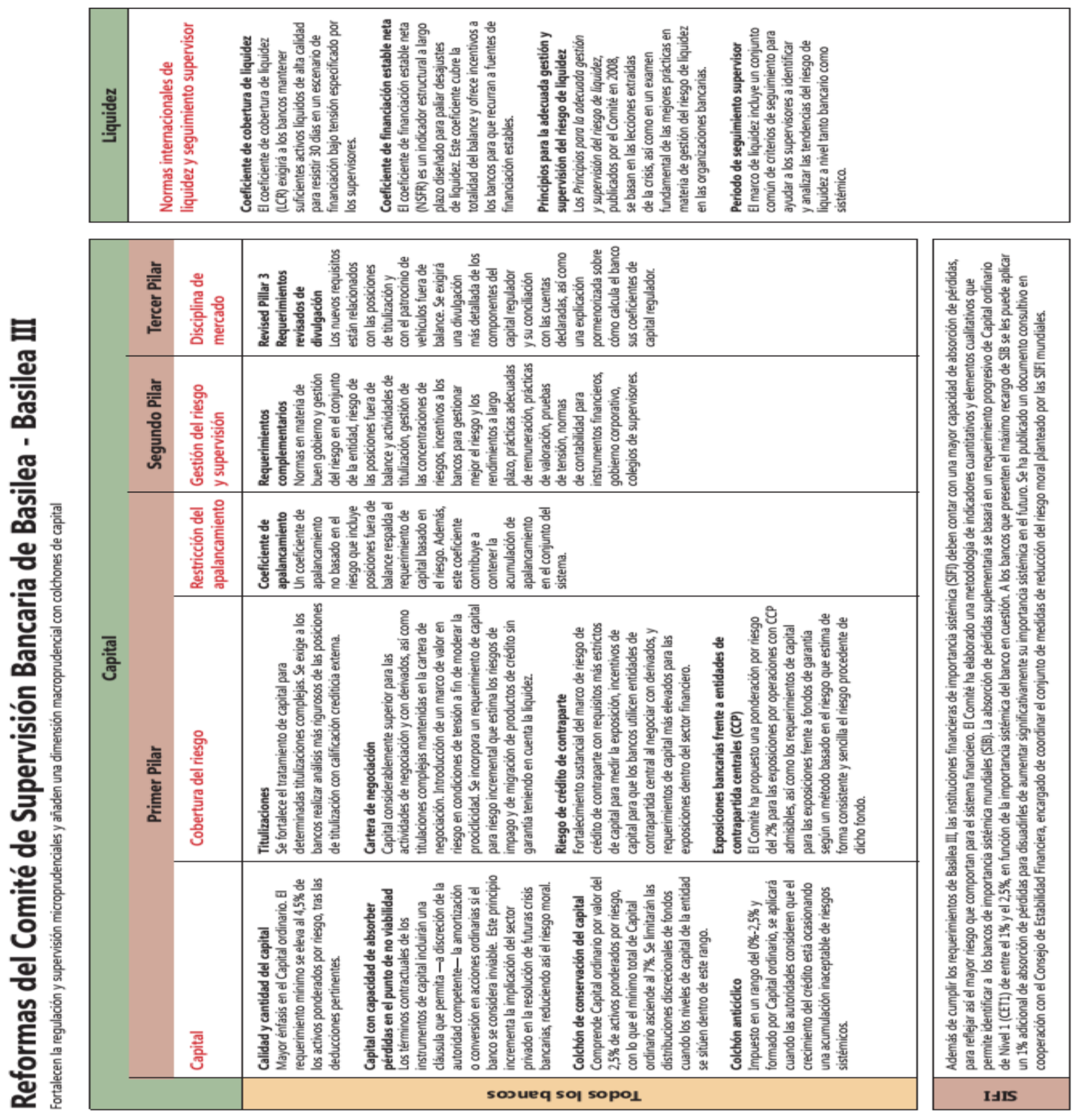

Fuente: Bank International Settlements (revisado el 10 de octubre de 2015). Basilea III. En: http://www.bis.org/bcbs/basel3/b3summarytable_es.pdf 


\subsubsection{Regulación vigente en el Perú}

En el año 2003, la SBS inicio la implementación de los acuerdos propuestos por el Comité de Basilea. El Reglamento para la Evaluación y Clasificación del Deudor y la Exigencia de Provisiones se modificó en noviembre del año 2008. Dentro de este reglamento se publicó el Régimen General para la constitución de provisiones pro cíclicas que obliga a las entidades bancarias a establecer adicionalmente provisiones genéricas en los episodios de crecimiento económico. Esto último con el motivo de ser usados cuando el ciclo económico se revierta a episodios de contracción y desaceleración. El proceso de acumulación de estas provisiones adicionales ocurre cuando la entidad reguladora indica que la regla pro cíclica está vigente.

En el mismo año 2008, la SBS abordó los Requerimientos Mínimos de Capital (Pilar 1), estableciendo que los niveles de patrimonio de las entidades financieras han de ser mayores al diez por ciento (10\%) de los activos ponderados por riesgo.

En respuesta a las recomendaciones planteadas en Basilea, durante el año 2009 la Superintendencia presentó las normas correspondientes a los requerimientos de patrimonio efectivo por riesgo de crédito, riesgo de mercado y riesgo operacional. En el año 2010 dicho Reglamento para el Requerimiento de Patrimonio Efectivo por Riesgo de Crédito entro en vigencia.

También se aprobó el Reglamento para el Requerimiento de Patrimonio Efectivo por Riesgo de Mercado, cuyo cálculo incorpora: los riesgos asociados a la volatilidad de los precios de los valores dentro de la Cartera de Negociación, el riesgo por las tasas de interés de instrumentos, el riesgo por exposición en moneda extranjera o cambiario y el riesgo por valoración de mercancías (commodities). El Reglamento ayuda a suavizar los futuros impactos por 
posibles fluctuaciones económicas y sensibiliza los requerimientos de capital ante el perfil o apetito de riesgo de cada institución.

El Pilar II que se refiere al Proceso de Exámen Supervisor ha cobrado notoriedad a raíz de la crisis financiera internacional. El objetivo de este Pilar es que existan procesos de evaluación de suficiencia de capital dentro de cada banco. Solo las empresas bancarias con los procesos de administración sofisticados y modernos pueden ejecutarlo debido a que se trata de un ejercicio complejo de replicar.

La SBS se encuentra en proceso de implementación de las nuevas normas regulatorias señalados en Basilea III. El Perú posee indicadores y niveles de capital prudencial por encima del requerido. Producto de ello, se puede afirmar que actualmente existen amortiguadores para ser ejecutados durante episodios de estrés económico. 


\subsection{Prueba de estrés}

Una Prueba de estrés es una herramienta esencial para el análisis de la estabilidad del sector financiero y la viabilidad de políticas reguladoras. Sin embargo, la prueba tiene un impacto limitado ya que no necesariamente está atada a una acción posterior. A nivel internacional no existe un claro consenso acerca de las características que debe poseer una prueba de estrés óptima. Depende de que tan pesimistas sean los supuestos del escenario para guiar acciones preventivas y debe ser interpretado a la luz de las hipótesis formuladas. Es decir, la importancia de los programas de pruebas de estrés está condicionados a la rigurosidad de los choques que serán modelados en el escenario adverso.

Los lineamientos que deben seguir las instituciones al momento de realizar un proceso de pruebas han sido publicados por el Comité de Supervisión bancaria de Basilea en un documento con el nombre de "Principios de prácticas de Prueba de estrés y Supervisión" (BCBS, 2009). Estos incorporan los temas de transparencia metodológica y resultados verificables.

Una fuente importante para construir la metodología del estudio es el documento publicado por la European Banking Authority, "Metodología de Prueba amplia de la Unión Europea" (EBA, 2014). Este documento se actualiza de forma continua incorporando los últimos resultados obtenidos por el Programa.

Publicado por la Cámara de gobernadores de la Reserva Federal, el Acta Dodd-Frank de pruebas de estrés del año 2014 muestra la metodología y resultados llevados a cabo en las pruebas obligatorias en Estados Unidos

haciendo especial foco en el escenario de supervisión y de capital estresado (BG FRS, 2014). La primera prueba utiliza metodologías cuantitativas para 
determinar si el capital del banco es suficiente para absorber las pérdidas causadas por un escenario económico adverso. La segunda prueba que es más cualitativa, debido a que corrobora que las intuiciones tengan un proceso robusto de planeamiento de capital para que sea ejecutado en momentos difíciles del negocio.

Cabe mencionar que el marco teórico de las pruebas de resistencia está en pleno auge y evolución, debido a la importancia que han cobrado las pruebas en los episodios posteriores a la crisis y las necesidades regulación recientes.

Una de las consecuencias de la crisis financiera internacional fue la crítica a la validez de las pruebas de estrés a las instituciones financieras. Se revelaron las deficiencias de las herramientas para detectar vulnerabilidades. Como lo reveló el Programa de Evaluación del Capital (2009) llevada a cabo en Estados Unidos, las herramientas no son del todo seguras o a prueba de errores y resultan ser independientes del diagnóstico. Después de los hechos sucedidos, las autoridades como el Fondo Monetario Internacional (FMI) no eran capaces de identificar los verdaderos riesgos y exposiciones por eso no se abastecían de tiempo para prevenir las posibles vulnerabilidades. Más allá de las inadecuadas técnicas para capturar los complejos instrumentos financieros, la falta de solidez para tratamiento superficial y deficientes de un escenario fueron un factor determinante.

Por ejemplo, un punto sensible para el mercado es la comunicación de los resultados de las pruebas de estrés. Siempre los supervisores con las entidades tratan de equilibrar la convocatoria en búsqueda de una mayor transparencia para evitar alarmas innecesarias en el mercado y a la creación de profecías autocumplidas. 


\subsubsection{Casos en otros países}

En Chile, el Banco Central de Chile fue la entidad encargada de la gestionar la Pruebas de estrés para evaluar la estabilidad del sistema financiero. Sus ejercicios son de periodicidad semestral. Su análisis es de carácter sistémico con un enfoque Top Down. Las pruebas realizadas se centran en dos clases de riesgo. La prueba de riesgo crédito busca relacionar la pérdida asociada a los préstamos bancarios con la capacidad de pago de los deudores, el gasto de provisión, el crecimiento del producto, las tasas de interés y el nivel de endeudamiento. Para el riesgo mercado se calcula el riesgo de exposición por tipo de cambio ante una fluctuación en la cotizaciones y el riesgo de tasa de interés, centrado en el análisis de descalce y de duración. (Jara, 2007)

En Brasil, el Fondo Monetario Internacional y el Banco Central de Brasil trabajaron en conjunto para la ejecución del Programa de Evaluación del Sector Financiero. Estimaron la resiliencia del sistema bancario a través de tres ejercicios. La Prueba de solvencia analizó la resiliencia del sistema ante tres escenarios macroeconómicos adversos. La Prueba de liquidez calculó la resiliencia de los bancos en un escenario de retiro masivo de depósitos y un descalce en la maduración de cuentas. El análisis de contagio simulo un potencial efecto de choque por exposición interbancaria. Los resultados corroboraron que en el sistema bancario de Brasil existen suficientes amortiguadores de capital, niveles de liquidez adecuados y capacidad para cumplir con los estándares de Basilea III ante un contagio directo por exposición. (IMF, 2013)

En los años 2010, 2011 y 2014 la European Banking Authority (EBA) condujo una prueba de estrés para el sistema bancario de la Unión Europea para determinar la resiliencia de las instituciones financieras ante un hipotético escenario adverso en el mercado. Este escenario adverso se describe como una hipotética situación de recesión mundial. Los tipos de riesgo considerados incluyen riesgo crédito, mercado, soberano, de cobertura y de costo de fondeo. 
Para que un banco resulte aprobado, ante un escenario adverso su capital de mejor calidad Tier 1 se debía situar por encima del 5.5\%. De los 123 bancos participantes en el ejercicio del año 2014, 24 bancos fallaron en la prueba por un descalce en su capital. (EBA, 2014)

\subsection{Literatura correspondiente a las Pruebas de Estrés}

Demirguc-Kunt y Detrgiache sostienen que los factores como bajas tasas de crecimiento del PBI acompañado por niveles altos de tasas de intereses e inflación incrementen las probabilidades de que ocurran problemas sistémicos. (Demirguc-Kunt, 1998)

Aguilar estudió el impacto de la economía, la evolución de los portafolios de créditos y las tasas activas sobre la mora de los créditos justificando así el comportamiento contracíclico de la morosidad bancaria. A su vez sustento la existencia de una relación inversa entre la evolución de los créditos y las tasas activas en relación al deterioro de los portafolios de créditos. (Aguilar, 2004)

Vennet, Baele y de Jonghe señalan que existe mayor probabilidad de hallar garantías, colaterales, de mejor calidad crediticia en los episodios de contracción económica que en los periodos de expansión a causa de que existen problemas de asimetría de información inherentes. (Vennet, 2004)

Dell Ariccia indica que las pautas y los reglamentos para la aprobación de solicitudes crediticias de los bancos son configurados por la postura estratégica que toman en relación a la información (EEFF's, calificación crediticia y comportamiento histórico) recaba de los clientes. A raíz de la existencia de problemas de selección adversa producida por la existencia de información asimétrica, los bancos ejecutan búsquedas y análisis profundos es para evitar clientes que poseen la mayor probabilidad de incumplir en el pago de 
los préstamos. Sin embargo cuando se dan los procesos de expansión económica, los estándares de aprobación de créditos disminuyen. (Dell'Ariccia, 2008)

Bazerque y Cabrera señalan que los indicadores que influyen en la probabilidad de incumplimiento del cliente son el porcentaje de dolarización, el nivel de los préstamos y el comportamiento histórico. Mientras que la variable económica que más repercute de forma global sobre la probabilidad de incumplimiento es la evolución del producto bruto interno del país. (Bazerque, 2011)

Fernández sostiene que cuando suceden periodos de expansión masiva, los bancos se vuelven excepcionalmente optimistas bajando sus tasas activas y suavizando los estándares de aprobación de créditos con el motivo de aumentar el volumen de nuevos desembolsos. (Fernández, 2011) 


\section{CAPÍTULO II: ESQUEMA Y EVOLUCIÓN}

En el presente capítulo se estudiarán las variables que conforman los tres modelos que serán aplicados en el siguiente capítulo de contrastación de hipótesis. Primero, se explicará la evolución de los principales agentes económicos del sistema financiero nacional dentro del periodo de estudio. Segundo, se estudiará las principales cuentas de los Estados Financieros de las entidades seleccionadas de la Banca Múltiple en el Perú. Después se entrará al detalle de los diversos indicadores de desarrollo como el nivel de Créditos Directos colocados, Depósitos, Adeudos y obligaciones financieras, entre otro. De manera seguida, se repasará la situación de los indicadores de Riesgo Crédito de los portafolios de créditos de las entidades seleccionadas. Finalmente, se estudiarán las variables económicas como el PBI y las tasas de interés que serán utilizadas en el modelamiento del capítulo posterior.

\subsection{Descripción de los agentes económicos}

\subsubsection{Instituciones Reguladoras}

En el mercado existen dos grandes instituciones reguladoras:

\section{Banco Central de Reserva del Perú}

En 1922 se promulgó la Ley № 4500 que creó al Banco Central de Reserva del Perú como un organismo constitucional autónomo del Estado Peruano. Tiene como misión preservar la estabilidad monetaria y goza de autonomía de decisión. Es el encargado de la ejecución de la política monetaria en el país, conducido bajo un esquema de metas explicitas de inflación. El Banco Central de Reserva toma decisiones de política monetaria que establecen la tasa de interés de referencia del mercado interbancario. 
La transparencia es una característica intrínseca del Banco Central de Reserva debido a que las decisiones de política monetaria se publican en notas informativas, reportes de inflación y reportes de estabilidad financiera.

Los instrumentos de política monetaria son los siguientes (BCRP, 2009):

Certificados de depósito del BCRP (CD BCRP): sirven para la esterilización de los excedentes de liquidez de las entidades bancarias. Existen los Certificados de Depósito Reajustables, los cuales se reajustan a la variación del tipo de cambio correspondiente al periodo de tiempo entre la emisión y el vencimiento; los Certificados de Depósito Liquidables en Dólares, que es equivalente a una acción de compra temporal de dólares americano en el mercado spot esterilizada con la colocaciones del certificado de depósito; los Certificado de Depósito con Tasa de Interés Variable, los cuales se reajustan en función a la tasa de interés de referencia de la política monetaria; y los Depósitos a Plazo que son utilizado para retirar liquidez en episodios de grandes entradas de capitales de corto plazo.

Operaciones de reporte (REPO): Tienen la finalidad de brindar liquidez de corto plazo a las entidades bancarias en situación de estrechez de liquidez. Cuando se ejecuta una operación de reporte, la base monetaria se incrementa y al efectuarse la recompra de los títulos la base disminuye.

Compra-venta de moneda extranjera: Las intervenciones cambiarias buscan minimizar la volatilidad del tipo de cambio, sin establecer un nivel sobre el mismo. Solo apuntan a disminuir los movimientos bruscos de la cotización de la divisa que puedan deteriorar de forma acelerada los balances de los agentes económicos. No existe una meta en relación al precio de la divisa. 
Swap cambiarios: El emisor paga o recibe una tasa fija en moneda extranjera más la variación el tipo de cambio en razón de recibir o pagar una tasa variable en moneda nacional. Son instrumentos utilizados para reducir el nivel de volatilidad del tipo de cambio producido por la evolución del mercado de derivados. Al no existir algún desembolso, esta transacción no afecta la base monetaria.

Créditos de regulación monetaria. Es una instrumento de ventanilla conocido como redescuento que cubre los descalces de liquidez de las entidades financieras del sistema peruano.

REPO directa: se diferencia de la REPO original debido a que se realiza fuera de la subasta de cierre de la operación y se aceptan un mayor rango de colaterales.

Deposito Overnight: son instrumentos de regulación monetaria que permiten que las entidades financieras efectúen depósitos a un día de plazo y son remunerados a una tasa fijada por el BCRP para así reducir la liquidez. Sirven para automáticamente retirar los excedentes de fondos en cuentas corrientes luego de cubrir el requerido por encaje.

Tasa de Encaje legal: es el porcentaje de los depósitos que se tiene que mantener en reserva y no pueden utilizarse para medios de intermediación financiera. En otras palabras, son los activos líquidos que se deben mantener para fines de regulación monetaria en efectivo y como depósitos en cuenta corriente. La tasa de encaje se utiliza para controlar la disponibilidad de fondos prestables en el sistema. También el encaje sirve para asegurar que el cumplimiento de las obligaciones con los depositantes no se vea interrumpido por la inexistencia o falta de liquidez. En el País la intermediación en moneda extranjera implica un mayor riesgo (riesgo cambiario); por ello el encaje en moneda extranjera es más elevado en comparación al de moneda nacional. 
Al Banco Central de Reserva también le compete (BCRP, 2009):

Administración de reservas internacionales: En situaciones o periodos de turbulencia económica en el país con respecto a los mercados financieros y de divisas, las reservas son utilizadas para asegurar la estabilidad macroeconómica. La política de administración de las reservas internacionales del país no solo toma en consideración garantizar y conservar la liquidez de estas, sino también obtener rendimientos positivos de los fondos.

Emisión de billetes y monedas: El banco es la única entidad que puede atender la demanda de dinero del país. Para sustentar la existencia de un sistema de transacciones fluido, la ejecución del Programa Monetario del Banco Central considera tres factores: cantidad, calidad y tipos de denominación demanda. La demanda de dinero se divide en los siguientes flujos: la primera correspondiente a la reposición continua generada por la necesidad de reemplazar billetes o monedas deteriorados y la segunda, correspondiente a las necesidades y dinamismo de la economía del país.

\section{Superintendencia de Banca, Seguros y AFP (SBS)}

Se creó con el nombre de Superintendencia de Bancos en el año de 1931 con la finalidad de controlar y supervisar los bancos que conformaba el sistema financiero. Actualmente, es el organismo encargado de la regulación y supervisión del sistema financiero, del sistema de seguros y del sistema privado de pensiones. Tiene como misión resguardar los intereses del público, velar por la inclusión financiera, fomentar la trasparencia de información entre las instituciones y prevenir y luchar en contra del financiamiento del terrorismo y el lavado de activos. El enfoque de la SBS es crear un aparato que incentive que las empresas participantes del mercado financiero tomen decisiones de 
promuevan la estabilidad del sistema y salvaguarden la solvencia en el largo plazo.

Entre las principales funciones y atribuciones de la Superintendencia esta:

- Aprobar la organización y funcionamiento de personas jurídicas que tengan por fin realizar operaciones dentro del sistema privado de pensiones.

- Interpretar los alcances de las normas legales que rigen a las empresas en el sistema financiero.

- Establecer las normas generales que regulen los contratos e instrumentos financieros.

- Velar por el cumplimiento de las leyes y reglamentos que rige al sistema financiero.

- Disponer la individualización de riesgos por cada empresa de manera separada. 


\subsubsection{Banco}

Es una empresa financiera que gestiona operaciones y servicios de carácter financiero, funciona como un sistema de pagos, acepta depósitos de dinero del público y utiliza los depósitos, junto a su propio capital y de otras fuentes, para otorgar préstamos en el mercado. Es un Intermediario financiero indirecto ya que se encarga de ofrecer sus propias promesas de pago para los agentes superavitarios de la economía y con los fondos obtiene promesas de pago a los agentes deficitarios. El termino de banca de operaciones múltiple se refiere al hecho de brindar en conjunto los servicios de depósito, ahorro, financiero, hipotecario, fiduciario entre otros. (BCRP, 2011):

Desde el punto de vista económico, su principal función es la asignación de recursos a través de la utilización eficiente de los fondos. Debido a ello, existe una correlación positiva entre intermediación financiera y crecimiento económico. Si se interrumpen o paralizan los servicios que otorgan, se generan externalidades en la economía ya que el Banco trabaja con dinero de terceros. Dentro de las principales tareas que cumplen los Bancos están: brindar acceso a un sistema de pagos, la gestión del riesgo de sus activos y el procesamiento de información.

La principal operación económica que ofrecen los Banco es el créditos, que es una promesa de pago de algún, servicio o dinero en el futuro (BCRP, 2011). Para que un Banco coloque un crédito en el sistema, primero debe poseer los fondos necesarios y cumplir con las regulaciones. Para ello, necesita contar con los suficientes niveles de depósitos, fondos de otras entidades y patrimonio que respalde sus operaciones. A partir de ahí, se gestionan los procesos de evaluación para determinar si la colocación del crédito resultan rentables para el negocio. A razón de cada crédito, se asigna una provisión que es calculada de acuerdo al monto colocado, el nivel de riesgo de la operación, la clasificación financiera y otras regulaciones adicionales. Finalmente, existe un monto de capital requerido en el patrimonio para hacer frente al caso en que se incumpla 
con el pago del crédito. Según el pago de las cuotas, el Banco contabilizará como ingresos los intereses cobrados y los servicios financieros realizados.

Antes del periodo de tiempo del estudio (2001-2014), en la Banca Peruana ocurrieron hechos importantes que explicar. A inicios de la década de los noventas, se dieron una serie de reformas de ajuste estructural dentro del sector bancario para enfrentar los desajustes macro económicos de la época. El contexto económico era complicado por la hiperinflación, déficit de la balanza de pagos y el déficit fiscal. La política aplicada en dicho periodo fuel el shock del precio bienes y servicios públicos y la elección de un ancla monetaria. Este resulto en una recesión económica que socavo la inercia inflacionaria. (Gonzales, 2007)

En paralelo se ejecutaron reformas al sector financiero. En 1990 se derogó la Ley de Estatización de la Banca y se redactó una nueva Ley General de Instituciones Bancarias, Financieras y de Seguros. Punto claves fue la determinación del encaje mínimo legal de hasta 9\%, la liberalización de la tasa de interés, la apertura a la inversión extranjera, el desarrollo de las céntrales de riesgo, el cierre del mercado único de cambios, la creación del fondo de seguros de depósito y la liberalización las importaciones. A causa de lo anterior, en los años posteriores se dio la estabilización de la economía y la liberalización financiera. Se dinamizó al Perú frente a otros países de la región y a la par ocurrió el fortalecimiento de la supervisión y esquemas de regulación. (ASBANC, 2014)

A finales de los noventas se dio un evento catalogado como las crisis bancarias. La repercusión de choques y la represión del fenómeno del niño genero una ruptura en la cadena de pagos que desembocó en la realización de pérdidas dentro del Sistema Bancario. Incluso las empresas de primer orden que ya poseían líneas de créditos aprobadas no podían disponer de los recursos otorgados debido a que los Bancos utilizaban sus fondos disponibles para pagar sus obligaciones con el exterior. Ante este escenario, surgió como alternativa la 
fusión de empresas. Esto conllevó a la desaparición de unas y la fusión de otras entidades. Como fuente de apoyo al contexto, se ejecutó un programa de Canje de Cartera por Bonos del Tesoro Público, el Programa de Consolidación Patrimonial del Sistema Financiero y el Programa de Adquisiciones Activos del Banco de la Nación. (Velarde, 2001)

A partir del 2002 surge el sector de la Micro Finanzas, conformado por las Cajas Rurales de Ahorro y Crédito y las Micro financieras, a raíz de la aparición de un nuevo nicho en el mercado compuesto por la pequeña y mediana empresa. Esto repercutiría en el nacimiento de nuevos productos financieros adaptados a las necesidades de los segmentos por parte de la Banca (Webb, 2009). A partir del año 2004 se vivió una etapa de crecimiento en los indicadores de la Banca Comercial Privada, dentro de un contexto positivo de la economía del país. Ejemplo de ello fue el crecimiento de las colocaciones y los depósitos, disminución de la mora e incremento de las utilidades reportadas (ASBANC, 2005). A partir del periodo de estabilización, entraron nuevos participantes a la Banca en el año 2006 como el Scotiabank y el HSBC Bank Perú.

Mientras tanto en Estados Unidos, en paralelo se estaba desatando el colapso de la Burbuja Inmobiliaria. Esto género en el 2007 la Crisis de Hipotecas SubPrime provocado por el incumplimiento en los pagos de las deudas. Esto repercutió en una crisis económica y de liquidez que se expandió al sistema financiero internacional (Bellod, 2010). Durante el año 2009, el Sistema Peruano se encontraba pendiente de las repercusiones. A pesar de la situación complicada a nivel mundial, la Economía Peruana logró resistir los escenarios negativos del exterior a causa de su fortaleza macroeconómica. Superada la etapa más crítica de la crisis, la economía de Perú logró continuar con su crecimiento y el desarrollo de la Banca.

Los factores claves para la evolución de la Banca en la última década fueron: la expansión del sector Retail o la Banca Minorista, la aparición de 
nuevas metodologías de evaluación de créditos, la ampliación de la oferta de productos financieros para los distintos segmentos de clientes, el incremento del nivel de transacciones mediante la apertura de canales electrónicos y la dependencia a los sistemas de información.

Para el periodo de análisis se utilizarán los 5 Principales Bancos de Operaciones Múltiples del Sistema Bancario Peruano (Banco de Crédito del Perú BCP, BBVA Banco Continental, Scotiabank, Interbank y el Banco Interamericano de Finanzas). Se está desagregando por Entidad debido a qué se espera determinar en el proceso de análisis del estudio si es que algún comportamiento anómalo es producto del Sistema en conjunto o de un participante en específico. También, para comparar distintos comportamientos y resultados entre entidades. Este conjunto seleccionado representa el $87 \%$ de la participación total de los créditos directos en el mercado. De haber incluido un participante al Banco Financiero, el porcentaje de participación hubiera incrementando en $2.7 \%$. A continuación, a este grupo inicialmente mencionado se le identificará como las Principales Entidades seleccionadas de la Banca Múltiple (Figura 2.1). El Banco Scotiabank recién inicio sus operaciones oficialmente en el año 2006, a partir de la adquisición del accionariado del Banco Sudamericano y al Banco Wiese Sudameris. Por ello, para el periodo de análisis antes de dicha fecha, se está agrupando a las dos entidades como Banco Scotiabank. 
Figura 2.1

Créditos Directos por Banco y participación. Cierre dic. 2014. (en miles de nuevos soles, en porcentajes)

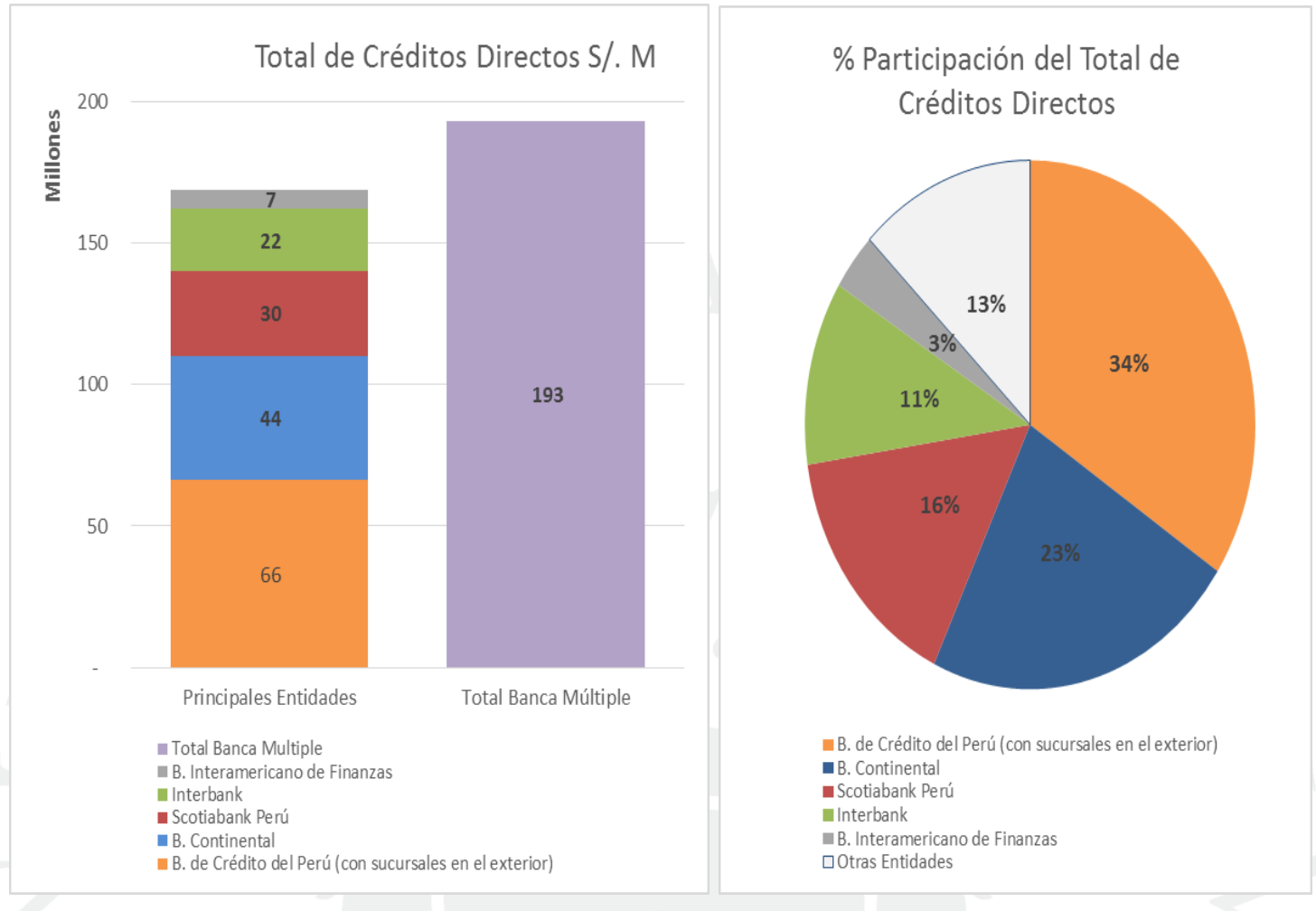

Fuente: SBS (revisado el 1 de mayo del 2015). Boletín Estadístico de Banca Múltiple. En: http://sbs.gob.pe/app/stats/EstadisticaBoletinEstadistico.asp?p=1\#

A inicios del año 2000 existían 15 Bancos en el mercado Peruano, los que después se reducirían a 10 empresas para el año 2005. Progresivamente irían creciendo a 16 entidades en el 2009, número el cual no ha tenido variaciones importantes hasta el 2015.

La Participación de mercado en los créditos directos colocados del Banco de Crédito BCP y del BBVA Continental, las dos entidades de mayor presencia del sector, se han mantenido establea alrededor del $34 \%$ y $23 \%$ respectivamente. La participación del Banco Scotiabank antes de su ingreso oficial en el mercado estaba por encima del $20 \%$ y actualmente circula alrededor del 15\%. El Banco Interbank ha ido paulatinamente aumento su participación de 
$7 \%$ a inicios del 200 a 11\% a finales del 2014. El Banco Interamericano de Finanzas se ha mantenido rezagado con una participación del $4 \%$ en el periodo de estudio.

En la industria bancaria se verifica que existe Competencia Monopolística. Esto producto a que el indicador de competencia $\mathrm{H}$ de Panzar y Rosse es aproximado a 0.5. Este índice $\mathrm{H}$ se define como la suma de las elasticidades de los ingresos financieros con el precio de los factores de producción de la industria; es una medida agregada de competencia y no brinda conclusiones sobre la situación de los distintos productos financieros. El comportamiento de este indicado $\mathrm{H}$ en los últimos años evidencia que la competencia en la industria bancaria nacional ha crecido ligeramente. (Céspedes, 2014)

\subsection{Descripción de las variables}

A continuación, se definen las variables que se utilizarán en el Capítulo 3 y se analiza su evolución durante el periodo de estudio.

\subsubsection{Balance General}

Es un informe contable que refleja la situación financiera y económica de una empresa. Se estructura a través de tres cuentas: el activo, el pasivo y el patrimonio. El activo está constituido principalmente por los créditos desembolsados por parte del banco, el dinero disponible para dar soporte a las transacciones y la cartera de inversiones. El pasivo se compone en su mayoría por los depósitos otorgados por el público y las obligaciones con otras instituciones. El patrimonio se concentra en el capital social y en reservas. 
Se presenta la composición del Balance General Agregado de los 5 Principales Bancos de Operaciones Múltiples en el Perú al cierre del año 2014: El Disponible corresponde el 22\% del activo. Los fondos Interbancario son los fondos depositados entre los Bancos y en las reservas del BCR que representan el 0,2\%. Las Inversiones después de restar las Provisiones tienen el 8\%. El 1,3\% corresponde a activos fijos. Las obligaciones con el público representan el $62 \%$ de los pasivos. Los Adeudados, que son las obligaciones financieras con otras entidades, componen el 18\%. El Patrimonio equivale al 10\%. (Tabla 2.1)

Tabla 2.1

Balance General Agregado de los 5 Principales Bancos de Operaciones Múltiples.

Cierre dic.2001-dic. 2014. (en miles de nuevos soles)

\begin{tabular}{|c|c|c|c|c|c|c|c|}
\hline \multicolumn{8}{|c|}{$\begin{array}{l}\text { Balance General Agregado de los } 5 \text { Principales Bancos de Operacio } \\
\qquad \begin{array}{l}31 / 12 / 2001---31 / 12 / 2014 \\
\text { (En miles de nuevos soles) }\end{array}\end{array}$} \\
\hline \multirow[b]{2}{*}{ ACTIVOS } & \multicolumn{2}{|c|}{ \% Participación } & \multirow{2}{*}{$\begin{array}{r}\text { Nuevos soles } \\
\text { dic-14 } \\
\end{array}$} & \multirow[b]{2}{*}{ PASIVOS } & \multicolumn{2}{|c|}{ \% Participación } & \multirow{2}{*}{$\begin{array}{r}\text { Nuevos soles } \\
\text { dic-14 } \\
\end{array}$} \\
\hline & dic-01 & dic-14 & & & dic-01 & dic-14 & \\
\hline Disponible & $23.4 \%$ & $21.9 \%$ & $54,896,300$ & Obligaciones con el público & $71.1 \%$ & $61.7 \%$ & $154,847,434$ \\
\hline Fondos interbancarios & $0.4 \%$ & $0.2 \%$ & 574,992 & $\begin{array}{l}\text { Depósitos del sistema } \\
\text { financiero y organismos } \\
\text { internacionales }\end{array}$ & $1.4 \%$ & $1.3 \%$ & $3,239,252$ \\
\hline $\begin{array}{l}\text { Inversiones netas de } \\
\text { provisiones }\end{array}$ & $11.8 \%$ & $8.3 \%$ & $20,923,487$ & Fondos interbancarios & $0.4 \%$ & $0.2 \%$ & 514,800 \\
\hline $\begin{array}{l}\text { Créditos netos de } \\
\text { provisiones y de ingresos } \\
\text { no devengados }\end{array}$ & $52.0 \%$ & $64.3 \%$ & $161,444,598$ & $\begin{array}{l}\text { Adeudos y obligaciones } \\
\text { financieras }\end{array}$ & $11.6 \%$ & $18.1 \%$ & $45,369,109$ \\
\hline $\begin{array}{l}\text { Cuentas por cobrar netas } \\
\text { de provisiones }\end{array}$ & $1.8 \%$ & $1.6 \%$ & $4,011,300$ & $\begin{array}{l}\text { Obligaciones en circulación } \\
\text { no subordinadas }\end{array}$ & $1.1 \%$ & $4.0 \%$ & $10,025,786$ \\
\hline Rendimientos por cobrar & $1.3 \%$ & $0.5 \%$ & $1,249,832$ & Cuentas por pagar & $0.7 \%$ & $1.5 \%$ & $3,856,630$ \\
\hline $\begin{array}{l}\text { Bienes realizables, } \\
\text { recibidos en pago y } \\
\text { adjudicados netos }\end{array}$ & $0.6 \%$ & $0.1 \%$ & 127,748 & $\begin{array}{l}\text { Intereses y otros gastos } \\
\text { por pagar }\end{array}$ & $0.5 \%$ & $0.3 \%$ & 754,564 \\
\hline $\begin{array}{l}\text { Inmuebles, mobiliario y } \\
\text { equipo neto }\end{array}$ & $3.9 \%$ & $1.3 \%$ & $3,354,450$ & Otros pasivos & $1.9 \%$ & $0.6 \%$ & $1,392,923$ \\
\hline \multirow[t]{3}{*}{ Otros activos } & $4.7 \%$ & $1.7 \%$ & $4,357,261$ & Provisiones & $0.0 \%$ & $0.5 \%$ & $1,157,812$ \\
\hline & & & & $\begin{array}{l}\text { Obligaciones en circulación } \\
\text { subordinadas }\end{array}$ & $1.4 \%$ & $2.0 \%$ & $4,921,756$ \\
\hline & & & & Patrimonio & $9.8 \%$ & $9.9 \%$ & $24,859,901$ \\
\hline Total Activos & $100 \%$ & $100 \%$ & $250,939,969$ & Total Pasivo + Patrimonio & $100 \%$ & $100 \%$ & $250,939,969$ \\
\hline
\end{tabular}

Fuente: SBS (revisado el 1 de mayo del 2015). Boletín Estadístico de Banca Múltiple.

En: http://sbs.gob.pe/app/stats/EstadisticaBoletinEstadistico.asp? $\mathrm{p}=1 \#$ 
Figura 2.2

Evolución de los Activos de los 5 Principales Bancos de Operaciones Múltiples.

Periodo 2002-2014. (\% Var Anual)

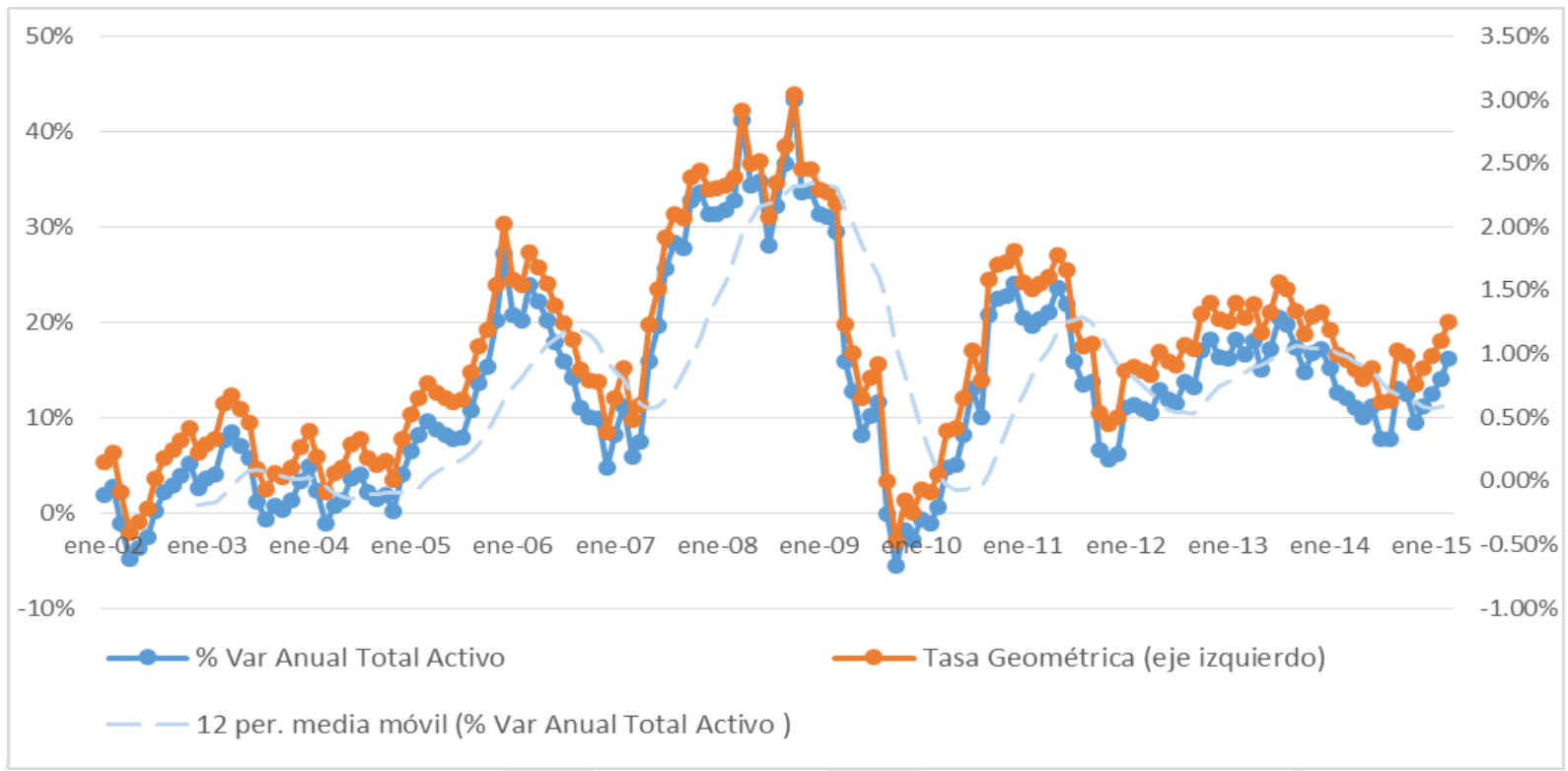

Fuente: SBS (revisado el 1 de mayo del 2015). Boletín Estadístico de Banca Múltiple.

En: http://sbs.gob.pe/app/stats/EstadisticaBoletinEstadistico.asp?p=1\#

En la evolución del crecimiento de los activos de los 5 Principales Bancos de Operaciones Múltiples en el Perú observamos tres periodos de tiempo definidos: el primer periodo, compuesto por un crecimiento anual de hasta $30 \%$ en diciembre del 2005 que fue seguido por una desaceleración en el año 2006; el segundo periodo, conformado por una aceleración importante de la tasa de crecimiento hasta que en el 2008 ocurrió la crisis financiera internacional y se desacelero la tasa de crecimiento hasta llegar a niveles negativos en el año 2009.

(Figura 2.2)

La composición de los activos se mostraba estable, sin un crecimiento nominal significativo hasta el año 2006. A partir del año 2007 comienzan a crecer los créditos netos colocados en la economía, de manera nominal y también en su participación relativa en la hoja del Balance General (Figura 2.2). 
También se registra un crecimiento nominal de las inversiones netas de los bancos, presionados por la necesidad de obtener un rendimiento adicional, diversificado y externo al giro del negocio. (Figura 2.3)

El 66\% del Disponible le pertenece a la cuenta Banca y Corresponsales. El ratio de participación de Disponibles ha disminuido levemente en el periodo analizado y se visualiza que ha sido sujeto a reajustes en periodos de tiempo específico. Esto obedece a las necesidades en determinado fechas de contar con las reservas adecuadas de liquidez.

El nivel de cuentas por cobrar se ha mantenido estable en el periodo de información recogido. Hay que revisar un periodo a finales del año 2010 donde la participación de inversiones netas se contrae para que el nivel de disponibles aumente (Figura 2.4). De este brusco movimiento se puede despejar que se trata de un proceso de liquidación de inversiones en búsqueda de mejorar los niveles de liquidez para enfrentar alguna situación en específico. Al cierre del año 2014, las inversiones netas de provisiones estaban parcialmente (53\%) compuestas por inversiones disponibles a la venta. 
Figura 2.3

Composición de los Activos de los 5 Principales Bancos de Operaciones Múltiples.

Periodo 2001-2014. (\% Participación)

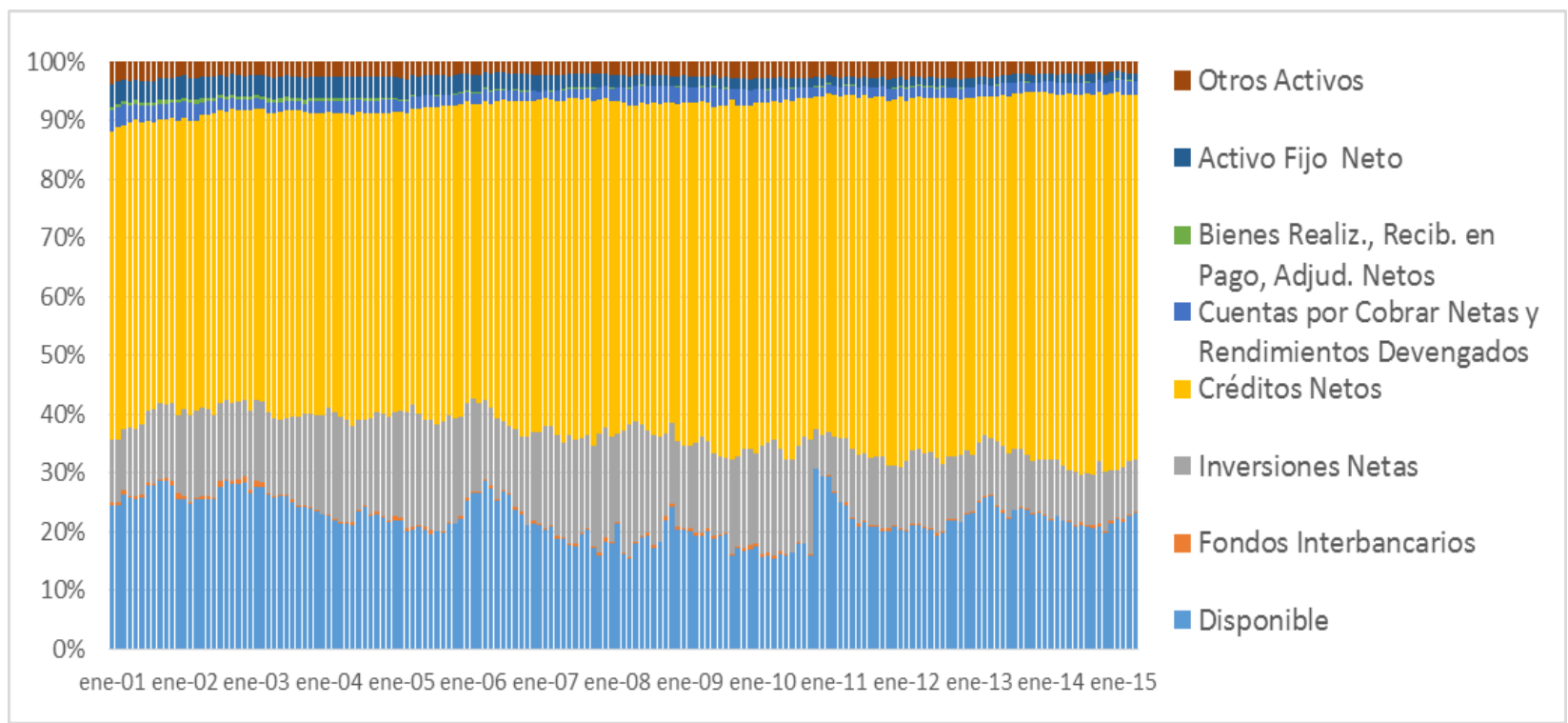

Fuente: SBS (revisado el 1 de mayo del 2015). Boletín Estadístico de Banca Múltiple.

En: http://sbs.gob.pe/app/stats/EstadisticaBoletinEstadistico.asp?p=1\#

Figura 2.4

Evolución de los Activos de los 5 Principales Bancos de Operaciones Múltiples.

Periodo 2001-2014. (En miles de nuevos soles)

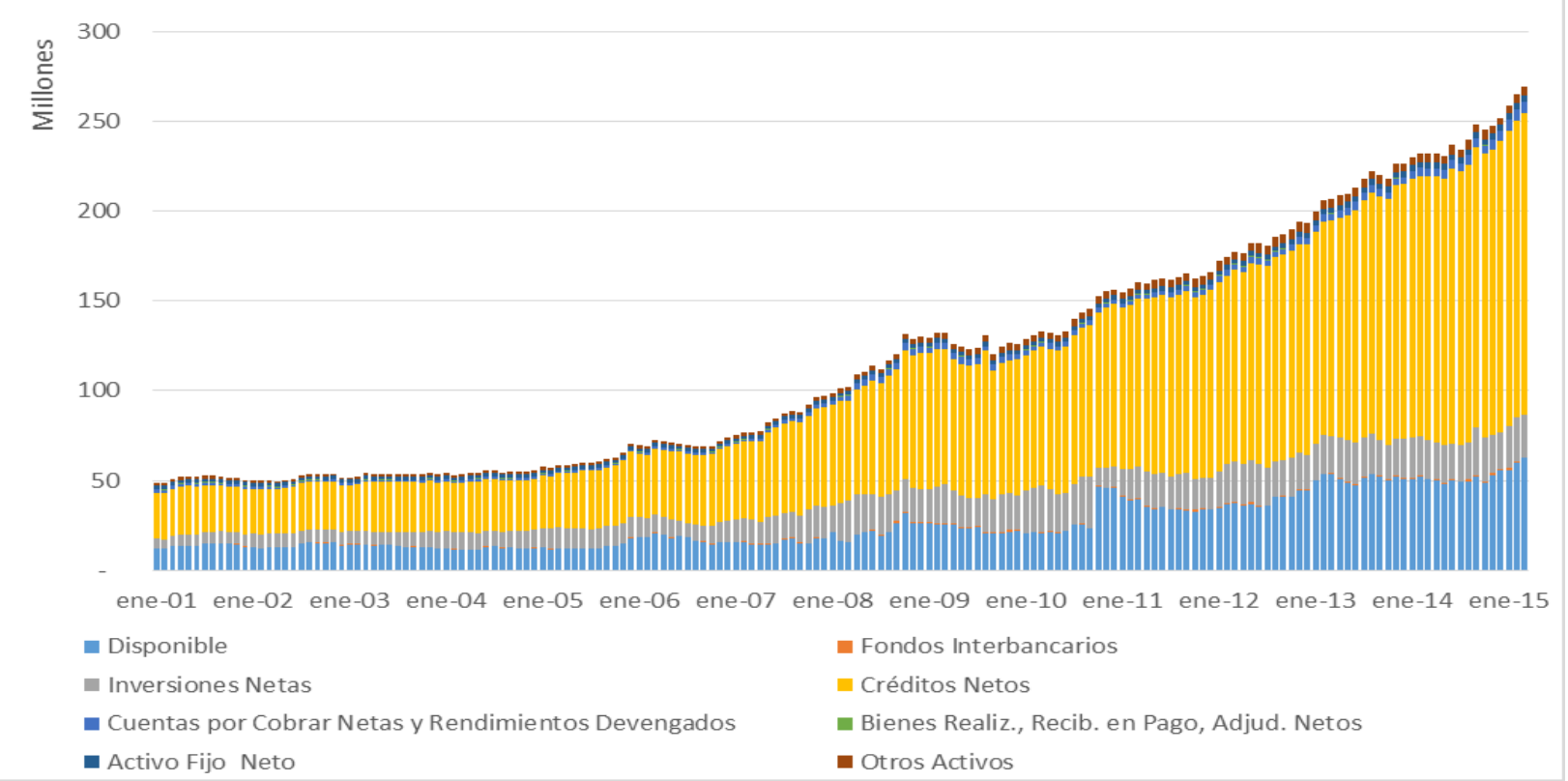

Fuente: SBS (revisado el 1 de mayo del 2015). Boletín Estadístico de Banca Múltiple.

En: http://sbs.gob.pe/app/stats/EstadisticaBoletinEstadistico.asp?p=1\# 
Revisando la vista por pasivos se registra que la composición de las cuentas se ha mantenido constante hasta el año 2007, donde el inicio de la expansión genero modificación en la distribución de los pasivos. Desde el año 2007 los pasivos con el público han sostenido el crecimiento continuo de los pasivos; sin embargo han perdido participación en el total de cuentas. (Figura 2.5)

Las dos cuentas que han crecido nominalmente y relativamente en participación a la vez son los adeudos y obligaciones financieras y las obligaciones en circulación. A partir del 2009 se redujeron los pasivos con el sistema financiero y otros organismos internacionales (Figura 2.6). Las cuentas y gastos por pagar de la banca múltiple se han mantenido constantes y a razón del crecimiento general de los pasivos.

Figura 2.5

Evolución del Pasivo y del Patrimonio de los 5 Principales Bancos de Operaciones Múltiples. Periodo 2002-2014. (Porcentaje Variación Anual)

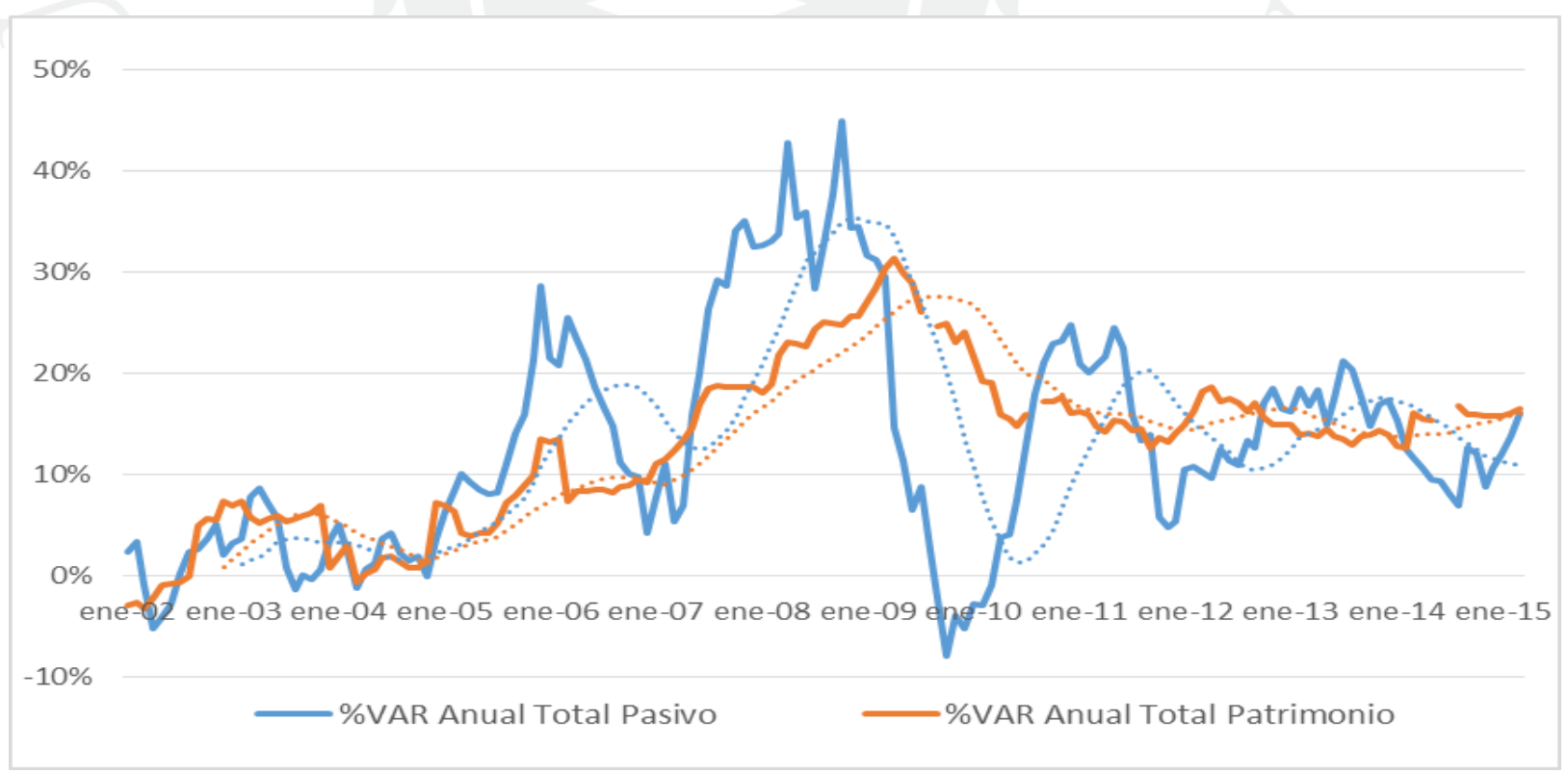

Fuente: SBS (revisado el 1 de mayo del 2015). Boletín Estadístico de Banca Múltiple. En: http://sbs.gob.pe/app/stats/EstadisticaBoletinEstadistico.asp?p=1\# 
Figura 2.6

Composición de los Pasivos de los 5 Principales Bancos de Operaciones Múltiples.

Periodo 2001-2014. (\% Participación)

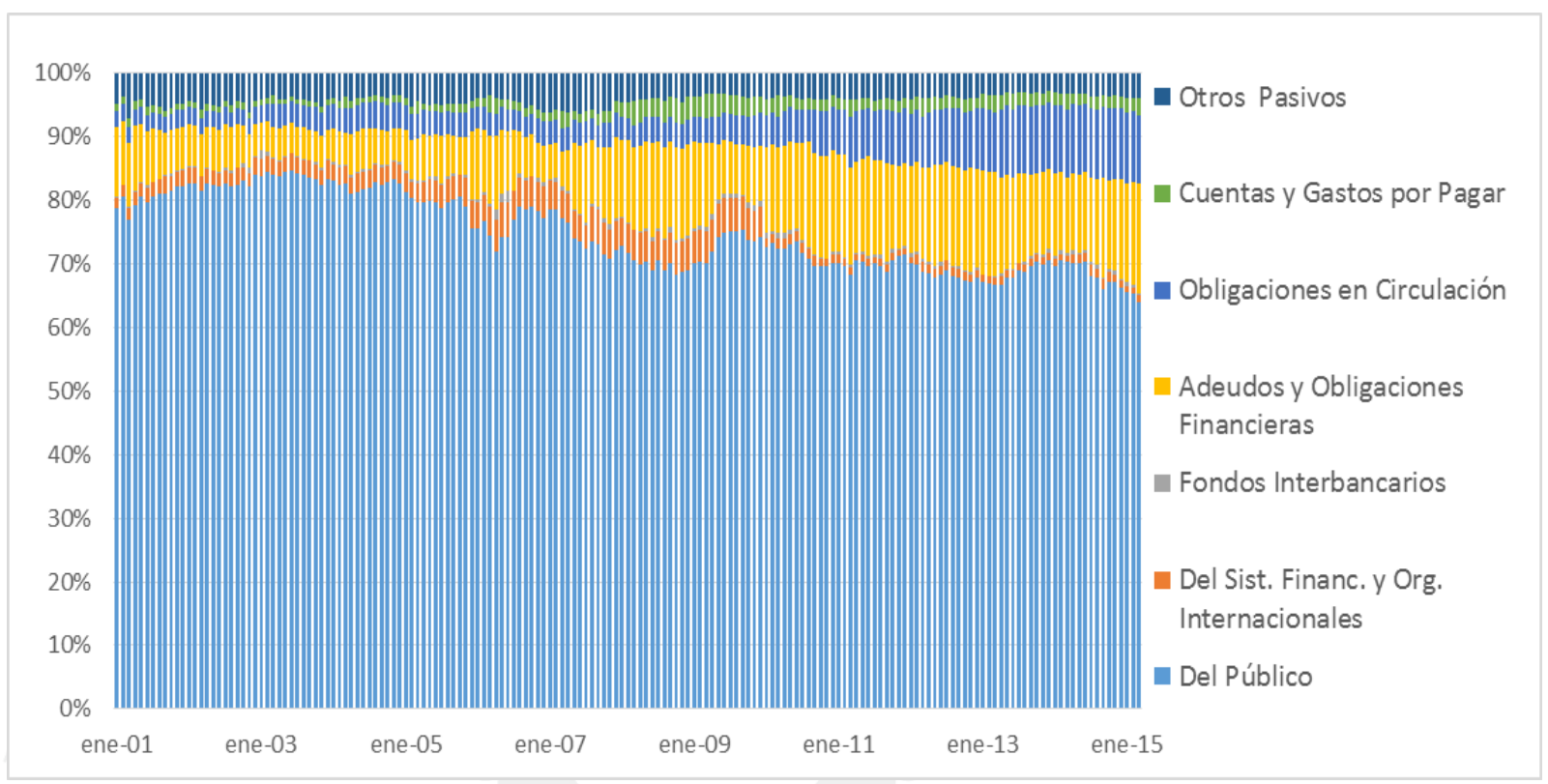

Fuente: SBS (revisado el 1 de mayo del 2015). Boletín Estadístico de Banca Múltiple.

En: http://sbs.gob.pe/app/stats/EstadisticaBoletinEstadistico.asp?p=1\#

Figura 2.7

Evolución de los Pasivos de los 5 Principales Bancos de Operaciones Múltiples.

Periodo 2001-2014. (En miles de nuevos soles)

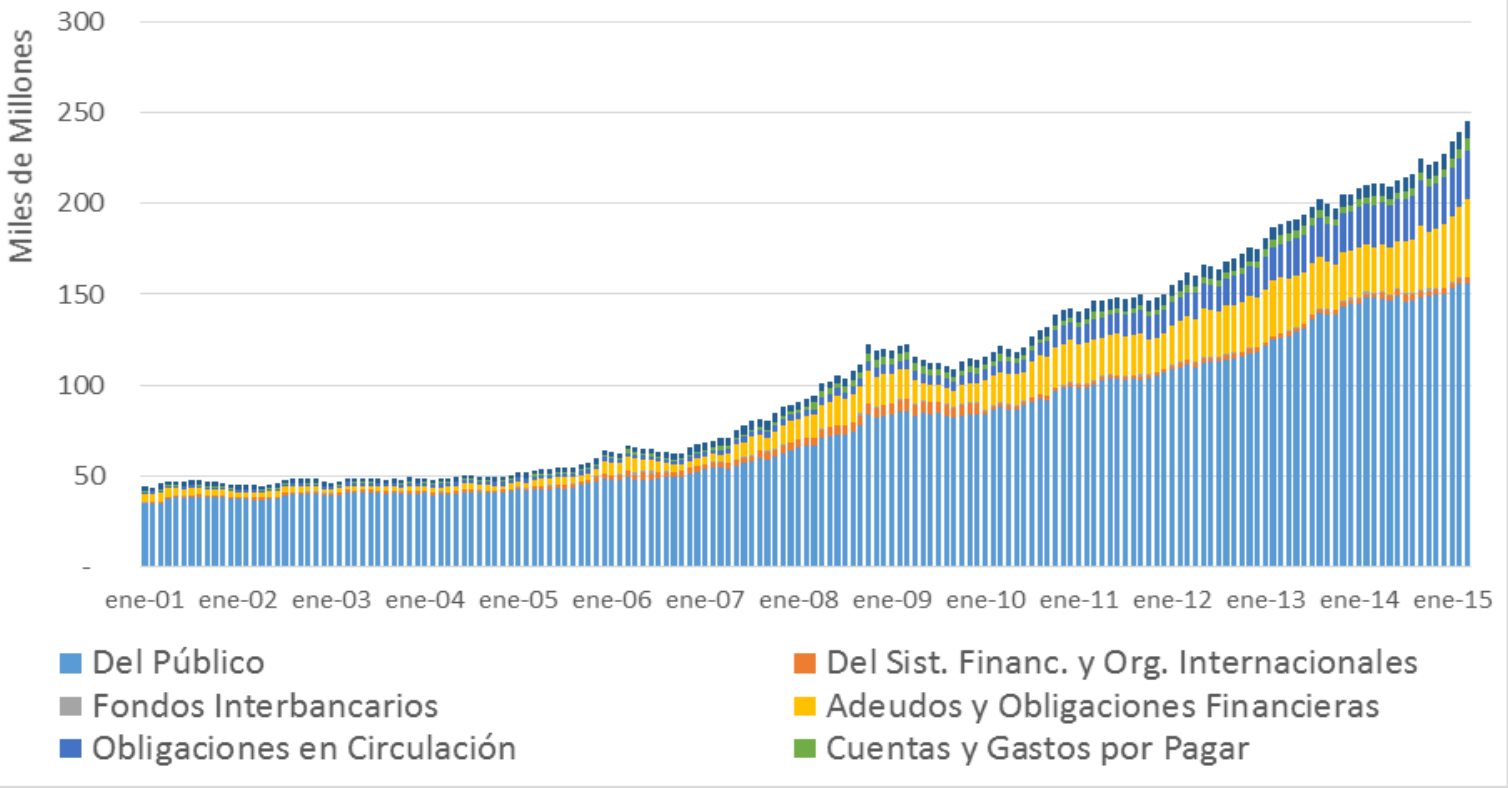

Fuente: SBS (revisado el 1 de mayo del 2015). Boletín Estadístico de Banca Múltiple.

En: http://sbs.gob.pe/app/stats/EstadisticaBoletinEstadistico.asp? $\mathrm{p}=1 \#$ 


\subsubsection{Créditos Directos colocados}

Son los Préstamos desembolsados correspondientes a productos financieros directos. La cartera o portafolio del Banco es la suma de los créditos vigentes, restructurados, refinanciados, vencidos y en cobranza judicial. Se pueden clasificar según tipo, categoría crediticia, modalidad y situación.

Los préstamos directos son los créditos otorgados mediante la firma de un contrato, el cual se amortiza en cuotas o con un solo pago. Los créditos para actividades empresariales poseen una mayor participación que los créditos de consumo e hipotecarios en el país. Los créditos al sector comercio y al sector de la industria manufacturera poseen la mayor participación en el país. (Figura 2.8)

El arrendamiento financiero es un contrato en el cual la institución financiera entrega en uso un activo al cliente a cambio del pago de una renta durante un plazo. Al término del plazo, el arrendatario tendrá la opción de comprarlo. La tasa de crecimiento del producto se ha estancado desde el año 2010. Representan el $12 \%$ de los créditos directos y el saldo se ubica por encima de los S/. 20 mil millones. (Figura 2.8)

Los créditos Hipotecarios para vivienda son otorgados a personas naturales para la adquisición y construcción de vivienda propia, siempre que los créditos se otorguen amparados con hipotecas inscritas. Su nivel de crecimiento se ha desacelerado pasando del $20 \%$ al $15 \%$ anual. El portafolio de créditos hipotecarios asciende a alrededor de S/.30 mil millones. (Figura 2.8)

Las Tarjetas de Crédito son créditos concedidos para adquirir bienes o servicios en establecimientos afiliados o retirar efectivo, bajo condiciones establecidas contractualmente. En los últimos 2 años ha crecido a tasas alrededor del $10 \%$. A cierre del año 2014 el saldo de tarjetas de crédito es de S/. 13 mil millones. (Figura 2.8) 
Figura 2.8

Evolución por Tipo de Crédito Directo de los 5 Principales Bancos de Operaciones

Múltiples. Periodo 2001-2014. (En miles de nuevos soles)
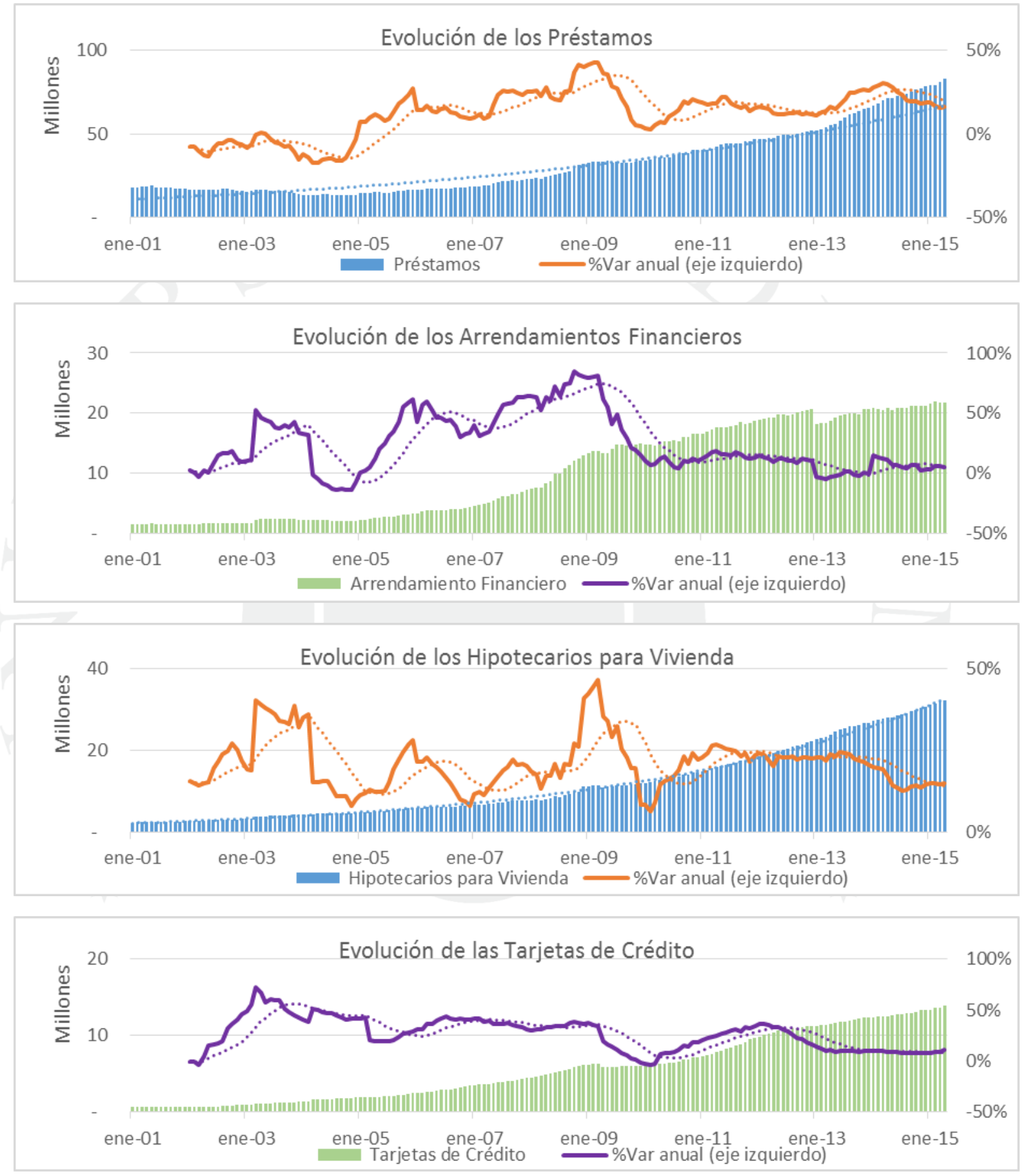

Fuente: SBS (revisado el 1 de mayo del 2015). Boletín Estadístico de Banca Múltiple.

En: http://sbs.gob.pe/app/stats/EstadisticaBoletinEstadistico.asp? $\mathrm{p}=1 \#$ 
Figura 2.9

Evolución de los saldos en Créditos Directos de los 5 Principales Bancos de Operaciones Múltiples. Periodo 2002-2014. (En miles de nuevos soles)

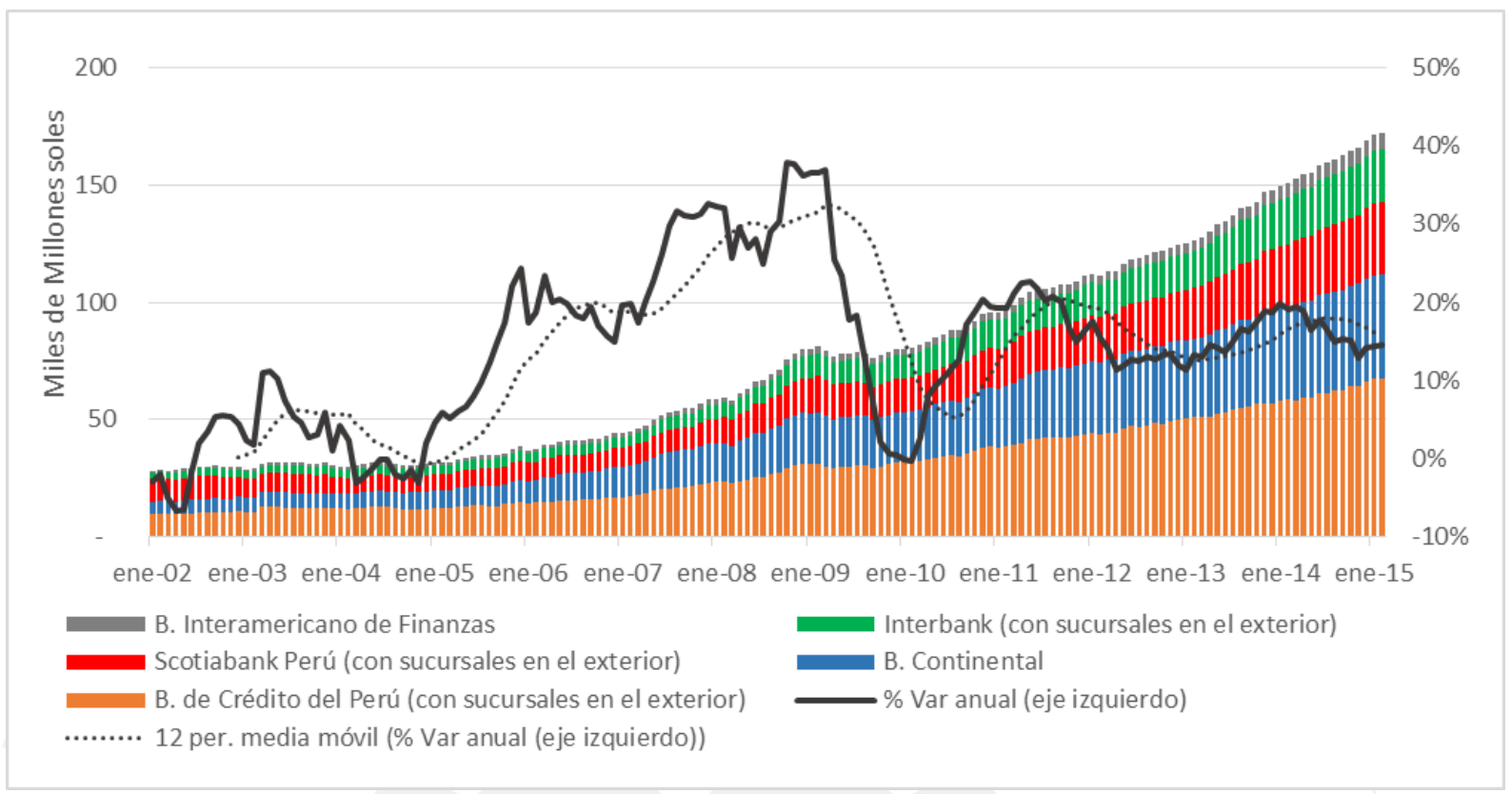

Fuente: SBS (revisado el 1 de mayo del 2015). Boletín Estadístico de Banca Múltiple.

En: http://sbs.gob.pe/app/stats/EstadisticaBoletinEstadistico.asp?p=1\#

Figura 2.10 Evolución de los saldos de Créditos Directos vigentes de los 5 Principales

Bancos de Operaciones Múltiples. Periodo 2001-2014. (En miles de nuevos soles)

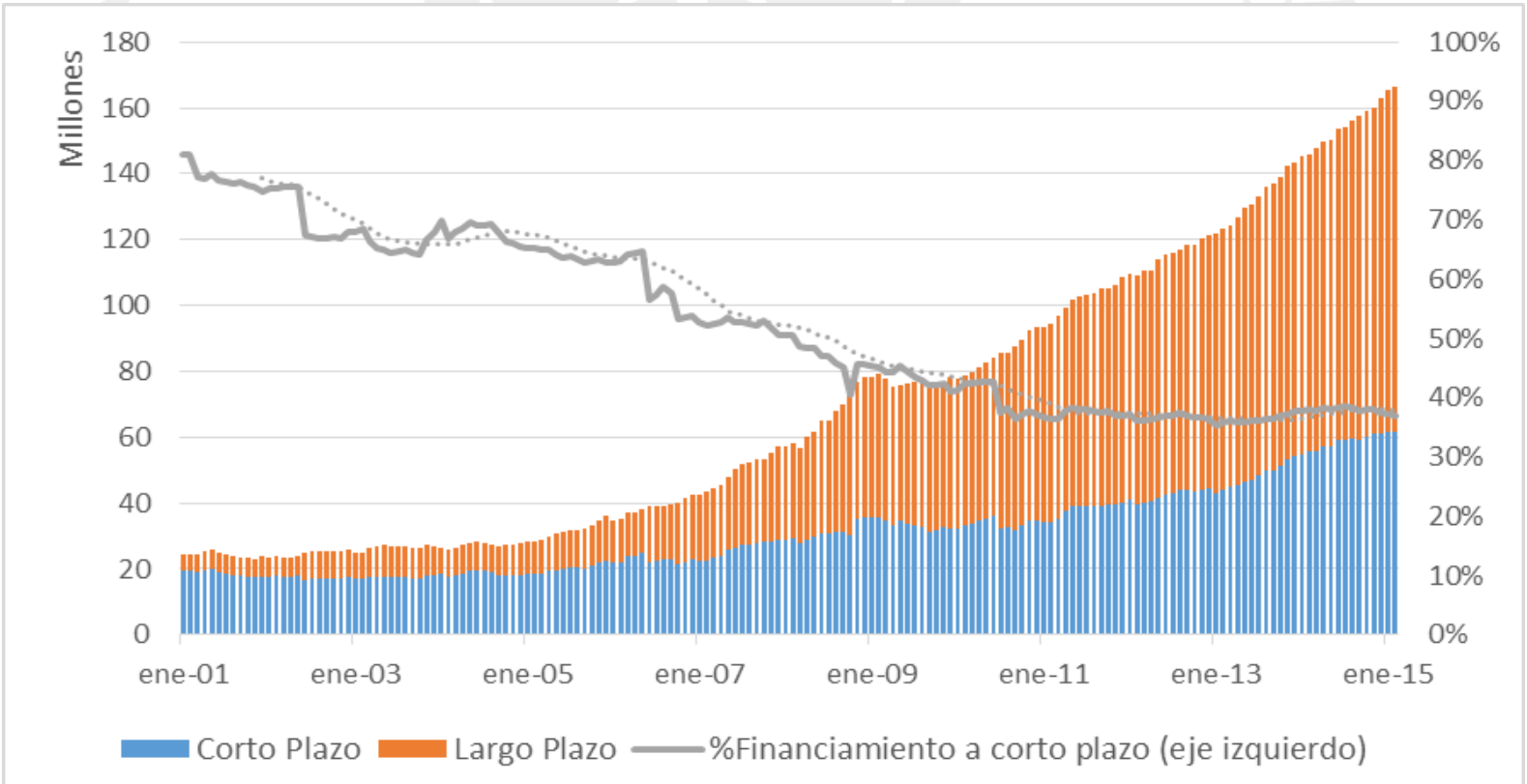

Fuente: SBS (revisado el 1 de mayo del 2015). Boletín Estadístico de Banca Múltiple.

En: http://sbs.gob.pe/app/stats/EstadisticaBoletinEstadistico.asp?p=1\# 


\subsubsection{Depósitos}

Son el conjunto de obligaciones de la empresa bancaria por los depósitos a la vista, de ahorro y plazo. A su vez, sirven como fuente para el financiamiento de los créditos en el mercado financiero. Se registra como una captación de recursos, en donde la entidad financiera se halla en posición deudora con respecto al cliente contribuyente.

Al termino del año 2014 los depósitos de los 5 Principales Bancos de Operaciones Múltiples del Sistema Bancario Peruano se sitúan por encima de los S/. 160 mil millones. Sin embargo a partir del año 2014 se ha registrado una desaceleración del crecimiento anual del $20 \%$ al 5\%. (Figura 2.11). Las captaciones están conformados por Depósitos a Plazo (38\%), a la Vista (30\%) y Ahorro (28\%). Esta composición se ha mantenido constante desde el año 2009.

\section{(Figura 2.12)}

El nivel de recaudación de depósitos brinda al intermediario financiero mayor liquidez y mayor cantidad de activos que pueda prestar. Sin embargo, implica un aumento de las obligaciones de la institución. Representa uno de los componentes más sensibles al contexto económico, ya que los acreedores de los Depósitos pueden decidir retirar su dinero y la entidad se ve en la obligación, de acuerdo al contrato pactado, a devolver el dinero y eso puede implicar una disminución en el Balance General o un descalce de temporal ente Activos y Pasivos. 
Figura 2.11

Evolución de los Depósitos de los 5 Principales Bancos de Operaciones Múltiples.

Periodo 2001-2014. (En miles de nuevos soles)

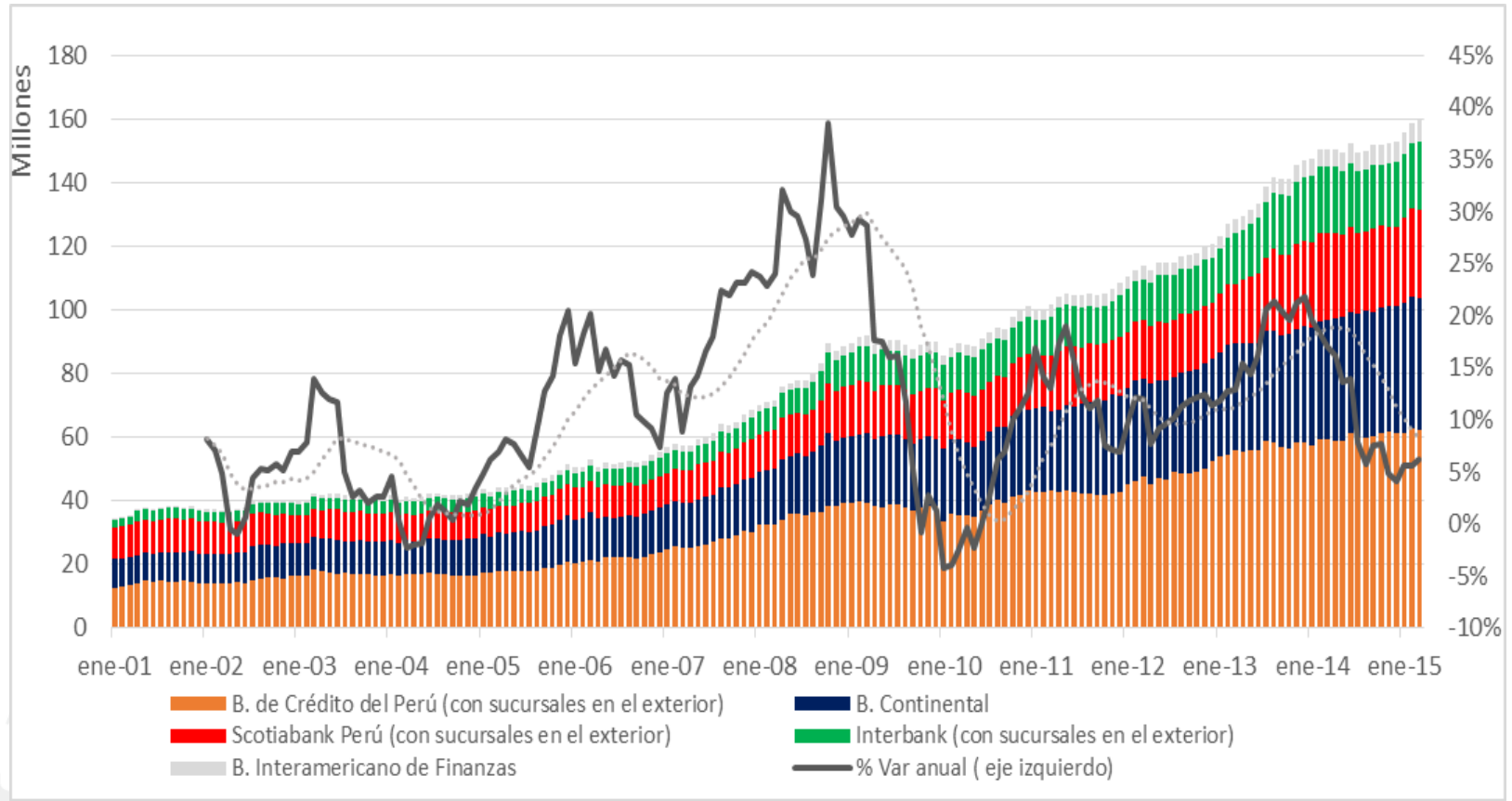

Fuente: SBS (revisado el 1 de mayo del 2015). Boletín Estadístico de Banca Múltiple.

En: http://sbs.gob.pe/app/stats/EstadisticaBoletinEstadistico.asp?p=1\#

Figura 2.12

Composición de los Depósitos de los 5 Principales Bancos de Operaciones Múltiples.

Periodo 2001-2014. (\% Participación)

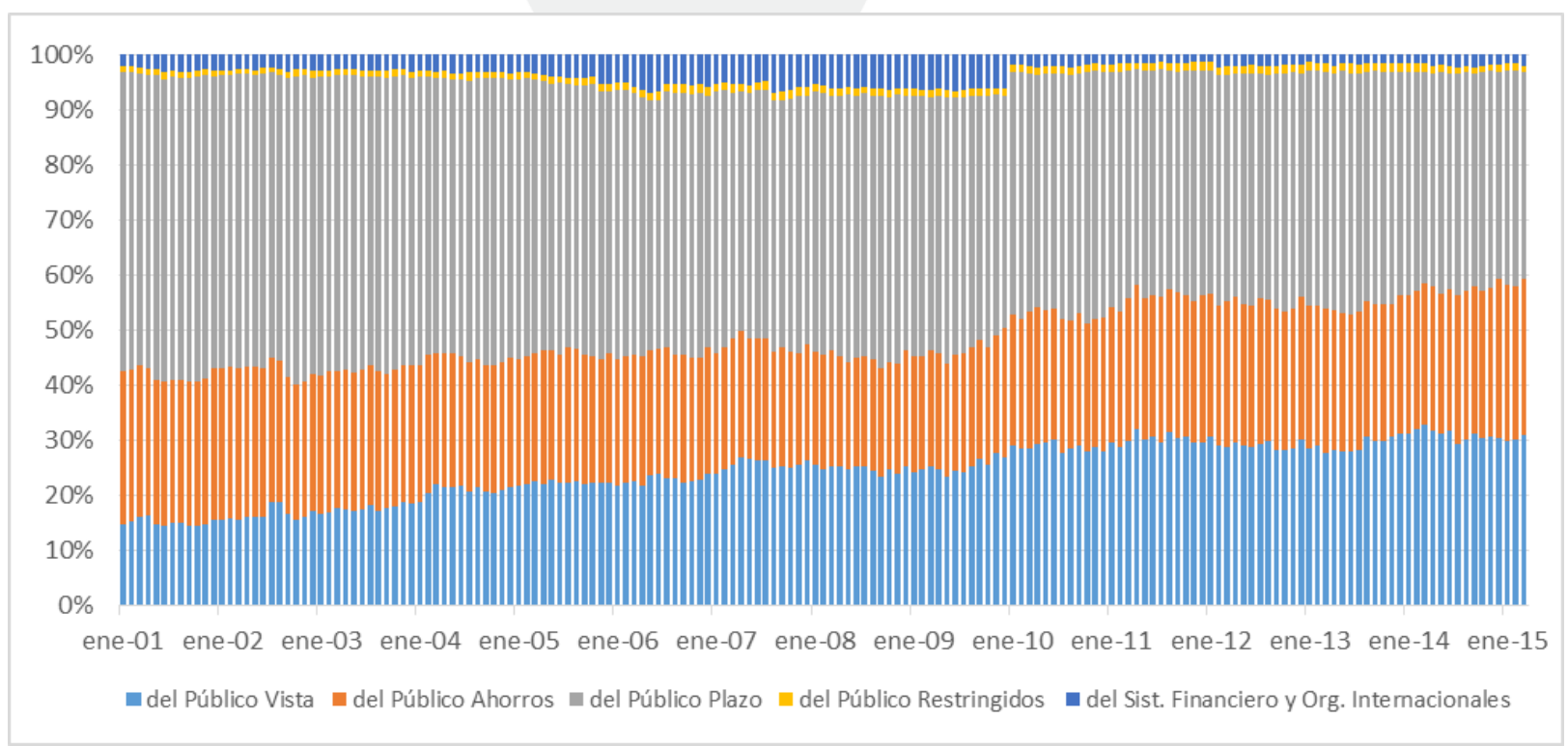

Fuente: SBS (revisado el 1 de mayo del 2015). Boletín Estadístico de Banca Múltiple.

En: http://sbs.gob.pe/app/stats/EstadisticaBoletinEstadistico.asp?p=1\# 


\subsubsection{Adeudos y obligaciones con entidades nacionales y del exterior}

Comprende las obligaciones de la empresa Bancaria por obtención de recursos y financiamiento bajo distintas modalidades contractuales, de corto y largo plazo, contratados por las entidades financieras del exterior que realizan intermediación financiera.

Los 5 Principales Bancos de Operaciones Múltiples del Sistema Bancario Peruano registran Adeudos y Obligaciones financieras por S/. 40 mil millones al cierre del año 2014. Alrededor de S/.22 mil millones son con Instituciones del Exterior. El nivel de Adeudos agregado muestra un comportamiento estacional. A partir de finales del año 2013, el crecimiento de los adeudos con instituciones del País ha crecido a altas tasas, mientras que los Adeudos con el Exterior se han estancado. De manera similar, el nivel de adeudos de largo plazo está retrocediendo en relación al nivel de adeudos de corto plazo. Esto ha repercutido que en el último año, el monto de adeudos agregado haya crecido por encima del $50 \%$. (Figura 2.13)

Desde el año 2008 inicio un proceso de expansión agresivo de las obligaciones con el exterior a largo plazo. Esta cuenta no tenía una participación significativa hasta finales del 2007. Se registra que durante el año 2009, correspondiente a la Crisis Financiera Internacional, se contrajo las Obligaciones con el Exterior de Corto plazo y se contrarresto dicho efecto con el incremento de las obligaciones con instituciones del País al Corto plazo. Es decir, las deudas de corto plazo con el exterior se sustituyeron con obligaciones de instituciones nacionales. Durante este contexto no se afectaron ni el volumen ni participación de las obligaciones con el exterior de largo plazo (Figura 2.13). 
Hasta el año 2014, las deudas a largo plazo con el exterior llegaron a representar el $50 \%$ del total de obligaciones. A partir del último año se está reemplazando estas obligaciones de largo plazo con el exterior por deuda de instituciones del País de Corto plazo (Figura 2.14)

Al cierre del año 2014, las obligaciones con Instituciones del país representan el $47 \%$ mientras que las obligaciones con instituciones del exterior es el 53\%. Según el umbral de tiempo de la obligación, el $49 \%$ es de corto plazo y el $51 \%$ de largo plazo. 
Figura 2.13

Evolución de los Adeudos y Obligaciones Financieras de los 5 Principales Bancos de Operaciones Múltiples. Periodo 2001-2014. (En miles de nuevos soles)

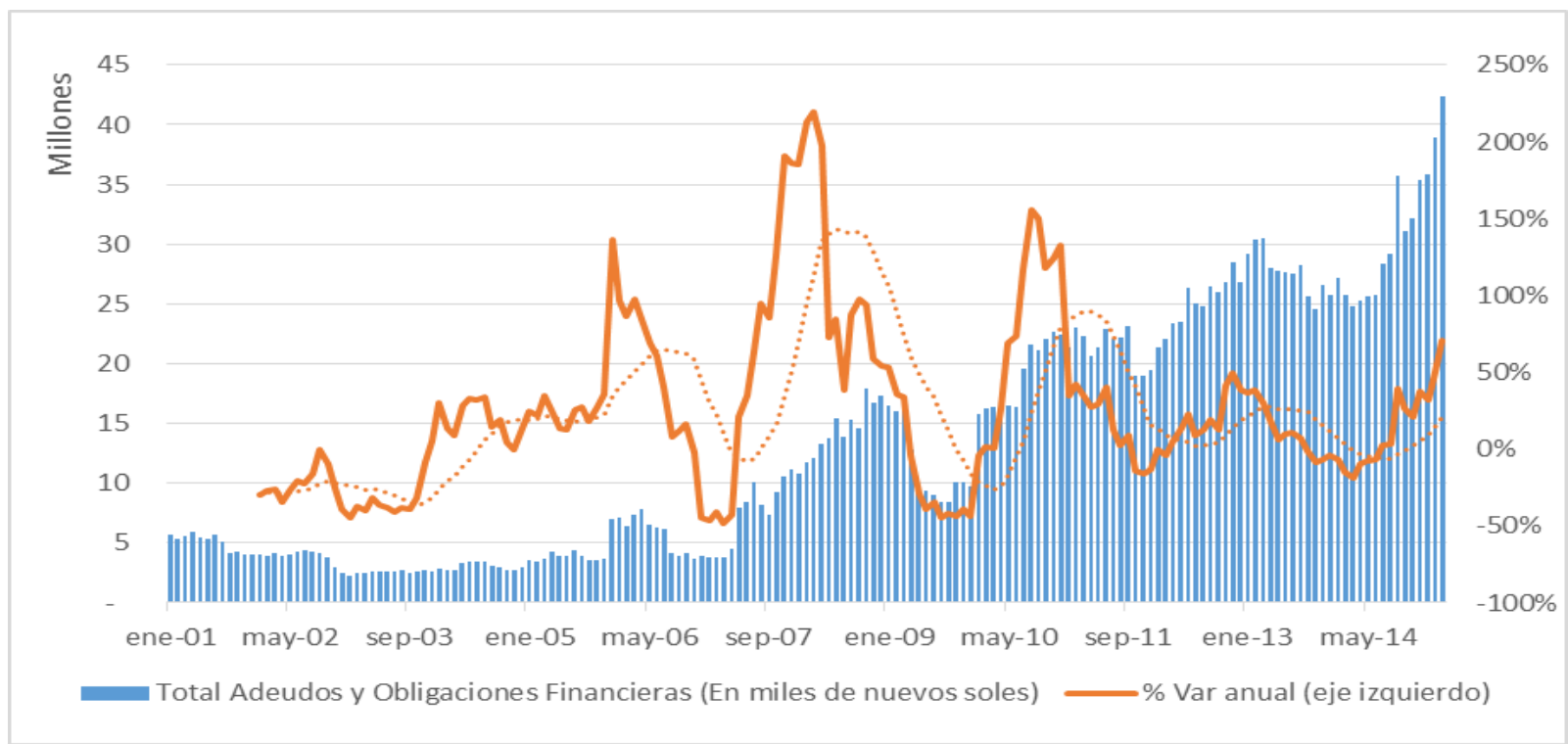

Fuente: SBS (revisado el 1 de mayo del 2015). Boletín Estadístico de Banca Múltiple.

En: http://sbs.gob.pe/app/stats/EstadisticaBoletinEstadistico.asp?p=1\#

\section{Figura 2.14}

Composición de los Adeudos y Obligaciones Financieras de los 5 Principales Bancos de Operaciones Múltiples. Periodo 2001-2014. (\% Participación)

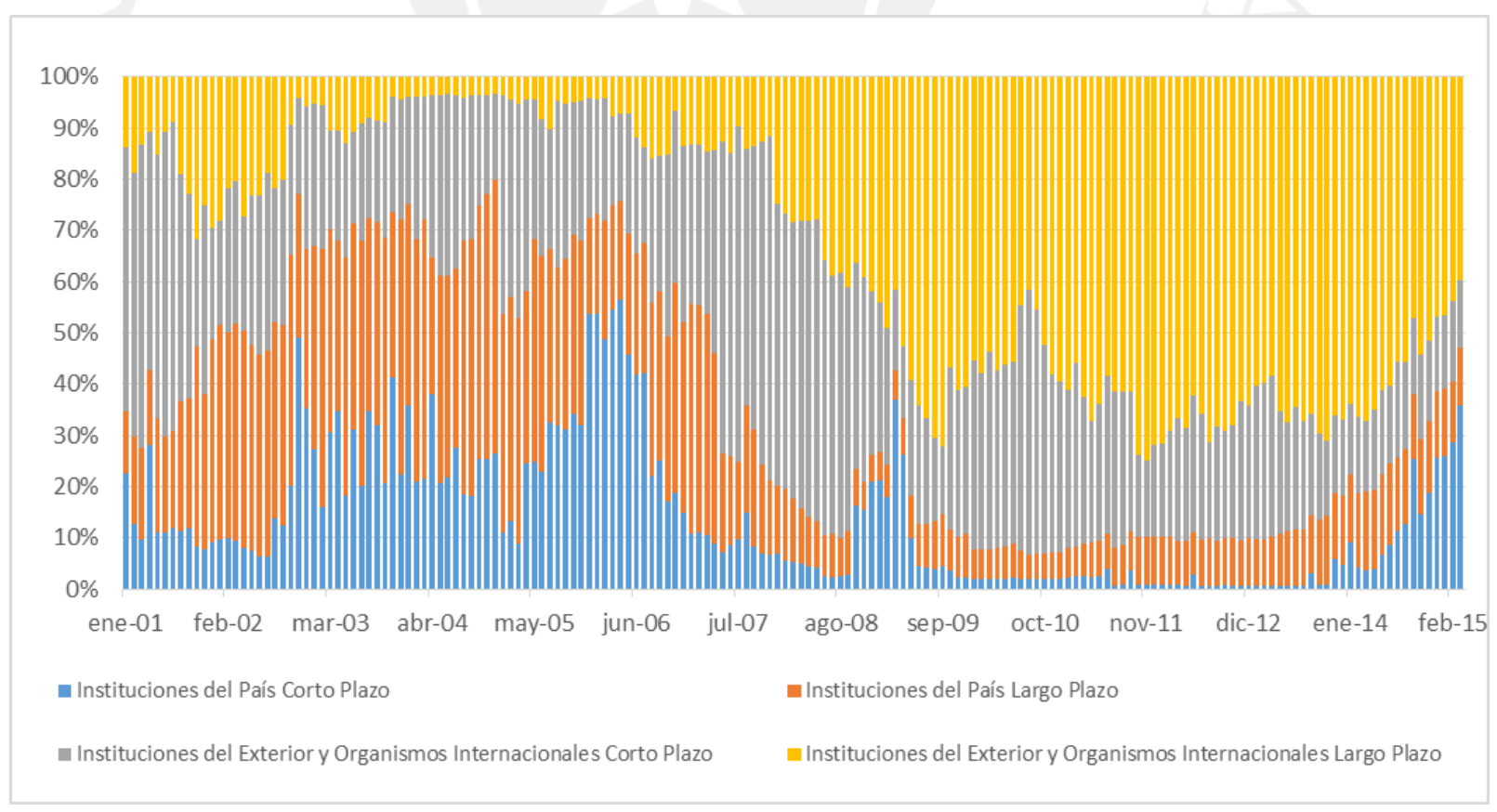

Fuente: SBS (revisado el 1 de mayo del 2015). Boletín Estadístico de Banca Múltiple.

En: http://sbs.gob.pe/app/stats/EstadisticaBoletinEstadistico.asp? $\mathrm{p}=1 \#$ 


\subsubsection{Indicadores de Morosidad y Calidad de Cartera}

La Cartera Créditos Directos Colocados se puede desagregar según situación: Créditos Vigentes, cuyos pagos están al día; Créditos Refinanciados, que han sido modificados con respecto a su contrato original; Créditos Reestructurados, donde el cronograma de pagos ha sido alterado; Créditos Vencidos, los cuales no han sido amortizados en la fecha estipulado y se encuentran impagos; y los Créditos en Cobranza Judicial, que se encuentran en proceso de litigio legal. Los indicadores de Morosidad pertenecen al enfoque de Riesgo Crédito. Estos indicadores sirven para hallar la proporción de créditos directos de la cartera que se encuentra en una situación de deterioro como los créditos reestructurados, refinanciados, vencidos y en cobranza judicial. La cartera atrasada es la suma de los créditos vencidos y en cobranza judicial.

Un aumento de la morosidad o riesgo realizado es un indicador negativo para el Banco ya que repercute directamente en la solvencia de la empresa. Un Banco amortiza el impacto de una situación real de impago a través de las Provisiones. Sin embargo, si el nivel de morosidad supera un determinado umbral, el Banco se encontraría en una situación de pérdida real. Por ello, es prioridad del Banco colocar los créditos a los clientes con mejor perfil para atender sus obligaciones. Para ello, los Bancos se basan en metodologías y procesos dentro del esquema de análisis del Riesgo Crediticio.

La Cartera Deteriorada o de Alto Riesgo es la suma de los créditos reestructurados, refinanciados, vencidos y en cobranzas judiciales; por lo tanto resulta una medición más sensible de la situación de Riesgo Crédito. Al termino del año 2014, el ratio de Cartera Atrasada Agregada de los 5 Principales Bancos de Operaciones Múltiples llego al 2.30\%, acumulando un crecimiento de 32 puntos básicos con respecto al año anterior. A su vez, el ratio de Cartera Deteriorada fue de $3.32 \%$, acumulando un crecimiento de 50 puntos básicos con respecto al año pasado. (Figura 2.16) 
Durante los años 2004 y 2008 la expansión de los Créditos Vigentes, por un aumento en el nivel de desembolsos, repercutió que los indicadores de morosidad descendieran. Esto se muestra en las mayores tasas de crecimiento de los créditos vigentes. Esto fue producto de la mejor situación económica que atravesaba el país en dichos años. (Figuras 2.15, 2.16 y 2.18).

Durante los años 2008 y 2009 los Créditos Directos crecieron a tasas anuales por encima del 30\%; sin embargo a partir de mediados del año 2009 los Créditos en situación Vencido incrementaron abruptamente sus tasas de crecimiento anual, llegando al 80\%. A inicios del año 2010 se repitió dicho comportamiento, pero ahora en los Créditos en situación de Cobranza Judicial. Se puede interpretar que el ciclo de expansión de la Cartera de Créditos Directos fue frenado por la Crisis Financiera Internacional, repercutiendo así en que los créditos llegaran a caer en situación judicial. De manera similar, se puede revisar un efecto similar, pero de menor tamaño, durante los año 2013 y 2014.

Desde el año 2012 el crecimiento de los créditos Vencidos y en Cobranza Judicial ha sido mayor al de los créditos Vigentes. Esto explica el aumento en general en los indicadores de Deterioro en los últimos 3 años. (Figura 2.15)

Al momento de revisar los indicadores de deterioro por cada banco de manera individual, se observa que las políticas de gestión de riesgo son distintas en cada entidad. Por ejemplo, el Banco BBVA Continental posee un mayor porcentaje de refinanciados y reestructurados (1.76\%); mientras que el Banco Interbank tiene un menor porcentaje en cobranza judicial y un mayor porcentaje de vencidos $(0.79 \%$ y $1.75 \%)$. Para el desarrollo de la contrastación de la hipótesis, se utilizará el ratio de Cartera Deteriorada o de Alto Riesgo debido a que es un indicador mucho más sensible que abarca todos los estados de deterioro del crédito. 
Figura 2.15

Variación anual de los Créditos Directos según situación. Periodo 2002-2014. (\%)

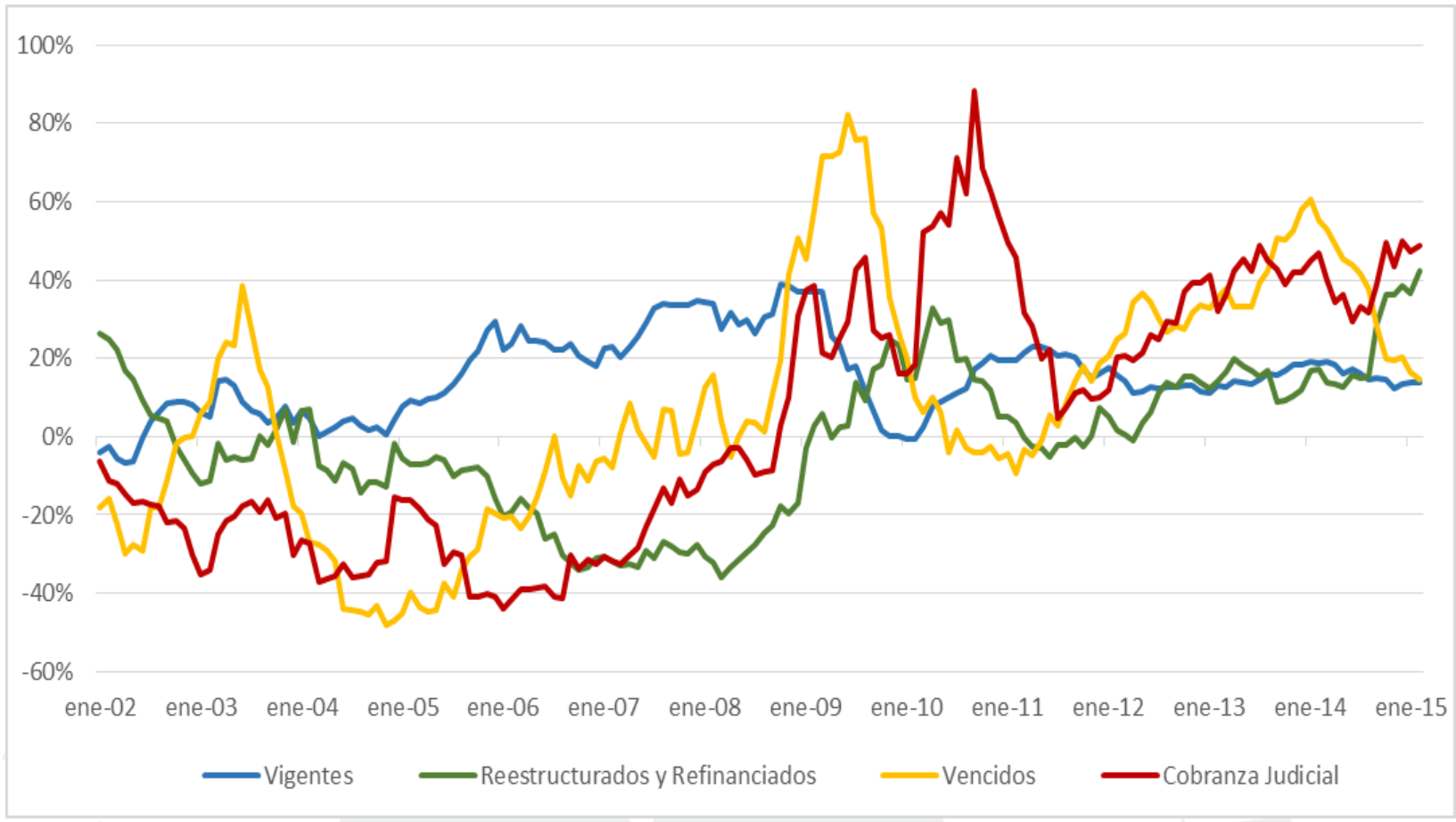

Fuente: SBS (revisado el 1 de mayo del 2015). Boletín Estadístico de Banca Múltiple.

En: http://sbs.gob.pe/app/stats/EstadisticaBoletinEstadistico.asp?p=1\#

Tabla 2.2

Indicadores de Riesgo Crediticio

\begin{tabular}{|l|l|}
\hline \multicolumn{2}{|l|}{ Indicadores de Riesgo Crédito } \\
\hline Tasa Cartera Refinanciada & $\%($ Refinanciados/ Total Créditos Directos) \\
\hline Tasa Cartera Vencida & $\%($ Vencidos/ Total Créditos Directos) \\
\hline $\begin{array}{l}\text { Tasa Cartera en Cobranza } \\
\text { Judicial }\end{array}$ & $\%($ en Cobranza Judicial/ Total Créditos Directos) \\
\hline $\begin{array}{l}\text { Tasa Cartera Atrasada o } \\
\text { Morosa }\end{array}$ & $\%($ Vencidos + en Cobranza Judicial/ Total Créditos Directos) \\
\hline $\begin{array}{l}\text { Tasa Cartera Deteriorada o } \\
\text { de Alto Riesgo }\end{array}$ & $\begin{array}{l}\%(\text { Refinanciados + Reestructurados + Vencidos + en Cobranza } \\
\text { Judicial/ Total Créditos Directos) }\end{array}$ \\
\hline
\end{tabular}

Fuente: Elaboración Propia 
Figura 2.16

Indicadores de Riesgo Crédito Agregado de los 5 Principales Bancos de Operaciones Múltiples. Periodo 2001-2014. (\% del total de créditos directos)

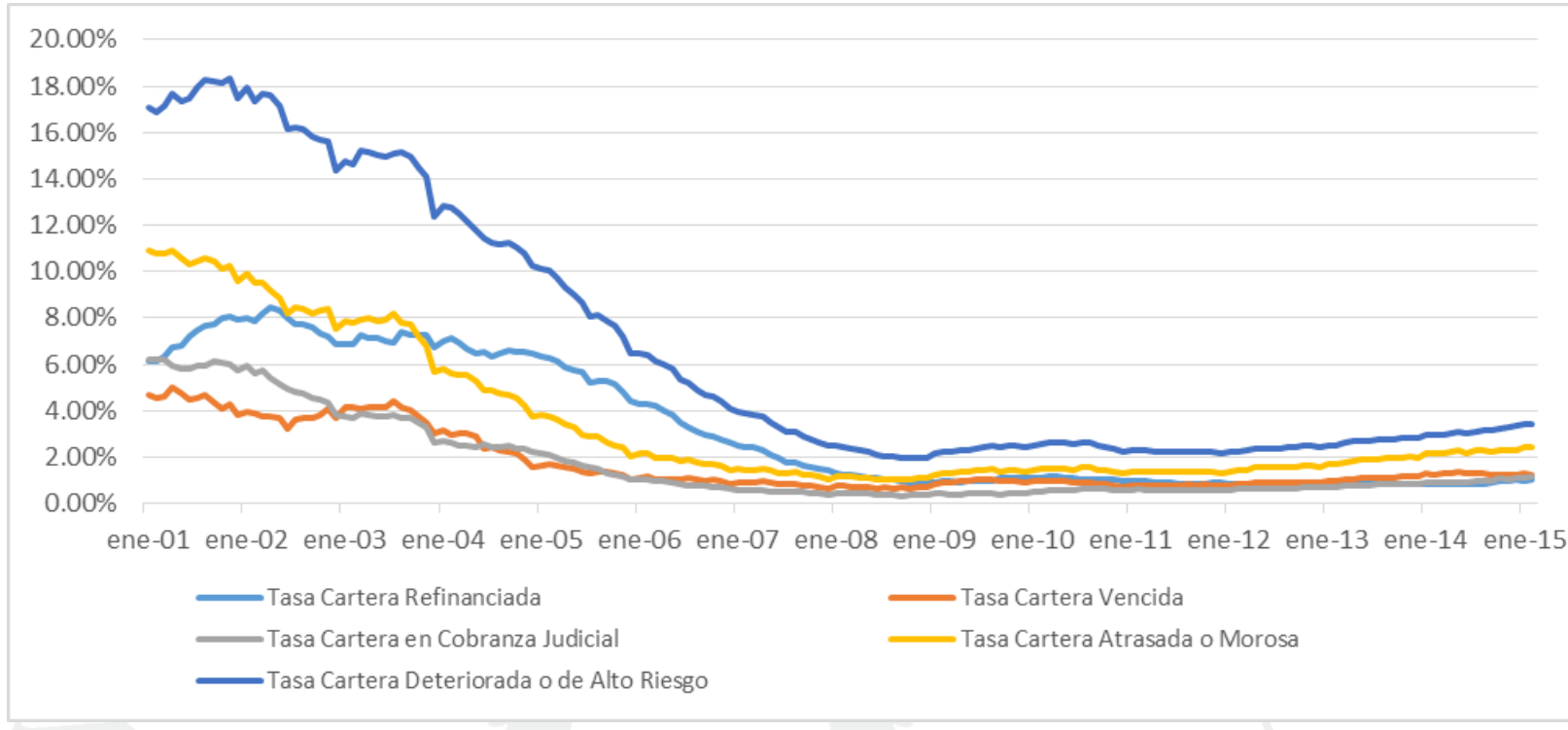

Fuente: SBS (revisado el 1 de mayo del 2015). Boletín Estadístico de Banca Múltiple.

En: http://sbs.gob.pe/app/stats/EstadisticaBoletinEstadistico.asp?p=1\#

Figura 2.17

Indicadores de Riesgo Crédito Agregado de los 5 Principales Bancos de Operaciones Múltiples. Periodo 2011-2014. (\% del total de créditos directos)

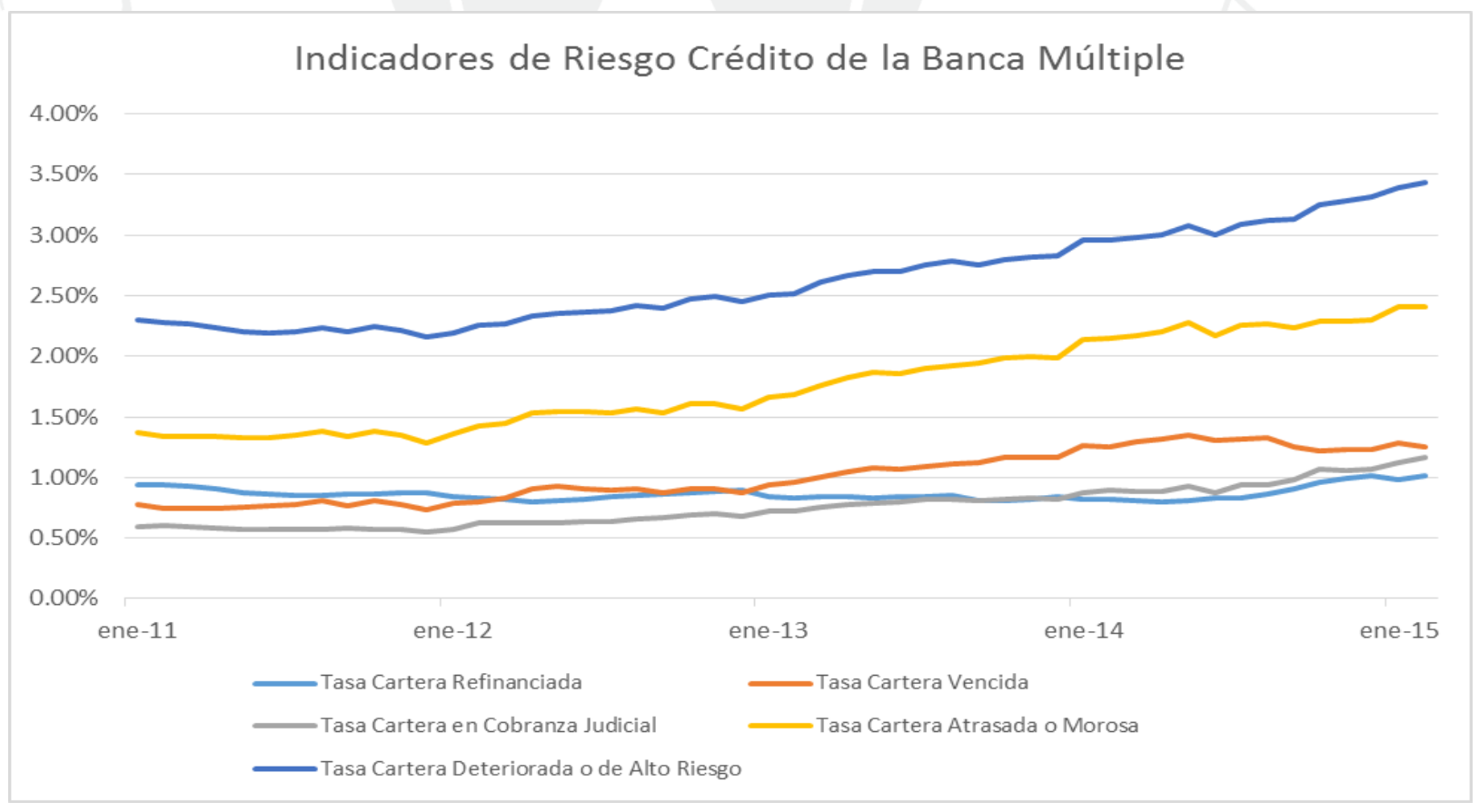

Fuente: SBS (revisado el 1 de mayo del 2015). Boletín Estadístico de Banca Múltiple.

En: http://sbs.gob.pe/app/stats/EstadisticaBoletinEstadistico.asp? $\mathrm{p}=1 \#$ 
Figura 2.18

Tasa de Deterioro (\% Cartera Deteriorada) Agregada de los 5 Principales Bancos de Operaciones Múltiples. Periodo 2001-2014. (\% del total de créditos directos)

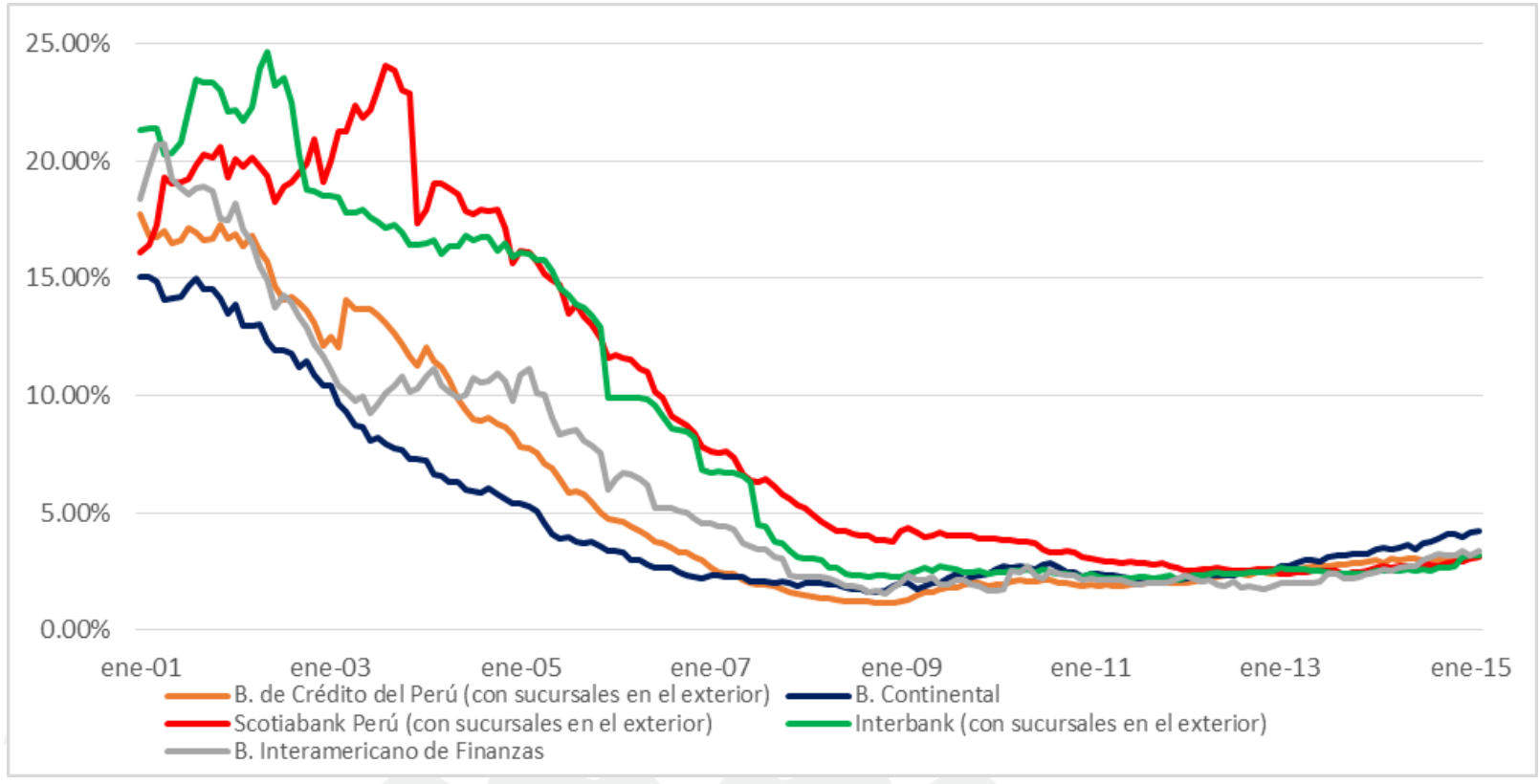

Fuente: SBS (revisado el 1 de mayo del 2015). Boletín Estadístico de Banca Múltiple.

En: http://sbs.gob.pe/app/stats/EstadisticaBoletinEstadistico.asp?p=1\#

Figura 2.19

Tasa de Deterioro (\% Cartera Deteriorada) Agregada de los 5 Principales Bancos de Operaciones Múltiples. Periodo 2011-2014. (\% del total de créditos directos)

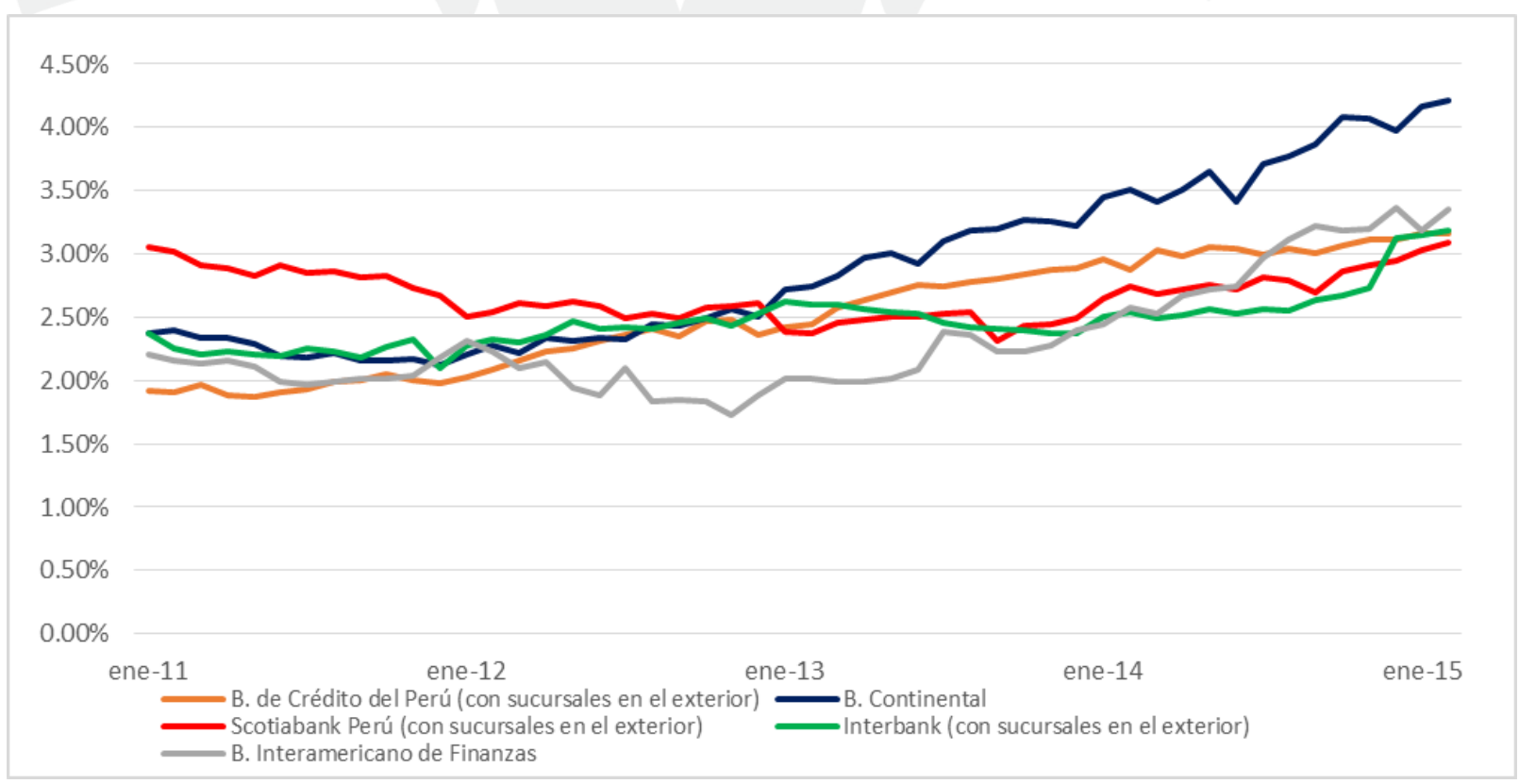

Fuente: SBS (revisado el 1 de mayo del 2015). Boletín Estadístico de Banca Múltiple.

En: http://sbs.gob.pe/app/stats/EstadisticaBoletinEstadistico.asp?p=1\# 


\subsubsection{Estado de Resultados (Estado de Ganancias y Pérdidas)}

Es un Estado Financiero que explica los ingresos y gastos generados durante el periodo de ejercicio anual de la empresa. Para el caso de los Bancos, la principal fuente de ingresos son los Ingresos Financieros provenientes de los intereses cobrados por los préstamos, por los fondos interbancarios y saldos positivos en la diferencia de cambio. Los Gastos Financieros son los intereses pagados por los depósitos, los adeudos y obligaciones financieras, el saldo negativos por diferencia de cambio y demás cargas financieras. De las dos últimas cuentas explicadas se desprende el margen financiero bruto.

Los ingresos por servicios financieros provienen de las Cuentas por Cobrar, por Operación de Créditos Contingentes y por Arrendamiento. El gasto por servicios financieros incluye los gastos por cuentas por pagar y por costo de venta de bienes y servicios. Los gastos administrativos incluye los gastos en salarios del personal, servicios por terceros entro otros.

A medida que los balances de los bancos han crecido, los ingresos han evolucionado a la par. La suma de ingresos financieros se ha llegado a triplicar mientras los resultados netos del ejercicio se han quintuplicado en todo el periodo de análisis para la banca múltiple. Sigue siendo importante la participación de los gastos administrativos ya que el desarrollo y la eficiencia del sistema bancario han sido posible por el crecimiento de los organigramas administrativos.

La vista por márgenes nos indica que ha mejorado la eficiencia en el control de los gastos de los Bancos. El Margen Bruto (Ing. Fin. - Gasto Fin. / Ing. Fin) creció de $52 \%$ (2001) a 74\% (2014). Esto debido a que durante el periodo de estudio se cuadruplicaron los Ingresos Financieros (4x) mientras que los Gastos Financieros solo se duplicaron (2x). El margen Bruto se ha 
mantenido alrededor del $74 \%$ desde el cierre del año 2009. Los Márgenes Financieros Netos que descuentan el gasto por Provisiones se han mantenido alrededor del $60 \%$ durante el periodo de estudio, esto debido a que las Provisiones han crecido a la misma velocidad. (Figura 2.22)

Las Provisiones son las cuentas que reflejan las pérdidas y ganancias no realizadas del negocio que repercuten directamente en los resultados del ejercicio contable y de darse una situación adversa pueden disminuir los fondos del capital económico. Las Provisiones Genéricas se constituyen de forma preventiva sobre los créditos desembolsados clasificados en la categoría Normal, Las Provisiones Específicas, que se constituyen sobre los créditos relacionados a clientes que han sido clasificados en una categoría de mayor riesgo distinta a la Normal. Es la cuenta que ajusta el valor de la cartera de créditos en función de la clasificación de riesgo del deudor. (Figura 2.22)

Los Gastos Administrativos han crecido en mayor proporción que los Ingresos por Servicios Financieros, lo que ha provocado que el Margen Operacional Neto retroceda a $42 \%$ en Dic-2014. El margen neto paso de ser 5\% a $27 \%$ en el transcurso de 14 años. Los Resultados del Ejercicio Neto han crecido ininterrumpidamente desde la década pasada; no solo a causa del aumento de los Ingresos Financieros sino también por mejores Ratios de Eficiencia de manera general. (Figuras 2.20 y 2.22) 
Tabla 2.3

Estado de Ganancias y Pérdidas Agregado de los 5 Principales Bancos de Operaciones Múltiples. Cierre dic. 2014. (en miles de nuevos soles)

Estado de Ganancias y Pérdidas Agregado de los 5 Principales Bancos de Operaciones Múltiples

31/12/2001 - 31/12/2014(En miles de nuevos soles) \% Dic 01 \% Dic 14 S/.M Dic 14

\begin{tabular}{|l|l|l|l|}
\hline Ingresos financieros & $100 \%$ & $100 \%$ & $18,292,737$ \\
\hline Gastos financieros & $48 \%$ & $26 \%$ & $4,666,121$ \\
\hline Margen financiero bruto & $52 \%$ & $74 \%$ & $13,626,616$ \\
\hline Provisiones para créditos directos & $13 \%$ & $15 \%$ & $2,817,170$ \\
\hline Margen financiero neto & $39 \%$ & $59 \%$ & $10,809,446$ \\
\hline Ingresos por servicios financieros & $21 \%$ & $22 \%$ & $4,051,596$ \\
\hline Gastos por servicios financieros & $1 \%$ & $3 \%$ & 597,054 \\
\hline Margen operacional & $59 \%$ & $78 \%$ & $14,263,988$ \\
\hline Gastos administrativos & $41 \%$ & $36 \%$ & $6,554,161$ \\
\hline Margen operacional neto & $17 \%$ & $42 \%$ & $7,709,827$ \\
\hline Provisiones, depreciación y amortización & $13 \%$ & $4 \%$ & 751,568 \\
\hline Otros ingresos y gastos & $2 \%$ & $0 \%$ & 61,175 \\
\hline Resultado antes de impuesto a la renta & $5 \%$ & $27 \%$ & $5,017,196$ \\
\hline Impuestos a la renta & $38 \%$ & $7,019,434$ \\
\hline Resultado neto del ejercicio & $11 \%$ & $2,002,239$ \\
\hline
\end{tabular}

Fuente: SBS (revisado el 1 de mayo del 2015). Boletín Estadístico de Banca Múltiple.

En: http://sbs.gob.pe/app/stats/EstadisticaBoletinEstadistico.asp?p=1\# 
Figura 2.20

Evolución del Estado de Resultados (G y P) Agregado de los 5 Principales Bancos de Operaciones Múltiples. Periodo 2001-2014. (En miles de nuevos soles)

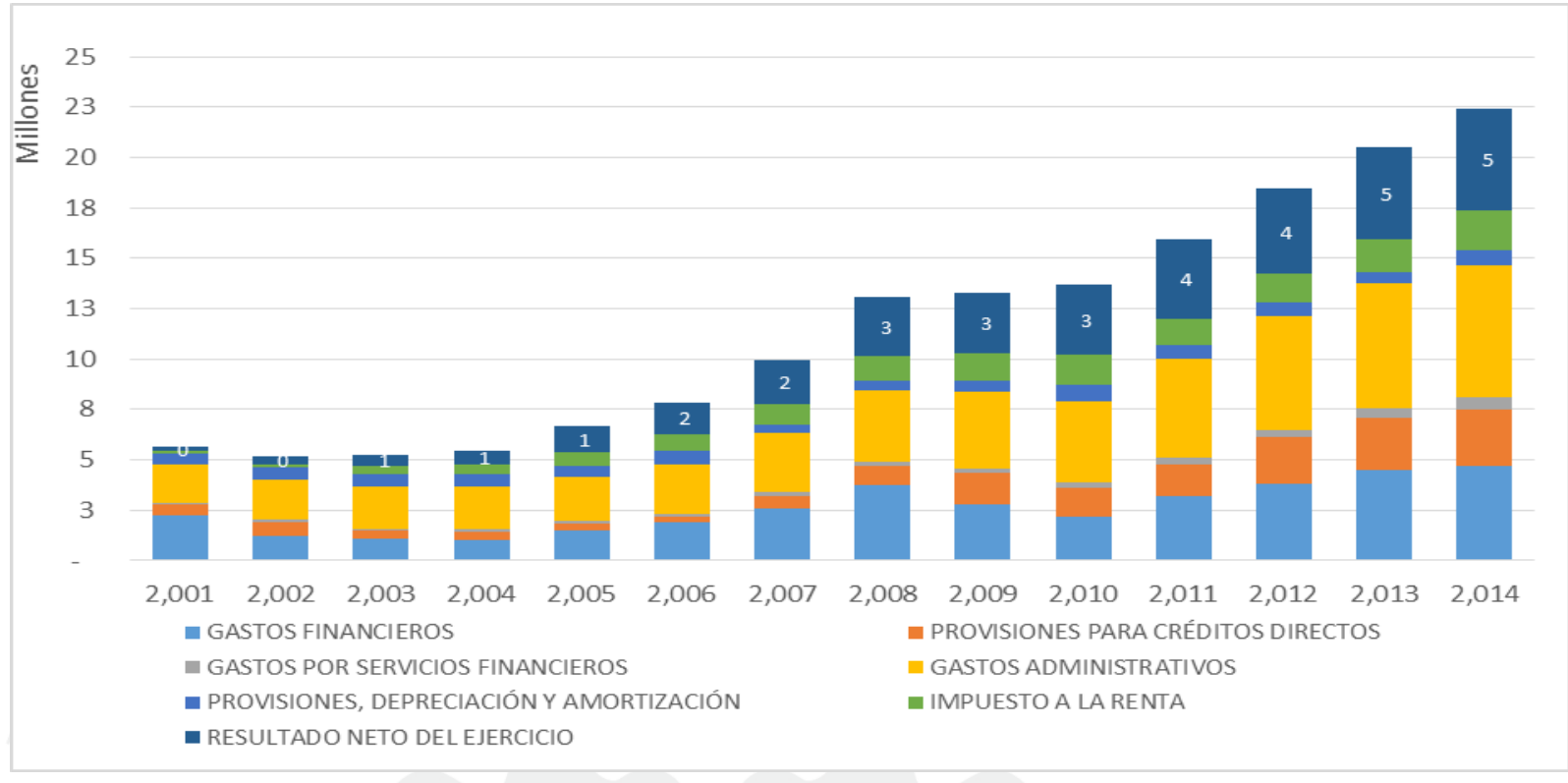

Fuente: SBS (revisado el 1 de mayo del 2015). Boletín Estadístico de Banca Múltiple. En: http://sbs.gob.pe/app/stats/EstadisticaBoletinEstadistico.asp?p=1\#

\section{Figura 2.21}

Evolución de los Ingresos Financieros de los 5 Principales Bancos de Operaciones Múltiples (resultado mensual). Periodo 2001-2014. (En miles de nuevos soles)

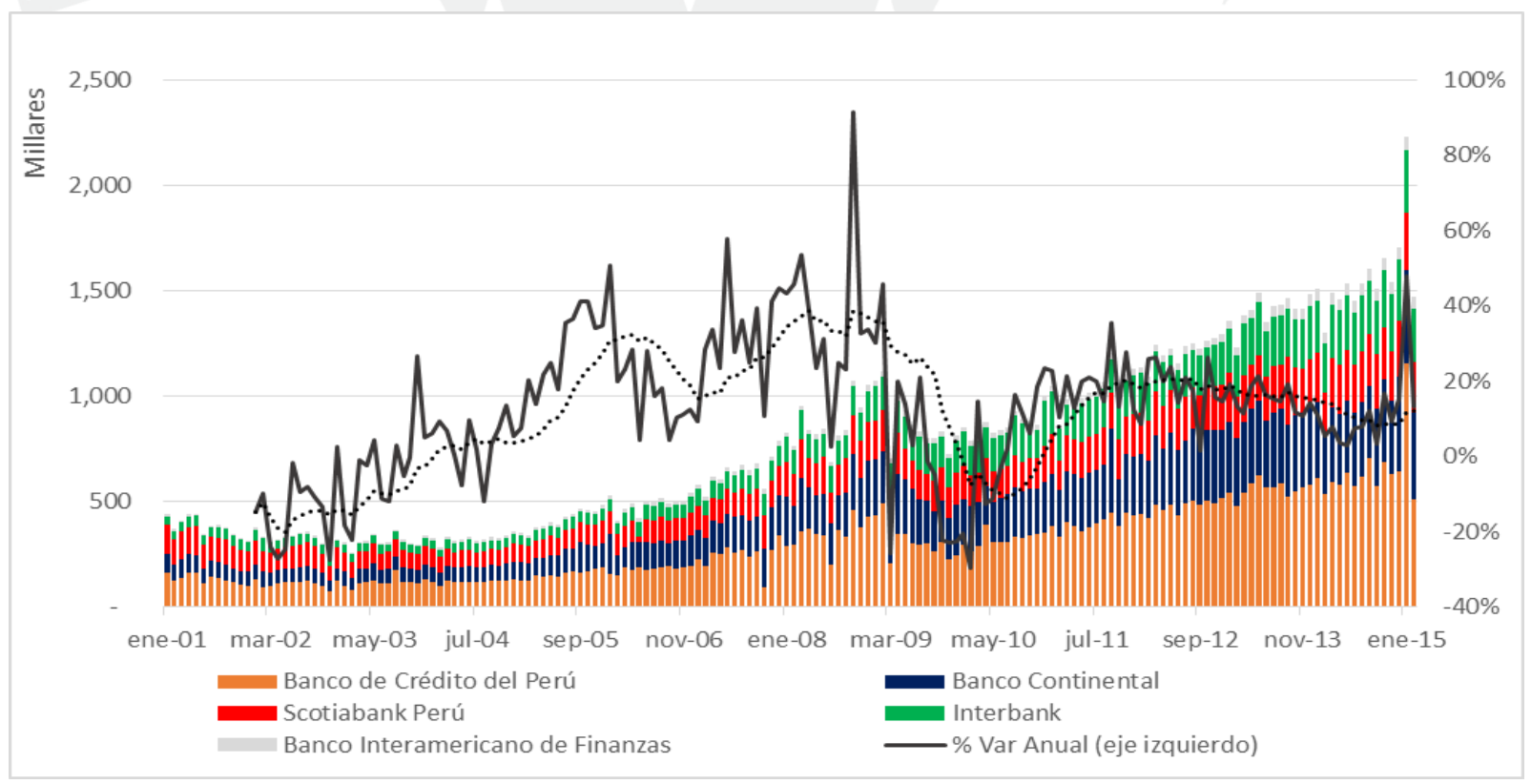

Fuente: SBS (revisado el 1 de mayo del 2015). Boletín Estadístico de Banca Múltiple.

En: http://sbs.gob.pe/app/stats/EstadisticaBoletinEstadistico.asp?p=1\# 
Figura 2.22

Evolución de los Márgenes de Rentabilidad de los 5 Principales Bancos de Operaciones Múltiples. Periodo 2001-2014. (\% en relación a los Ingresos Financieros)

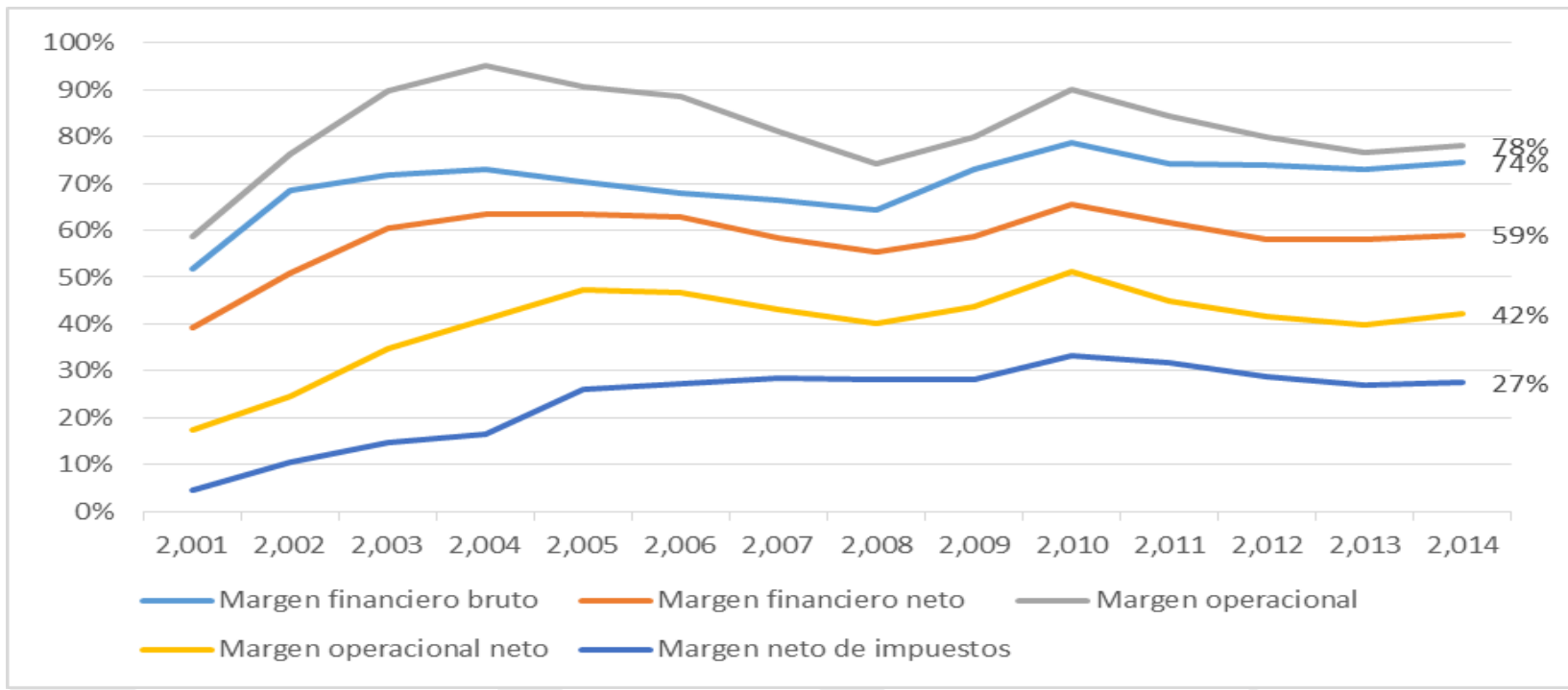

Fuente: SBS (revisado el 1 de mayo del 2015). Boletín Estadístico de Banca Múltiple.

En: http://sbs.gob.pe/app/stats/EstadisticaBoletinEstadistico.asp?p=1\#

Figura 2.23

Gasto de Provisión anualizado de los 5 Principales Bancos de Operaciones Múltiples.

Periodo 2001-2014. (En miles de nuevos soles)

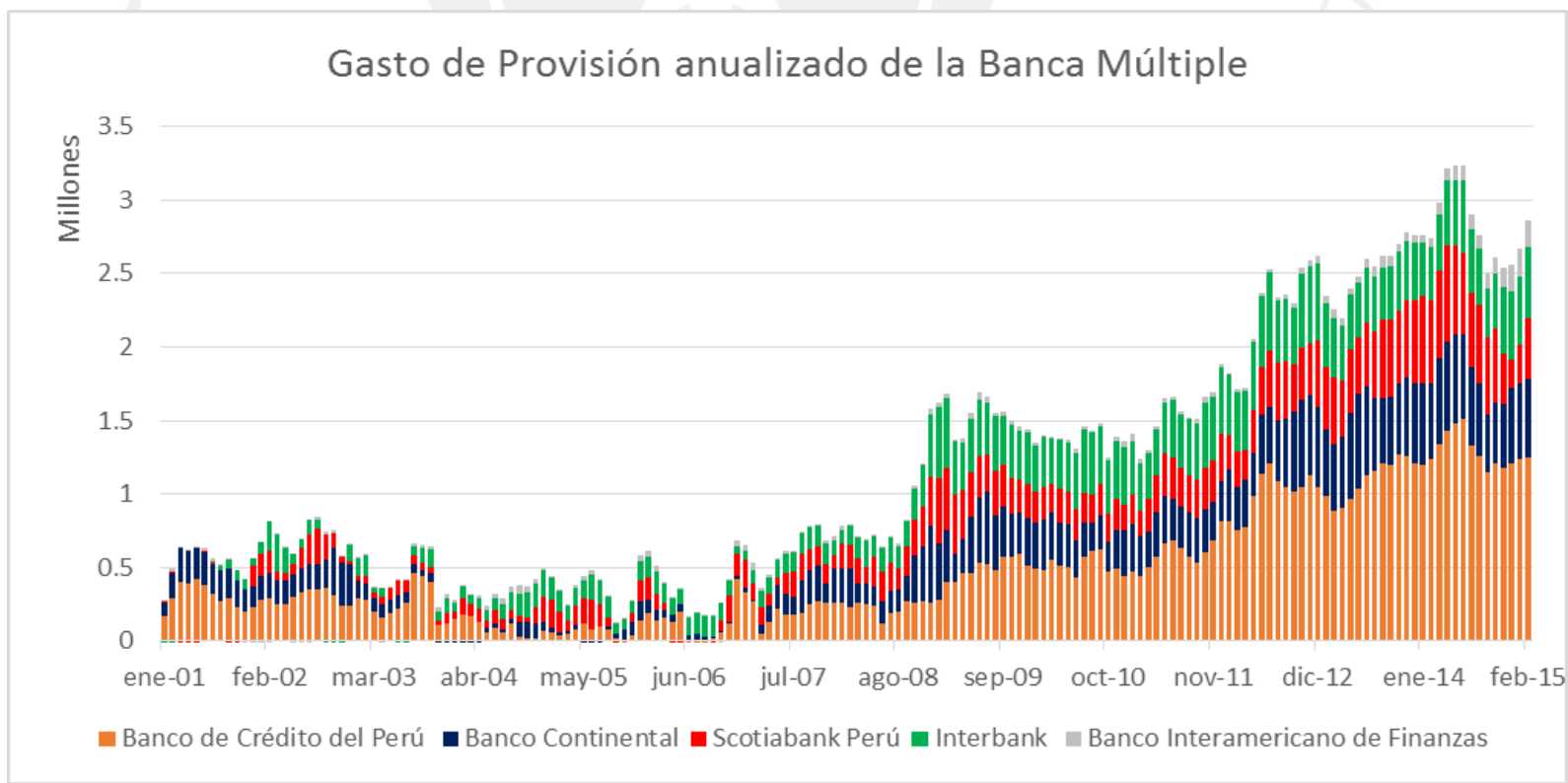

Fuente: SBS (revisado el 1 de mayo del 2015). Boletín Estadístico de Banca Múltiple.

En: http://sbs.gob.pe/app/stats/EstadisticaBoletinEstadistico.asp?p=1\# 


\subsubsection{Producto Bruto Interno}

Es el valor monetario de la producción de bienes y servicios de demanda final de un país durante un periodo determinado de tiempo. Es una magnitud de flujo. No incorpora bienes de producción intermedio. Ya que el producto interno es una agregado, las unidades de medida contenidas en él son heterogéneas. Por lo tanto el producto interno es el resultado de la multiplicación de factores reales, las unidades de bienes y servicios, y monetarios, integrado por precios.

A partir de ahí se tiene dos definiciones: el PBI nominal que es la suma del valor monetario de los bienes y servicios producidos en un país a precios actuales durante un año y el PBI real que se define como la suma del valor monetario de todos los bienes y servicios producidos a precios constantes, es decir, los precios se toman de un año base. Recién, con este último indicado se puede calcular el crecimiento o variación anual del PBI real. En este ejercicio se utilizara la tasa de crecimiento real del PBI como la variable endógena de la economía ya que es un indicador propio de la evolución de la economía local.

Figura 2.24

\% Variación de 12 meses del PBI Real. Periodo 2004-2014. (En porcentaje)

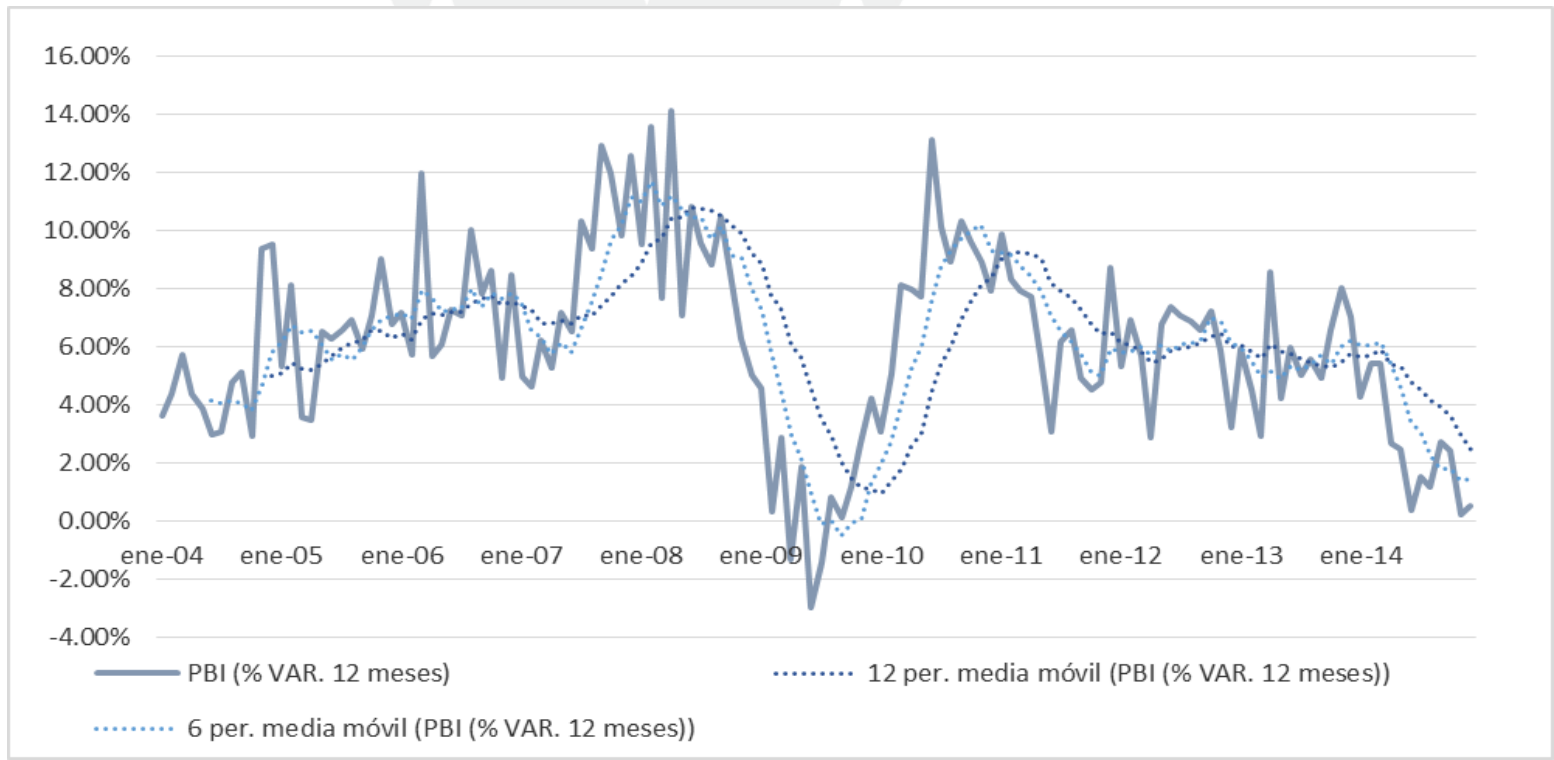

Fuente: INEI (revisado el 1 de mayo del 2015). Sistema de Información Económica. En: https://www.inei.gob.pe/estadisticas/indice-tematico/economia/ 
En la década de 2000, se registró un crecimiento sin precedentes del PBI que se explica por la mejora en la productividad total de factores (PTTF). La PTF es una medida del efecto de las economías de escala en la producción nacional, en otras palabras, mide la eficiencia en el uso de factores productivos promovido por cambios tecnológicos. (Ledesma, 2010)

La Crisis financiera internacional llego a desacelerar el crecimiento potencial del PBI en el año 2009. Esto repercutió en la rápida recuperación del PBI que se registró a partir del año 2010. El producto potencial es el nivel de producto que prevalecería en la economía si es que todos los mercados fuesen competitivos. (Ledesma, 2010)

\subsubsection{Tasas de Interés}

Es un porcentaje con respecto a un monto mediante el cual se paga por el uso del dinero; por lo tanto, es un indicador del costo del crédito. Refleja cuanto paga un deudor a un acreedor por usar su dinero durante un periodo. Representa el equilibrio entre el riesgo y la rentabilidad asociada al uso del dinero en relación a un contexto y tiempo determinado.

La Tasa de interés activa es el porcentaje que los bancos, dadas las disposiciones regulatorios y la situación del mercado, cobran a sus clientes por los distintos servicios crediticios que otorgan. Son activas ya que el recurso es a favor del banco. Según la moneda del prestado se utiliza la tasa activa en moneda nacional TAMN o la tasa activa en moneda extranjero TAMEX. En el caso peruano, esta última tasa corresponde a los créditos en dólares. La tasa interés interbancaria es la tasa pagada por los bancos por prestamos entre ellos. Esta tasa fluctúa por encima de la tasa de los créditos por regulación monetaria, que son los préstamos que realizar el BCRP para suplir las necesidades de liquidez en el corto plazo, y por debajo de la tasa overnight, que son los depósitos de muy corto plazo que realizan los bancos en el BCRP con sus 
fondos sobrantes al final del día. Existe la tasa interbancaria en moneada nacional TIMN y la tasa interbancaria en moneda extranjera TIMEX.

La tasa de rendimiento del Tesoro de EE.UU. es el retorno de la inversión, expresado como un porcentaje de las obligaciones de deuda del gobierno estadounidense. En otras palabras, es la tasa de interés que el gobierno de EE.UU. paga por los préstamos de dinero a distintos plazos de tiempo. Esta tasa influyen en los préstamos y son una aproximación de como los inversionistas se sienten acerca de la economía. La tasa de rendimiento de los bonos de la Resera Federal de EE.UU. a 10 años sirve como aproximación de la tasa de interés de largo plazo (RL: Rate Long Term). La tasa de rendimiento de los bonos de la Reserva Federal de EE.UU. a 3 meses sirve como aproximación de la tasa de interés de corto plazo (RS: Rate Short Term). 


\section{CAPÌTULO III: CONTRASTACIÓN DE HIPÓTESIS}

A continuación se desarrollaran tres pruebas de estrés ligadas a la cuantificación de distintas clases de riesgo. Primero se explicará el objetivo e hipótesis a desarrollar, después se expondrá y analizara el modelo, se aplicara la prueba de estrés, se aplicara el modelo haciendo mención a la metodología utilizada y finalmente se contrastaran los resultados obtenidos. En este ejercicio, los escenarios adversos se están estimando a partir de impactos o variaciones en las variables como el PBI, el margen de intermediación, las tasas de interés, los depósitos y los adeudos y obligaciones para luego determinar los efectos acumulados. Es importante señalar que resulta crucial determinar hasta qué grado la Banca Múltiple es sensible a impactos por variaciones de variables exógenas a la economía local, ya que estas variables representan el conjunto de factores macroeconómicos, los cuales no se pueden controlar. Una Banca Múltiple sólida y dinámica es la que no se encuentra condicionada a los impactos de un escenario macroeconómico adverso.

\subsection{Objetivos e hipótesis}

Los objetivos son:

\section{a. Objetivo General}

Cuantificar y analizar los impactos generados en los indicadores de riesgo de crédito, de mercado y de liquidez de la banca múltiple en escenarios de estrés. Para alcanzar dicho objetivo, se modelarán y simularán escenarios a partir de las pruebas de estrés. Cada ejercicio de estrés está ligado al estudio de una clase de riesgo en específico. 


\section{Objetivo Específico 1 Modelo de Riesgo Crédito:}

Se estimará el riesgo de crédito a través de un modelo satélite que explique la tasa de deterioro y el riesgo del portafolio de créditos medida a través del gasto en provisiones. Esta se construye a partir de la interacción de las variables como el producto bruto interno y las tasas de interés a corto y largo plazo.

\section{Objetivo Específico 2 Modelo de Riesgo Mercado:}

Modelar el riesgo de tasa de interés de la banca ya que es el principal instrumento de generación de ingresos y está afecto al desenvolvimiento del mercado externo. Esto será necesario para determinar la sensibilidad de las utilidades en cuanto a fluctuaciones o variaciones en las tasas de interés o del producto bruto interno.

\section{Objetivo Específico 3 Modelo de Riesgo Liquidez:}

Proponer un modelo de estrés de liquidez que explique la dinámica ante una contracción del canal de financiamiento en la banca múltiple. Se estimará un modelo de panel de Vectores Auto Regresivos. El modelo buscará explicar la distribución de las amortizaciones de liquidez en los bancos y las posteriores reacciones de recuperación.

Se plantea como hipótesis:

\section{b. Hipótesis General}

En un escenario de estrés adverso en la banca múltiple, producido por la variación en las variables endógenas y exógenas a la economía del país, no existiría un impacto significativo en los indicadores de gestión del riesgo producido por las variables exógenas a la economía del país. Esto debido a que los indicadores de gestión del riesgo son más sensibles a variaciones en las variables endógenas a la economía del país. 


\section{Hipótesis específica 1 Modelo de Riesgo de Crédito:}

Se asume que la tasa de deterioro y el gasto de provisiones de los créditos bancarios son dependientes en mayor grado a variaciones de variables económicas locales que variaciones de variables externas. Por ello, los indicadores de riesgo de crédito dependen más del contexto económico local que de variables externas.

\section{Hipótesis especifica 2 Modelo de Riesgo Mercado:}

El margen financiero de la banca múltiple no son sensibles a movimientos de la tasas de interés en los mercados. Esto se explica porque las ganancias por los préstamos están más correlacionadas al desempeño de la economía local.

\section{Hipótesis especifica 3 Modelo de Riesgo Liquidez:}

El impacto por una contracción del canal de fondeo de liquidez con adeudos y obligaciones de origen nacional es mayor al impacto de una contracción del canal de fondeo de liquidez con adeudos y obligaciones de origen externo.

\subsection{Prueba de Estrés de Riesgo de Crédito}

Esta prueba analizará los mecanismos de transmisión el ciclo económico sobre la calidad de los créditos directos de la banca múltiple. A medida que ha ido creciendo el volumen de los portafolios de créditos directos, a los bancos les resulta más difícil obtener información de la capacidad de pago de los nuevos prestatarios. Cuando aumenta el crecimiento de la economía, los portafolios de créditos se incrementan y, a su vez, el nivel riesgo también debido a que crece el desembolso a los deudores con dudosa capacidad de pago. Desde este punto derivan los estudios de información asimétrica y selección adversa. El deterioro puede ser un factor mayor en una etapa expansiva del ciclo económico. Por lo 
tanto, en los ciclos de crecimiento económicos la regulación a las instituciones financieras debería ser más estricta para que al terminar, los ciclos expansivos no se materialicen en crisis. Como se analizó en el Capítulo 2, el Perú ha vivido un ciclo expansivo del crecimiento de las colocaciones y, a su vez, un incremento en la variedad de productos a ofrecidos en el mercado.

El gasto por provisiones resulta un variable interesante pero no utilizada ampliamente para hacer aproximaciones del impacto sobre la calidad crediticio de los portafolios en un contexto de auge económico a comparación de la tasa de deterioro. Esto debido a que la tasa de morosidad de un portafolio depende de la relación entre los créditos en situación de morosidad y el total de créditos que comprende el portafolio y la interpretación del ratio puede estar sesgada por el rápido crecimiento del denominador; mientras que el gasto de provisiones nos indica el impacto por el deterioro en la clasificación crediticia del cliente. Como se detalló en el capítulo 2, se utilizará la tasa de deterioro que es el porcentaje correspondiente a cartera deteriorada o cartera de alto riesgo

En el Perú el sistema de asignación de provisiones se estructura de la siguiente manera: se constituyen provisiones específicas para los créditos con clientes que posean una clasificación de riesgo mayor a la normal y para los créditos con clasificación normal se les establecen provisiones genéricas. Además, está la constitución de la provisión pro cíclica que se activa a partir de los indicadores de crecimiento del PBI. Esto último es necesario para tener un resguardo en cara al riesgo potencial de un crecimiento excesivo de los créditos colocados y las consecuencias de no gestionar de manera correcta el apetito de riesgo. 


\subsubsection{Metodología del Modelo de Riesgo Crédito}

La metodología propuesta para aplicar la prueba de estrés de riesgo de crédito corresponde a Van den End (2006). El objetivo de este ejercicio se centra en analizar y cuantificar el impacto de variables macroeconómicas; por ende, no se incluye variables control de los factores microeconómicos. Los modelos están principalmente enfocados al análisis de escenarios, limitándose a cuantificar solamente la primera ronda de efectos de los choques. El modelo no es aplicable para explicar los resultados de una segunda ronda de efectos, debido a que no abarca todas las interrelaciones entre el sector financiero y el sector económico.

Para la prueba de estrés del riesgo de crédito en la banca múltiple se ha desarrollado un modelo satélite de forma reducida. En el modelo de riesgo de crédito, se utilizara dos ecuaciones básicas. En la primera ecuación se estima la relación entre el deterioro de la cartera de créditos y una serie de variables macroeconómicas clave. Se interpreta que el ratio de cartera deteriorada es producto del crecimiento del índice del PBI real y la diferencia entre las tasas de largo y corto plazo. En la segunda ecuación, la tasa de deterioro junto con una serie de variables macro se utiliza para explicar el nivel de provisiones por pérdidas relativizado al volumen de los cerditos colocados. Se interpreta que el ratio de provisiones por pérdida entre la cartera de créditos es producto del crecimiento del índice del PBI real, de la tasas de largo plazo y de la tasa de deterioro.

Ecuación 3.1 Modelo de Tasa de Deterioro

$$
\begin{aligned}
& \lambda(\text { Tasa Deterioro })_{t}=a+\beta_{1}\left(\text { PBI }_{t}\right)+\beta_{2}(\text { Tasa LargoPlazo } t \text { Tasa Corto Pazlo })+v_{t} \\
& \lambda(\text { Tasa Deterioro })_{t}=\alpha+\beta_{1}\left(\text { PBI }_{t}\right)+\beta_{2}\left(\text { Spread }_{t}\right)+v_{t}
\end{aligned}
$$


Ecuación 3.2 Modelo de Provisiones por Pérdida en relación a la Cartera de Créditos

$$
\left.\lambda\left(\frac{\text { Provisiones por Perdida }}{\text { Creditos }}\right)_{i t}=\beta_{1}\left(\text { PEI } I_{\mathrm{t}}\right)+\beta_{2} \text { (Tasa LargoPlazo }\right)+\beta_{\mathrm{a}} \lambda(\text { Tasa Deterioro })_{\mathrm{t}}+n_{\mathrm{t}}
$$

La tasa de deterioro es el porcentaje de la cartera deterioro o de alto riesgo en relación al total de la cartera. La variable PBI es la tasa de crecimiento del producto bruto interno real. La tasa de corto plazo es una aproximación de la tasa libre de riesgo. La diferencia entre la tasas de interés de largo plazo menos la tasa de corto plazo es el término de propagación. El ratio de provisiones por pérdidas entre créditos es una medida de riesgo crédito que captura la realización del impago y la ejecución de la provisión. En este casos se utiliza el Logit $\lambda(X)_{t}=\ln \left(\frac{X_{t}}{1-X_{t}}\right)$ para tomar en consideración dos escenarios: que la variable dependiente alcance valores negativos y una posible relación no lineal en las dos ecuaciones descritas.

La inclusión de variables micro económicas brindaría una idea de los fundamentos subyacentes acerca del comportamiento de los bancos. Sin embargo, para el propósito de vincular los balances de los bancos a escenarios macroeconómicos, el modelo se restringe a un número limitado de variables. A partir de las dos ecuaciones anteriores se puede derivar implícitamente la pérdida esperada (Expected Loss) el incumplimiento utilizando la siguiente identidad: 
Ecuación 3.3 Modelo de Pérdida Esperada

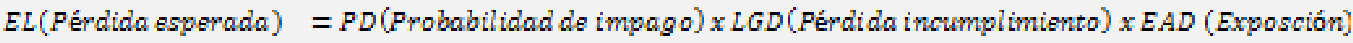

$E L(P$ érdida esperada) $/ E A D$ (Exposción) $=P D$ (Probabitidad de impago) $x L G D$ (Pérdida incumplimiento)

(Provisiones por Pérdida)/Creditos) = Tasa Deterioro $x$ LGD(Pérdida incumplimiento)

La división entre la pérdida espera (Expected loss) y la exposición (Exposure at default) es una aproximación del ratio de provisiones por pérdida entre la carrera de créditos. La probabilidad de impago es una estimación de la tasa de deterioro. Estimando las ecuaciones 3.1 y 3.2 e incluyéndolas en la ecuación 3.3, la pérdida dado el incumplimiento puede ser estimado de manera implícita. Esto nos permite determinar el impacto sobre de este indicador ante los escenarios de estrés. En el Pilar I del marco estructural de Basilea II, se requiere el uso de dicho indicador. 
A continuación, se hace una crítica al modelo planteado y se explican los hechos estilizados:

Según el modelo original, las variables endógenas son ajustadas logísticamente, lo cual asegura que el ratio se mantenga de 0 a 1 . Esto se hace a fin de poder modelar relaciones no lineales. Sin embargo, dicho ajuste no será realizado en primera instancia, debido a que no puede presumirse que para el caso peruano no haya una relación no lineal o que no existiendo ésta linealidad no pudiera después linealizarse de manera simple. A su vez, dicho ajuste cambia la forma de la variable endógena a estimar por lo que las conclusiones e interpretaciones posteriores pueden ser llegar a ser muy frágiles o poco intuitivas (Maddala, 1983).

Dado que se trata de un sistema recursivo, es decir, un subsistema dentro de otro sistema; se pondera más la significancia global de los resultados antes que la individual (Kennedy, 1981). Esto con la finalidad de contar con una endógena estimada lo más precisa posible, sin dejar de lado alguna significancia individual. Por lo tanto, se modelara a partir de la suma agregada de las cuentas de los principales 5 bancos de operaciones múltiples del sistema y después se regresara para analizar a cada uno de manera individual. A efectos de comparación, igual se mantiene la estructura teórica del modelo de la ecuación 3.1.

En cuanto al modelo de la ecuación 3.2, se registran dos problemas econométricos y uno financiero-econométrico acerca de la redundancia o sobre identificación en un panel data artificial. Esto genera que no sea correcto econométricamente que haya dos ecuaciones con una relación recursiva pero con las mismas exógenas. Haciendo la excepción al caso de la variable endógena de la ecuación inicialmente estimada. Esto se debe a que esta última ya contiene la información de las variables exógenas y al incluirlas nuevamente en la segunda ecuación a estimar, genera una redundancia de efectos que no agregan sustento al modelo general y los distorsionaría. 
La cercanía conceptual entre la endógena y la tasa de deterioro sugiere que puede existir un problema de sobre significancia; o en otras palabras, que se trataría de una ecuación contable más que de una ecuación de comportamiento económico.

En lo referente a la ejecución de las prueba de estrés, se debe precisar lo siguiente: En el modelo original se indica que los modelos VAR son más flexibles, pero que no proveen una estructura con fundamento económico de un escenario de estrés, como si lo hacen los modelos macro-estructurales. No obstante, lo que el presente estudio plantea no es un análisis de impulso respuesta tradicional, sino se agregaran los resultados para reconstruir las distribuciones de probabilidad de las variables, antes y después de la innovación de Cholesky. Usualmente, el horizonte para captar el impulso es de 1 a 3 años; sin embargo, dado de que el modelo es mensual, este horizonte sólo podrá ser de 1 año.

El modelo VAR viene a ser la alternativa al modelo determinístico que se realiza con las ecuaciones 1 y 2 , por lo que ante este modelo más agregado, estas ecuaciones carecen de relevancia. El poco poder explicativo desde un punto de vista económico y la rigidez del modelo determinístico en las ecuaciones 1 y 2 , hacen que no sean necesarios, y el modelo debería enfocarse estrictamente en el enfoque VAR. A pesar de lo anterior, para lo único que podría servir el modelo determinístico es para comprobar que existe una significancia individual en el modelo. Así mismo, podría servir para elaborar el modelo VAR con las variables estimadas y no con las observadas de la endógena, aunque dicha especificación puede carecer de sentido en un modelo VAR que por definición incluye todos los efectos entre las variables (Sims, 1980). Si bien podría recomendarse utilizar el modelo determinístico para confirmar la existencia de una causalidad de las variables exógenas, el análisis previo de variables podría sugerir que no existe suficiente causalidad, por lo que el análisis determinístico también debería ser descartado, pero no así el VAR. 
Se realizarán los dos modelos, el determinístico (ecuaciones 3.1 y 3.2) y el VAR para la prueba de estrés. Se modelara a partir del agregado de los cinco principales bancos y el resultado final será automáticamente aplicado para cada uno de los bancos de manera individual. Esto permitirá y asegurará la comparabilidad del análisis entre los bancos. 


\subsubsection{Variables}

La información para modelos de riesgo crédito cubre el periodo desde enero 2003 hasta diciembre 2014. Para determinar la tasa de deterioro se utilizó el ratio conocido como cartera deteriorada o cartera de alto riesgo. Hay que mencionar que la determinación de vencido es distinto para cada tipo de producto financiero. Por ejemplo, los días de atraso permitidos para los créditos de consumo o para empresas es de 8 días, mientras los correspondientes a créditos hipotecarios son a partir de 30 días.

Para determinar el crecimiento del producto bruto internos se utilizó como fuente la base de datos del INEI, del cual se calculó el PBI real y a partir de ahí se calculó el porcentaje de variación anual. Para la tasa de interés de largo plazo se utilizó como aproximación la tasa de rendimiento de los bonos de la Resera Federal de EE.UU. a 10 años. De manera similar para la tasa de interés de corto plazo se utilizó como aproximación la tasa de rendimiento de los bonos de la Reserva Federal de EE.UU. a 3 meses. Esta aproximación para determinar las tasas de interés de largo y corto plazo corresponde a la metodología aplicada por Van den End (2006).

Para el gasto de provisiones, se ubicó el gasto en los estados de ganancia y pérdida de cada banco y se calculó el gasto generado en específico de cada mes. Después para normalizar la serie se le dividió por el saldo de la cartera de créditos directos. A este ratio en adelante se le llamará como tasa de provisiones. 
El análisis se efectuó sobre las información agregada de los 5 Principales Bancos de Operaciones Múltiples del Sistema Bancario Peruano (Banco de Crédito del Perú BCP, BBVA Banco Continental, Scotiabank, Interbank y el Banco Interamericano de Finanzas) que en conjunto representan el $87 \%$ de la participación del mercado de créditos.

Tabla 3.1.

Variables del Modelo de Riesgo Crédito. Elaboración Propia.

\begin{tabular}{|c|c|c|c|c|c|}
\hline \multicolumn{5}{|c|}{ Variables del Modelo de Riesgo Crédito } & Periodicidad \\
\hline Nomenclatura & Definición & Tipo & Unidades & Fuente \\
\hline $\begin{array}{c}\text { Tasa deterioro ( } \% \\
\text { Cartera Deteriorada o } \\
\text { de Alto Riesgo) }\end{array}$ & $\begin{array}{c}\text { Créditos vencidos, refinanciados, } \\
\text { reestructurados y en proceso judicial en } \\
\text { relación al total del portafolio de Créditos } \\
\text { Directos }\end{array}$ & Mensual & Ratio & $\begin{array}{c}\text { Porcentaje } \\
(\%)\end{array}$ & SBS \\
\hline $\begin{array}{c}\text { Crecimiento PBI Real } \\
\text { Plazo }\end{array}$ & Variación anual del PBI real & Mensual & Real & $\begin{array}{c}\text { Porcentaje } \\
(\%)\end{array}$ & INEI \\
\hline $\begin{array}{c}\text { Tasa de interés de Largo } \\
\text { Federal de EE.UU. a 10 años }\end{array}$ & $\begin{array}{c}\text { Tasa de rendimiento de los bonos de la Resera } \\
\text { Tasa de interés de corto } \\
\text { plazo }\end{array}$ & $\begin{array}{c}\text { Tasa de rendimiento de los bonos de la } \\
\text { Reserva Federal de EE.UU. a 3 meses }\end{array}$ & Mensual & $\begin{array}{c}\text { Nominal } \\
\text { Porcentaje } \\
(\%)\end{array}$ & $\begin{array}{c}\text { Reserva } \\
\text { Federal } \\
\text { EEUU }\end{array}$ \\
\hline $\begin{array}{c}\text { Gasto de Provisiones } \\
\text { entre saldo de créditos } \\
\text { directos }\end{array}$ & $\begin{array}{c}\text { Se calculó el gasto generado en específico de } \\
\text { cada mes. Después para normalizar la serie se } \\
\text { le dividió por el saldo de la cartera de créditos } \\
\text { directos. }\end{array}$ & Mensual & $\begin{array}{c}\text { Nominal } \\
\text { Ratio }\end{array}$ & $\begin{array}{c}\text { Porcentaje } \\
(\%)\end{array}$ & $\begin{array}{c}\text { Reserva } \\
\text { Federal } \\
\text { EEUU }\end{array}$ \\
\hline
\end{tabular}




\subsubsection{Aplicación de la metodología}

\subsubsection{Ecuación 3.1 Modelo de Tasa de Deterioro}

Primero, se le aplico un análisis de correlograma a la serie histórica de la tasa de deterioro (TD_TOP5) que confirmó que no es estacionaria en niveles, por lo que se utilizará la primera diferencia. Esta conclusión se aplica para todas las demás series individualmente. El análisis de correlograma sirve para determinar cuál es el modelo inicial apropiado para representar la dependencia dinámica. (Tablas 3.1.1 y 3.1.2)

Para el Producto Bruto Interno se está utilizando el indicador del PBI Real (IPBI) de forma mensual. Debido a que se registra un fuerte componente estacional, se procede a separarla mediante el filtro Census x-12. (Figura 3.1.1). Este último filtro, también conocido como X12 - ARIMA, es un método basado en los promedios móviles, que logra el ajuste estacional con el desarrollo de un sistema de factores que explican la variación estacional de una serie. Para la diferencia o spread de tasas (la tasa de largo plazo o RL risk long term menos la tasa de corto plazo o RF risk free rate) no se registra estacionalidad.

Se procede con el análisis bivariable para analizar la posible existencia de relaciones causales (Figura 3.1.2). Al revisar dicha figura se sugiere que existe una relación estable entre el PBI y la tasa de deterioro, que no es lineal, pero si polinómica y negativa. Lo cual no quiere decir que no pueda existir una relación lineal en parámetros. Por el contrario, la relación entre la tasa de deterioro y las tasas de interés, y en particular el spread no sólo se muestran no lineales sino también con un importante quiebre estructural. 
Tabla 3.1.1.

Análisis de Correlograma

\begin{tabular}{|c|c|c|c|c|c|c|}
\hline \multicolumn{3}{|c|}{ Date: 05/05/15 Time: 20:19 } & \multicolumn{4}{|c|}{$\begin{array}{l}\text { Sample: } 2000 \mathrm{M} 01 \text { 2015M12 } \\
\text { Included observations: } 170\end{array}$} \\
\hline Autocorrelation & Partial Correlation & & $\mathrm{AC}$ & PAC & Q-Stat & Prob \\
\hline.$\left.\right|^{* * * * * * *}$ &. $\mid * * * * * * *$ & 1 & 0.98597622 & 0.98597622 & 168.199053 & 0 \\
\hline.$\left.\right|^{* * * * * * *}$ & $.1 . \quad \mid$ & 2 & 0.97227038 & 0.0043543 & 332.727954 & 0 \\
\hline. $\mid * * * * * * *$ & $*|. \quad|$ & 3 & 0.95690882 & -0.0662723 & 493.053235 & 0 \\
\hline. $\mid * * * * * * *$ & $*|. \quad|$ & 4 & 0.93988032 & -0.06931293 & 648.654954 & 0 \\
\hline.$\left.\right|^{* * * * * * *}$ & .1 .1 & 5 & 0.92298987 & -0.00197331 & 799.623785 & 0 \\
\hline.$\left.\right|^{* * * * * * *}$ & $.1 . \quad 1$ & 6 & 0.90547183 & -0.02426109 & 945.802255 & 0 \\
\hline.$|* * * * * *|$ & $*|. \quad|$ & 7 & 0.88632238 & -0.06602347 & 1086.72244 & 0 \\
\hline.$|* * * * * *|$ & .1 .1 & 8 & 0.86589894 & -0.05700909 & 1222.05327 & 0 \\
\hline.$|* * * * * *|$ & $.1 . \quad 1$ & 9 & 0.84510809 & -0.01731141 & 1351.76404 & 0 \\
\hline.$|* * * * * *|$ &.$|. \quad|$ & 10 & 0.82434189 & 0.00065544 & 1475.94989 & 0 \\
\hline.$|* * * * * *|$ &.$|. \quad|$ & 11 & 0.80222197 & -0.05518496 & 1594.30018 & 0 \\
\hline.$|* * * * * *|$ & $.1 . \quad 1$ & 12 & 0.78186148 & 0.05145647 & 1707.43074 & 0 \\
\hline$.||^{* * * * *} \mid$ & $*|. \quad|$ & 13 & 0.75903587 & -0.09058846 & 1814.73138 & 0 \\
\hline$.||^{* * * * *} \mid$ & .1 .1 & 14 & 0.73712654 & 0.02171674 & 1916.57571 & 0 \\
\hline$.||^{* * * *} \mid$ &. $\mid . \quad 1$ & 15 & 0.7141846 & -0.04642608 & 2012.796 & 0 \\
\hline$.||^{* * * * *} \mid$ &.$|. \quad|$ & 16 & 0.69200337 & 0.02282423 & 2103.71885 & 0 \\
\hline.$|* * * * *|$ & $.1 . \quad 1$ & 17 & 0.66987615 & -0.0105893 & 2189.47692 & 0 \\
\hline.$|* * * * *|$ &.$|. \quad|$ & 18 & 0.6494806 & 0.05227283 & 2270.62274 & 0 \\
\hline.$|* * * * *|$ &. $\mid . \quad 1$ & 19 & 0.62769403 & -0.06459196 & 2346.91779 & 0 \\
\hline$.||^{* * * *} \mid$ &.$|. \quad|$ & 20 & 0.60526859 & -0.04023138 & 2418.33163 & 0 \\
\hline.$|* * * *|$ &.$|. \quad|$ & 21 & 0.58301595 & -0.00678969 & 2485.03565 & 0 \\
\hline.$|* * * *|$ &.$|. \quad|$ & 22 & 0.56082495 & -0.00876085 & 2547.17551 & 0 \\
\hline.$|* * * *|$ &.$|. \quad|$ & 23 & 0.53951742 & 0.02674444 & 2605.0745 & 0 \\
\hline$.||^{* * * *} \mid$ & $.1 . \quad 1$ & 24 & 0.52048628 & 0.04991301 & 2659.32992 & 0 \\
\hline$.||^{* * *} \mid$ & $*|. \quad|$ & 25 & 0.49932018 & -0.07970435 & 2709.60671 & 0 \\
\hline$.||^{* * *} \mid$ & $.1 . \quad 1$ & 26 & 0.47827886 & -0.02948676 & 2756.05581 & 0 \\
\hline$.\left.\right|^{* * *} \mid$ &. $\mid . \quad 1$ & 27 & 0.45601894 & -0.04721689 & 2798.57716 & 0 \\
\hline.$|* * *|$ &.$|. \quad|$ & 28 & 0.43393061 & -0.01293734 & 2837.35018 & 0 \\
\hline$.\left.\right|^{* * *} \mid$ &. $\mid . \quad 1$ & 29 & 0.41166428 & -0.01154741 & 2872.49365 & 0 \\
\hline $.1^{* * *} \mid$ &.$|. \quad|$ & 30 & 0.38876626 & -0.05978681 & 2904.06015 & 0 \\
\hline$.\left.\right|^{* * *} \mid$ &. $\mid . \quad 1$ & 31 & 0.36495106 & -0.0450243 & 2932.07781 & 0 \\
\hline$.\left.\right|^{* *} \quad \mid$ &.$|. \quad|$ & 32 & 0.34083998 & -0.02236102 & 2956.69278 & 0 \\
\hline$.\left.\right|^{* *} \quad \mid$ &.$|. \quad|$ & 33 & 0.31695035 & 0.00518412 & 2978.1335 & 0 \\
\hline$.\left.\right|^{* *} \quad \mid$ &.$|. \quad|$ & 34 & 0.29432658 & 0.03310569 & 2996.75855 & 0 \\
\hline$.\left.\right|^{* *} \quad \mid$ &.$|. \quad|$ & 35 & 0.271946 & 0.00468442 & 3012.77657 & 0 \\
\hline$.\left.\right|^{* *} \quad \mid$ & $. l^{*} \quad \mid$ & 36 & 0.25350737 & 0.10550013 & 3026.79998 & 0 \\
\hline
\end{tabular}


Tabla 3.1.2

Prueba de Raíz Unitaria

\begin{tabular}{|c|c|c|c|c|}
\hline \multicolumn{5}{|c|}{$\begin{array}{l}\text { Augmented Dickey Fuller Unit Root Test on TD_TOP5 } \\
\text { Null Hypothesis: TD_TOP5 has a unit root } \\
\text { Exogenous: Constant, Linear Trend } \\
\text { Lag Length: } 12 \text { (Automatic - based on SIC, maxlag=13) }\end{array}$} \\
\hline \multicolumn{3}{|c|}{ Augmented Dickey-Fuller test statistic } & -2.109319 & 0.5362 \\
\hline Test critical values: & $\begin{array}{l}1 \% \text { level } \\
5 \% \text { level } \\
10 \% \text { level }\end{array}$ & & $\begin{array}{r}-4.017568 \\
-3.4387 \\
-3.143666\end{array}$ & \\
\hline \multicolumn{5}{|c|}{$\begin{array}{l}\text { *MacKinnon (1996) one-sided p-values. } \\
\text { Augmented Dickey-Fuller Test Equation } \\
\text { Dependent Variable: D(TD_TOP5) } \\
\text { Method: Least Squares } \\
\text { Date: 05/05/15 Time: } 20: 20 \\
\text { Sample (adjusted): } 2002 \mathrm{M} 02 \text { 2015M02 } \\
\text { Included observations: } 157 \text { after adjustments }\end{array}$} \\
\hline Variable & Coefficient & Std. Error & t-Statistic & Prob. \\
\hline TD_TOP5(-1) & -0.012813 & 0.006075 & -2.109319 & 0.0367 \\
\hline D(TD_TOP5 $(-1))$ & -0.100908 & 0.071818 & -1.405051 & 0.1622 \\
\hline D(TD_TOP5(-2)) & 0.122409 & 0.071667 & 1.708013 & 0.0898 \\
\hline D(TD_TOP5(-3)) & -0.022872 & 0.070777 & -0.323153 & 0.7471 \\
\hline D(TD_TOP5(-4)) & -0.036129 & 0.069364 & -0.52086 & 0.6033 \\
\hline D(TD_TOP5(-5)) & 0.008421 & 0.069098 & 0.121871 & 0.9032 \\
\hline D(TD_TOP5(-6)) & 0.09791 & 0.067819 & 1.443701 & 0.151 \\
\hline D(TD_TOP5(-7)) & -0.036661 & 0.066324 & -0.552758 & 0.5813 \\
\hline D(TD_TOP5(-8)) & -0.066928 & 0.066169 & -1.011471 & 0.3135 \\
\hline D(TD_TOP5(-9)) & -0.175776 & 0.066151 & -2.657184 & 0.0088 \\
\hline D(TD_TOP5(-10)) & -0.097954 & 0.065014 & -1.506664 & 0.1341 \\
\hline D(TD_TOP5(-11)) & 0.046451 & 0.063336 & 0.733399 & 0.4645 \\
\hline D(TD_TOP5(-12)) & 0.411843 & 0.062767 & 6.56142 & 0 \\
\hline C $--1-1$ & -0.121056 & 0.112862 & -1.0726 & 0.2853 \\
\hline @TREND(2000M01) & 0.00115 & 0.000744 & 1.546491 & 0.1242 \\
\hline R-squared & 0.484325 & Mean depe & endent var & -0.078714 \\
\hline Adjusted R-squared & 0.433484 & S.D. depenc & dent var & 0.23482 \\
\hline S.E. of regression & 0.176743 & Akaike info & criterion & -0.537578 \\
\hline Sum squared resid & 4.435801 & Schwarz cri & iterion & -0.24558 \\
\hline Log likelihood & 57.19985 & Hannan-Qu & dinn criter. & -0.418987 \\
\hline F-statistic & 9.526235 & Durbin-Wat & tson stat & 2.053468 \\
\hline Prob(F-statistic) & 0 & & & \\
\hline
\end{tabular}


Figura 3.1.1

Evolución del PBI Real.

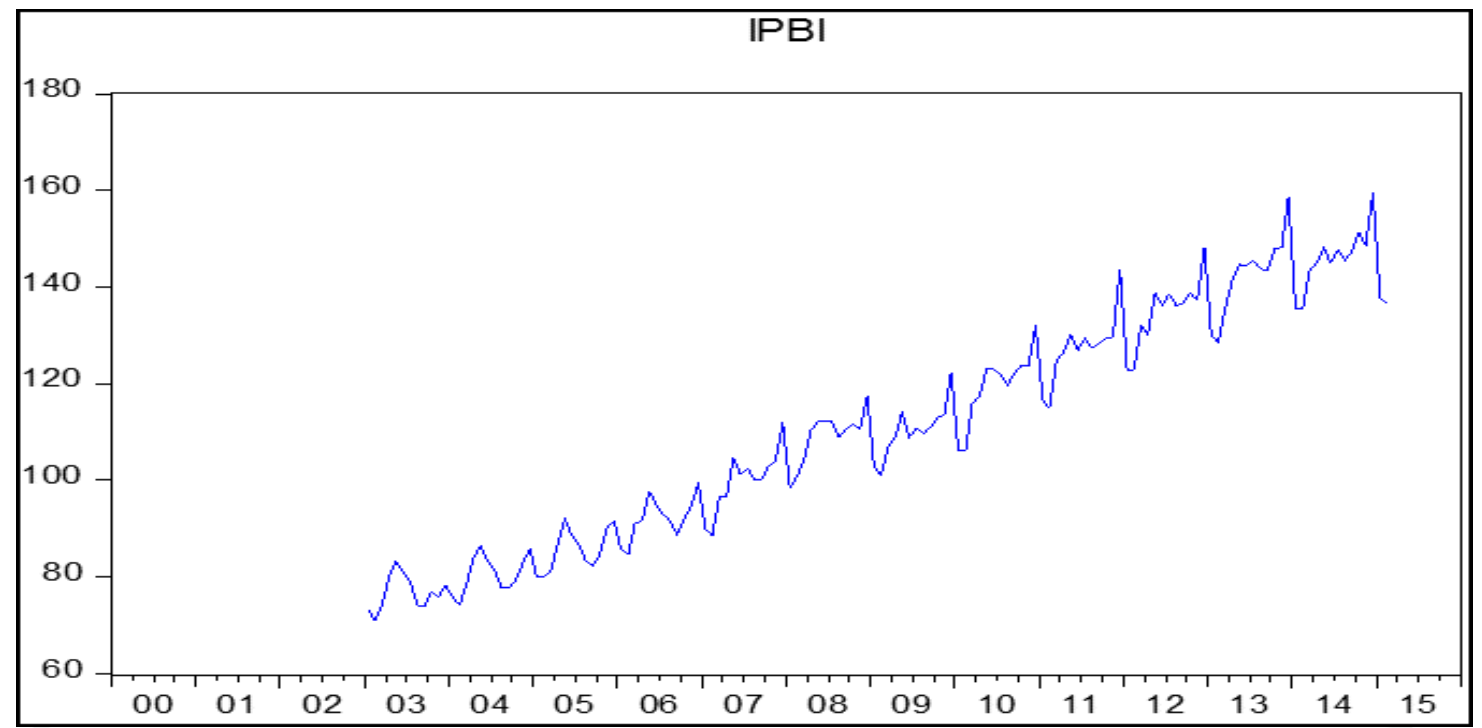

Figura 3.1.2

Análisis Bivariable de la Tasa de Deterioro con las variables explicativas

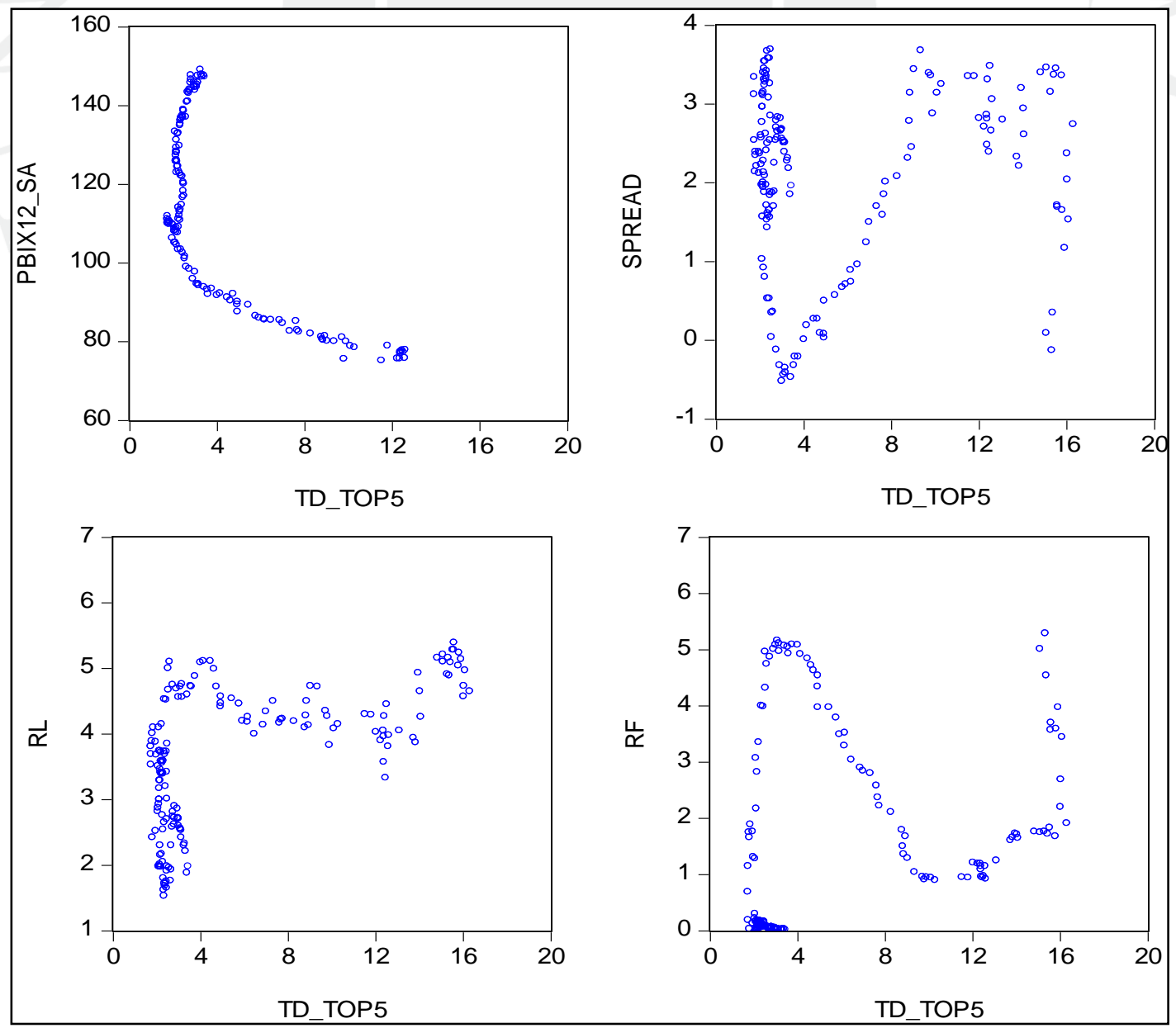


El spread de tasas presenta una relación de función sigmoide o en forma de "S", lo cual podría sugerir la aplicación de una transformación logística para el spread. No obstante, esta transformación es inviable, debido a que el spread tiene valores negativos en algunos meses. A partir del análisis, resulta útil transformar logísticamente la tasa de deterioro (Figura 3.1.3). De ello, puede observarse que si bien la dispersión ha disminuido debido a esta transformación, no se puede eliminar el hecho de que la relación es inestable; sólo que ahora a una escala más reducida. Esto último se debe a que si bien la tasa de largo plazo (RL) tiene una tendencia a la baja, parecida a la de la tasa de deterioro (TD_TOP5), ello no ocurre con la tasa de corto plazo (RF), la cual converge eventualmente con la de largo plazo. Consecuentemente, se busca captar una relación positiva no lineal con el PBI, pero no con el Spread.

Figura 3.1.3

Transformación Logística de la tasa deterioro (TD_TOP5)

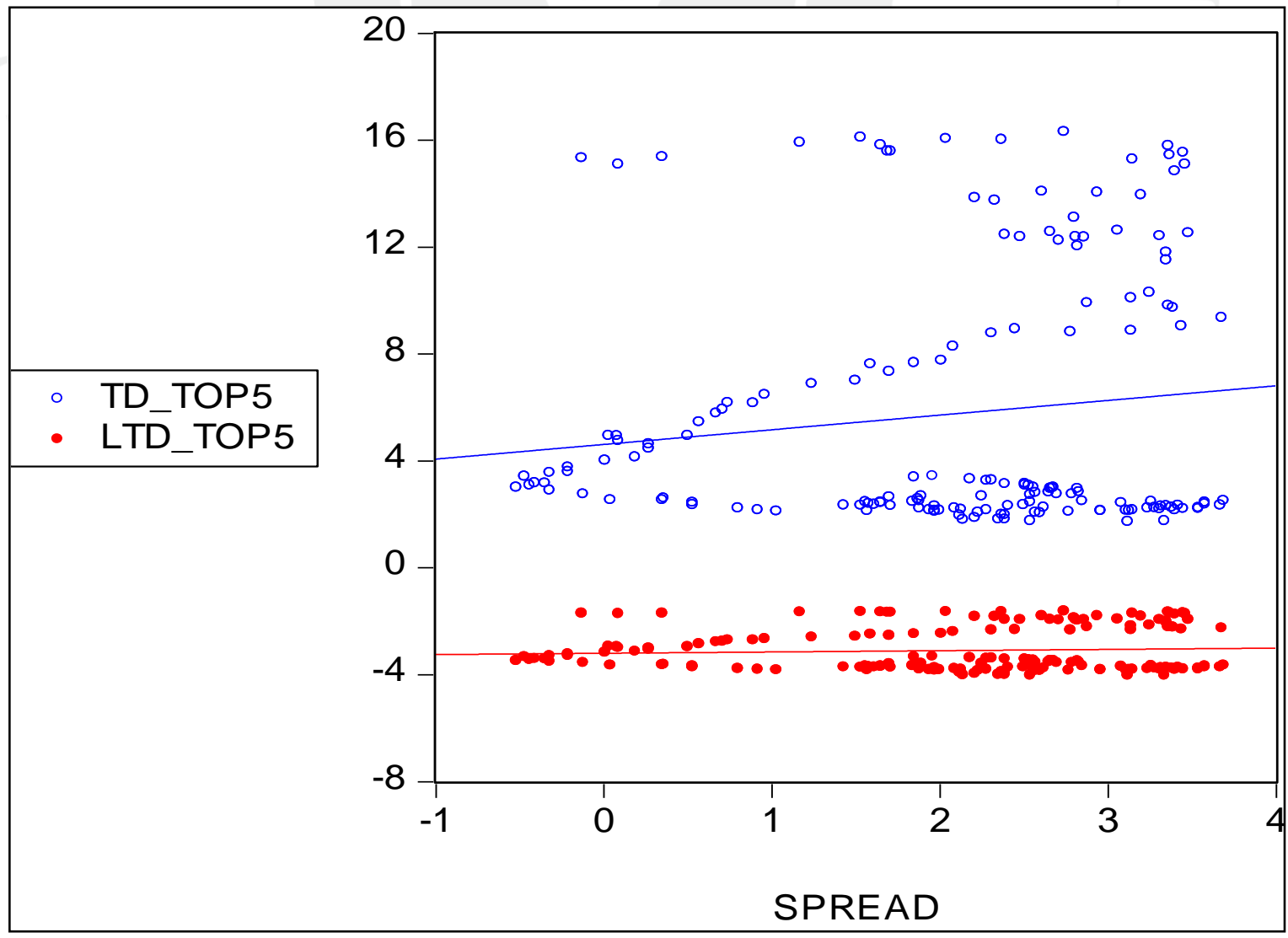


Al estimar la ecuación 3.1 en su versión original, el resultado mostro que las variables exógenas sobrexplican a la endógena; es decir, absorben las variaciones por encima de las que tiene la endógena. Es decir, la significancia general es parcial. (Tabla 3.1.3)

Se realizó un ajuste, transformando el PBI al cuadrado y se corrió el modelo alternativo, mejorando la significancia hasta en 0.95 del estadístico $\mathrm{R}$ cuadrado. Se observó que el modelo seguía manteniendo un nivel de auto correlación no deseable (estadístico Durbin Watson) y por lo tanto se procedió a ajustar. El mismo ajuste de auto correlación eliminó la significancia individual de las exógenas y disparo la explicatividad global. En paralelo, el modelo revelo una fuerte volatilidad al inicio del periodo de estudio ajustado, esto es enero del año 2003.

Se ajustó el modelo, eliminando la doble consideración del PBI, incorporando solamente un término con la potencia al cuadrado; manteniendo así la auto regresividad. Después, se solucionó la auto-correlación y la no significancia individual de, al menos, una exógena. No obstante, se presentó una importante volatilidad en el año 2003; la cual quedo confirmada al momento de aplicar la prueba de estabilidad de los errores, Cusum2.

La prueba de estabilidad Cusum examina el comportamiento de los residuos recursivos. Cusum2 es una medida alternativa aunque no equivalente a la original. Esta consiste en emplear los cuadrados de los residuos recursivos, permitiendo comprobar desviaciones no aleatorias desde la línea del valor medio. 
Tabla 3.1.3 Prueba de ensayo de la ecuación 3.1 en su versión original

\begin{tabular}{|c|c|c|c|c|}
\hline \multicolumn{5}{|c|}{$\begin{array}{l}\text { Dependent Variable: TD_TOP5 } \\
\text { Method: Least Squares } \\
\text { Date: } 05 / 05 / 15 \text { Time: } 20: 20 \\
\text { Sample (adjusted): } 2003 \mathrm{M} 012015 \mathrm{M} 02 \\
\text { Included observations: } 146 \text { after adjustments }\end{array}$} \\
\hline Variable & Coefficient & Std. Error & t-Statistic & Prob. \\
\hline $\mathrm{C}$ & 14.06567 & 0.822233 & 17.10 & 0 \\
\hline PBIX12_SA & -0.104037 & 0.007264 & -14.32 & 0 \\
\hline SPREAD & 0.832738 & 0.148727 & 5.599 & 0 \\
\hline R-squared & 0.599085 & \multicolumn{2}{|c|}{ Mean dependent var } & 4.248249 \\
\hline Adjusted R-squared & 0.593478 & \multicolumn{2}{|c|}{ S.D. dependent var } & 3.157394 \\
\hline S.E. of regression & 2.013126 & \multicolumn{2}{|c|}{ Akaike info criterion } & 4.257588 \\
\hline Sum squared resid & 579.5326 & \multicolumn{2}{|c|}{ Schwarz criterion } & 4.318895 \\
\hline Log likelihood & -307.8039 & \multicolumn{2}{|c|}{ Hannan-Quinn criter. } & 4.282499 \\
\hline F-statistic & 106.842 & \multicolumn{2}{|c|}{ Durbin-Watson stat } & \multirow[t]{2}{*}{0.027575} \\
\hline Prob(F-statistic) & 0 & & & \\
\hline
\end{tabular}

Si bien pudo tratar esta volatilidad con el uso de dos o más dummies, así como otros elementos; lo que se aprecia es que la tasa de deterioro ha tenido un importante nivel de volatilidad entre los años 2002 y 2004. Además, la distribución de los errores es profundamente leptocurtica. Por lo tanto, se optó por reducir la muestra para excluir este periodo de volatilidad, lo cual sería consistente con la eliminación del ruido que podría existir por la etapa de inestabilidad del sector bancario múltiple a causa de las diversas reestructuraciones que sufrió el sector en dicho periodo.

A pesar de que los coeficientes y los indicadores estadísticos resultaron más estables; la inestabilidad paramétrica y de los errores no se dispersaron. Así mismo, se presentó una ligera anormalidad de errores, por la presencia de un outlier en diciembre de 2005. Se procedió a ajustar dicho outlier con una dummy. En este caso se utiliza la variable ficticia o dummy, que señala fenómenos en específico que poseen incidencia sobre la variable endógena. Se le asignan dos valores arbitrarios que indican si se da o no el fenómeno. Esto, con 
el objetivo de no introducir información al modelo que genere una estimación incorrecta.

Este ajuste permitió la normalidad de errores y reducción de la inestabilidad de los parámetros de la prueba Cusum2. También, la prueba de estabilidad de Ramsey RESET indico que el modelo estaría bien distribuido. La prueba del error de especificación de la ecuación de regresión o prueba RESET de Ramsey es una prueba general de especificación para el modelo de regresión lineal. Esta prueba verifica si las combinaciones no lineales de los valores ajustados ayudan a explicar la variable endógena. El motivo detrás de la prueba es determinar si las combinaciones no lineales de las variables explicativas tiene algún poder de explicación sobre la variable endógena, entonces el modelo está mal especificado.

Se probó con un modelo alternativo, con las variables endógenas en logaritmos y con rezagos según lo necesarios. Con estos resultados se solucionó el problema de la inestabilidad Cusum2.

Debido a que la inestabilidad se debía a la insuficiencia en la absorción del comportamiento de la endógena por pocas exógenas, se probó regresar el polinomio del PBI a su forma original, es decir, a dos términos sin dummy. El modelo absorbe todo el error en la prueba Cusum, y parcialmente en la prueba Cusum2. La inclusión de las variables dummies para los outliers no mejoró significativamente la estabilidad del modelo, sino que lo empeoró. Para mejorar este ajuste, se estimó el modelo con el spread al cuadrado, lo que repercutió en que el modelo sea más robusto.

Esto demostró que la principal causa de la inestabilidad de los errores sería la forma funcional. Siendo así, se procedió a incorporar logaritmos a todos los elementos. Para el caso del spread, se mantuvo el cuadrado, debido a que cuenta con valores negativos. Alternativamente se probó un proceso ARIMA, el 
cual requirió a la variable endógena en diferencias para atenuar la no estacionariedad, pero los resultados no fueron satisfactorios.

Se estimó un nuevo modelo para la ecuación 3.1 que será referido como ecuación 3.4 en lo siguiente (Tabla 3.4)

Ecuación 3.4 Modelo econométrico de la Tasa de Deterioro

(tasa deterioro $)=C+\alpha P B I \times 12_{g a}+\beta P B I \times 12_{g a}{ }^{2}+\gamma$ Spread $^{2}+\delta\left(\right.$ tasa deterioro $\left._{t-1}\right)$

Cabe señalar que el nuevo modelo es no lineal en variables pero lineal en parámetros y, al mismo tiempo, es menos intrusivo en comparación a un modelo que requiera de transformación de variables por linealizacion.

Se procedió a estimar el nuevo modelo (Figura 3.1.4). Después se presenta la bondad de ajuste, similitud entre la seria observada y la estimada, del nuevo modelo (Figura 3.1.5). Se procedió a aplicar el nuevo modelo de la ecuación 3.4 a las series de cada banco individualmente para la ejecución de la prueba de estrés.

La ecuación 3.4 nos indica que el PBI muestra una relación significativa con la tasa de deterioro; no obstante, dicha relación cambia según el impacto que tenga en el PBI. Al sumar ambos coeficientes se observa que el impacto agregado del PBI es negativo. Esto se interpreta a que si el PBI aumenta, se genera una tendencia a la reducción del deterioro de la cartera y si el PBI disminuye su crecimiento, la tasa de deterioro aumentara. Este es congruente, ya que el proceso expansivo de los portafolios es producto y resultado del crecimiento de la economía. 
En cuanto al Spread de tasas, se observa una relación positiva y significativa, con lo cual se sugiere que a mayor spread de tasas de interés, mayor será la tasa de deterioro. Ello puede deberse a que el margen financiero derivado de un mayor spread implica un mayor riesgo para los portafolios de créditos de los bancos y por lo tanto repercute en la selección adversa. Los demás elementos son variables de ajuste del modelo, por lo tanto no requieren interpretación.

Para brindar robustez al modelo se corrieron diversas pruebas de diagnóstico de residuos. Se verifico la normalidad de los residuos a través del histograma de la prueba de normalidad y el estadístico Jarque Bera. El estadístico Jarque Bera es un indicador de la desviación de la distribución. (Tabla 3.1.5)

Se utilizó el Test Breusch-Godfrey para validar los supuestos aplicados en el modelo de regresión y detectar la presencia de dependencia serial que no haya sido considerada dentro del modelo. Este test de autocorrelacion hace uso de los errores generados en el modelo. Se comprueba que no existe correlación serial. (Tabla 3.1.6)

Se corrió la prueba de Heterocedasticidad ARCH con 1 rezago y se verificó que no se presenta el en modelos. Se dice que un modelo presenta heterocedasticidad cuando la varianza de las perturbaciones no es constante a los largo de las observaciones, resultando en un error del cálculo y pérdida de eficiencia del estimador (Tabla 3.1.7). Se aplicó el diagnostico de estabilidad de la prueba RESET de Ramsey y se comprobó que no existe omisión de variables, que la forma de la función sea incorrecta y correlación entre loas exógenos y los residuos (Tabla 3.1.8). Se graficó los resultados de las pruebas de estimación de recursivos Cusum y Cusum2 que descartaron una posible inestabilidad en los coeficientes. (Figuras 3.1.6 y 3.1.7) 
Tabla 3.1.4:

Estimación de la ecuación 3.4

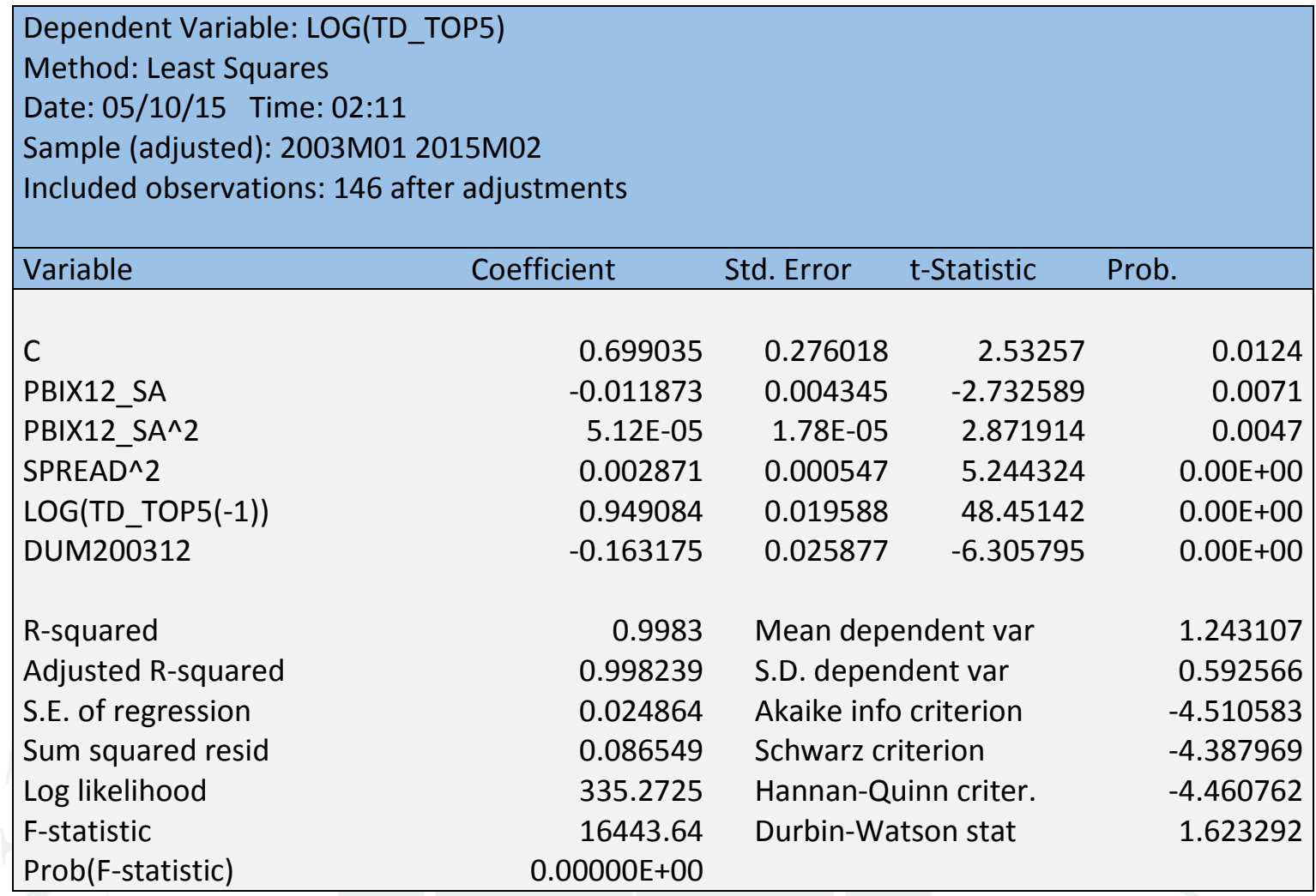

Figura 3.1.4

Estimación del modelo de la ecuación 3.4

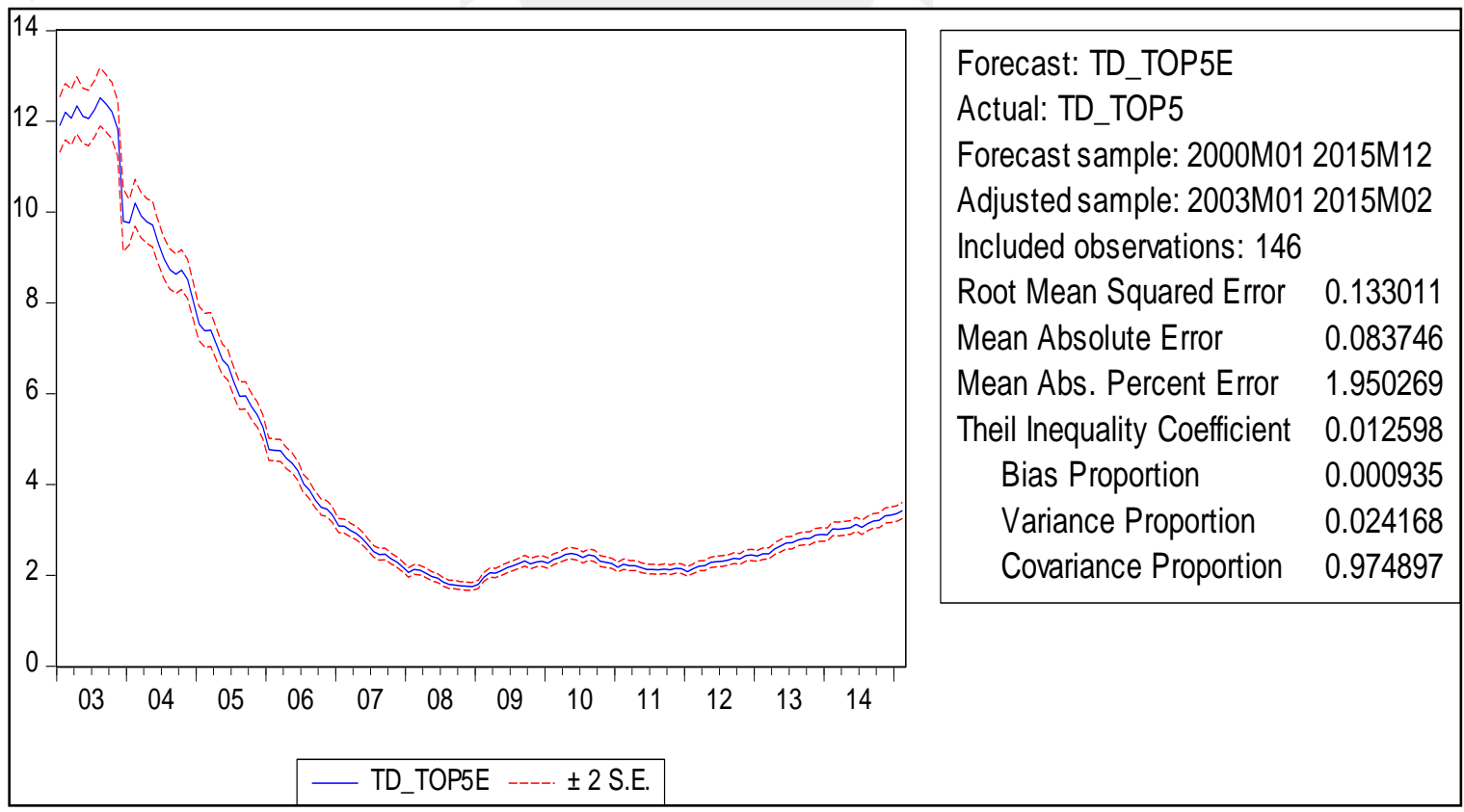


Figura 3.1.5

Estimación de la Bondad de ajuste del modelo de la ecuación 3.4

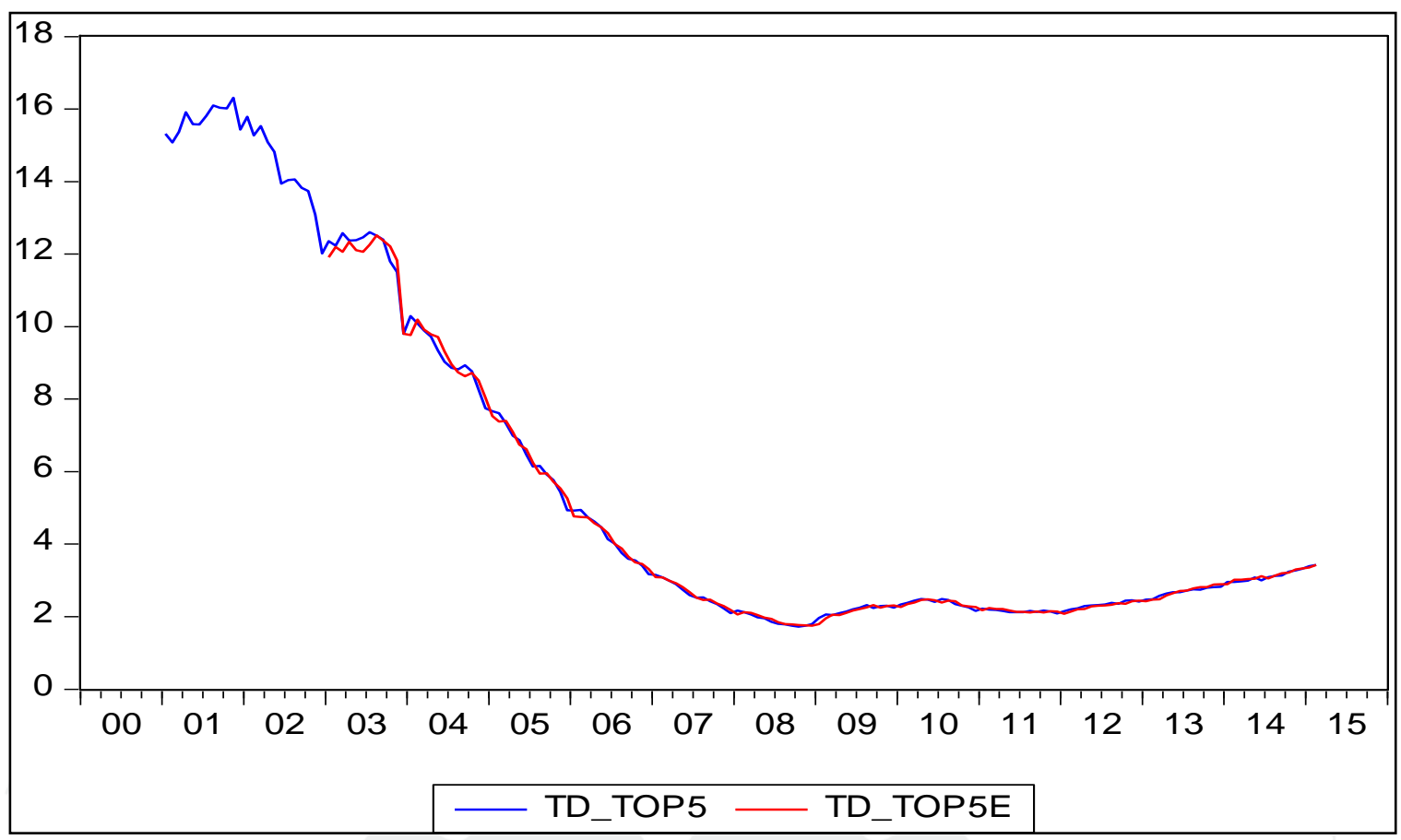

Tabla 3.1.5

Diagnóstico de Residuos - Histograma de prueba de Normalidad

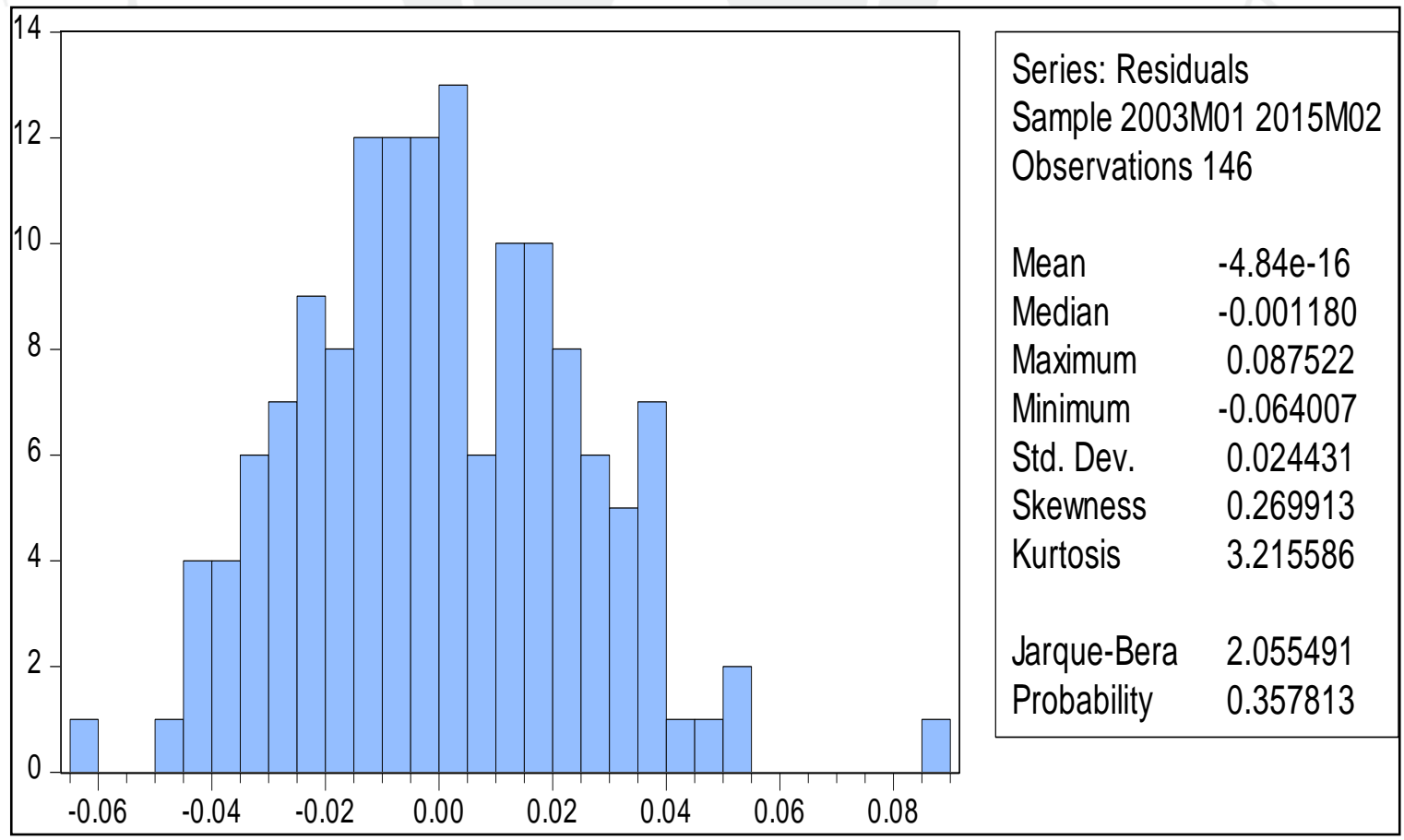


Tabla 3.1.6

Diagnóstico de Residuos - Prueba de correlación serial LM

\begin{tabular}{|c|c|c|c|c|}
\hline \multicolumn{5}{|c|}{ Breusch-Godfrey Serial Correlation LM Test: } \\
\hline F-statistic & 2.502822 & \multicolumn{2}{|l|}{ Prob. $F(2,138)$} & 0.0856 \\
\hline Obs*R-squared & 5.110456 & \multicolumn{2}{|c|}{ Prob. Chi-Square(2) } & 0.0777 \\
\hline \multicolumn{5}{|l|}{ Test Equation: } \\
\hline Dependent Variable: RESID & & \multicolumn{3}{|c|}{ Sample: 2003M01 2015M02 } \\
\hline Method: Least Squares & & \multicolumn{3}{|c|}{ Included observations: 146} \\
\hline \multicolumn{5}{|c|}{ Date: 05/10/15 Time: 12:51 } \\
\hline \multicolumn{5}{|c|}{ Presample missing value lagged residuals set to zero. } \\
\hline Variable & Coefficient & Std. Error & t-Statistic & Prob. \\
\hline $\mathrm{C}$ & 0.125108 & 0.281893 & 0.443812 & 0.6579 \\
\hline PBIX12_SA & -0.001948 & 0.004434 & -0.439298 & 0.6611 \\
\hline $\mathrm{PBIX} 12 \_\mathrm{SA}^{\wedge} 2$ & 7.95E-06 & $1.82 \mathrm{E}-05$ & 0.436807 & 0.6629 \\
\hline $\mathrm{SPREAD}^{\wedge} 2$ & $4.88 \mathrm{E}-05$ & 0.000542 & 0.090092 & 0.9283 \\
\hline LOG(TD_TOP5(-1)) & -0.009177 & 0.020061 & -0.457449 & 0.6481 \\
\hline DUM200312 & 0.003078 & 0.025791 & 0.119332 & 0.9052 \\
\hline RESID(-1) & 0.194642 & 0.087029 & 2.236519 & 0.0269 \\
\hline RESID(-2) & -0.021355 & 0.086572 & -0.246675 & 8.06E-01 \\
\hline R-squared & 0.035003 & Mean depen & dent var & $-4.84 \mathrm{E}-16$ \\
\hline Adjusted R-squared & -0.013946 & S.D. depende & nt var & 0.024431 \\
\hline S.E. of regression & 0.024601 & Akaike info c & riterion & -4.518816 \\
\hline Sum squared resid & 0.083519 & Schwarz crite & rion & -4.35533 \\
\hline Log likelihood & 337.8735 & Hannan-Quin & in criter. & -4.452388 \\
\hline F-statistic & 0.715092 & Durbin-Wats & on stat & 1.985269 \\
\hline Prob(F-statistic) & 0.659312 & & & \\
\hline
\end{tabular}

Tabla 3.1.7 Prueba de Heterocedasticidad ARCH con 1 rezago

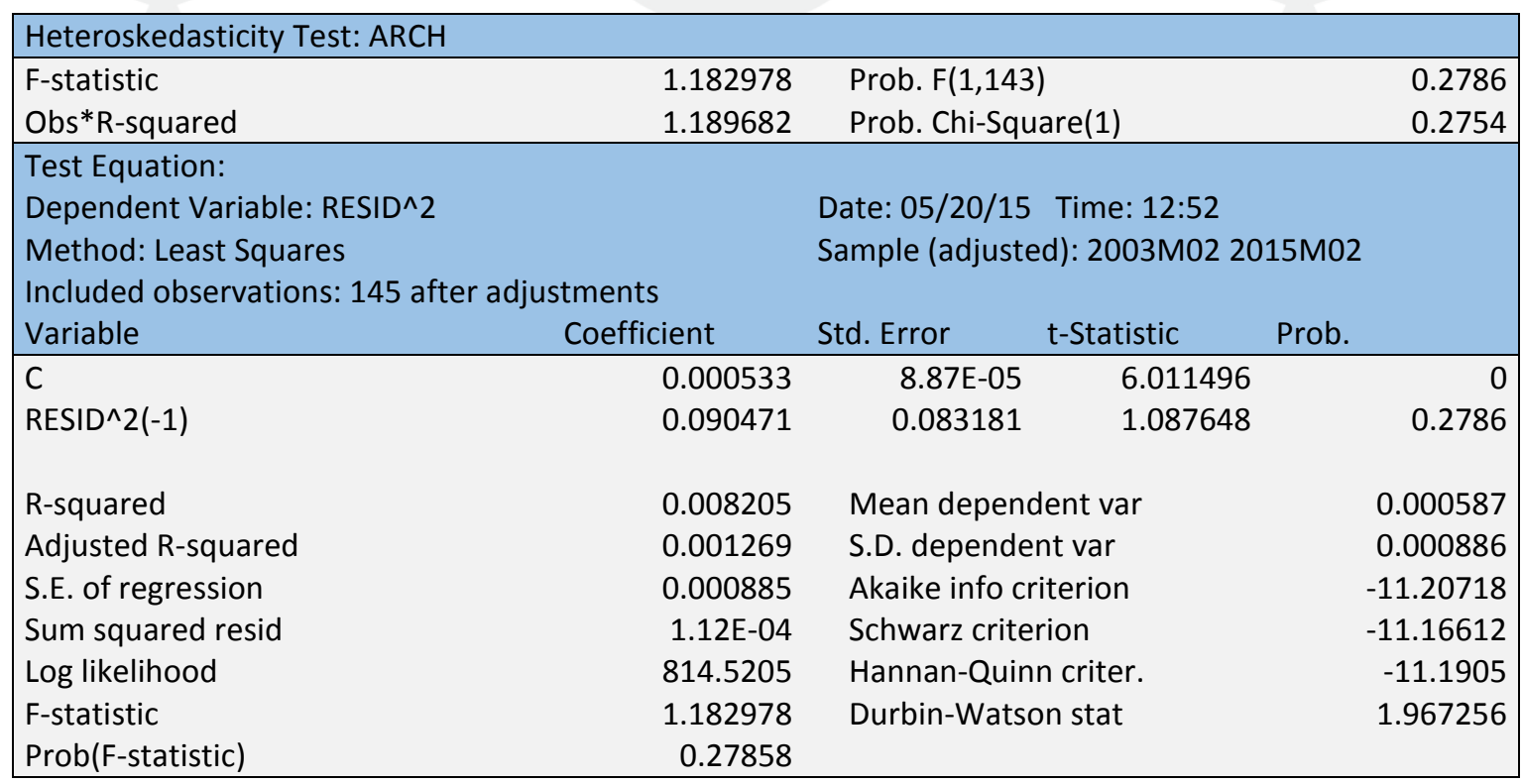


Tabla 3.1.8

Diagnostico de Estabilidad - Prueba RESET de Ramsey

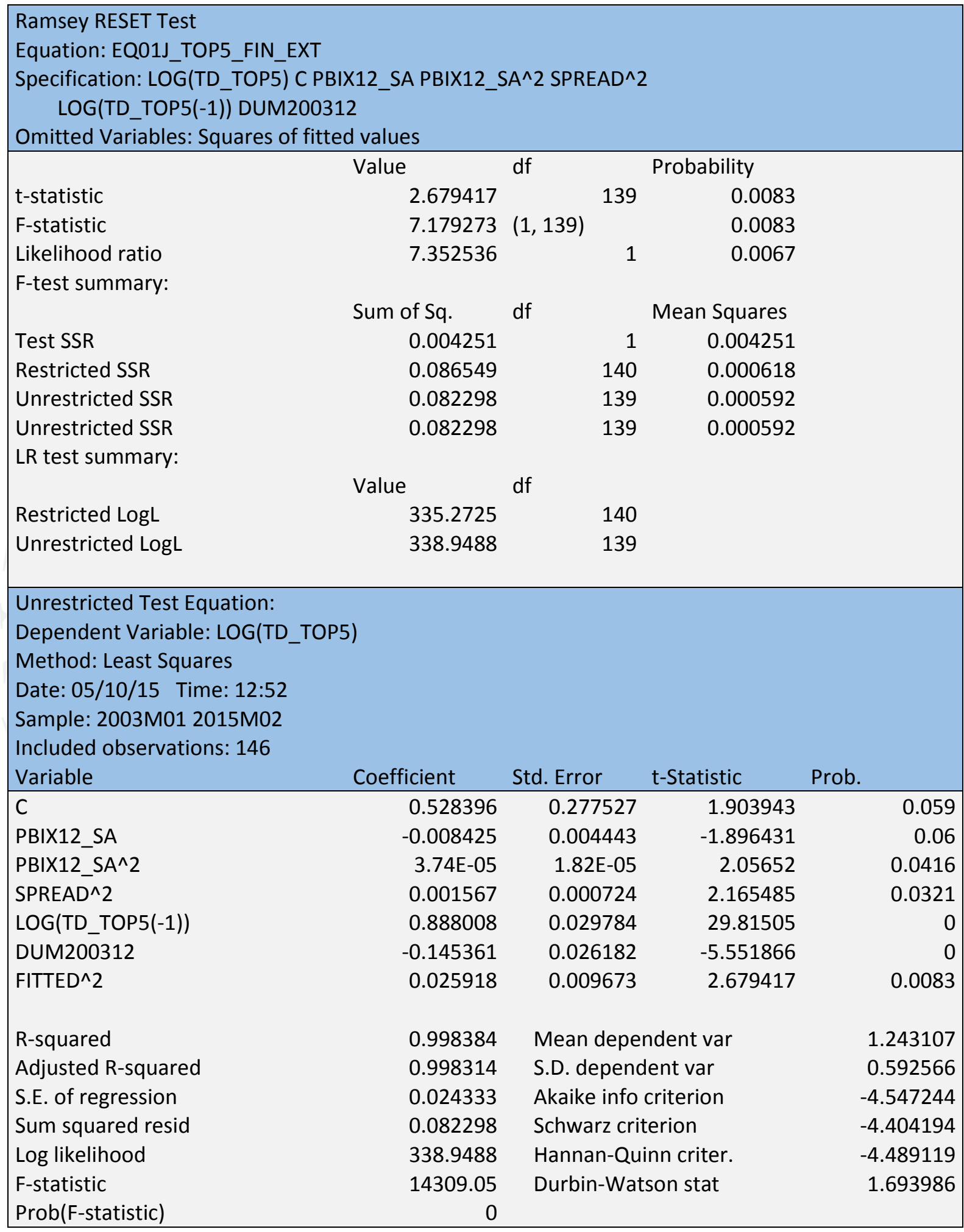


Figura 3.1.6

Estimadores Recursivos - Prueba CUSUM

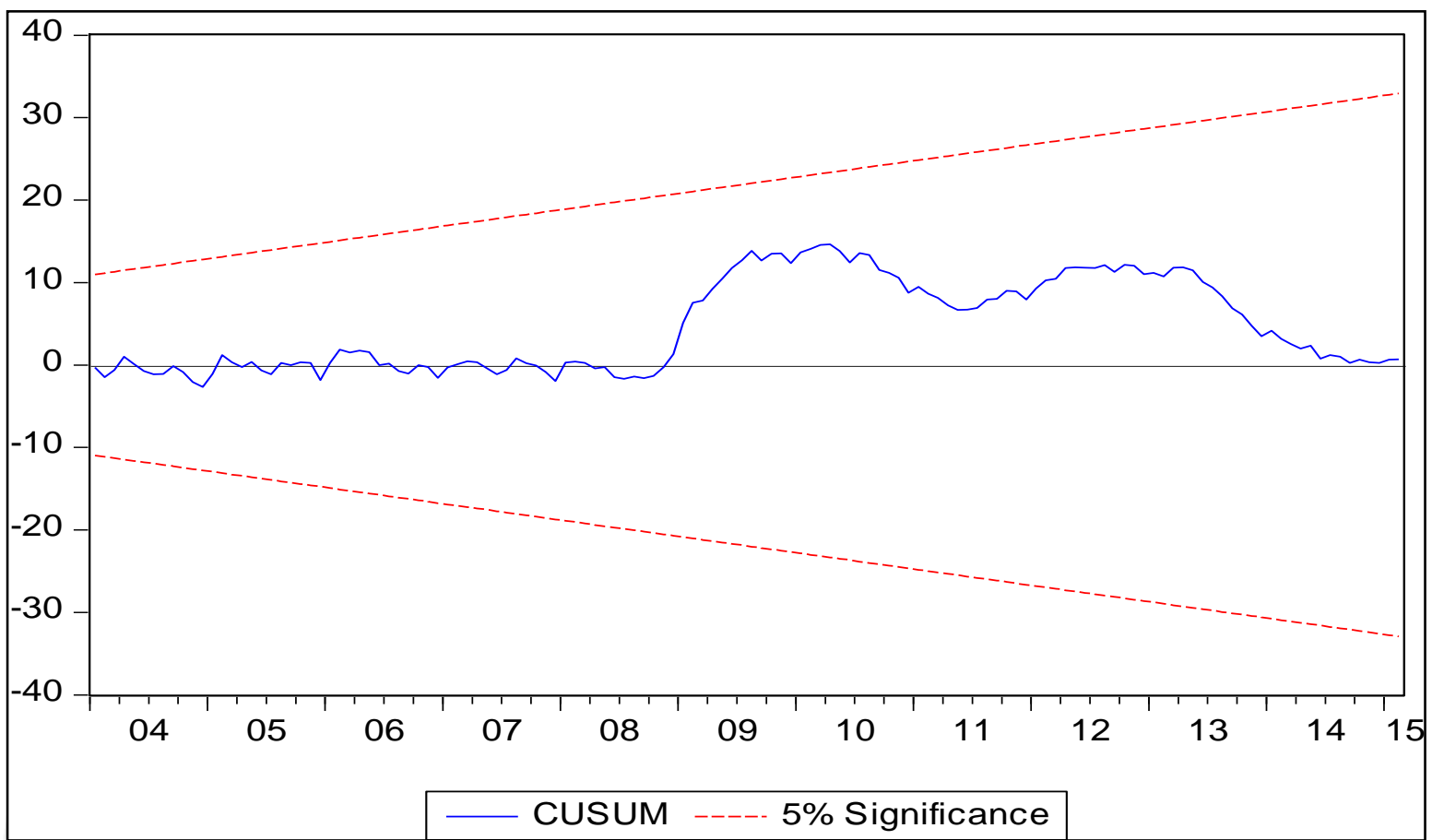

Figura 3.1.7

Estimadores Recursivos- Prueba de cuadrados CUSUM/ CUSUM2

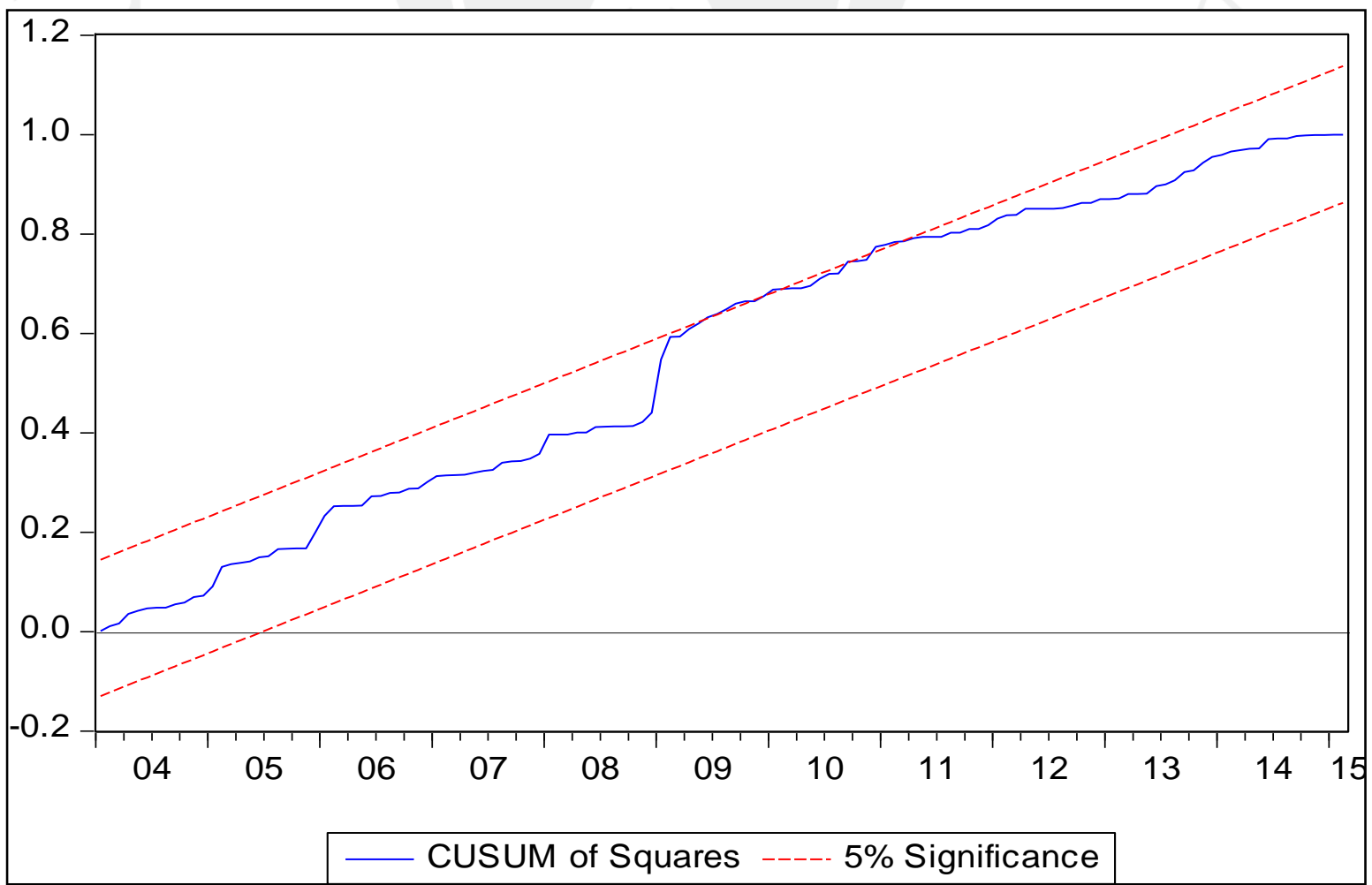




\subsubsection{Ecuación 3.2 Modelo de Provisiones en relación a la Cartera de Créditos}

Se observó que la relación entre la tasa de deterioro y la tasa de provisiones es linealmente débil en algunos casos; no obstante, se interpreta que existirían dos etapas. Una correspondiente a las tasas de deterioro bajas y otro para las tasas superiores. Siendo así, es factible implementar un modelo de quiebre estructural con dummies. Por lo tanto, primero se resolverá el problema del quiebre estructural y después el auto regresivo. Al mismo tiempo se observa que ambas variables requieren un ajuste de linealidad, dado que su no linealidad tienen características diferenciadas, con lo cual podría no existir una combinación lineal entre ellas, salvo que se transformen. Considerando para el estudio como prioridad un modelo consistente y robusto antes que un modelo explicativo. (Figura 3.1.8)

Se ejecutó el modelo inicial de la ecuación 3.2 y los resultados no fueron satisfactorios. Se registró auto correlación, inestabilidad paramétrica y no linealidad. La variable endógena no es estacionaria de acuerdo a la prueba de raíz unitaria (Tabla 3.1.9). Se procedió a corregir la autocorrelación con el uso de dos rezagos en la variable endógena. Resultado de esto, el indicador de Durbin Watson fue cercano a 2. Esto repercutió en que mejorará la explicatividad global. 
Figura 3.1.8

Relación entre las variables

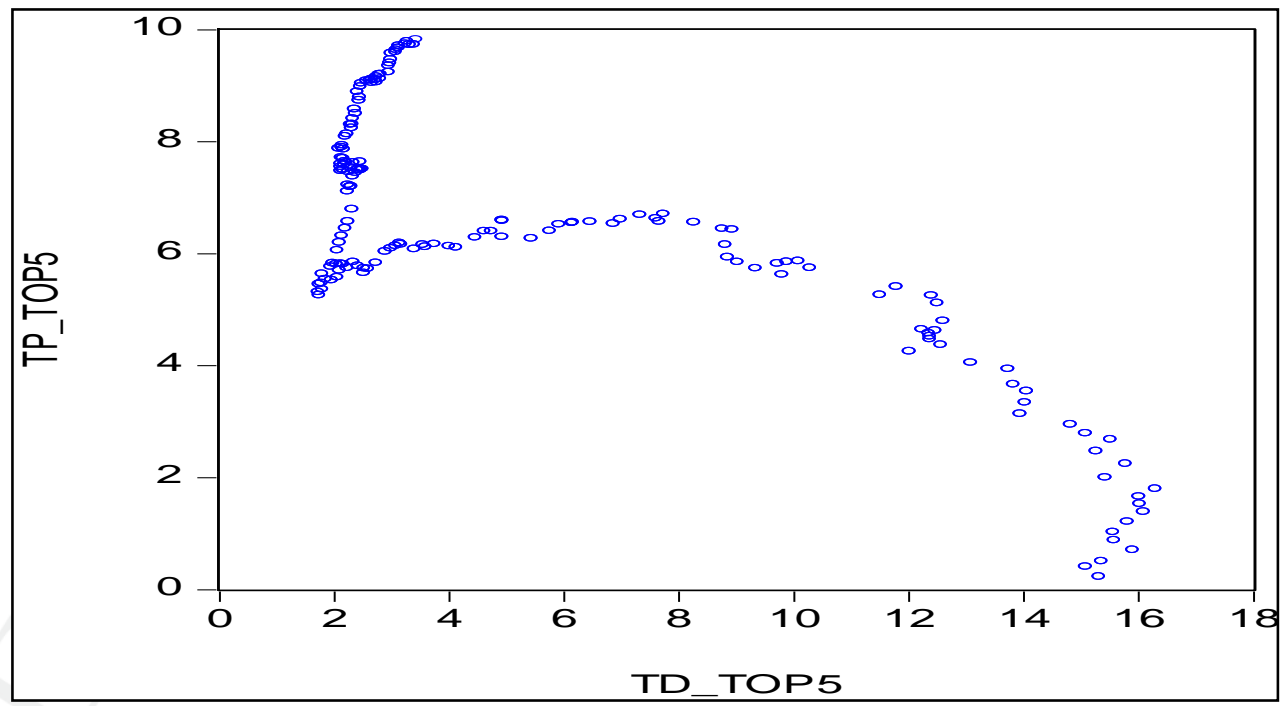

Tabla 3.1.9

Prueba de Raíz Unitaria para Provisiones (TP_top5)

\begin{tabular}{|c|c|c|c|c|}
\hline \multicolumn{5}{|c|}{$\begin{array}{l}\text { Null Hypothesis: TP_TOP5 has a unit root } \\
\text { Exogenous: Constant, Linear Trend } \\
\text { Lag Length: } 1 \text { (Automatic - based on SIC, maxlag=13) }\end{array}$} \\
\hline & & & t-Statistic & Prob. $*$ \\
\hline \multicolumn{3}{|c|}{ Augmented Dickey-Fuller test statistic } & -3.003806 & 0.1343 \\
\hline \multirow[t]{3}{*}{ Test critical values: } & $1 \%$ level & & -4.013608 & \\
\hline & $5 \%$ level & & -3.436795 & \\
\hline & $10 \%$ level & & -3.142546 & \\
\hline \multicolumn{5}{|c|}{$\begin{array}{l}\text { *MacKinnon (1996) one-sided p-values. } \\
\text { Augmented Dickey-Fuller Test Equation } \\
\text { Dependent Variable: D(TP_TOP5) } \\
\text { Method: Least Squares } \\
\text { Date: 05/10/15 Time: 06:42 } \\
\text { Sample (adjusted): } 2001 \mathrm{M03} 2015 \mathrm{M} 02 \\
\text { Included observations: } 168 \text { after adjustments }\end{array}$} \\
\hline Variable & Coefficient & Std. Error & t-Statistic & Prob. \\
\hline TP_TOP5(-1) & -0.027652 & 0.009205 & -3.003806 & 0.0031 \\
\hline $\mathrm{D}\left(\overline{T P} \_T O P 5(-1)\right)$ & 0.296944 & 0.072584 & 4.091046 & 0.0001 \\
\hline C & 0.143416 & 0.031191 & 4.597951 & 0 \\
\hline @TREND(2000M01) & 0.000738 & 0.000404 & 1.82558 & 0.0697 \\
\hline R-squared & 0.196982 & Mean depen & ident var & 0.056033 \\
\hline Adjusted R-squared & 0.182293 & S.D. depende & ent var & 0.118436 \\
\hline S.E. of regression & 0.107098 & Akaike info $c$ & criterion & -1.606625 \\
\hline Sum squared resid & 1.881075 & Schwarz crite & erion & -1.532245 \\
\hline Log likelihood & 138.9565 & Hannan-Quir & nn criter. & -1.576438 \\
\hline F-statistic & 13.40986 & Durbin-Wats & son stat & 2.089044 \\
\hline Prob(F-statistic) & 0 & & & \\
\hline
\end{tabular}


Es de notar que las principales variables como las tasas tiene una particular relación, donde su correlación aumenta con el tiempo. Esta particularidad es el motivo por el cual se genera un rechazo al modelo inicial, además de poseer un elevado nivel de heterocedasticidad. Debido a que existe heterocedasticidad de series de tiempo, se procedió a transformar las variables y aplicar un modelo GARCH. Con ambos ajustes, desapareció el problema de Heterocedasticidad y se recuperó la significancia del modelo.

Se concluyó con el nuevo modelo de la ecuación 3.2, que en adelante será la ecuación 3.5 (Tabla 3.1.10)

Ecuación 3.5 Modelo econométrico de la tasa de Provisiones

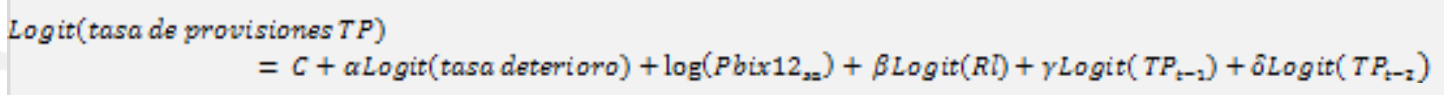

Se procedió a observar la evolución de los residuos (Figura 3.1.9), se verifico la normalidad de los residuos (Tabla 3.1.11) y la estimación de la endógena (Figura 3.1.10). Finalmente, se contrasta el resultado de la estimación con la variable endógena observada (Figura 3.1.11).

La ecuación 3.5 revela que existe una relación directa, positiva y linealizada entre las tasas de deterioro y las provisiones. Contrario a lo previsto, dados los ajustes al modelo y la interacción con las demás variables, el impacto de la tasa de deterioro es significativo. No hay indicios que exista un sesgo provocado por una relación contable entre las variables. 
En segundo lugar, el PBI muestra esta vez una relación directa con las provisiones, desde un punto de vista inmediato. Esto significa que, a pesar que la economía pueda crecer, esto no sólo implica un crecimiento de los créditos vigentes, sino también de los impagos, lo cual requiere la asignación de nuevas provisiones por el volumen de crecimiento. Este efecto es aún mayor que el de la tasa de deterioro, con lo cual ambos factores se retroalimentan para que la tasa de provisiones aumentara de manera excesiva en el periodo de estudio. (Tabla 3.1.10)

El modelo sugiere que una mayor tasa de interés de largo plazo repercute en una menor tasa de aprovisionamiento. No obstante, desde hace varios años se observa que la tasa de interés de largo plazo disminuye. (Tabla 3.1.10)

Con la prueba de Normalidad se verificó que no existen desviaciones en la distribución de los residuos (Tabla 3.1.11). Se estimó la prueba de heterocedasticidad ARCH LM donde se descartó la inconsistencia en la varianza de las perturbaciones (Tabla 3.1.12). 
Tabla 3.1.10

Estimación del modelo de la ecuación 3.5

\begin{tabular}{|c|c|c|c|c|}
\hline \multirow{2}{*}{\multicolumn{5}{|c|}{ Dependent Variable: LTP_TOP5 }} \\
\hline & & & & \\
\hline \multicolumn{5}{|c|}{ Method: ML - ARCH (Marquardt) - Normal distribution } \\
\hline \multicolumn{5}{|c|}{ Date: 05/05/15 Time: 02:51 } \\
\hline \multicolumn{5}{|c|}{ Sample (adjusted): 2003M01 2015M02 } \\
\hline \multicolumn{5}{|c|}{ Included observations: 146 after adjustments } \\
\hline \multicolumn{5}{|c|}{ Convergence achieved after 11 iterations } \\
\hline \multicolumn{5}{|c|}{ Presample variance: backcast (parameter $=0.7$ ) } \\
\hline \multicolumn{5}{|c|}{$\operatorname{GARCH}=\mathrm{C}(7)^{*} \operatorname{RESID}(-1)^{\wedge} 2+(1-\mathrm{C}(7))^{*} \mathrm{GARCH}(-1)$} \\
\hline Variable & Coefficient & Std. Error & z-Statistic & Prob. \\
\hline C & -0.300079 & 0.035254 & -8.511913 & 0 \\
\hline LTD_TOP5 & 0.010142 & 0.004446 & 2.281397 & 0.0225 \\
\hline LOG(PBIX12_SA) & 0.038126 & 0.008916 & 4.276354 & 0 \\
\hline LRL & -0.011874 & 0.005223 & -2.273293 & 0.023 \\
\hline LTP_TOP5(-1) & 1.141726 & 0.101014 & 11.30263 & 0 \\
\hline \multirow[t]{2}{*}{ LTP_TOP5(-2) } & -0.187992 & 0.099045 & -1.89805 & 0.0577 \\
\hline & \multicolumn{4}{|l|}{ Variance Equation } \\
\hline $\operatorname{RESID}(-1)^{\wedge} 2$ & 0.137169 & 0.039773 & 3.448781 & 0.0006 \\
\hline GARCH(-1) & 0.862831 & 0.039773 & 21.69371 & 0 \\
\hline R-squared & 0.992336 & \multicolumn{2}{|c|}{ Mean dependent var } & -2.601579 \\
\hline Adjusted R-squared & 0.992063 & \multicolumn{2}{|c|}{ S.D. dependent var } & 0.220781 \\
\hline S.E. of regression & 0.01967 & \multicolumn{2}{|c|}{ Akaike info criterion } & -5.36619 \\
\hline Sum squared resid & 0.054166 & \multicolumn{2}{|c|}{ Schwarz criterion } & -5.22314 \\
\hline Log likelihood & 398.7318 & \multicolumn{2}{|c|}{ Hannan-Quinn criter. } & -5.308065 \\
\hline Durbin-Watson stat & 2.015622 & & & \\
\hline
\end{tabular}

Figura 3.1.9

Residuos del modelo de la ecuación 3.5

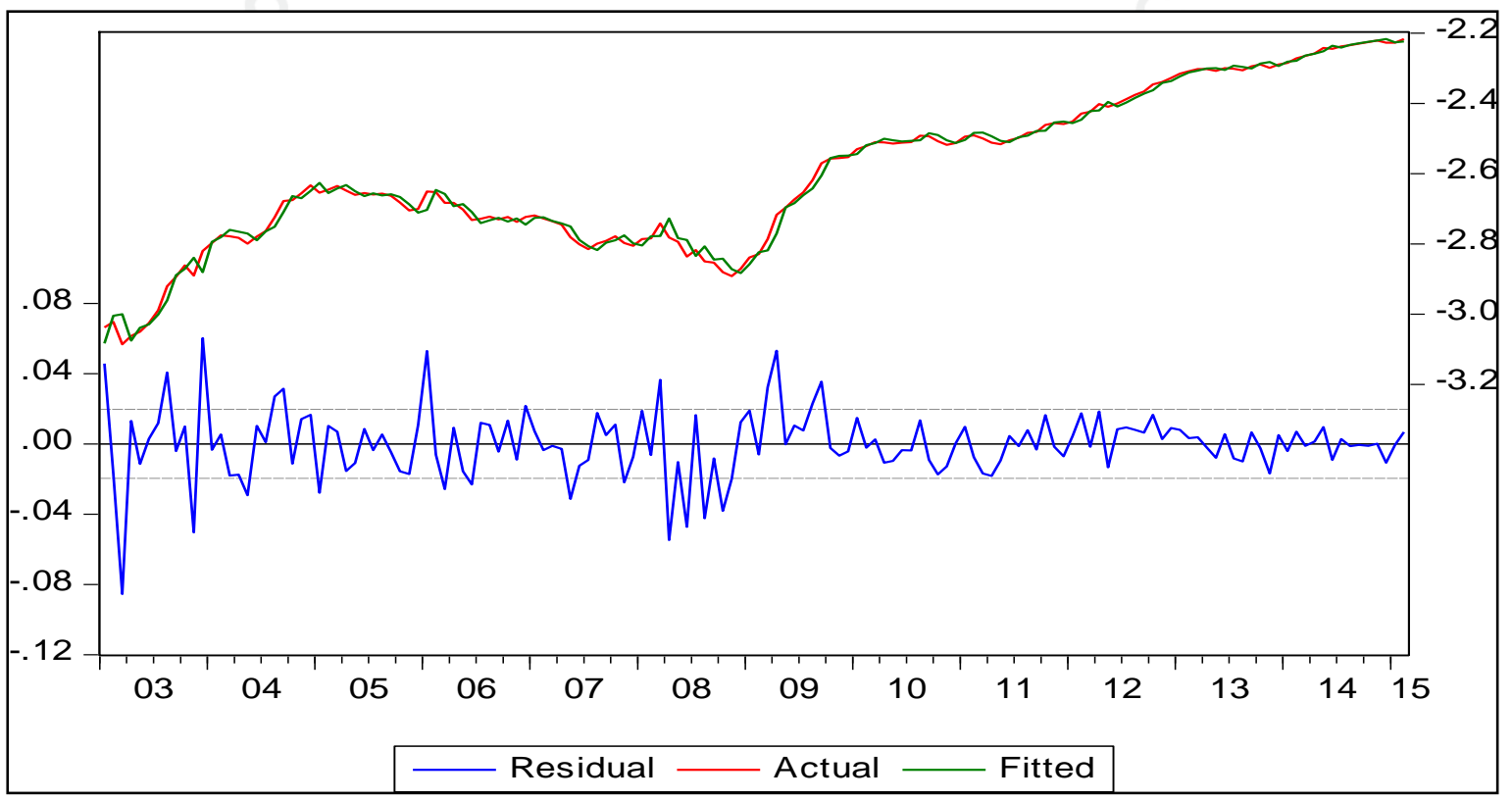


Tabla 3.1.11

Diagnostico de Residuos -Histograma de Prueba de Normalidad

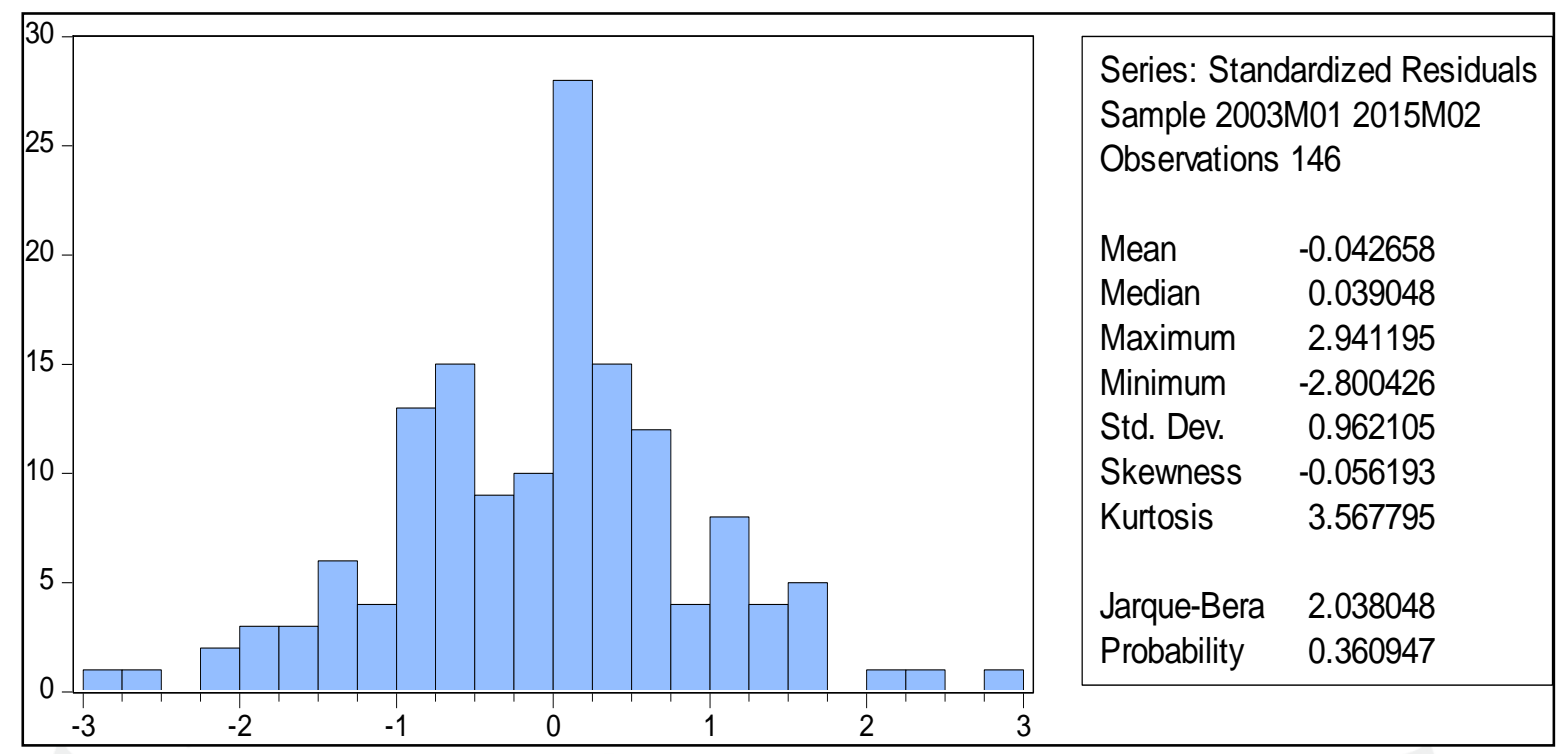

Figura 3.1.10

Estimación del modelo de la ecuación 3.5

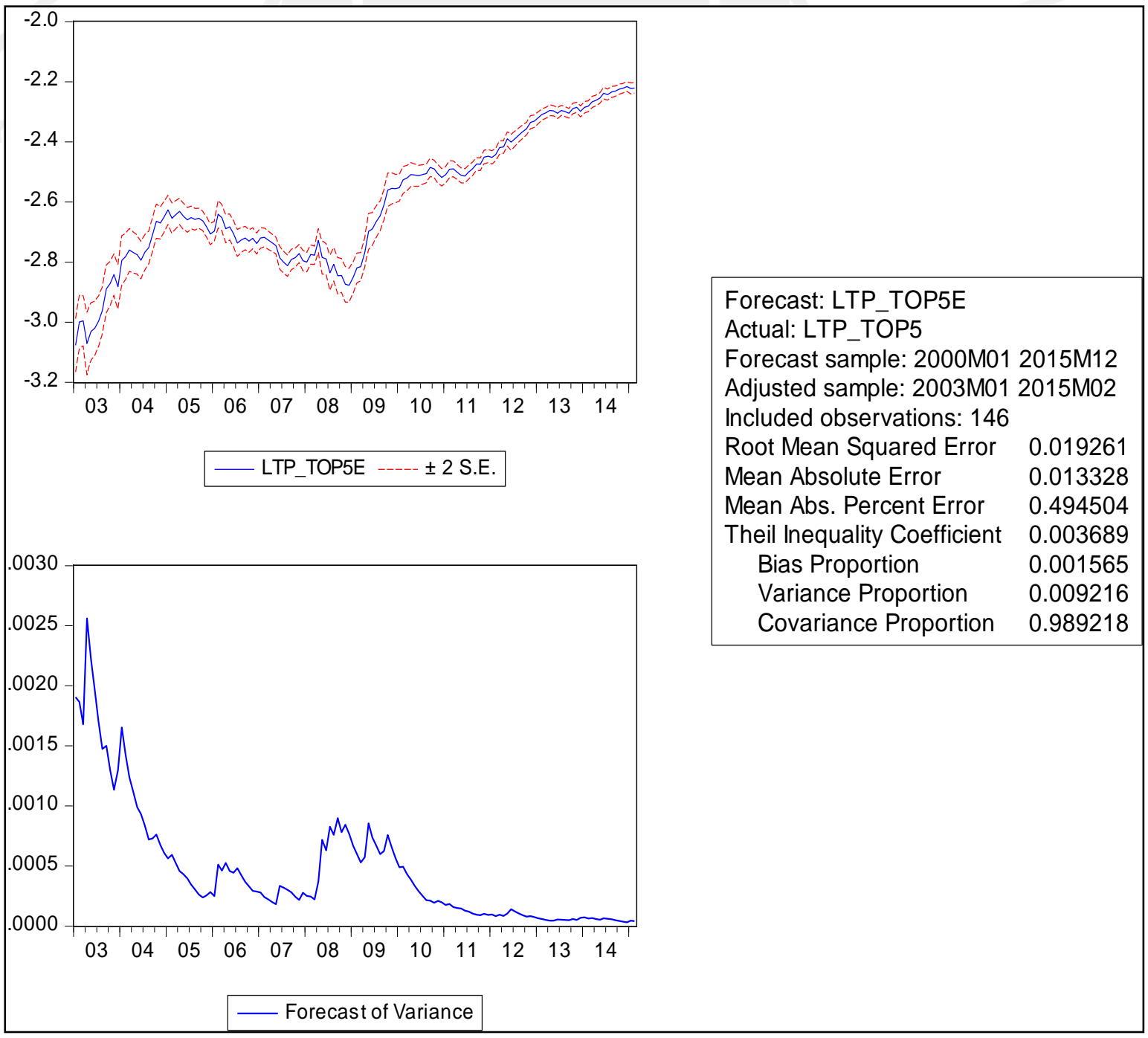


Figura 3.1.11

Estimación de la variable endógena en el modelo de la ecuación 3.5

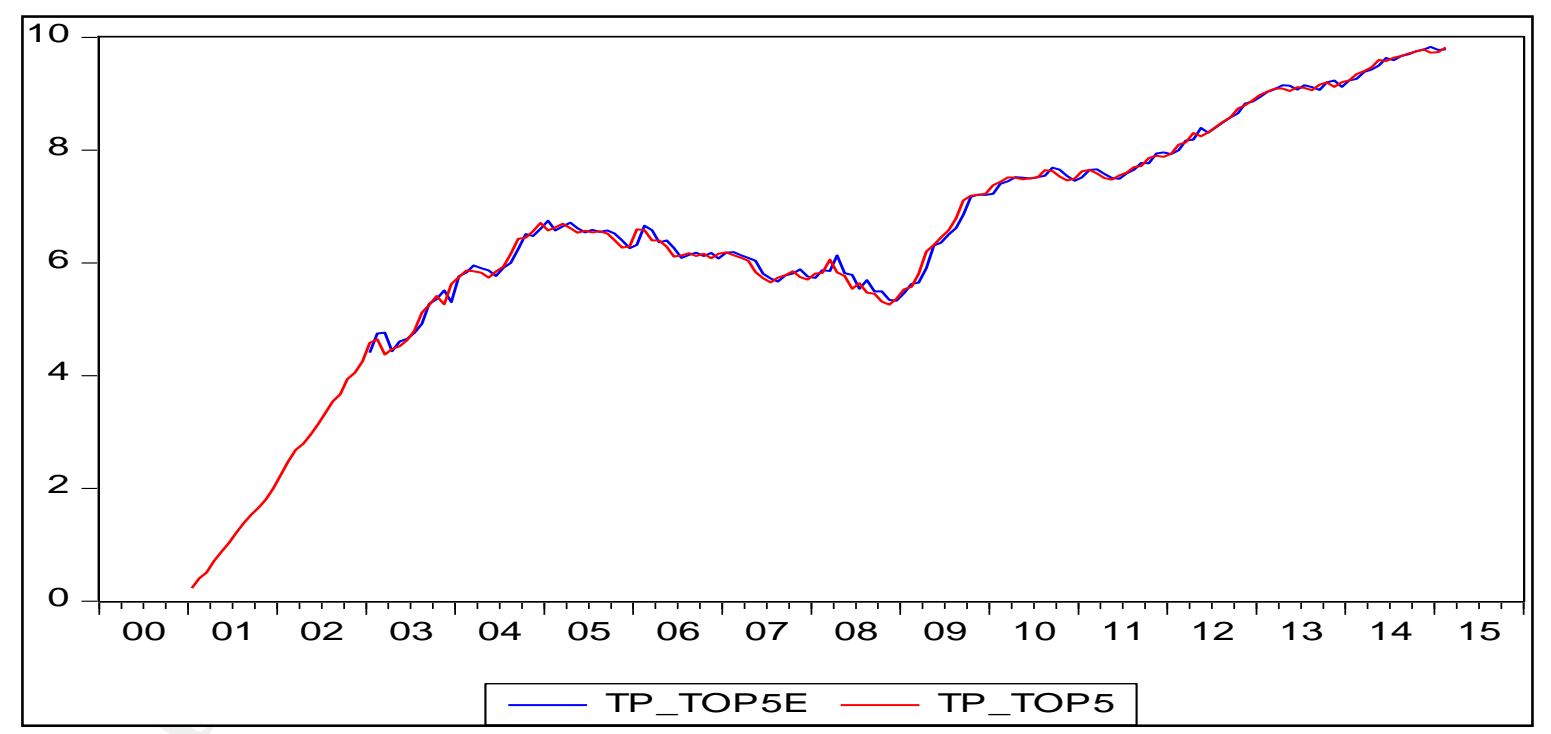

Tabla 3.1.12

Prueba de Heterocedasticidad ARCH LM

\begin{tabular}{|c|c|c|c|c|}
\hline \multicolumn{5}{|c|}{ Heteroskedasticity Test: ARCH } \\
\hline F-statistic & 0.040234 & \multicolumn{2}{|c|}{ Prob. F(1,143) } & 0.8413 \\
\hline Obs*R-squared & 0.040785 & \multicolumn{2}{|c|}{ Prob. Chi-Square(1) } & 0.84 \\
\hline \multicolumn{5}{|c|}{$\begin{array}{l}\text { Test Equation: } \\
\text { Dependent Variable: WGT_RESID^2 } \\
\text { Method: Least Squares } \\
\text { Date: } 05 / 20 / 15 \text { Time: } 12: 33 \\
\text { Sample (adjusted): } 2003 \mathrm{M} 02 \text { 2015M02 } \\
\text { Included observations: } 145 \text { after adjustments }\end{array}$} \\
\hline Variable & Coefficient & Std. Error & t-Statistic & Prob. \\
\hline $\mathrm{C}$ & 0.906135 & 0.146191 & 6.198316 & 0 \\
\hline WGT_RESID^2(-1) & 0.01678 & 0.083656 & 0.200583 & 0.8413 \\
\hline R-squared & 0.000281 & \multicolumn{2}{|c|}{ Mean dependent var } & 0.921659 \\
\hline Adjusted R-squared & -0.00671 & \multicolumn{2}{|c|}{ S.D. dependent var } & 1.488474 \\
\hline S.E. of regression & 1.49346 & \multicolumn{2}{|c|}{ Akaike info criterion } & 3.653765 \\
\hline Sum squared resid & 318.9502 & \multicolumn{2}{|c|}{ Schwarz criterion } & 3.694823 \\
\hline Log likelihood & -262.8979 & \multirow{2}{*}{\multicolumn{2}{|c|}{ Hannan-Quinn criter. }} & 3.670448 \\
\hline F-statistic & 0.040234 & & 1.999511 \\
\hline Prob(F-statistic) & 0.841309 & & & \\
\hline
\end{tabular}




\subsubsection{Aplicación de la Prueba de Estrés: Simulación VAR Impulso-Respuesta}

La prueba de estrés para el riesgo crédito está construida a partir de la aplicación de Van den End (2006), con una serie de ajustes propios de un modelo VAR.

Este modelo exige que todas las variables sean endógenas y exógenas en una matriz que las interrelaciones y proceda a estimar a todas como un conjunto. Se utilizó solamente dos rezagos con el fin de que sea coincidente con las ecuaciones determinísticas 3.4 y 3.5. Con la información de las interacciones, se estimó el modelo de impulso-respuesta. Se precisa que los impulsos corresponden solamente a las variables exógenas que se utilizaron en las ecuaciones anteriores y las respuestas serán las variables endógenas de dichas ecuaciones. Para precisar, la función impulso respuesta muestra como un cambio en la variable exógena se transmitirá al resto de variables explicadas a través de una estructura dinamica que representa el modelo VAR.

La interpretación del proceso es el siguiente: cuando ocurre un cambio en la variable exógena equivalente a una desviación Cholesky (Dof adjusted), la variable endógena se verá afectada durante un periodo de tiempo correspondiente. El impacto no es inmediato de un solo periodo, sino inter temporal. En este ejercicio se está considerando tres tipos de desviaciones por un impacto: en el PBI, en el Spread y en la tasa a largo plazo. 
Para la aplicación de la prueba se tomó en consideración dos opciones adicionales para hacer compatibles los resultados con el modelo propuesto. Primero, se utilizó una simulación de Montecarlo para la elaboración de los impulsos y respuestas, correspondiente 100 iteraciones o repeticiones. Segundo, se utilizó el impacto o respuesta acumulada, a fin de observar e interpretar el último dato del impacto, pues este conlleva todo el efecto de la desviación Cholesky generada producto de la simulación. Esta última opción permite extraer el dato final que representa la desviación acuñada en la variable original, a fin de construir las distribuciones de las variables endógenas con el efecto estrés. El mismo procedimiento es repetido para cada banco individualmente.

La estimación de los Vectores Auto regresivos se muestra en el Tabla 3.1.13. Se graficaron las funciones impulso respuestas para cada tipo de impacto en el Figura 3.1.12. Se resumió las desviaciones acumulado para cada tipo de variable endógena y el conjunto de muestra; es decir el resultado de los tres tipos de impactos en cada variables para cada muestra (Tabla 3.1.15).

Para la nomenclatura se utilizará lo siguiente: Impacto de la variación del PBI (stress_macro), impacto de la variación del spread (stress_margen) e impacto de la variación de la tasa de largo plazo RL ( stress_tasa). Las distribuciones resultantes con respecto a las variables endógenas a nivel global, se muestran en los Figuras 3.1.15 y 3.1.16.

Las desviaciones se utilizaron para construir las nuevas distribuciones, de la siguiente manera: 
Ecuación 3.6

$$
\begin{array}{r}
\text { Td } \text { stress }_{i, j}=T d_{j}+\text { desviacion }_{i, j} \\
T p \text { stress }_{i, j}=T p_{j}+\text { desviacion }_{i, j}
\end{array}
$$

Donde i es la unidad transversal y j es el tipo de estrés sea macroeconómico por variación del PBI (stress_macro), por variación del spread (stress_margen) o por variación de la tasa de largo plazo (stress_tasa).

La interpretación de estas Figuras es similar a la recogida en la investigación de Van den End (2006), salvo que no es la distribución de probabilidad sino la de frecuencia, aunque se sigue compartiendo la misma lógica (distribución, asimetría, sesgo y curtosis). En todos los casos se observa que existe un cambio importante en la distribución de las frecuencias, lo cual indica que los impactos de las variables elegidas no son irrelevantes, lo cual queda complementado por la significancia encontrada en las ecuaciones determinísticas. (Figuras 3.1.12, 3.1.13 y 3.1.14)

Se recoge que si existe un impacto estructural y dinámico (estrés) de los indicadores financieros y macroeconómicos seleccionados sobre la tasas de deterioro y tasa de provisiones en la banca múltiple.

Para el caso de la tasa de deterioro, el impacto acumulado a los doce meses del PBI (0.55) es de mayor dimensión que los otros dos escenarios. Por lo tanto, se comprueba que el impacto del PBI, que representa a las variables endógenas de la economía, posee un mayor impacto en la evolución de la tasas de deterioro. Esto es congruente con la hipótesis de la prueba de riesgo crédito.

(Tabla 3.1.15) 
Para el caso de la tasas de provisión, verificamos que midiendo el impacto acumulado a 12 meses, la tasas a largo plazo posee un mayor impacto absoluto sobre la evolución de esta variable. Esto desestima la hipótesis planteada para la prueba de riesgo crédito, debido a que observamos que la variable exógena de la economía posee mayor impacto.

En los Figuras de distribución se estima la probabilidad de que la variable dependiente del modelo alcance un valor del eje inferior dado determinado impacto por escenario de estrés. (Figuras 3.1.15, 3.1.16 y 3.1.17) 
Tabla 3.1.13 Estimación de Vectores Auto regresivos

\begin{tabular}{|c|c|c|c|c|c|}
\hline \multirow{2}{*}{\multicolumn{3}{|c|}{$\begin{array}{l}\text { Vector Autoregression Estimates } \\
\text { Sample (adjusted): 2003M03 2015M02 } \\
\text { Standard errors in () \& t-statistics in [] }\end{array}$}} & $\begin{array}{l}\text { Date: 05/11/15 Tim } \\
\text { Included observatior }\end{array}$ & Date: 05/11/15 Time: 04:41 & ments \\
\hline & & \multirow[b]{2}{*}{ TP_TOP5 } & & & \\
\hline & TD_TOP5 & & PBIX12_SA & SPREAD & $\mathrm{RL}$ \\
\hline \multirow[t]{3}{*}{ TD_TOP5(-1) } & 0.871287 & 0.023776 & 0.028635 & 0.127978 & 0.101568 \\
\hline & -0.08 & -0.05181 & -0.62132 & -0.10756 & -0.10155 \\
\hline & [ 10.8913] & [0.45893] & {$[0.04609]$} & [ 1.18988$]$ & {$[1.00017]$} \\
\hline \multirow[t]{3}{*}{ TD_TOP5(-2) } & 0.126332 & -0.021397 & -0.191024 & -0.117226 & -0.107532 \\
\hline & -0.07998 & -0.05179 & -0.62117 & -0.10753 & -0.10153 \\
\hline & [ 1.57958$]$ & {$[-0.41311]$} & {$[-0.30752]$} & {$[-1.09019]$} & {$[-1.05917]$} \\
\hline \multirow[t]{3}{*}{ TP_TOP5(-1) } & 0.530566 & 1.118973 & 0.409142 & 0.007482 & 0.016992 \\
\hline & -0.1356 & -0.08781 & -1.05314 & -0.18231 & -0.17213 \\
\hline & [ 3.91283] & [ 12.7426] & [ 0.38850$]$ & [ 0.04104] & [ 0.09872] \\
\hline \multirow[t]{3}{*}{ TP_TOP5(-2) } & -0.616271 & -0.138676 & 0.041794 & -0.093941 & 0.030448 \\
\hline & -0.13875 & -0.08986 & -1.07765 & -0.18655 & -0.17613 \\
\hline & {$[-4.44152]$} & {$[-1.54329]$} & {$[0.03878]$} & {$[-0.50357]$} & [0.17287] \\
\hline \multirow[t]{3}{*}{ PBIX12_SA(-1) } & 0.030689 & -0.00085 & 0.489662 & 0.032042 & 0.013592 \\
\hline & -0.00998 & -0.00646 & -0.07752 & -0.01342 & -0.01267 \\
\hline & [ 3.07462] & {$[-0.13154]$} & [ 6.31640] & [ 2.38772] & [ 1.07272$]$ \\
\hline \multirow[t]{3}{*}{ PBIX12_SA(-2) } & -0.021918 & 0.000787 & 0.465363 & -0.028361 & -0.022347 \\
\hline & -0.00974 & -0.00631 & -0.07565 & -0.0131 & -0.01236 \\
\hline & {$[-2.25017]$} & [0.12478] & [ 6.15146$]$ & {$[-2.16567]$} & {$[-1.80735]$} \\
\hline \multirow[t]{3}{*}{ SPREAD(-1) } & -0.054736 & -0.02418 & -0.007419 & 1.218576 & 0.032423 \\
\hline & -0.09929 & -0.0643 & -0.77113 & -0.13349 & -0.12604 \\
\hline & {$[-0.55129]$} & {$[-0.37606]$} & {$[-0.00962]$} & [ 9.12875$]$ & {$[0.25725]$} \\
\hline \multirow[t]{3}{*}{ SPREAD(-2) } & 0.046021 & 0.041746 & 0.039304 & -0.273503 & -0.063748 \\
\hline & -0.0977 & -0.06327 & -0.75879 & -0.13135 & -0.12402 \\
\hline & [ 0.47106$]$ & [ 0.65980$]$ & [ 0.05180$]$ & {$[-2.08221]$} & {$[-0.51402]$} \\
\hline \multirow[t]{3}{*}{ RL(-1) } & 0.02488 & 0.005817 & -1.029578 & -0.095443 & 1.086921 \\
\hline & -0.10515 & -0.0681 & -0.8167 & -0.14138 & -0.13348 \\
\hline & [0.23661] & [0.08542] & {$[-1.26066]$} & {$[-0.67510]$} & [ 8.14273] \\
\hline \multirow[t]{3}{*}{ RL(-2) } & -0.025466 & -0.042196 & 0.938925 & 0.02745 & -0.228999 \\
\hline & -0.10075 & -0.06525 & -0.78251 & -0.13546 & -0.1279 \\
\hline & {$[-0.25276]$} & {$[-0.64669]$} & [ 1.19989] & [0.20265] & {$[-1.79051]$} \\
\hline \multirow[t]{3}{*}{ C } & -0.441272 & 0.25821 & 3.470422 & 0.488907 & 1.203909 \\
\hline & -0.30759 & -0.1992 & -2.38893 & -0.41354 & -0.39045 \\
\hline & {$[-1.43462]$} & [ 1.29625] & [ 1.45271$]$ & [ 1.18225$]$ & [ 3.08336] \\
\hline
\end{tabular}


Tabla 3.1.14

Estimación de Vectores Auto regresivos (Continuación de la Tabla 3.1.13)

\begin{tabular}{|c|c|c|c|c|c|}
\hline & TD_TOP5 & TP_TOP5 & PBIX12_SA & SPREAD & $R L$ \\
\hline R-squared & 0.997171 & 0.994684 & 0.997095 & 0.964449 & 0.958428 \\
\hline Adj. R-squared & 0.996958 & 0.994284 & 0.996876 & 0.961776 & 0.955302 \\
\hline Sum sq. resids & 3.717893 & 1.559288 & 224.2686 & 6.720456 & 5.991018 \\
\hline S.E. equation & 0.167195 & 0.108277 & 1.298549 & 0.224788 & 0.212239 \\
\hline F-statistic & 4687.836 & 2488.396 & 4564.678 & 360.8149 & 306.624 \\
\hline Log likelihood & 58.95209 & 121.5149 & -236.225 & 16.32818 & 24.60059 \\
\hline Akaike AIC & -0.666 & -1.53493 & 3.433686 & -0.074 & -0.1889 \\
\hline Schwarz SC & -0.43914 & -1.30807 & 3.660547 & 0.152858 & 0.037964 \\
\hline Mean dependent & 4.136464 & 7.072292 & 111.3446 & 2.050347 & 3.439722 \\
\hline S.D. dependent & 3.031489 & 1.432144 & 23.23417 & 1.149762 & 1.003876 \\
\hline \multicolumn{3}{|c|}{ Determinant resid covariance (dof adj.) } & \multicolumn{3}{|c|}{0.0000} \\
\hline \multicolumn{3}{|c|}{ Determinant resid covariance } & \multicolumn{3}{|c|}{0.0000} \\
\hline \multicolumn{3}{|c|}{ Log likelihood } & \multicolumn{3}{|c|}{60.3345} \\
\hline \multicolumn{3}{|c|}{ Akaike information criterion } & \multicolumn{3}{|c|}{-0.0741} \\
\hline \multicolumn{3}{|c|}{ Schwarz criterion } & \multicolumn{3}{|c|}{1.0602} \\
\hline
\end{tabular}

Tabla 3.1.15

Resultados medidos en desviaciones acumuladas (TD tasa deterioro y TP provisiones)

Resultados del stress a 12 meses -según impulso-respuesta- medido en desviaciones acumuladas en Valores Absolutos

\begin{tabular}{l|rr}
\multicolumn{1}{c}{ TD-TOP5 } & TP-TOP5 \\
\cline { 2 - 3 } STRESS-MACRO & 0.55 & 0.06 \\
STRESS-MARGEN & 0.22 & 0.09 \\
STRESS-TASA & 0.06 & 0.23 \\
\hline
\end{tabular}


Figura 3.1.12

Impulso Respuesta

Accumulated Response to Cholesky One S.D. Innovations \pm 2 S.E.

Accumulated Response of TD_TOP5 to PBIX12_SA

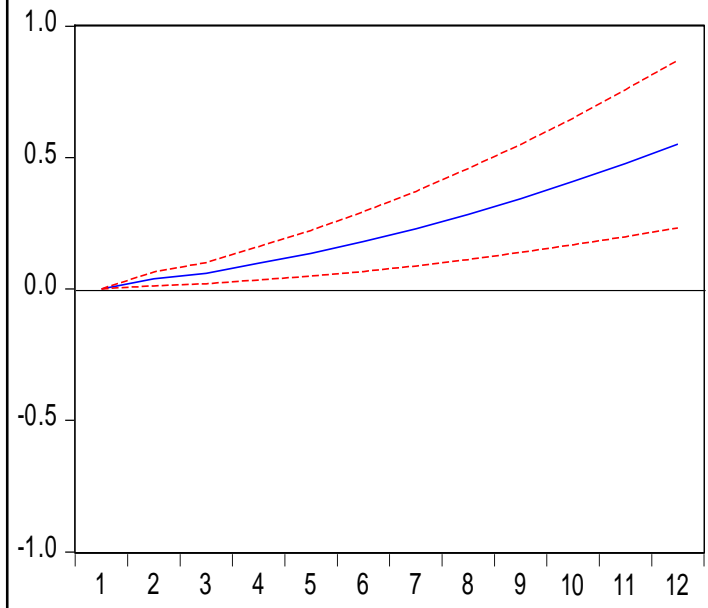

Accumulated Response of TP_TOP5 to PBIX12_SA

Accumulated Response of TD_TOP5 to SPREAD

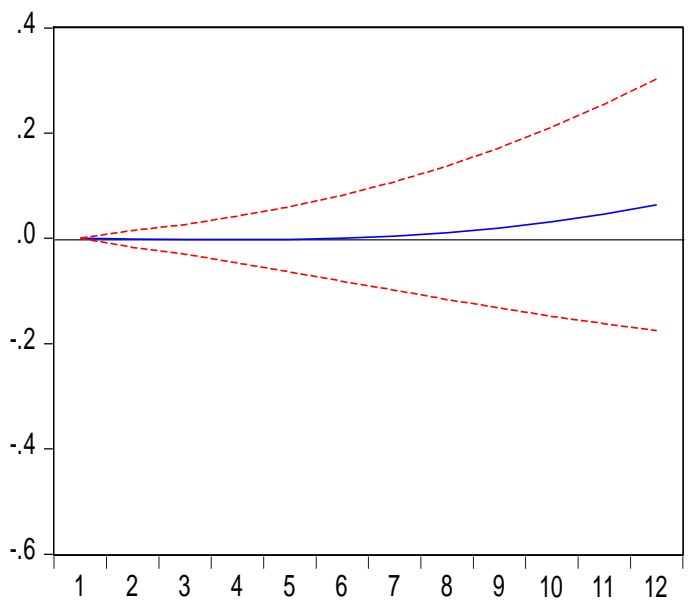

Accumulated Response of TP_TOP5 to SPREAD
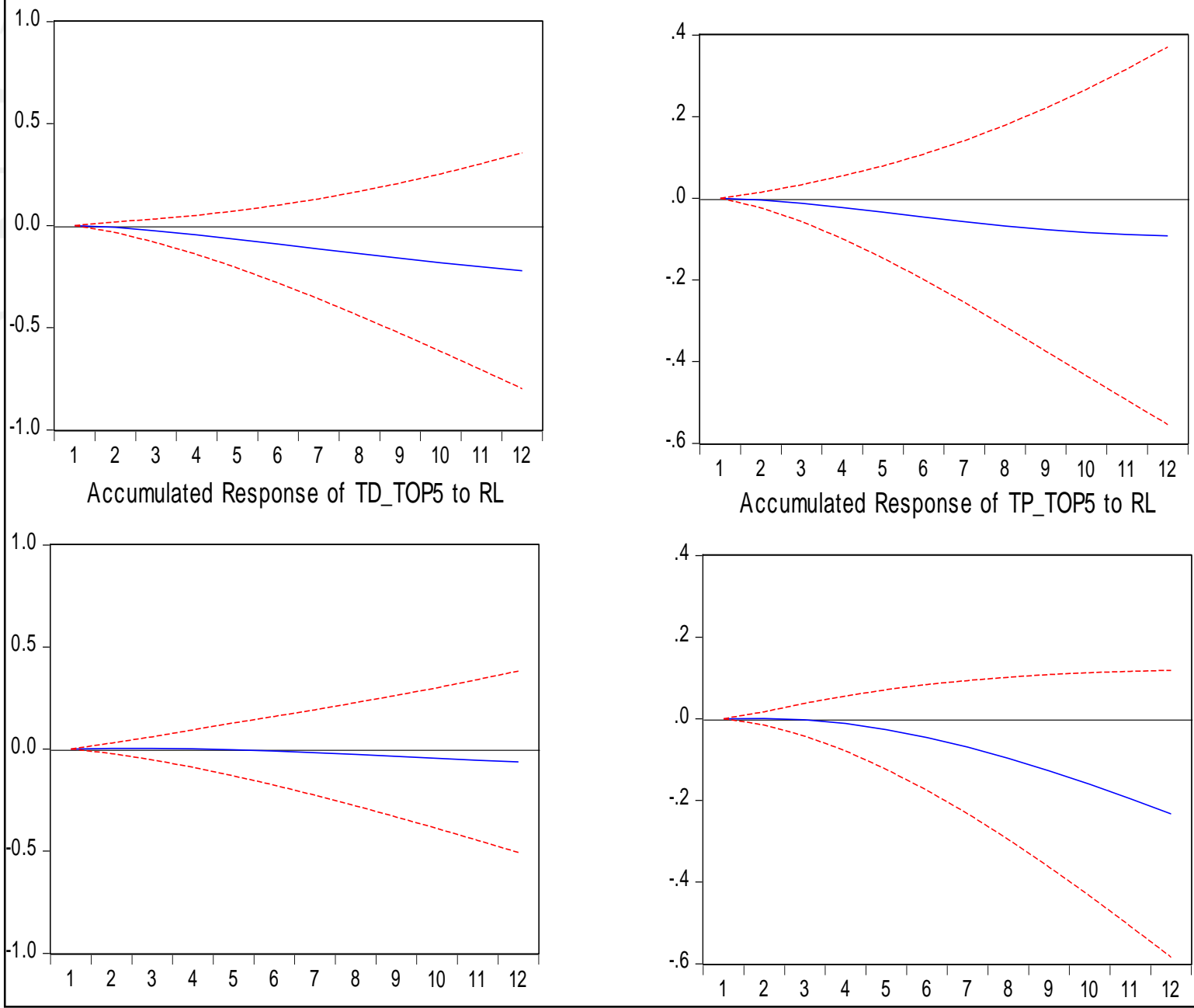
Figura 3.1.13

Impulso Respuesta para la Tasa Deterioro

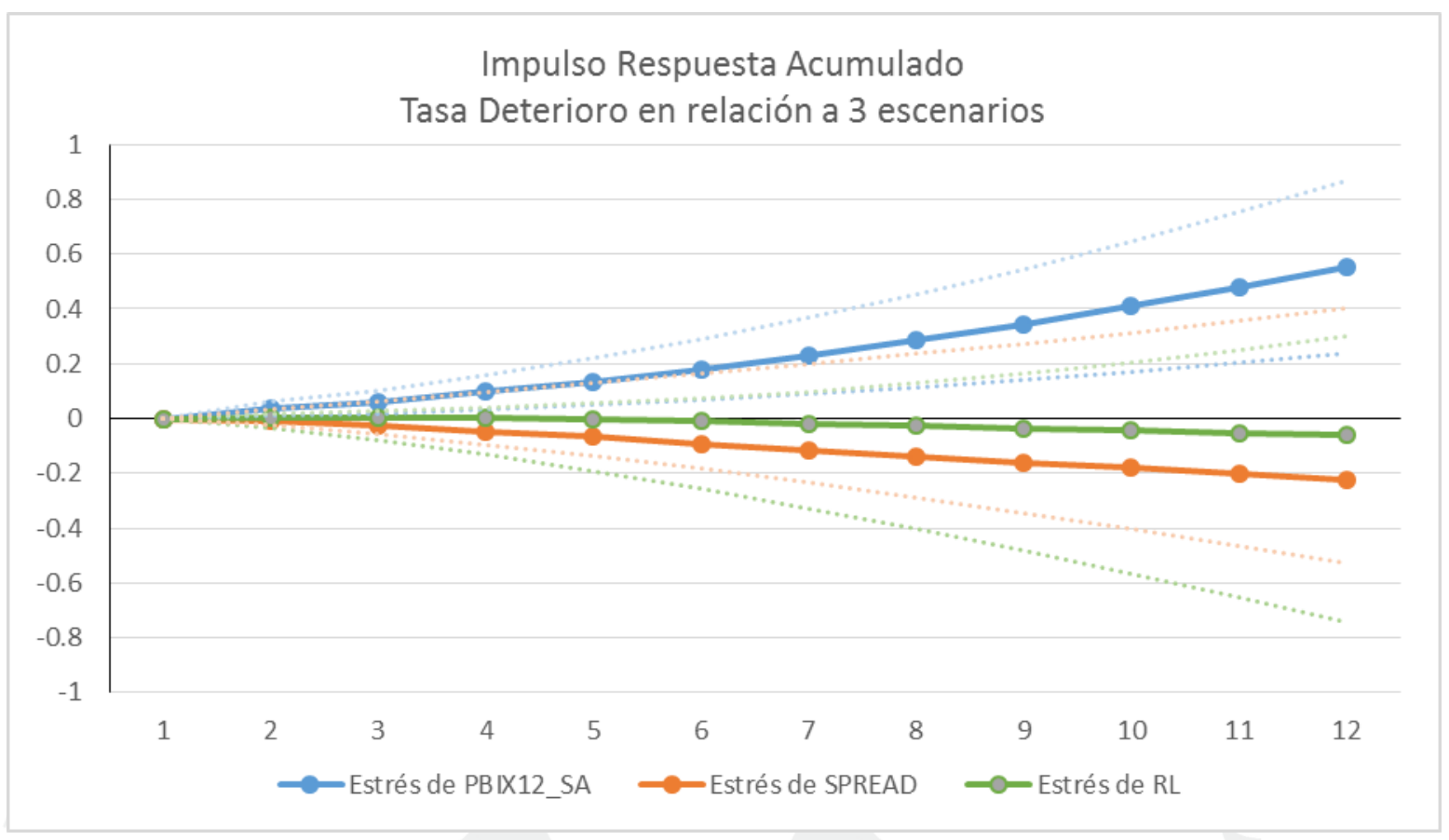

Figura 3.1.14

Impulso Respuesta para la Tasa de Provisiones

Impulso Respuesta Acumulado

Tasa Provisiones en relación a 3 escenarios

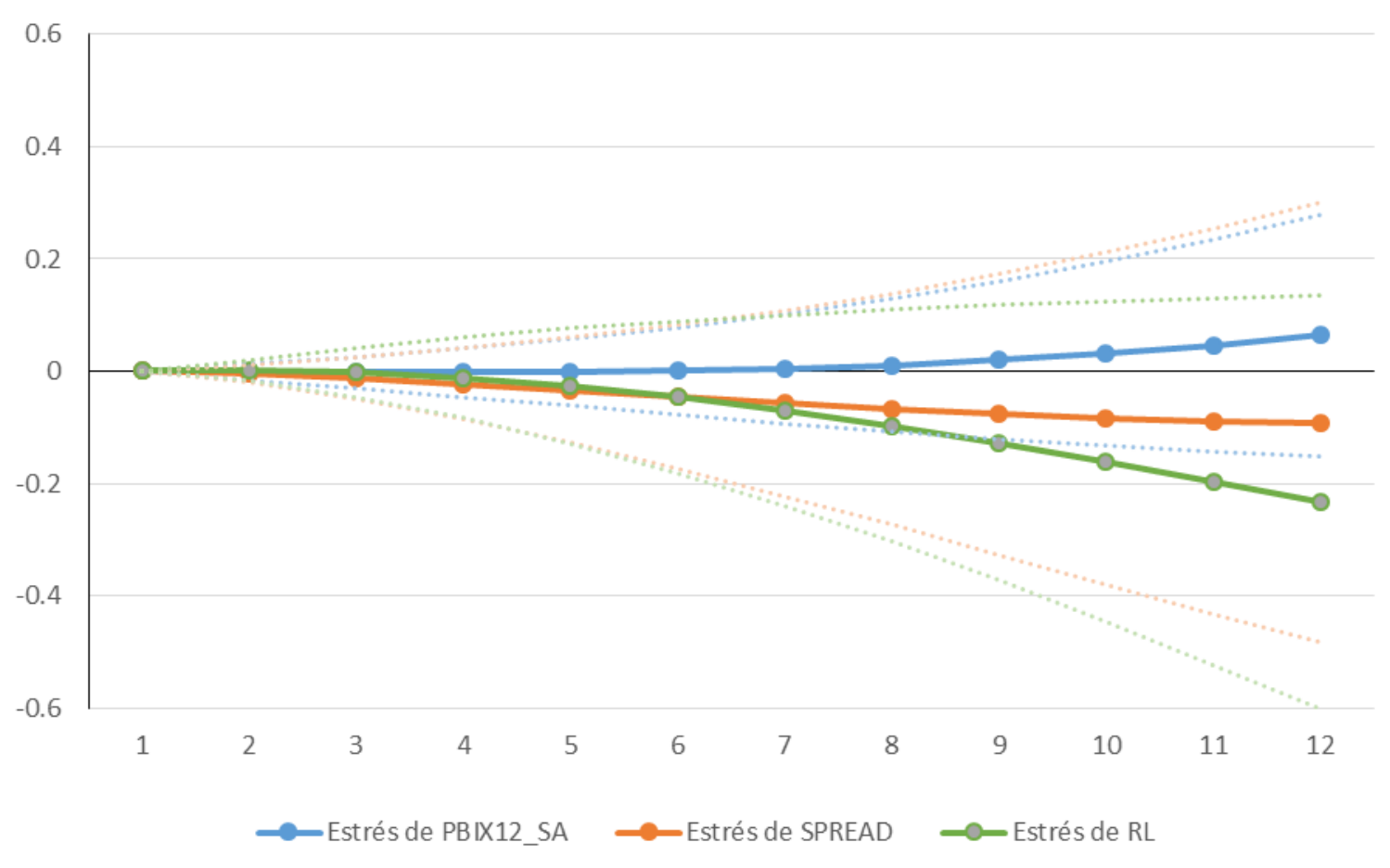


Figura 3.1.15

Distribución de las desviaciones de la variable endógena de la ecuación 3.4

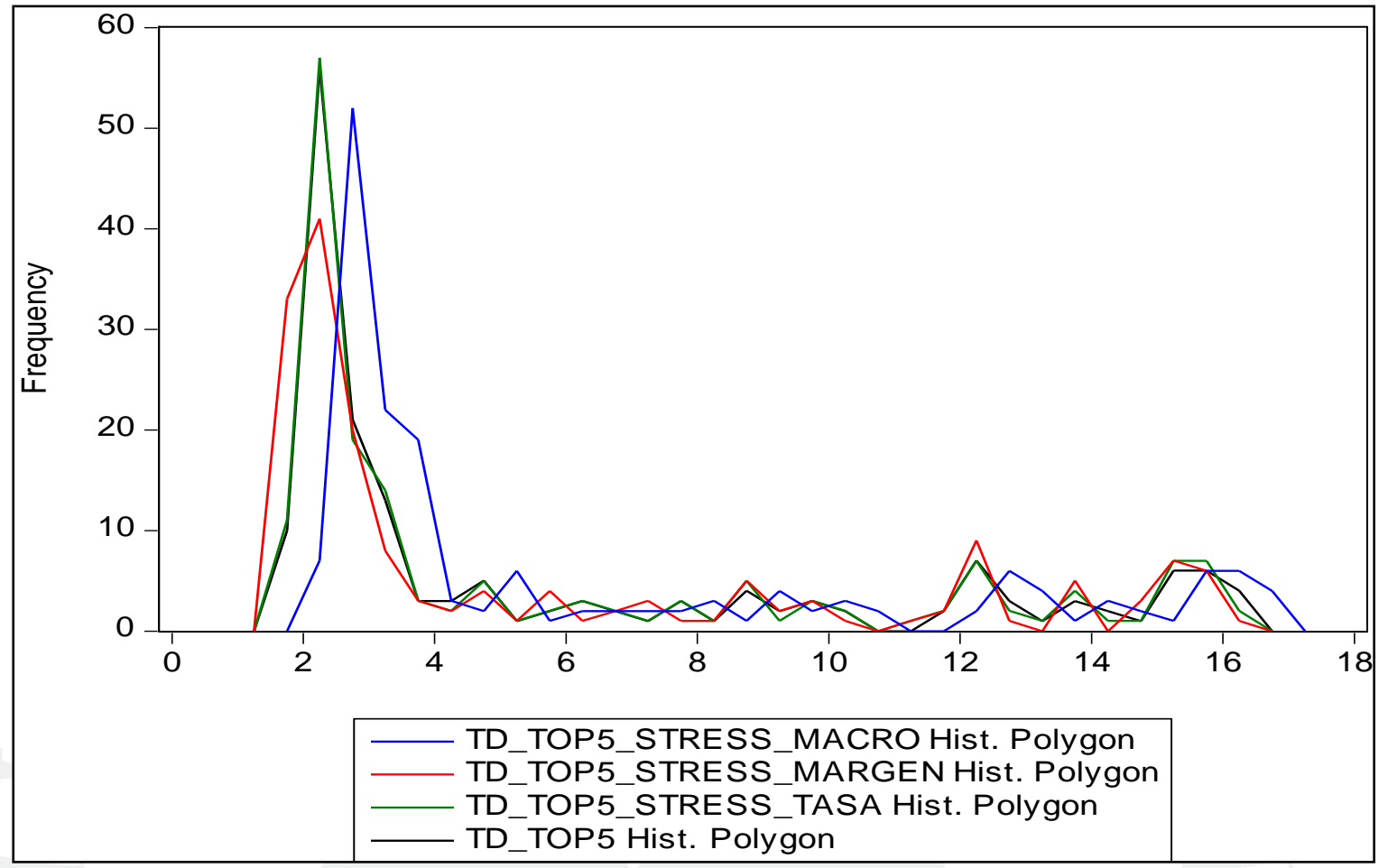

Figura 3.1.16

Distribución de las desviaciones de la variable endógena de la ecuación 3.5

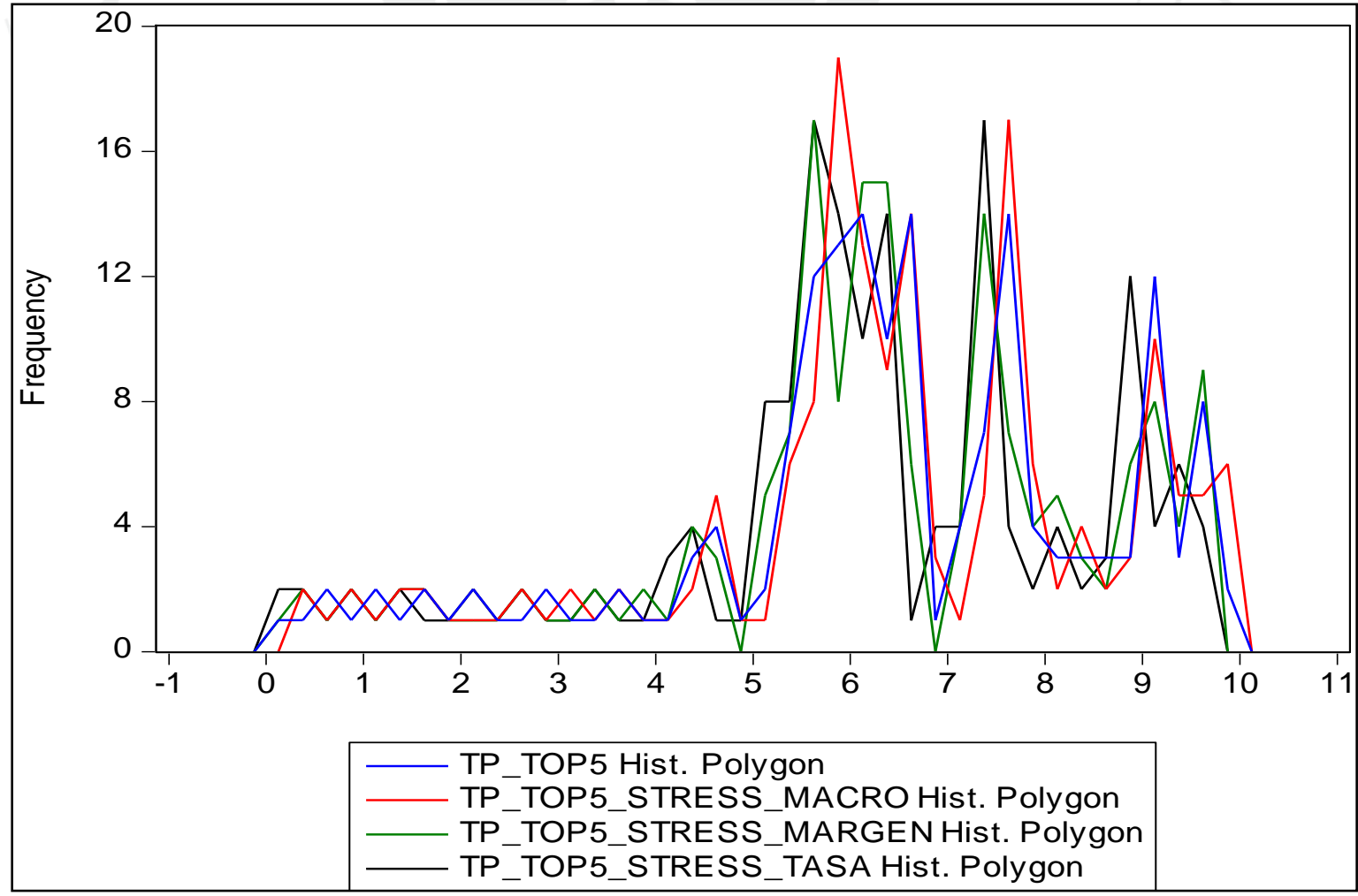


Figura 3.1.17

Detalle del Impacto en la distribución para la Tasa Deterioro
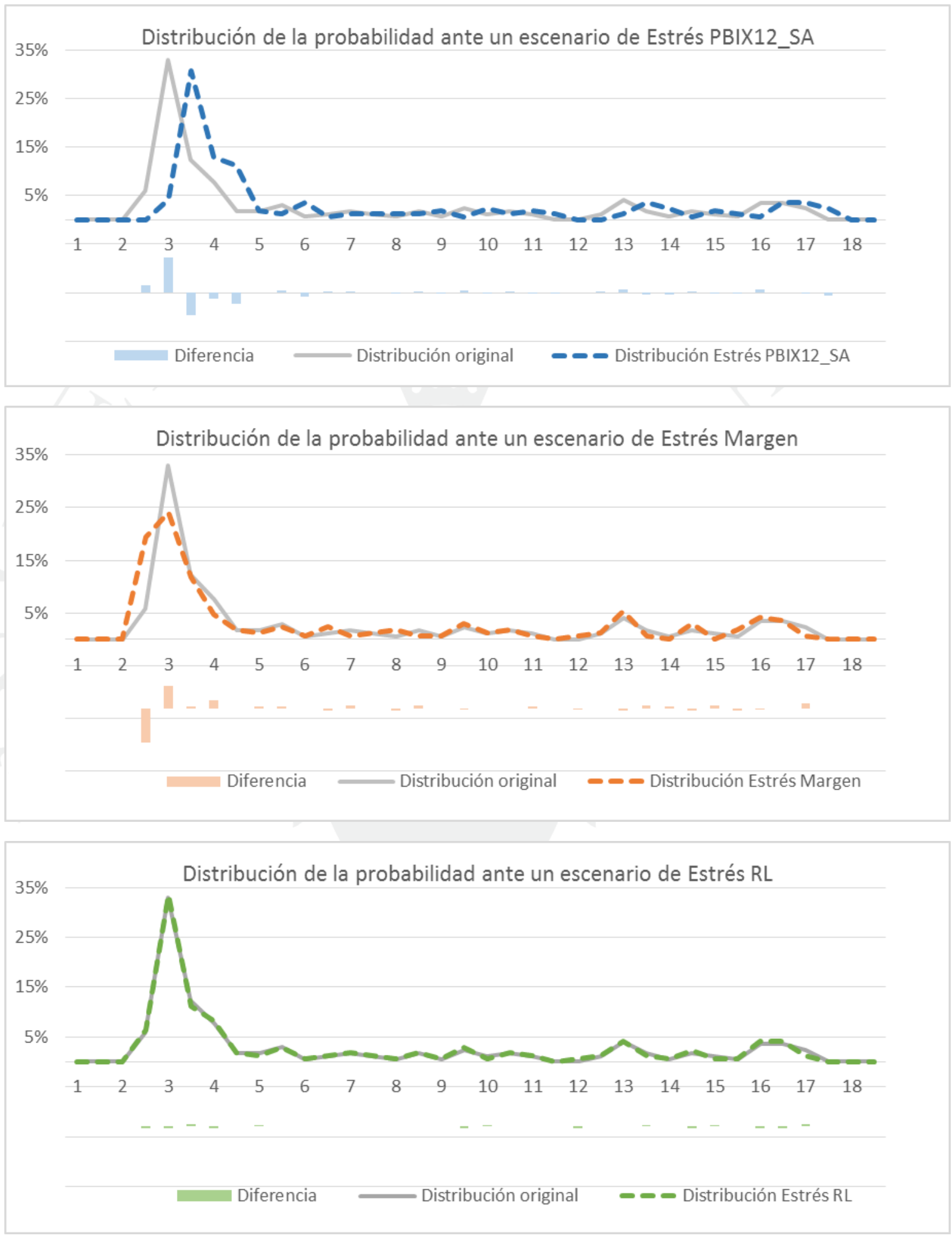
Figura 3.1.18

Detalle del Impacto en la distribución para la Tasa Provisiones
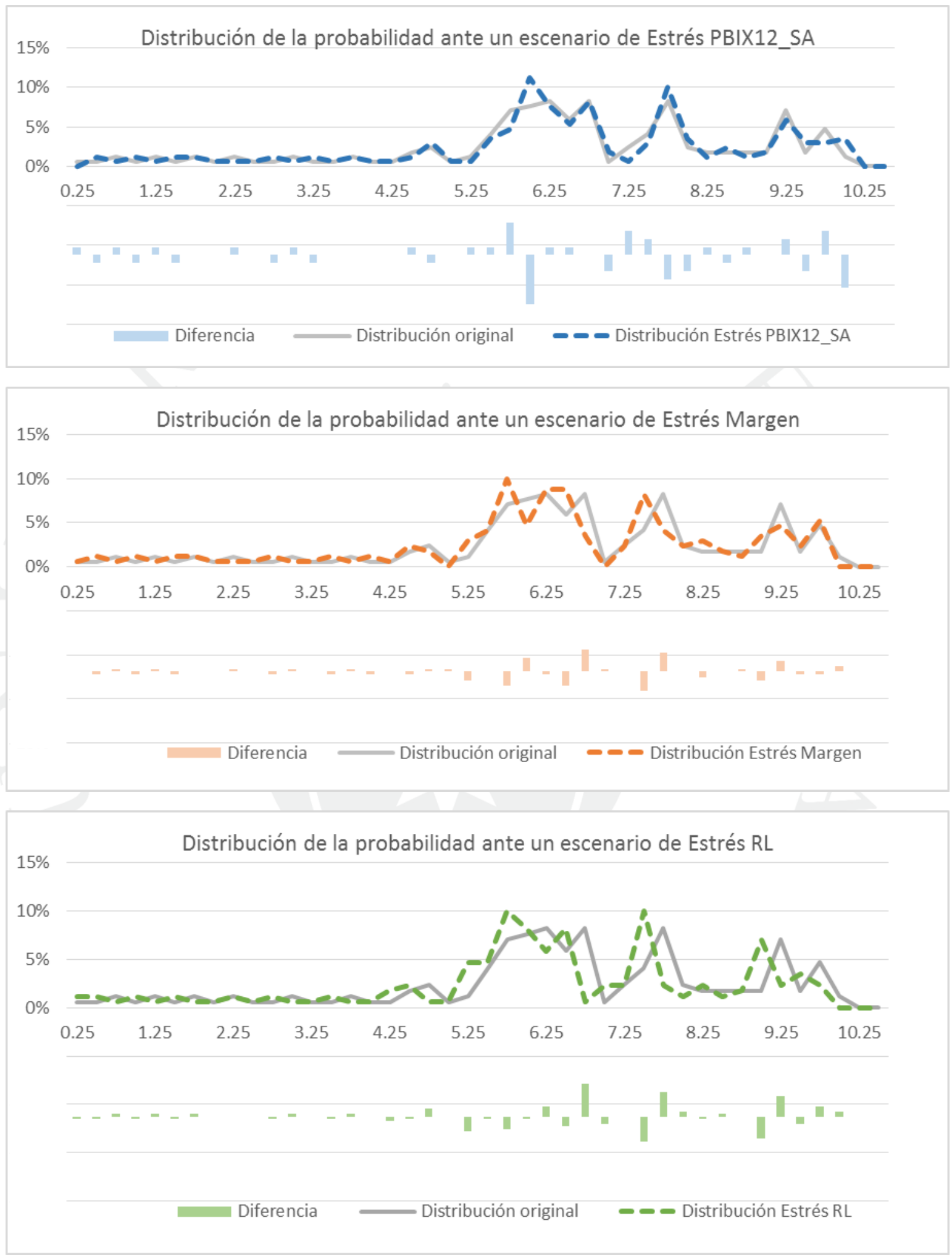


\subsection{Prueba de Estrés de Riesgo Mercado}

Cambios en la tasa de interés afecta las ganancias impactando en el margen financiero y otros ingresos y egresos sensibles. Cambios en la tasa de interés también afectan el valor subyacente de los activos, pasivos e instrumentos fuera del balance a causa de que le valor presente de los futuros flujos de caja cambian a medida que las tasa de interés se afectan.

Desde la perspectiva de valor económico se toma en cuenta el potencial impacto de los cambios de la tasa de interés en el valor presente de los flujos futuro de caja, esta sería la medición óptima del riesgo de tasa de interés. Sin embargo la mayoría de activos de los bancos son considerados a cierta maduración, por lo que la perspectiva de valor económico seria menos relevante en la práctica.

\subsubsection{Metodología del Modelo de Riesgo Mercado}

La metodología propuesta para su adaptación y aplicación para el caso peruano corresponde a Van den End (2006). El análisis del riesgo de tasa de interés es importante debido a que es el instrumento fuente de rentabilidad y el capital base de los bancos. Los cambios en las tasas de interés afectan directamente las ganancias. Los cambios en las tasas de interés también afectan el valor subyacente de los activos y pasivos del banco, debido a que el valor presente de los flujos de efectivo futuros cambian cuando las tasas de interés se modifican (desde un punto de vista de valor económico). 
Empleamos el siguiente modelo para estimar los Ingresos por intereses neto:

\title{
Ecuación 3.7 Modelo de los ingresos por intereses neto
}

\author{
$\Delta \operatorname{Ln}($ Ingresos por intereses neto $)=$ Ef ajustodos $+\beta_{2} P b i_{2}+\beta_{2} P b i_{1-1}+\beta_{2} P b i_{1-2}+\beta_{4} R L_{1-1}+\beta_{2} R S_{t-1}+\mu_{k}$
}

La tasa de crecimiento de la utilidad neta de las ganancias por intereses se explica por tres rezagos de la tasa de crecimiento del PBI real, el rezago de la tasa de interés activa de largo plazo (RL) y la tasa actual de financiamiento de corto plazo (RS).

Se espera que cuando aumente el PBI, la utilidad neta aumente a través de una expansión en la oferta de préstamos (efecto volumen). Un aumento de la tasa de financiamiento de corto plazo (Rate Short term RS) reduce el margen de interés del banco y sus ingresos. La tasa de largo plazo (Rate Long term RL) representa la tasa de los préstamos de los bancos. Por lo tanto, un aumento de la tasa activa a largo plazo RL aumenta la utilidad. El rezago de la RL se utiliza en lugar de la tasa actual porque el cambio de la tasa de interés de mercado no afectará de inmediato la tasa de interés que los bancos reciben de sus préstamos pendientes de ser amortizados. Los parámetros de la RS y RL capturan el efecto de los precios de financiación.

Los parámetros de las tasa activas de corto y largo plazo (RS y RL) capturan el efecto precio en el utilidad neta por interés. Incluir el termino de spread entre las dos tasa parecería ser más lógico que usar cada tasa por separado, pero esto es equivalente a aplicar una restricción a los parámetros de RS y RL. 


\subsubsection{Variables}

Para aproximarse al ingresos por interés neto se utilizó el uso el margen financiero mensual de la banca múltiple. El margen financiero es la diferencia entre los ingresos financieros y los egresos financieros. Los ingresos financieros incluyen los intereses generados por las inversiones, por los créditos directos, la diferencia de cambio y las ganancias por productos de financieros derivados. La participación de las ganancias por créditos directos en los ingresos financieros fue del $83 \%$ al cierre del año 2014. Esto debido a que representan el principal giro del negocio. Los gastos financieros son los intereses pagados por las obligaciones con el público, el adeudo y obligaciones financieros, obligaciones en circulación subordinadas, pérdidas en productos financieros derivados y pérdidas por inversiones. Esta información corresponde a los estados de ganancias y pérdidas que son publicados pro al SBS de manera mensual. Igual que en la anterior prueba, para el crecimiento del producto bruto internos se utilizó como fuente la base de Datos del INEI, del cual se calculó el PBI real y a partir de ahí se calculó el porcentaje de variación anual.

Para la tasa de largo plazo se utilizó la Tasa Activa promedio en moneda nacional TAMN y la Tasa Activa promedio en moneda extranjera TAMEX. Estas son las tasas de interés activas promedio de un conjunto de operación de crédito que tienen saldo vigente a la fecha. Esta información es publicada por el BCRP de manera mensual Para la tasa de corto plazo se utilizó la Tasas Interbancaria en moneda nacional TIMN y la Tasa Interbancaria en moneda extranjera TIMEX. Estas dos últimas son las tasas meta intermedia del BCRP Esta es la tasa correspondiente a la cual se conceden los préstamos entre las empresas bancarias. Esta información es publicada por el BCRP de manera mensual. 
Tabla 3.2.

Variables del Modelo de Riesgo Mercado. Elaboración Propia.

\begin{tabular}{|c|c|c|c|c|c|}
\hline \multicolumn{7}{|c|}{ Variables del Modelo de Riesgo Mercado } \\
\hline Nomenclatura & Definición & Periodicidad & Tipo & Unidades & Fuente \\
\hline $\begin{array}{c}\text { Margen } \\
\text { Financiero }\end{array}$ & $\begin{array}{c}\text { Diferencia entre los ingresos } \\
\text { financieros y los egresos } \\
\text { financieros }\end{array}$ & Mensual & Nominales & $\begin{array}{c}\text { Millones de } \\
\text { soles }\end{array}$ & SBS \\
\hline $\begin{array}{c}\text { Crecimiento PBI } \\
\text { Real }\end{array}$ & Variación anual del PBI real & Mensual & Real & $\begin{array}{c}\text { Porcentaje } \\
(\%)\end{array}$ & INEI \\
\hline TAMN & $\begin{array}{c}\text { Tasa activa promedio moneda } \\
\text { nacional }\end{array}$ & Mensual & Nominal & $\begin{array}{c}\text { Porcentaje } \\
(\%)\end{array}$ & BCRP \\
\hline TAMEX & Tasa activa promedio moneda & Mensual & Nominal & $\begin{array}{c}\text { Porcentaje } \\
(\%)\end{array}$ & BCRP \\
\hline TIMN & $\begin{array}{c}\text { Tasa interbancaria en moneda } \\
\text { nacional }\end{array}$ & Mensual & Nominal & $\begin{array}{c}\text { Porcentaje } \\
(\%)\end{array}$ & BCRP \\
\hline TIMEX & $\begin{array}{c}\text { Tasa interbancaria en moneda } \\
\text { extranjera }\end{array}$ & Mensual & Nominal & $\begin{array}{c}\text { Porcentaje } \\
(\%)\end{array}$ & BCRP \\
\hline
\end{tabular}




\section{Aplicación de la metodología}

Se estimó el modelo en su versión original; sin embargo los resultados no fueron satisfactorios. Las dummies y los procesos autoregresivos se adaptaron según cada nueva ecuación tratada, nunca se impusieron a priori. Se estimó un modelo GARCH, pero todos sus coeficientes resultaron no significativos. Como en el ejercicio anterior, se le aplico a la variable PBI el filtro Census x12 para retirar el efecto de estacionalidad. Se analizó la evolución de las variables a partir del análisis Bi variable (Figura 3.2.1)

A partir de ello, se buscaron alternativas. Se hicieron las siguientes transformaciones para estimar nuevas versiones del modelo: en diferencias, en segundas diferencias, en LogLin, logaritmo de la endógena lineal en las exógenas, (1 para el proceso AR y otro para el proceso dinámico autoregresivo) y LogLog, logaritmo de la endógena y logaritmos de las exógenas (1 para el proceso $\mathrm{AR}$ y otro para el proceso dinámico autoregresivo). De manera exploratoria se optó por eliminar la tasa interbancaria de la regresión en un modelo reducido pero los resultados no fueron satisfactorios a causa de su baja significancia y menor poder de explicación.

Se procedió a correr distintas combinaciones, comparando el estadístico F de Fisher y Criterio de errores de Akaike, por ejemplo, así como la significancia individual de los coeficientes. La conclusión de este análisis sostuvo la elección del modelo LogLog. 
Figura 3.2.1

Análisis Bi variable

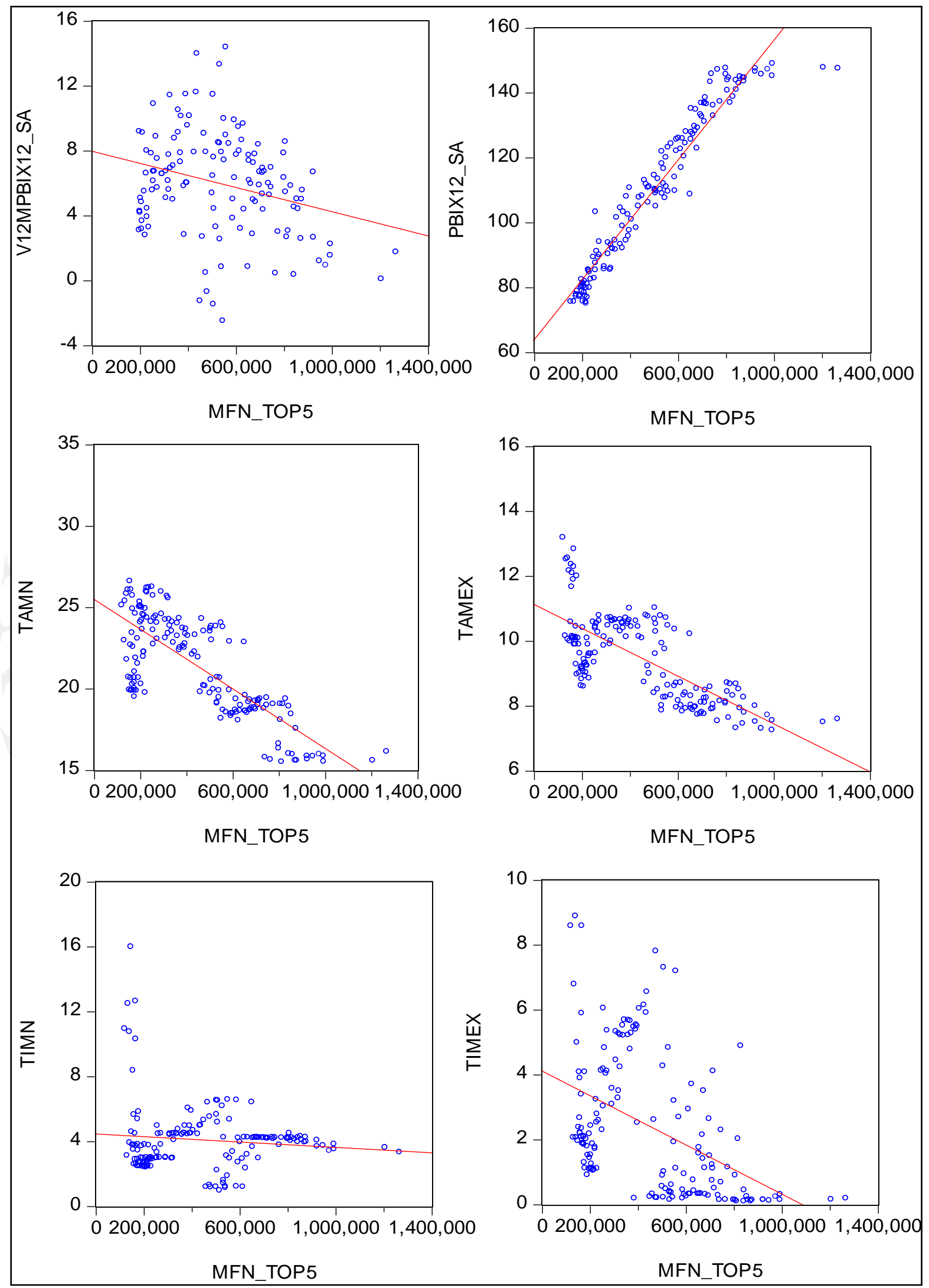


De antemano, se estimó que la variable TIMEX no iba a ser significativo por el diagrama de dispersión. La variable TAMN, debió haber salido significativo, de acuerdo al Figura de scatter; sin embargo al hacer el modelo combinado, el PBI y la TAMEX absorbieron el comportamiento de la endógena. La significancia individual no afecta la especificación del modelo; a menos que se busque objetivamente la significancia específica, afectando la validez de la ecuación. El nuevo modelo de la ecuación 3.7 es el siguiente (Tabla 3.2.1y Figura 3.2.2)

Ecuación 3.8 Modelo econométrico del margen financiero

$$
\log (\text { MFN })=C+\partial \log \left(\text { Pbix } 12_{\sigma \alpha}\right)+\beta \log (\text { tamex })+\gamma \log (\text { tamn })+\delta \log (\text { timn })+\mu \log (\text { timex })
$$

A partir de este modelo, se interpreta que una variación porcentual en el crecimiento del PBI real, la tasa activa en moneda nacional y extranjera y a la tasa interbancaria en moneda nacional y extranjera genera una variación porcentual en el margen financiero. Para brindar robustez al modelos se corrieron las pruebas respectivas para hacer el diagnostico de residuos. Se revisó a través de la prueba de normalidad del diagnóstico de residuos que los residuos se distribuyen normalmente (Tabla 3.2.2). Se descartó correlación en los residuos aplicando la prueba de Breusch-Godfrey con un rezago (Tabla 3.2.3). Se descartó presencia de Heterocedasticidad con la prueba de H. ARCH y la prueba de H. White (Tablas 3.2.4 y 3.2.5). Se comprobó la estabilidad de los coeficientes a través de la prueba RESET de Ramsey. (Tabla 3.2.6) 
Tabla 3.2.1

Estimación del modelo de la ecuación 3.8

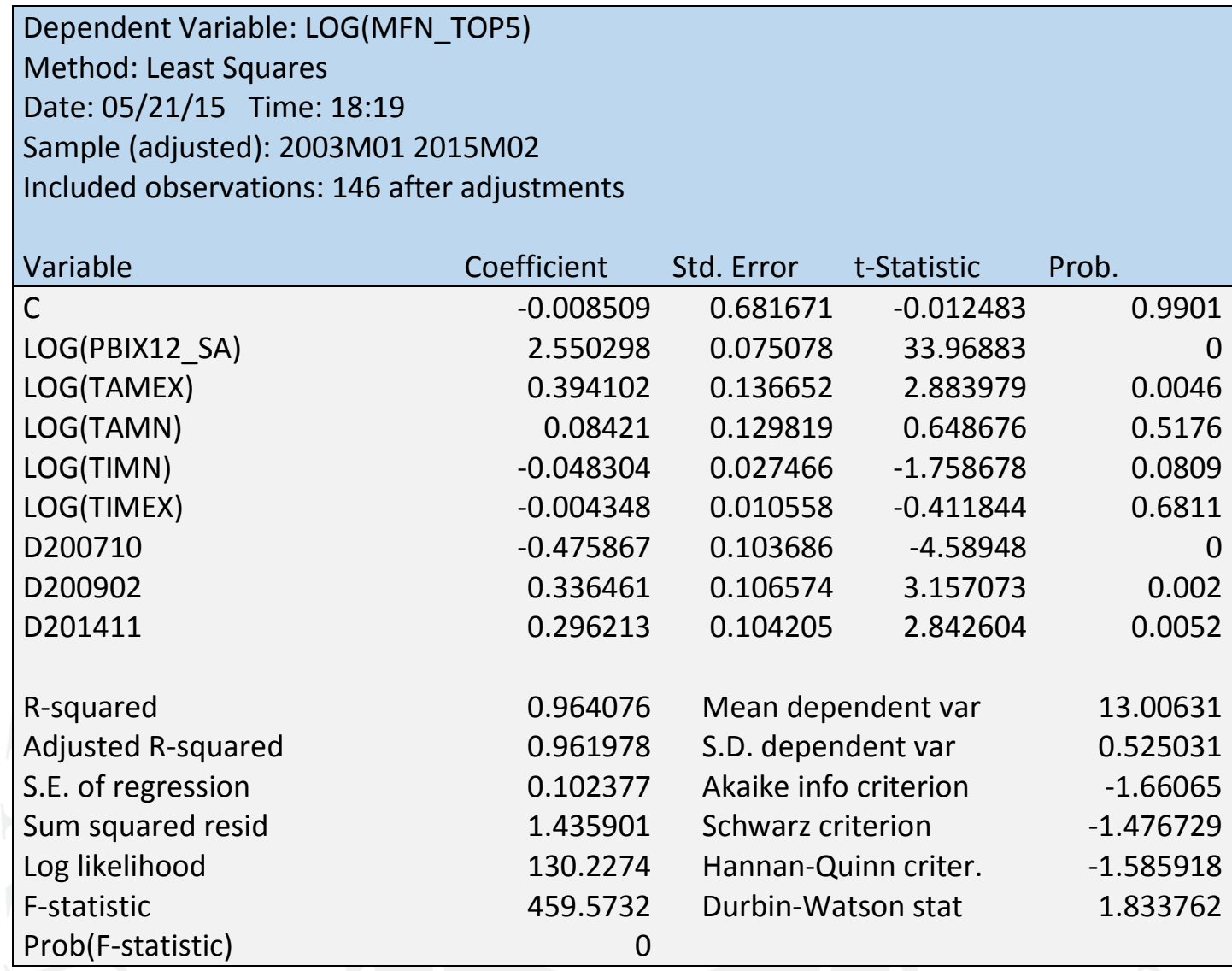

Tabla 3.2.2

Diagnostico de Residuos -Histograma de Prueba de Normalidad

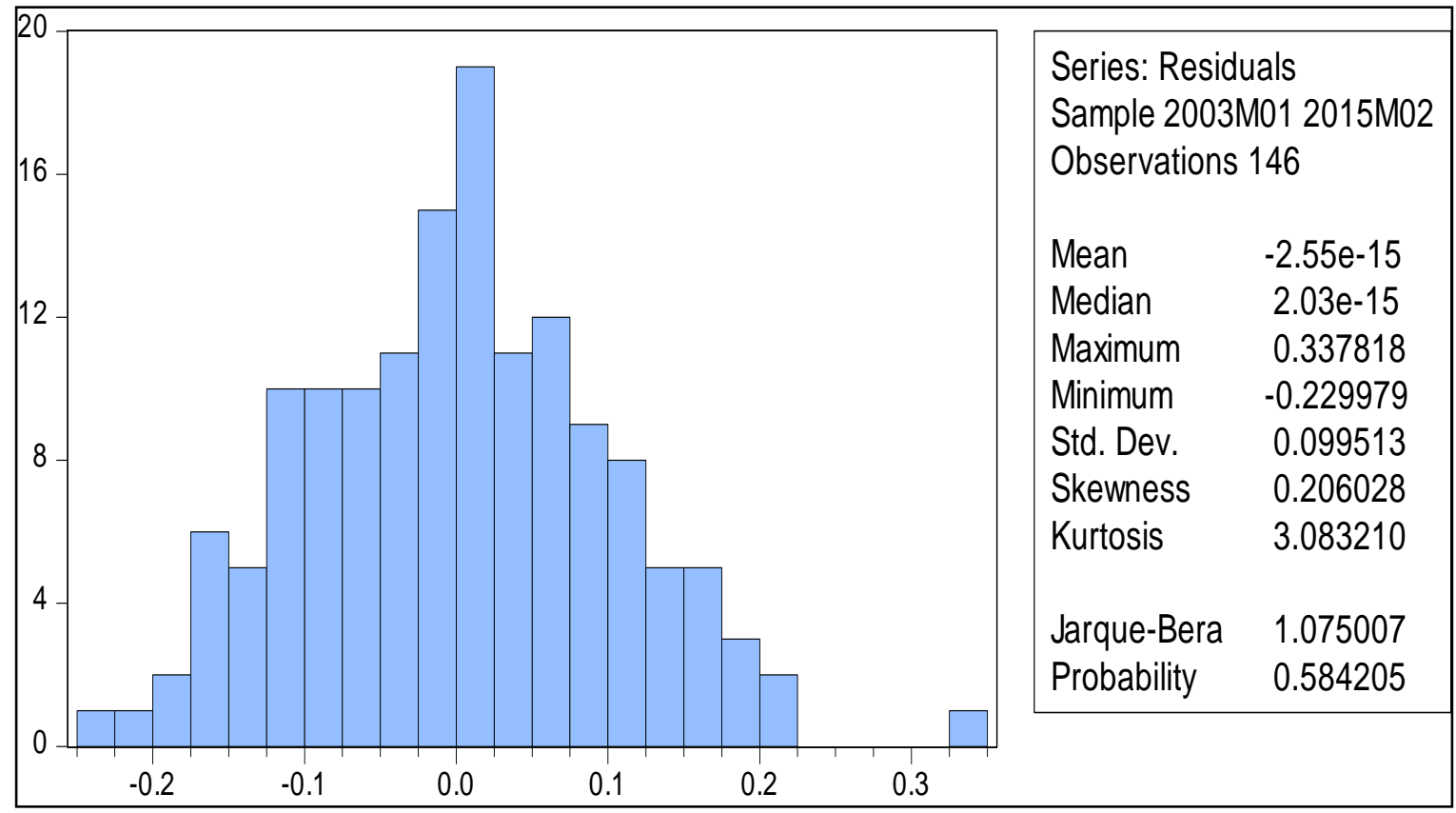


Tabla 3.2.3 Diagnostico de Residuos - Prueba de correlación serial LM

\begin{tabular}{|c|c|c|c|c|}
\hline \multicolumn{5}{|c|}{ Breusch-Godfrey Serial Correlation LM Test: } \\
\hline F-statistic & 0.837914 & \multicolumn{2}{|c|}{ Prob. F(1,136) } & 0.3616 \\
\hline Obs*R-squared & 0.894017 & \multicolumn{2}{|c|}{ Prob. Chi-Square(1) } & 0.3444 \\
\hline \multicolumn{5}{|c|}{$\begin{array}{l}\text { Test Equation: } \\
\text { Dependent Variable: RESID } \\
\text { Method: Least Squares } \\
\text { Date: } 05 / 24 / 15 \text { Time: } 00: 14 \\
\text { Sample: } 2003 \mathrm{M} 01 \text { 2015M02 } \\
\text { Included observations: } 146 \\
\text { Presample missing value lagged residuals set to zero. }\end{array}$} \\
\hline Variable & Coefficient & Std. Error & t-Statistic & Prob. \\
\hline C & 0.020603 & 0.682446 & 0.030189 & 0.976 \\
\hline LOG(PBIX12_SA) & -0.002208 & 0.075161 & -0.029372 & 0.9766 \\
\hline LOG(TAMEX) & -0.006072 & 0.136894 & -0.044355 & 0.9647 \\
\hline LOG(TAMN) & 0.000409 & 0.129896 & 0.00315 & 0.9975 \\
\hline LOG(TIMN) & 0.001655 & 0.027542 & 0.060092 & 0.9522 \\
\hline LOG(TIMEX) & $2.72 \mathrm{E}-05$ & 0.010564 & 0.002572 & 0.998 \\
\hline D200710 & 0.00258 & 0.103786 & 0.024856 & 0.9802 \\
\hline D200902 & -0.016888 & 0.108221 & -0.156048 & 0.8762 \\
\hline D201411 & -0.007007 & 0.104547 & -0.067024 & 0.9467 \\
\hline $\operatorname{RESID}(-1)$ & 0.08004 & 0.08744 & 0.915377 & 0.3616 \\
\hline R-squared & 0.006123 & \multicolumn{2}{|c|}{ Mean dependent var } & $-2.55 E-15$ \\
\hline Adjusted R-squared & -0.059648 & \multicolumn{2}{|c|}{ S.D. dependent var } & $9.95 \mathrm{E}-02$ \\
\hline S.E. of regression & 0.102438 & \multicolumn{2}{|c|}{ Akaike info criterion } & -1.653093 \\
\hline Sum squared resid & 1.427108 & \multicolumn{2}{|c|}{ Schwarz criterion } & -1.448737 \\
\hline Log likelihood & 130.6758 & \multirow{2}{*}{\multicolumn{2}{|c|}{$\begin{array}{l}\text { Hannan-Quinn criter. } \\
\text { Durbin-Watson stat }\end{array}$}} & -1.570058 \\
\hline F-statistic & 0.093102 & & & 2.00189 \\
\hline Prob(F-statistic) & 0.999703 & \multicolumn{2}{|c|}{ Durbin-Watson stat } & \\
\hline
\end{tabular}

Figura 3.2.2

Estimación de Residuos

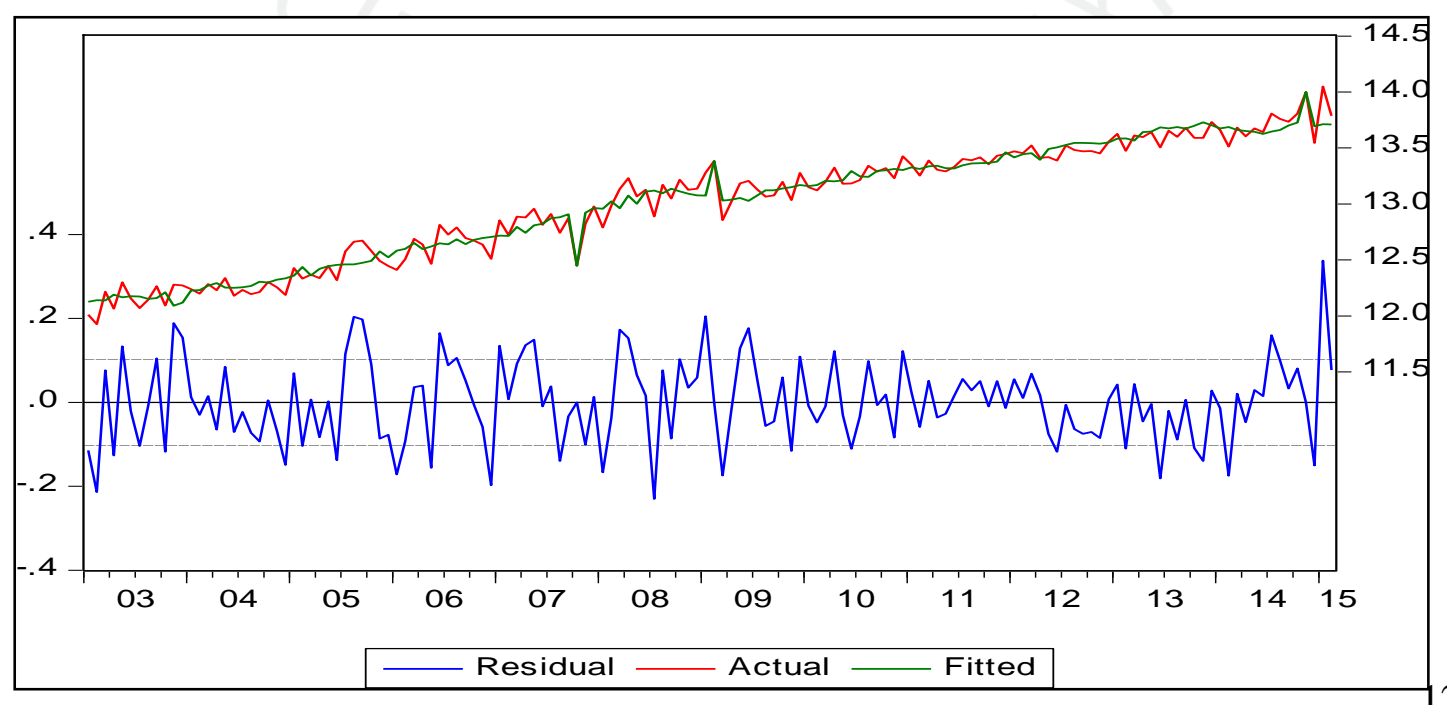


Tabla 3.2.4 Prueba de Heterocedasticidad ARCH

\begin{tabular}{|c|c|c|c|c|}
\hline \multicolumn{5}{|c|}{ Heteroskedasticity Test: ARCH } \\
\hline F-statistic & 0.372062 & \multicolumn{2}{|c|}{ Prob. $F(1,143)$} & 0.5429 \\
\hline Obs*R-squared & 0.376287 & \multicolumn{2}{|c|}{ Prob. Chi-Square(1) } & 0.5396 \\
\hline \multicolumn{5}{|c|}{$\begin{array}{l}\text { Test Equation: } \\
\text { Dependent Variable: RESID^2 } \\
\text { Method: Least Squares } \\
\text { Date: 05/24/15 Time: 00:20 } \\
\text { Sample (adjusted): } 2003 \mathrm{M} 02 \text { 2015M02 } \\
\text { Included observations: } 145 \text { after adjustments }\end{array}$} \\
\hline Variable & Coefficient & Std. Error & t-Statistic & Prob. \\
\hline $\mathrm{C}$ & 0.00931 & 0.001447 & 6.435474 & 0 \\
\hline $\operatorname{RESID} 2(-1)$ & 0.050946 & 0.083522 & 0.609969 & 0.5429 \\
\hline R-squared & 0.002595 & \multicolumn{2}{|c|}{ Mean dependent var } & 0.009813 \\
\hline Adjusted R-squared & -0.00438 & \multicolumn{2}{|c|}{ S.D. dependent var } & 0.014291 \\
\hline S.E. of regression & 0.014322 & \multicolumn{2}{|c|}{ Akaike info criterion } & -5.640331 \\
\hline Sum squared resid & 0.029332 & \multicolumn{2}{|c|}{ Schwarz criterion } & -5.599272 \\
\hline Log likelihood & 410.924 & \multirow{2}{*}{\multicolumn{2}{|c|}{$\begin{array}{l}\text { Hannan-Quinn criter. } \\
\text { Durbin-Watson stat }\end{array}$}} & -5.623647 \\
\hline F-statistic & 0.372062 & & & 1.95805 \\
\hline Prob(F-statistic) & 0.54285 & & & \\
\hline
\end{tabular}

Figura 3.2.3

Estimación del modelo de la ecuación 3.8

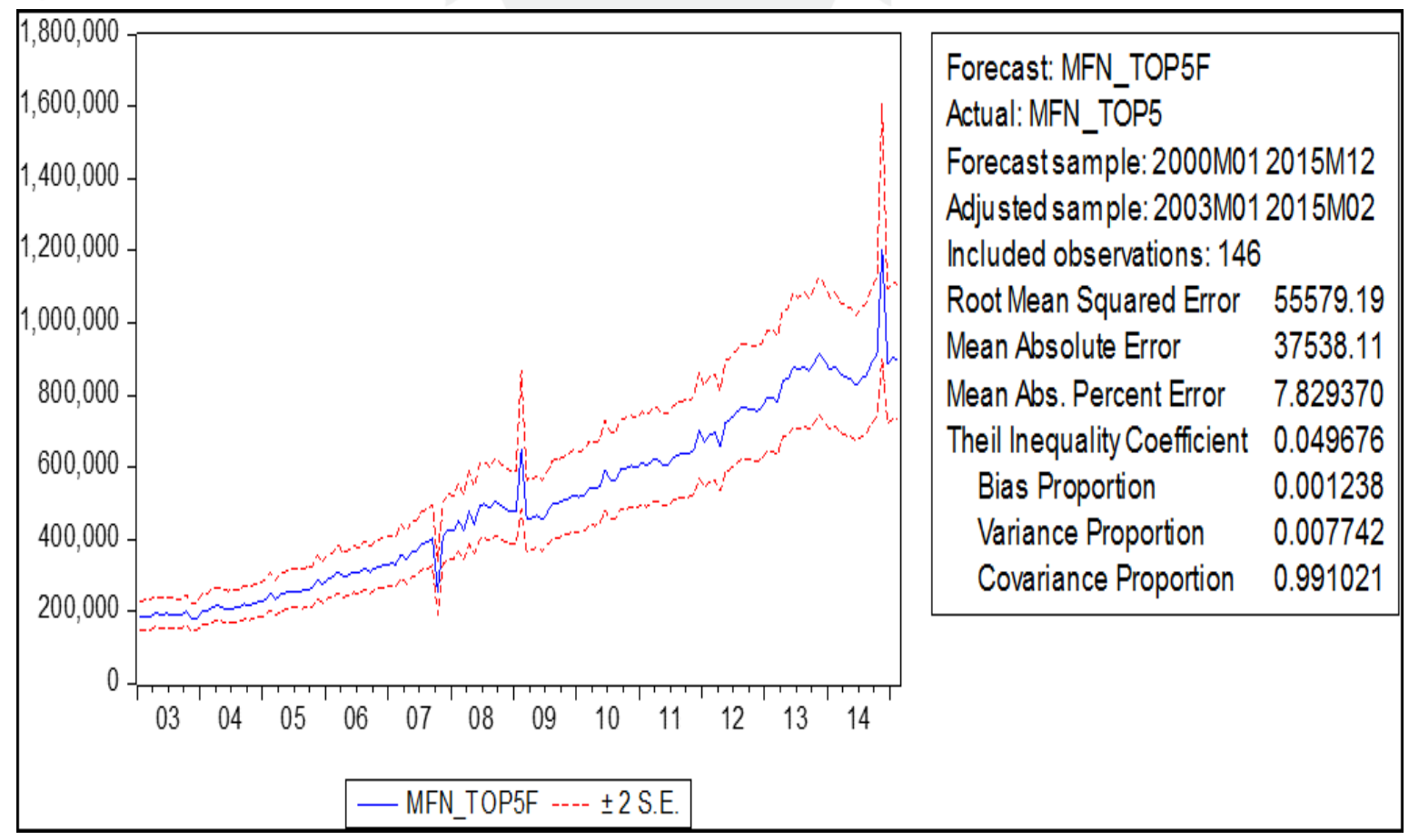


Tabla 3.2.5 Prueba de Heterocedasticidad White

\begin{tabular}{|c|c|c|c|c|}
\hline \multicolumn{5}{|l|}{ Heteroskedasticity Test: White } \\
\hline F-statistic & 1.306134 & \multicolumn{2}{|c|}{ Prob. $F(23,122)$} & 0.1774 \\
\hline Obs*R-squared & 28.84746 & \multicolumn{2}{|c|}{ Prob. Chi-Square(23) } & 0.1854 \\
\hline Scaled explained SS & 26.45733 & \multicolumn{2}{|c|}{ Prob. Chi-Square(23) } & 0.2798 \\
\hline \multicolumn{5}{|l|}{ Test Equation: } \\
\hline \multicolumn{5}{|l|}{ Dependent Variable: RESID^2 } \\
\hline \multicolumn{5}{|l|}{ Method: Least Squares } \\
\hline \multicolumn{5}{|l|}{ Date: 05/24/15 Time: 00:40 } \\
\hline \multicolumn{5}{|l|}{ Sample: 2003M01 2015M02 } \\
\hline \multicolumn{5}{|c|}{ Included observations: 146} \\
\hline \multicolumn{5}{|c|}{ Collinear test regressors dropped from specification } \\
\hline Variable & Coefficient & Std. Error & t-Statistic & Prob. \\
\hline $\mathrm{C}$ & 8.465286 & 11.49719 & 0.736292 & 0.463 \\
\hline LOG(PBIX12_SA)^2 & 0.196299 & 0.143109 & 1.371677 & 0.1727 \\
\hline LOG(PBIX12_SA)*LOG(TAMEX) & -0.059006 & 0.369902 & -0.159518 & 0.8735 \\
\hline LOG(PBIX12_SA)*LOG(TAMN) & 0.134941 & 0.289437 & 0.466219 & 0.6419 \\
\hline LOG(PBIX12_SA)*LOG(TIMN) & 0.028489 & 0.123156 & 0.231323 & 0.8175 \\
\hline LOG(PBIX12_SA)*LOG(TIMEX) & -0.011 & 0.034615 & -0.317774 & 0.7512 \\
\hline LOG(PBIX12_SA)*D200710 & -0.00109 & 0.003089 & -0.352913 & 0.7248 \\
\hline LOG(PBIX12_SA)*D200902 & -0.002929 & 0.003342 & -0.876257 & 0.3826 \\
\hline LOG(PBIX12_SA)*D201411 & -0.003796 & 0.00292 & -1.299801 & 0.1961 \\
\hline LOG(PBIX12_SA) & -2.115525 & 2.326548 & -0.909298 & 0.365 \\
\hline LOG $\left(T_{A M E X}\right)^{\wedge} 2$ & 0.475463 & 0.453757 & 1.047836 & 0.2968 \\
\hline LOG(TAMEX)*LOG(TAMN) & -0.09741 & 0.586805 & -0.166001 & 0.8684 \\
\hline LOG(TAMEX)*LOG(TIMN) & 0.014543 & 0.117278 & 0.124009 & 0.9015 \\
\hline LOG(TAMEX)*LOG(TIMEX) & -0.042148 & 0.041156 & -1.024119 & 0.3078 \\
\hline LOG(TAMEX) & -1.500532 & 3.665824 & -0.40933 & 0.683 \\
\hline $\operatorname{LOG}(T A M N)^{\wedge} 2$ & 0.072457 & 0.265874 & 0.272524 & 0.7857 \\
\hline LOG(TAMN)*LOG(TIMN) & 0.201852 & 0.18362 & 1.099289 & 0.2738 \\
\hline LOG(TAMN)*LOG(TIMEX) & 0.010317 & 0.051601 & 0.199929 & 0.8419 \\
\hline LOG(TAMN) & -1.056091 & 3.100563 & -0.340613 & 0.734 \\
\hline LOG(TIMN)^2 & -0.026242 & 0.013407 & -1.957323 & 0.0526 \\
\hline LOG(TIMN)*LOG(TIMEX) & -0.000573 & 0.007707 & -0.07433 & 0.9409 \\
\hline LOG(TIMN) & -0.735142 & 1.00071 & -0.73462 & 0.464 \\
\hline LOG(TIMEX)^2 & 0.001903 & 0.001905 & 0.998606 & 0.32 \\
\hline LOG(TIMEX) & 0.111611 & 0.291296 & 0.383154 & 0.7023 \\
\hline R-squared & 0.197585 & Mean de & pendent var & 0.009835 \\
\hline Adjusted R-squared & 0.04631 & S.D. depe & endent var & 0.014244 \\
\hline S.E. of regression & 0.01391 & Akaike in & fo criterion & -5.563204 \\
\hline Sum squared resid & 0.023606 & Schwarz c & criterion & -5.072748 \\
\hline Log likelihood & 430.1139 & Hannan-C & Quinn criter. & -5.363921 \\
\hline F-statistic & 1.306134 & Durbin-W & Vatson stat & 2.05761 \\
\hline Prob(F-statistic) & 0.177396 & & & \\
\hline
\end{tabular}


Tabla 3.2.6 Diagnostico de Estabilidad - Prueba RESET de Ramsey

\begin{tabular}{|c|c|c|c|c|}
\hline $\begin{array}{l}\text { Ramsey RESET Test } \\
\text { Equation: ECUACION } \\
\text { Specification: LOG(N } \\
\text { LOG(TAMN) LO }\end{array}$ & $\begin{array}{l}\text { C LOG(PBIX12 } \\
\text { G(TIMEX) D2 }\end{array}$ & $\begin{array}{r}\text { SA) LOG(TA } \\
0710 \text { D2009 }\end{array}$ & $\begin{array}{l}\text { MEX) } \\
02 \text { D201411 } \\
\end{array}$ & \\
\hline Omitted Variables: S & itted values & & & \\
\hline & Value & $d f$ & Probability & \\
\hline t-statistic & 1.733183 & 136 & 0.0853 & \\
\hline F-statistic & 3.003925 & $(1,136)$ & 0.0853 & \\
\hline Likelihood ratio & 3.189703 & 1 & 0.0741 & \\
\hline F-test summary: & Sum of Sq. & $d f$ & Mean Squares & \\
\hline Test SSR & 0.03103 & 1 & 0.03103 & \\
\hline Restricted SSR & 1.435901 & 137 & 0.010481 & \\
\hline Unrestricted SSR & 1.40487 & 136 & 0.01033 & \\
\hline Unrestricted SSR & 1.40487 & 136 & 0.01033 & \\
\hline LR test summary: & Value & $d f$ & & \\
\hline Restricted LogL & 130.2274 & 137 & & \\
\hline Unrestricted LogL & 131.8223 & 136 & & \\
\hline $\begin{array}{l}\text { Unrestricted Test Eq } \\
\text { Dependent Variable } \\
\text { Method: Least Squa }\end{array}$ & _TOP5) & $\begin{array}{l}\text { Date: } 05 / 24 / \\
\text { Sample: } 200 \\
\text { Included obs }\end{array}$ & $\begin{array}{l}\text { 15 Time: 00:4 } \\
\text { 3M01 2015M0 } \\
\text { servations: } 146\end{array}$ & \\
\hline Variable & Coefficient & Std. Error & t-Statistic & Prob. \\
\hline $\mathrm{C}$ & -17.18693 & 9.934559 & -1.730014 & 0.0859 \\
\hline LOG(PBIX12_SA) & 9.679566 & 4.11407 & 2.352796 & 0.0201 \\
\hline LOG(TAMEX) & 1.361845 & 0.574606 & 2.370049 & 0.0192 \\
\hline LOG(TAMN) & 0.219134 & 0.150566 & 1.455401 & 0.1479 \\
\hline LOG(TIMN) & -0.158048 & 0.068941 & -2.292512 & 0.0234 \\
\hline LOG(TIMEX) & -0.019427 & 0.013622 & -1.426173 & 0.1561 \\
\hline D200710 & -1.813281 & 0.778487 & -2.329236 & 0.0213 \\
\hline D200902 & 1.2953 & 0.563251 & 2.299687 & 0.023 \\
\hline D201411 & 1.20895 & 0.536689 & 2.252607 & 0.0259 \\
\hline FITTED^2 & -0.109989 & 0.063461 & -1.733183 & 0.0853 \\
\hline R-squared & 0.964852 & Mean dep & endent var & 13.00631 \\
\hline Adjusted R-squared & 0.962526 & S.D. deper & ndent var & 0.525031 \\
\hline S.E. of regression & 0.101636 & Akaike inf & o criterion & -1.668798 \\
\hline Sum squared resid & 1.40487 & Schwarz c & riterion & -1.464442 \\
\hline Log likelihood & 131.8223 & Hannan-Q & uinn criter. & -1.585763 \\
\hline F-statistic & 414.8186 & Durbin-W & atson stat & 1.885136 \\
\hline Prob(F-statistic) & 0 & & & \\
\hline
\end{tabular}




\subsubsection{Aplicación de la Prueba de Estrés- Simulación VAR Impulso-Respuesta}

Para la aplicación de la prueba de estrés se elaboró un modelo VAR para el conjunto de los 5 bancos, con el máximo de rezagos que permite el modelo para este caso (3-4 rezagos). Posteriormente se realizó el análisis ImpulsoRespuesta, con una simulación de Montecarlo para los siguientes 12 meses, en su versión no acumulada y acumulada. (Figura 3.2.4)

El impulso normal es el que se registra por cada mes, es decir, se asemeja a los rezagos distribuidos. Se parte del concepto de que el impulso en la exógena puede generar una respuesta ("reflejo") en la endógena que no es uniforme. Generalmente los efectos son convergentes. La respuesta acumulada se centra en el resultado final, debido a que concentra el efecto agregado durante todo el período de tiempo. Generalmente es divergente siempre y cuando la respuesta no tenga un impacto positivo y posteriormente uno negativo. De los Figuras de Impulso-Respuesta, se extrajo el valor acumulado al mes de maduración 12 del impacto de la variable exógena sobre el Margen Financiero Neto. En otras palabras, este es un impacto en capturado en medias. Seguido, se procedió a crear nuevas estimaciones de las series del Margen Financiero Neto incluyendo el efecto de estrés de cada exógena.

Ecuación 3.9

$$
M F N_{i}=M F N-R_{i}
$$

$\mathrm{R}$ es el impacto de la variable exógena sobre el Margen Financiero e i es el tipo de variable exógena que genere el escenario de estrés. Por lo tanto Ri es el valor acumulado al mes 12 del impacto de tuvo la variable exógena sobre el margen financiero. 
Figura 3.2.4

Impulso Respuesta

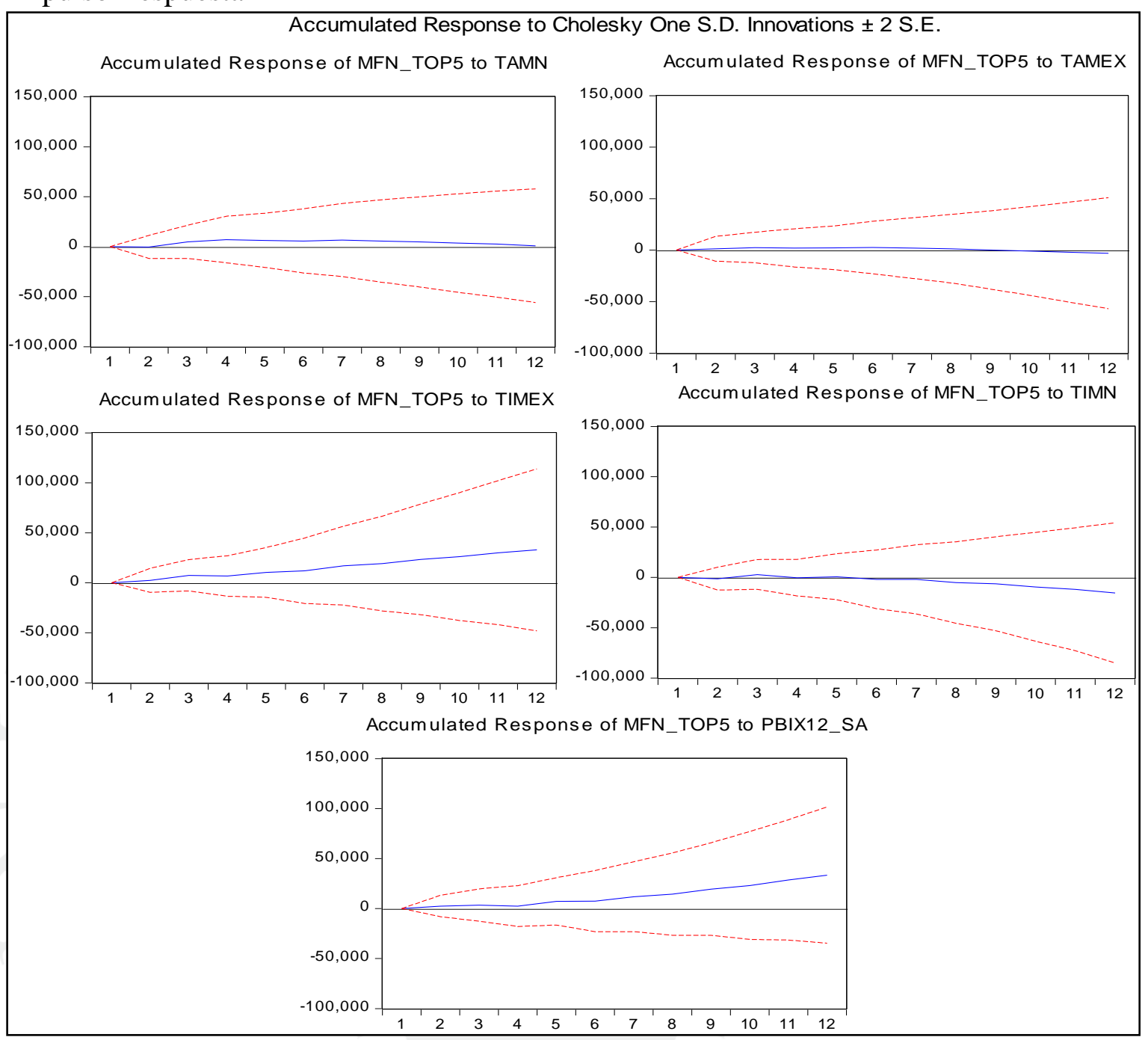

Tabla 3.2.7.

Resultados medidos en desviaciones acumuladas

RESULTADOS DEL STRESS A 12 MESES -SEGUN IMPULSORESPUESTA- MEDIDO EN DESVACIONES ACUMULADAS (VALORES ABSOLUTOS)

MFN_TOP5

PBI

TAMN

33,400

TAMEX

8,970

TIMN

3,010

TIMEX

15,600

33,000 
Figura 3.2.5

Distribución de las desviaciones de la variable endógena de la ecuación 3.8

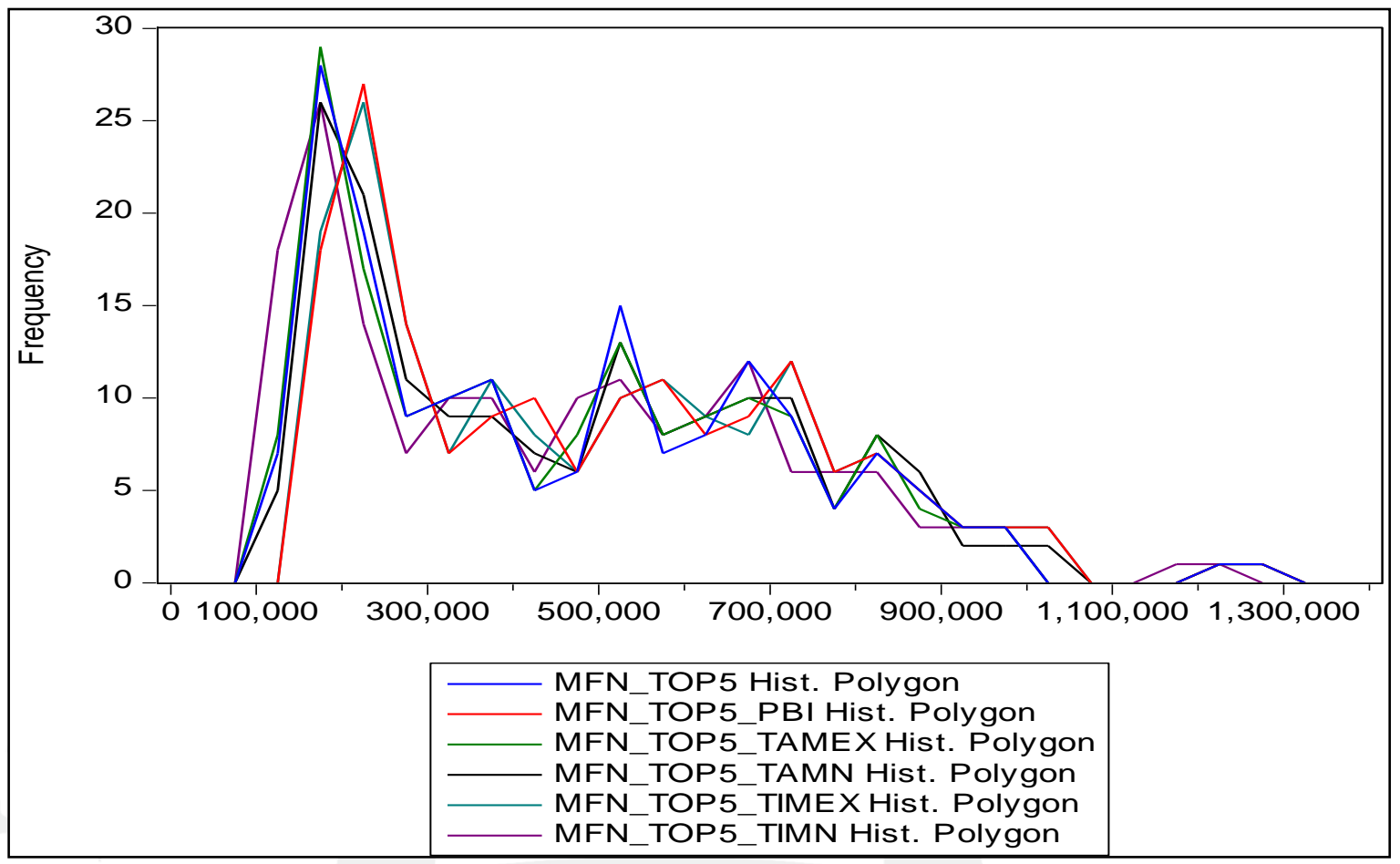

Figura 3.2.6

Desviación de la distribución por el PBI

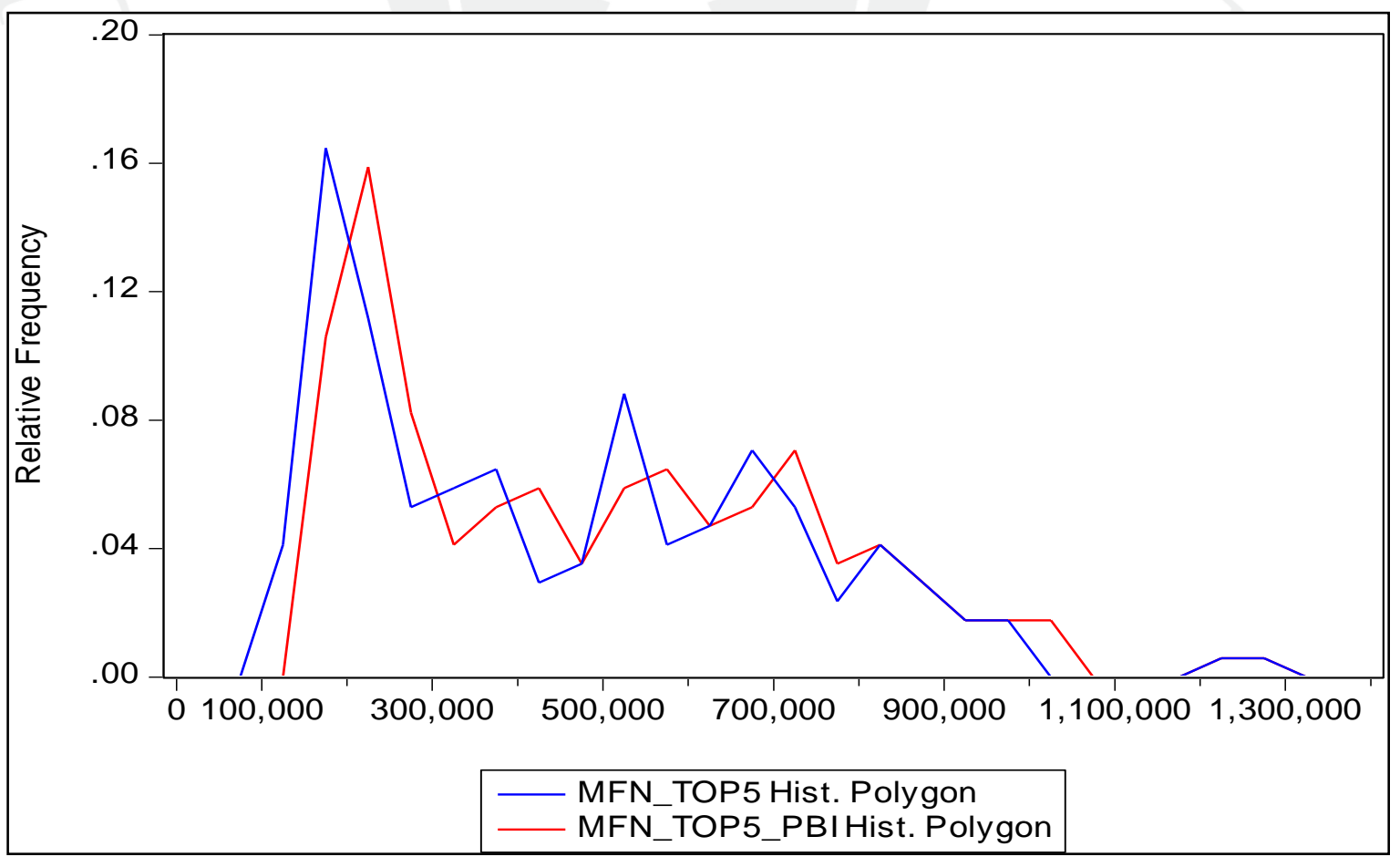


Se agruparon las series y se graficaron en la forma de distribuciones, para comparar las distribución original frente a la distribución de los diversos impactos. El análisis se centra en capturar la proporción del desplazamiento derivado de un impulso en las exógenas. (Figura 3.2.5).

Según el Figura 3.2.6 se interpreta que la variación del PBI genera un incremento en el valor medio de la distribución del Margen financiero, sin embargo no aumenta la probabilidad de que ocurra. Este desplazamiento de la distribución no significa que se alcancen valores mayores a la distribución original. A comparación de las otras desviaciones, una variación en el PBI es más significativa. Esto corrobora la hipótesis planteada para la prueba de riesgo de mercados debido a que se demuestra que la evolución del Margen Financiero está más ligado a la variable endógena de la economía.

Los Figuras 3.2.7 y 3.2.8 nos indican que no existe un claro impacto en la distribución del Margen Financiero producto de la variación en la tasas activa. Se corrobora que no existe un impacto significativo, por lo tanto una variación en las tasa de interés cobradas no generaría necesariamente un impacto proporcional en los ingresos de los bancos.

En el caso de las Tasas interbancaria en moneda nacional sí se registra un impacto negativo en la distribución; pero con una menor probabilidad. Se interpreta que si el fondeo interbancario se encarece, se generan mayores egresos que repercuten en el margen (Figura 3.2.9). Verificamos que para el caso de la Tasa interbancaria en moneda extranjera, existe un impacto positivo para la distribución, pero debido a que esta variable no es muy significativa no correspondería hacer conclusiones al respecto. (Figura 3.2.10). 
Figura 3.2.7

Desviación de la distribución por la TAMN

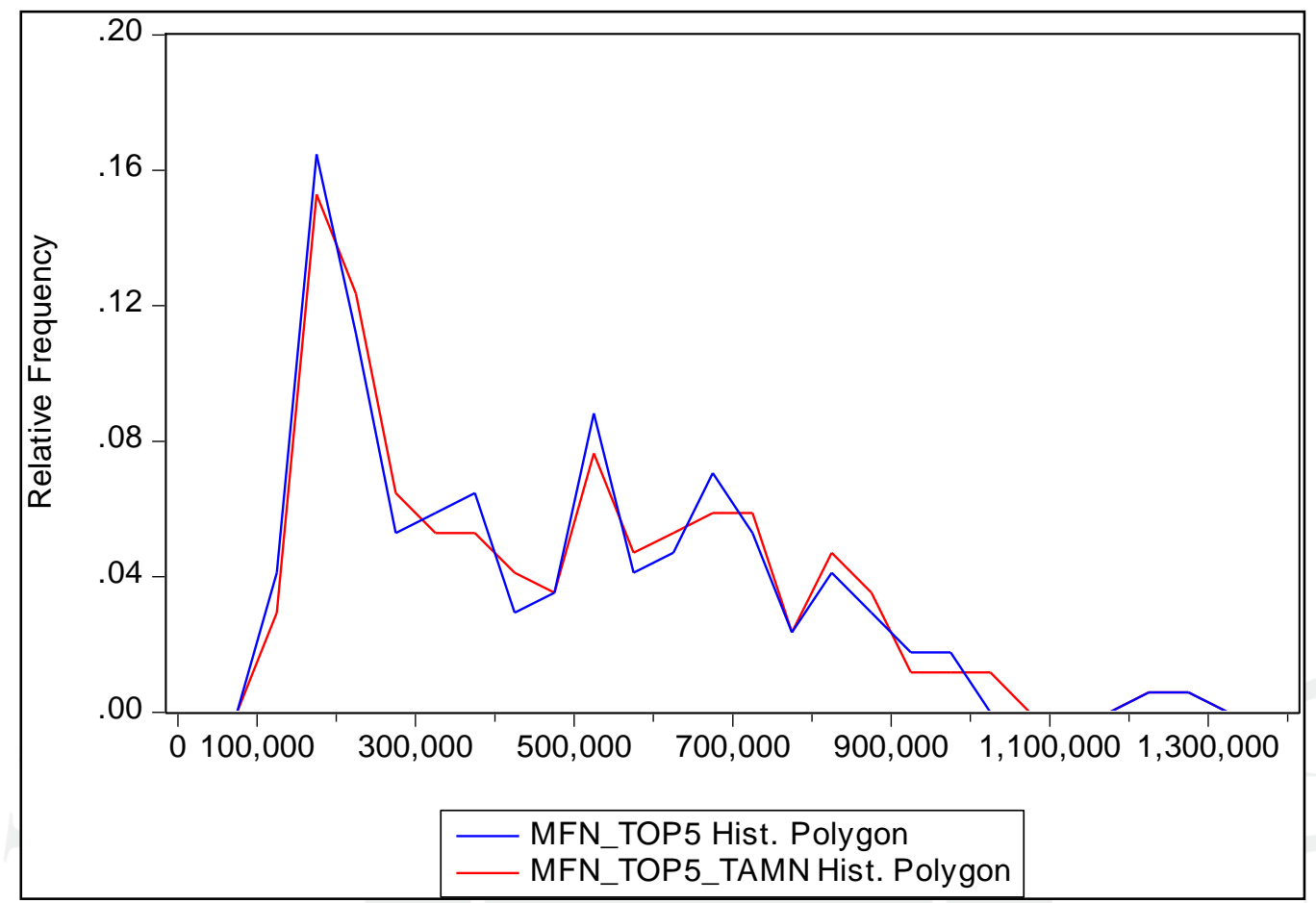

Figura 3.2.8

Desviación de la distribución por la TAMEX

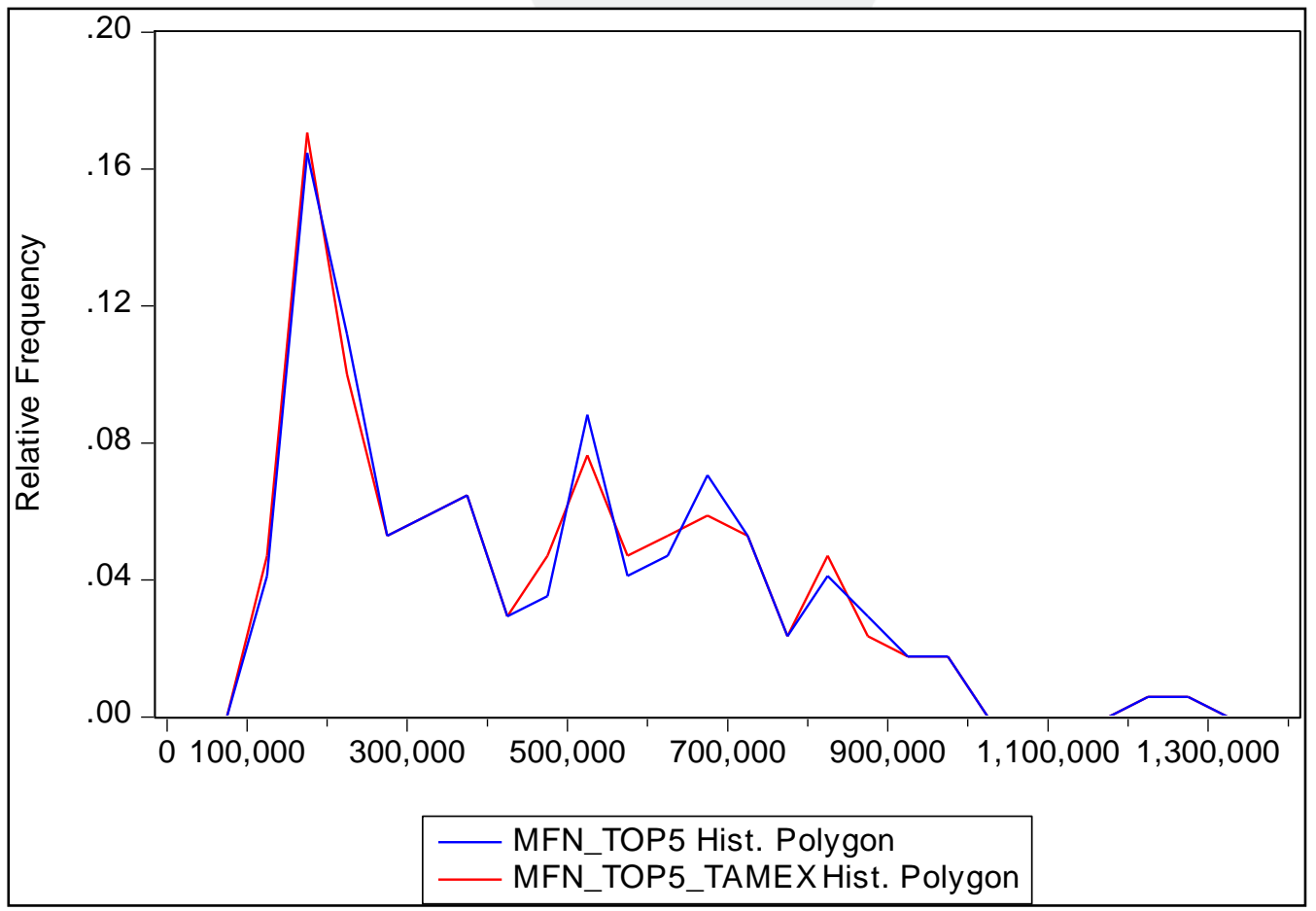


Figura 3.2.9

Desviación de la distribución por la TIMN

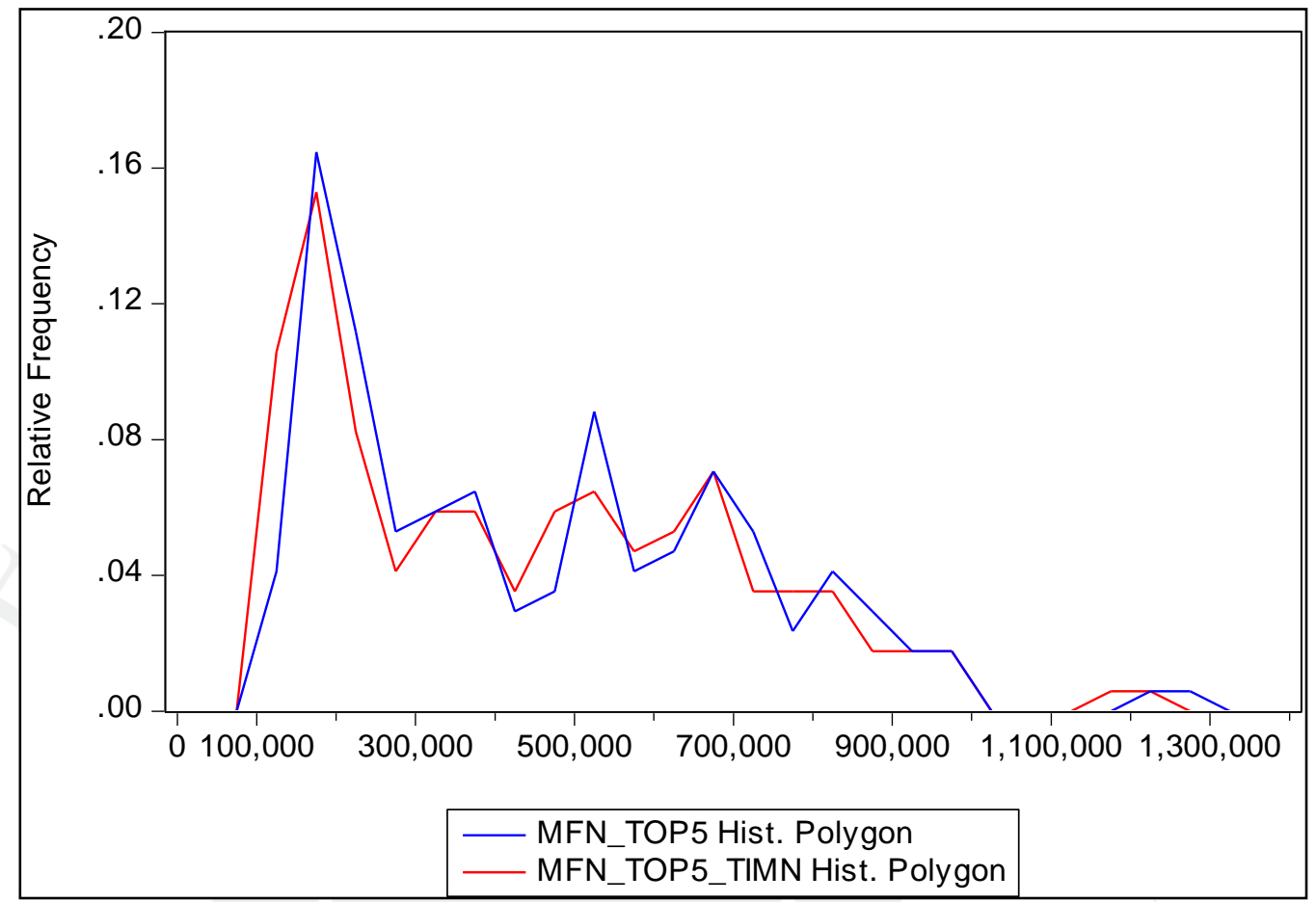

Figura 3.2.10

Desviación de la distribución por la TIMEX

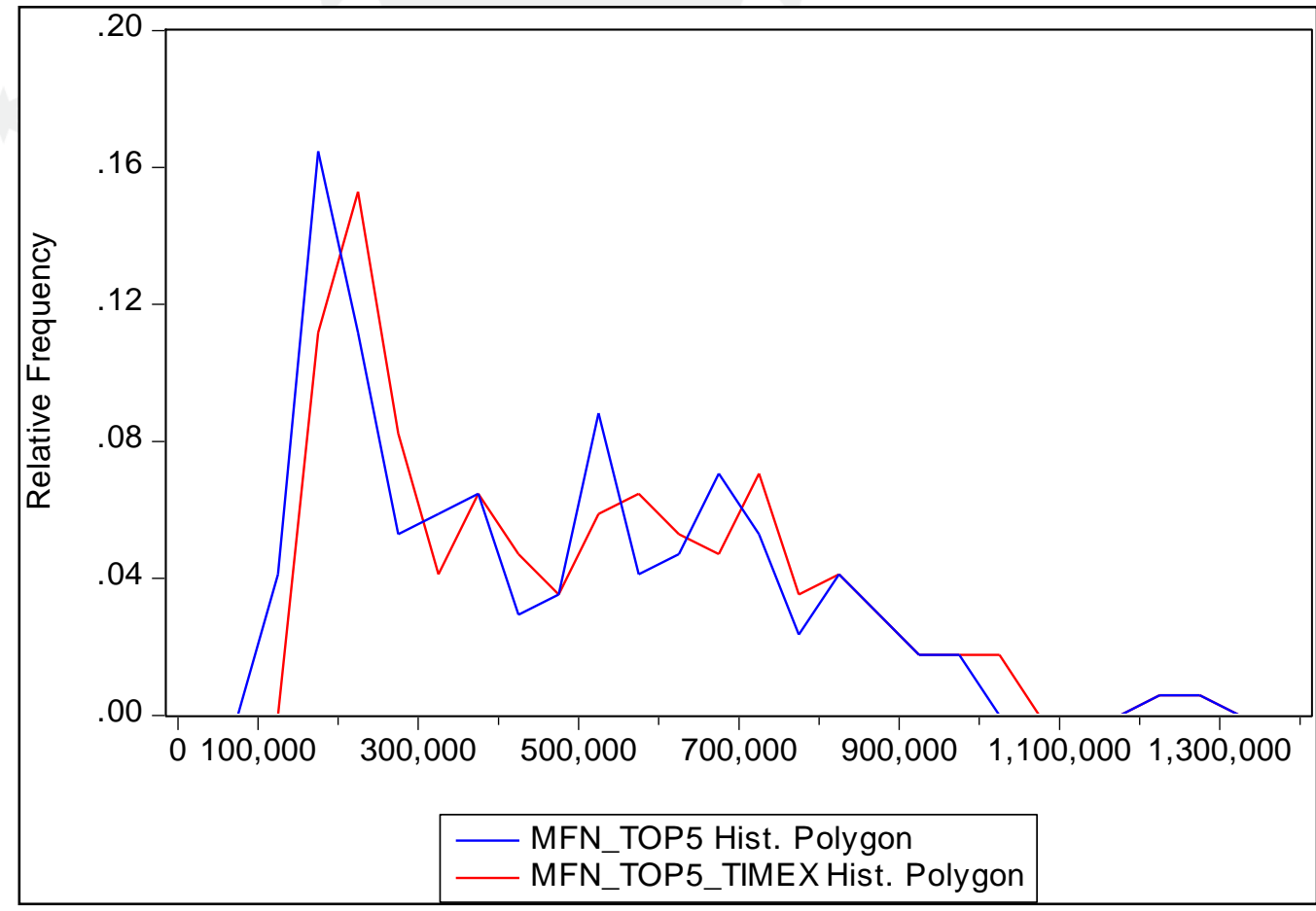




\subsection{Prueba de Estrés de Riesgo de Liquidez}

Los créditos otorgados por los bancos provienen de los pasivos, los cuales están comprendido por fondeo por Depósitos y fondeo por Adeudos y Obligaciones. Esta prueba de estrés busca revelar el riesgo de liquidez de los bancos en relación a la dependencia con el financiamiento externo (fondeo externo). El Fondeo por Adeudos y Obligaciones se refiere al uso de depósitos y otros pasivos de instituciones como los bancos, fondos de pensiones, fondos mutuos y otros intermediarios financiaros. Cuando el banco depende de fondeo a corto plazo para sostener activos ilíquidos a largo plazo, se vuelve vulnerable a retiro por parte de los acreditadores mayoristas. Este riesgo se ha manifestado desde el inicio de la crisis financiera internacional del 2007, cuando los bancos estadounidenses se vieron confrontados por severas contracciones de financiamiento de liquidez. Después de la caída de Lehman Brothers, el fondeo interbancario del sistema bancario estadounidense se agotó. El funcionamiento del mercado de fondos interbancarios fue severamente minado por el incremento del riesgo contraparte y el decrecimiento del colateral de alta calidad (garantía).

Para capturar la dinámica entre los activos y pasivos del banco, se utilizará un marco multiecuacional que conecta las variables del fondeo de los bancos a los activos del banco. Se asume que en el modelo las deudas son exógenamente débiles y los activos son endógenos, basados en la idea de que los bancos pueden determinar sus estrategias de inversión y de préstamo.

Se utiliza un panel de vectores autos regresivos (VAR). Una cualidad útil del modelo VAR es que puede generar funciones impulso respuesta ortogonalizadas, para identificar el impacto de un choque aislado de una variable a todas las variables del sistema. 
En el análisis nos centramos en los efectos de los choques de financiamiento, en particular de los depósitos y de los adeudos y obligaciones. También incluimos los spreads de tasas del mercado de dinero a nivel país para el control los costos del fondeo. Los ajustes de los préstamos de los bancos en respuesta a los choques de financiamiento son simulados, controlando la demanda de crédito, que es aproximada por un indicador económico. Incluyendo este indicador, el modelo captura ambos efectos de demanda y oferta de créditos. La oferta de dinero cambiará según la disponibilidad de suficiente volúmenes de fondeo.

\subsubsection{Metodología del Modelo de Riesgo Liquidez}

La metodología propuesta para su adaptación y aplicación para el caso peruano corresponde a De Haan (2015). Cuando los canales de financiamiento se cierran, los bancos se ubican en un problema de financiación de liquidez. Esta prueba medirá el impacto de una drástica disminución del nivel de financiamiento en los activos del banco. Se hará uso de un marco multiecuacional, tomando en cuenta las dinámicas de las interrelaciones entre los instrumentos para el manejo de la liquidez del banco. Los adeudos están clasificados como exógenos y los activos como endógenos debido al supuesto de que los bancos pueden escoger sus estrategias de inversión pero el financiamiento para ellos ya está dado.

Se utilizara un modelo de panel de vectores autoregresivos VAR, que toma en cuenta la heterogeneidad entre los bancos individualmente, incluyendo efectos ajustados. 


$$
\left[\begin{array}{l}
X t \\
Y i t
\end{array}\right]=A i+B(L)\left[\begin{array}{l}
X t \\
Y i t
\end{array}\right]+\in i t
$$

Donde el vector $\mathrm{X}$ son los costos de financiamiento para cada mes /año e $\mathrm{Y}$ es un vector que contiene las variables de los balances generarles de cada banco (i) y mes/año (t). A (i) es una matriz que contiene los efectos ajustados del banco y $\mathrm{B}(\mathrm{L})$ es una matriz polinómica con un operador de rezago. $\in$ es el término de error.

Los coeficientes del modelo VAR son estimados por el Sistema Generalizado de Momentos, usando el rezago de las variables como instrumentos. Los efectos ajustados son eliminados, expresando todas las variables como una desviación de su promedio. Cabe indicar que le Modelo VAR es un modelo de simulación, mas no de explicación.

Como los efectos ajustados están correlacionados con los regresores, resultado de la inclusión de rezagos de las variables dependientes; la diferenciación de promedios ordinaria generara un sesgo en los coeficientes. Frente a este problema, se utiliza una transformación de Helmert, la cual elimina los promedios proyectados de todas las observaciones de la muestra y preserva la ortogonalidad entre las variables transformadas y los regresores rezagados. Para que así, sean instrumentos válidos para calcular los coeficientes por el Sistema Generalizado de Momentos.

Como los choques son ortogonalizados, la respuesta de unas variables a un choque de otra variable puede ser interpretada como la reacción de la primera a la respuesta de la segunda, manteniendo los demás choques iguales a cero. Para ortogonlizar los choques, es necesario descomponer los residuos. Este procedimiento es conocido como la descomposición de Choleski. 
Para el modelo explicado, asumimos los siguientes supuestos. Los choques en el costo de financiamiento tienen un efecto inmediato en las variables del balance y responden con un rezago. Asumimos que las deudas de los bancos responden más rápido que los activos del banco. Esto refleja el hecho de que el financiamiento depende de condiciones de mercado que están fuera del control directo del banco. Finalmente, los activos más líquidos del balance se ajustan más rápido que los menos líquidos.

Dado que las funciones de Impulso-Respuesta se construyen a partir de los coeficientes estimados del modelo, es necesario tomar en cuenta los errores estándar de estos últimos. Utilizando simulaciones de Monte Carlo se calcula los errores estándar y se generan intervalos de confianza de las funciones de impulso respuesta. 


\subsubsection{Variables}

Por cada tipo de Crédito Directos, se está utilizando el porcentaje de participación con respecto al total del portafolio. Por lo tanto, se trabaja con la evolución de la composición de los créditos Directos. Esta información corresponda a la suministrada por el Boletín Estadístico de la SBS. De igual manera para el caso de los Depósitos, se está utilizando el porcentaje de participación de cada tipo de depositó con respecto al total. Para los adeudos y obligaciones se está utilizando también su porcentaje de participación.

Tabla 3.3.

Variables del Modelo de Riesgo Liquidez. Elaboración Propia.

\begin{tabular}{|c|c|c|c|c|c|}
\hline \multicolumn{5}{|c|}{ Variables del Modelo de Riesgo Liquidez } & \multirow[b]{2}{*}{ Fuente } \\
\hline Nomenclatura & Definición & Periodicidad & Tipo & Unidades & \\
\hline $\begin{array}{l}\text { Composición de } \\
\text { Créditos Directos }\end{array}$ & $\begin{array}{c}\text { Participación de los } \\
\text { distintos tipos de créditos } \\
\text { sobre el total del portafolio }\end{array}$ & Mensual & Nominales & $\begin{array}{l}\text { Porcentaje } \\
(\%)\end{array}$ & SBS \\
\hline $\begin{array}{l}\text { Composición de } \\
\text { Depósitos }\end{array}$ & $\begin{array}{c}\text { Participación de los } \\
\text { distintos tipos depósitos } \\
\text { entre el total }\end{array}$ & Mensual & Nominales & $\begin{array}{l}\text { Porcentaje } \\
\quad(\%)\end{array}$ & SBS \\
\hline $\begin{array}{l}\text { Composición de } \\
\text { Adeudos y } \\
\text { Obligaciones } \\
\text { Financieras }\end{array}$ & $\begin{array}{c}\text { Participación de los } \\
\text { distintos tipos de adeudos } \\
\text { y obligaciones financieras } \\
\text { entre el total }\end{array}$ & Mensual & Nominales & $\begin{array}{l}\text { Porcentaje } \\
\quad(\%)\end{array}$ & SBS \\
\hline Crecimiento PBI Real & $\begin{array}{c}\text { Variación anual del PBI } \\
\text { real }\end{array}$ & Mensual & Real & $\begin{array}{l}\text { Porcentaje } \\
(\%)\end{array}$ & INEI \\
\hline TAMN & $\begin{array}{c}\text { Tasa activa promedio } \\
\text { moneda nacional }\end{array}$ & Mensual & Nominal & $\begin{array}{c}\text { Porcentaje } \\
(\%)\end{array}$ & BCRP \\
\hline Spread & $\begin{array}{l}\text { Diferencia tasa de largo y } \\
\text { corto plazo }\end{array}$ & Mensual & Nominal & $\begin{array}{l}\text { Porcentaje } \\
(\%)\end{array}$ & $\begin{array}{l}\text { Reserva } \\
\text { Federal } \\
\text { EEUU }\end{array}$ \\
\hline
\end{tabular}




\subsubsection{Aplicación de la metodología}

Una vez agrupados los datos de los créditos, los depósitos y los adeudos y obligaciones, se optó por armar y analizar la matriz de correlaciones. La matriz de correlación sirve para medir la interdependencia en relaciones asociadas o entre cada pareja de variables y todo el mismo tiempo se identificaron casos de auto correlación elevada que pudieran llevar a multicolinealidad. La multicolinealidad es una situación en la que se presenta una fuerte correlación entre variables explicativas del modelo. Posteriormente se extrajeron los principales estadísticos descriptivos (Tabla 3.3.2).

Se observó que la serie de datos correspondiente a créditos del Comercio Exterior presenta periodos de tiempo con valores omitidos. De ello, se optó por separarlos, además no poseen una proporción significativa en comparación a los demás tipos de crédito. 
Para la aplicación del modelo de Panel VAR, se utilizaran las siguientes variables

\section{(Tabla 3.3.1):}

- Entorno económico financiero: que incluye el PBI, el Spread y la TAMN

- Créditos o usos de fondos: tipos de crédito directo.

- Fuentes de Fondos: Adeudos y obligación o fuente de financiamiento nacional o extranjero de corto y largo plazo.

- Fuentes de Fondeo por Depósitos: clases de Depósitos según plazo de disponibilidad.

Como se verá más adelante, será necesario eliminar algunas variables a fin de evitar un problema de matriz singular. Esto ocurre ya que los datos se expresan en porcentaje y suman 1, el determinante de las filas seria nulo y se borrarían las filas y columnas por propiedad. 
Tabla 3.3.1 Resumen de variables

\begin{tabular}{|c|c|c|c|}
\hline Clasificación & Cuenta & Abreviatura & $\begin{array}{l}\text { Tipo de Variable del } \\
\text { modelo }\end{array}$ \\
\hline Créditos Directos & Arrendamiento Financiero & C_ARREND & Endógena \\
\hline Créditos Directos & Cuentas Corrientes & C_CC & Endógena \\
\hline Créditos Directos & Comercio Exterior & C_COMEX & Endógena \\
\hline Créditos Directos & Fáctoring & C_FACT & Endógena \\
\hline Créditos Directos & Descuentos & C_DESC & Endógena \\
\hline Créditos Directos & Hipotecarios para Vivienda & C_HIPOV & Endógena \\
\hline Créditos Directos & Préstamos & C_PREST & Endógena \\
\hline Créditos Directos & Otros & C_OTROS & Endógena \\
\hline Créditos Directos & Tarjetas de Crédito & C_TDC & Endógena \\
\hline Depósitos & Depósitos del Público Ahorros & DEP_AH & Endógena \\
\hline Depósitos & Depósitos del Público Plazo & DEP_PLZ & Endógena \\
\hline Depósitos & Depósitos del Público Restringidos & DEP_RESTR & Endógena \\
\hline Depósitos & Depósitos del Sist. Financiero y Org. Internacionales & DEP_SFOI & Endógena \\
\hline Depósitos & Depósitos del Público Vista & DEP_V & Endógena \\
\hline Adeudos y Obligaciones Financieras & Instituciones del País Corto Plazo & OB_NCP & Endógena \\
\hline Adeudos y Obligaciones Financieras & Instituciones del Exterior Corto Plazo & $\mathrm{OB} \_\mathrm{XCP}$ & Endógena \\
\hline Adeudos y Obligaciones Financieras & Instituciones del País Largo Plazo & OB_NLP & Endógena \\
\hline Adeudos y Obligaciones Financieras & Instituciones del Exterior Largo Plazo & OB_XLP & Endógena \\
\hline Variable Exógena & Crecimiento Real PBI & IPBI & Exógena \\
\hline Variable Exógena & Diferencia Tasas & SPREAD & Exógena \\
\hline Variable Exógena & Tasa activa Moneda Nacional & TAMN & Exógena \\
\hline
\end{tabular}

Tabla 3.3.2 Estadísticos Descriptivos

\begin{tabular}{|l|rrrrrrr|}
\hline & Mean & Median & Maximum & Minimum & Std. Dev. & \multicolumn{1}{c}{ Skewness } & Kurtosis \\
\hline & & & & & & & \\
\hline C_ARREND & 12.89384 & 12.64083 & 27.34314 & 3.091297 & 5.766352 & 0.432369 & 2.606198 \\
C_CC & 1.680026 & 1.359957 & 8.119046 & 0.062917 & 1.308938 & 1.792944 & 7.334173 \\
C_FACT & 1.005155 & 1.033441 & 2.719461 & 0 & 0.588526 & 0.050578 & 2.180517 \\
C_DESC & 4.629257 & 4.445216 & 12.77703 & 1.302486 & 2.318905 & 1.280239 & 4.693299 \\
C_HIPOV & 14.83885 & 15.0116 & 22.64384 & 5.059445 & 4.044517 & -0.337744 & 2.413476 \\
C_PREST & 43.94504 & 43.76465 & 73.14788 & 24.56846 & 10.13516 & 0.584377 & 3.500214 \\
C_OTROS & 6.118235 & 3.537601 & 33.31612 & 0.053497 & 6.854983 & 1.747637 & 5.616346 \\
C_TDC & 6.179079 & 4.132677 & 17.21477 & 0.293103 & 4.631879 & 0.904583 & 2.549192 \\
DEP_AH & 22.37767 & 22.95772 & 36.7578 & 4.842927 & 6.820174 & -0.352382 & 2.481233 \\
DEP_PLZ & 49.91007 & 49.02475 & 76.40322 & 31.66267 & 9.409965 & 0.425368 & 2.332206 \\
DEP_RESTR & 1.730857 & 1.120715 & 6.278954 & 0 & 1.662286 & 0.537459 & 1.928741 \\
DEP_SFOI & 3.564452 & 2.436163 & 20.67136 & 0.470396 & 3.092934 & 1.686903 & 5.899513 \\
DEP_V & 22.38324 & 21.79432 & 37.59358 & 10.35087 & 6.627034 & 0.172764 & 1.903542 \\
OB_NCP & 12.79127 & 5.413562 & 98.78863 & 0 & 19.53876 & 2.417553 & 9.042287 \\
OB_XCP & 29.52436 & 27.36604 & 87.11542 & 0 & 20.89688 & 0.47118 & 2.320302 \\
OB_NLP & 22.48465 & 14.76644 & 95.84243 & 0 & 20.01972 & 1.434584 & 4.606957 \\
OB_XLP & 35.08392 & 30.72335 & 92.02994 & 0 & 27.849 & 0.363435 & 1.814378 \\
IPBI & 111.0547 & 110.7177 & 159.4772 & 71.05745 & 23.87872 & 0.102692 & 1.79878 \\
SPREAD & 2.088538 & 2.35 & 3.69 & -0.52 & 1.128505 & -0.72676 & 2.555614 \\
TAMN & 21.28185 & 20.73801 & 26.63 & 15.5293 & 3.0303 & -0.156288 & 1.986022 \\
\hline
\end{tabular}


Como puede observarse, existen tres grupos de endógenas: las de créditos, las de depósitos y las de obligaciones. Dentro de cada grupo, estas se expresan como porcentajes del mismo, por lo que la suma de sus elementos en todos los casos 1. Esta situación genera que no puedan utilizarse todas las variables pues ello generará una reducción no deseada de las columnas de las matrices del VAR y de ello un riesgo inminente de matriz singular.

Por tal motivo, se eliminará los componentes de los grupos que sean poco significativos o presenten una elevada cantidad de datos omitidos. En este caso se eliminaran los créditos al comercio exterior COMEX y los depósitos del sistema financiero y organismos internacionales SFOI.

No obstante, en el caso de las adeudos y obligaciones con terceros no depositantes, las cuatro fuentes de fondos son importantes para todos los bancos y el sector en general; con diversas elecciones en unos casos más importantes que en otros, pero en general el sector parece financiarse equitativamente.

Por lo tanto, se crearán tres modelos VAR por cada tipo de Crédito, uno con depósitos, otro con adeudos y obligaciones de locales y otro con adeudos y obligaciones extranjeras. Se estudiara el impacto en la composición del portafolio de créditos producido por la variación en los tipos de fondo.

Se elaboraron 24 modelos de panel Var. Por cada tipo de los créditos observados (8), se le aplicara individualmente el efecto impulso generado por una variación en los deposito (4), en los adeudos y obligaciones nacionales (2) y los adeudos y obligaciones extranjeros (2).

A diferencia de las pruebas de estrés anteriores, las variables exógenas como el Pbi, el spread y la tasa activa en moneda nacional no son los agentes de estrés sino variables que alimentan al modelo. 


\subsubsection{Aplicación de la Prueba de Estrés}

Se crearon se crearon las funciones impulso respuesta, siendo los impulsos todas las fuentes de fondos o financiamiento que tenga el modelo respuesta todos los tipo de crédito consignados en el modelo. El horizonte es de doce meses y con efecto acumulado. Nótese que los impactos asumen un supuesto Ceteris Paribus que los otros tipos de impacto no están incluidos en el modelo.

Luego de elaborar todos los modelos de efecto impulso respuesta, se procede a la interpretación. Las unidades del eje vertical de las Figuras impulso respuesta (IR), son las unidades de la variable (\% de participación dentro de los Créditos Directos), las cuales representan el aumento de ésta ante un shock equivalente a una desviación estándar de la endógena de impulso. Debe recordarse que este Figura representa los valores medios de impacto.

Se interpretara en orden según el porcentaje de participación del tipo de crédito directo en el total del portafolio: Préstamos (62\%), Otros créditos (11\%), Hipotecarios para vivienda (8.1\%), Descuentos (5.9\%), Arrendamiento financiero, $(5.15 \%)$, Cuentas corrientes $(3.73 \%)$, Tarjetas de crédito $2.19 \%$ y Factoring $0.94 \%$

En el Figura 3.3.1 se registra el impacto sobre los Préstamos. Existe una relación positiva con los depósitos a excepción de los Restringidos. Esto obedece a la lógica de que los ahorros de los agentes superavitarios son transferidos a los agente deficitarios y los bancos sirven de intermediario. Se registra que si el fondeo proviniera de entidades nacionales, los prestamos crecería su nivel participación por encima del 100\%. Para el caso de los Adeudos y Obligaciones Financieras con el extranjero existe una relación negativa ya que los préstamos son el principal giro del negocio por lo que la principal fuente del fondeo deberían ser los depósitos. 
En el Figura 3.3.2 se muestra el impacto sobre Otros Créditos directos. Ya que este conjunto es muy heterogéneo no se pueden realizar afirmaciones precisas al respecto. Lo que si resulta importante señalar es que posee una fuerte relación positiva con los obligaciones extranjeras a corto plazo, se intuye que debe obedecer a un tipo de crédito muy especificó el cual necesita resguardarse con fondeo de corto plazo para cerrar descalces de balance.

En el Figura 3.3.3 está el impacto sobre los créditos hipotecarios para vivienda. La relación con los depósitos ahorro, a plazo restringidos es positivo. También con las obligaciones extranjeras de largo plazo. Esto debido a que los créditos hipotecarios tienen un umbral de tiempo largo.

En el Figura 3.3.4 se registra el impacto sobre los Descuentos. Para este tipo de crédito existe una relación positiva con todos los tipos de depósito y obligaciones con entidades nacionales. Esto no ocurre con las obligaciones con entidades del extranjero donde el impacto sería mayor. 
Figura 3.3.1. IR Préstamos

\section{Directos}

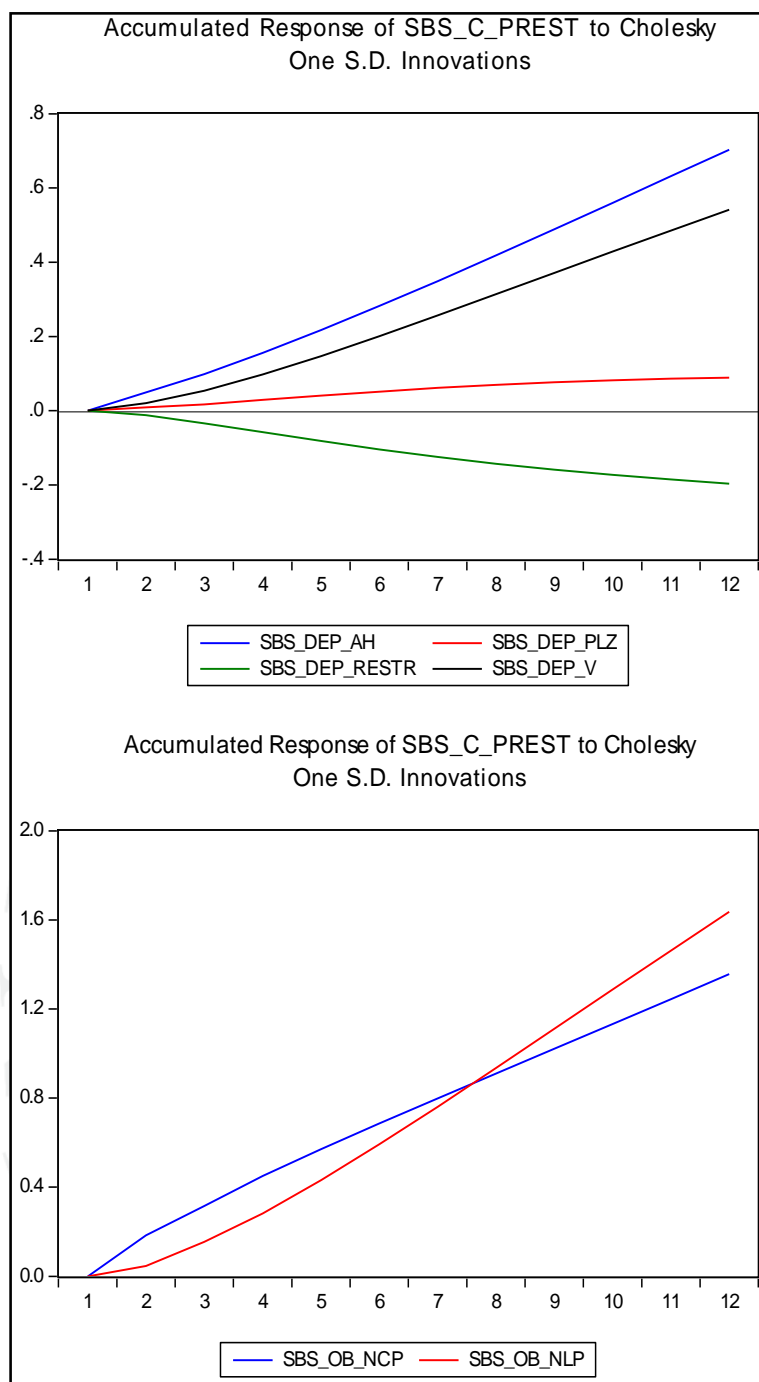

Accumulated Response of SBS_C_PREST to Cholesky One S.D. Innovations

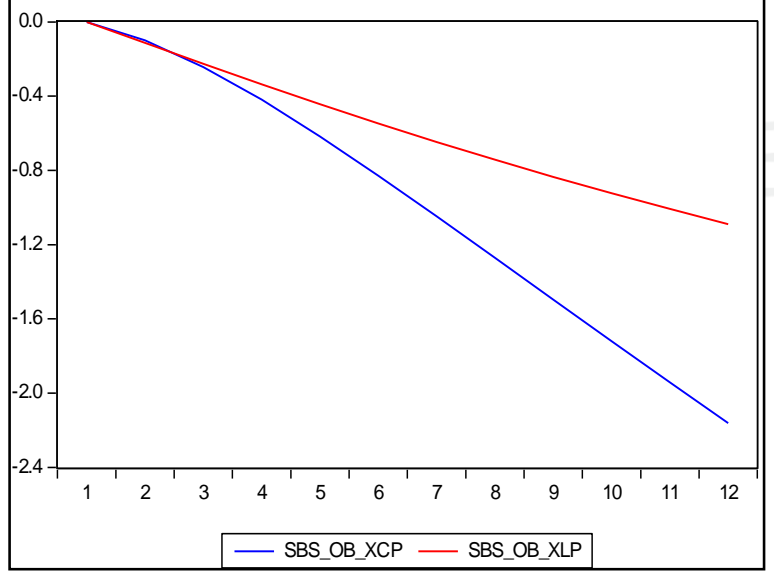

Figura 3.3.2. IR Otros Créditos

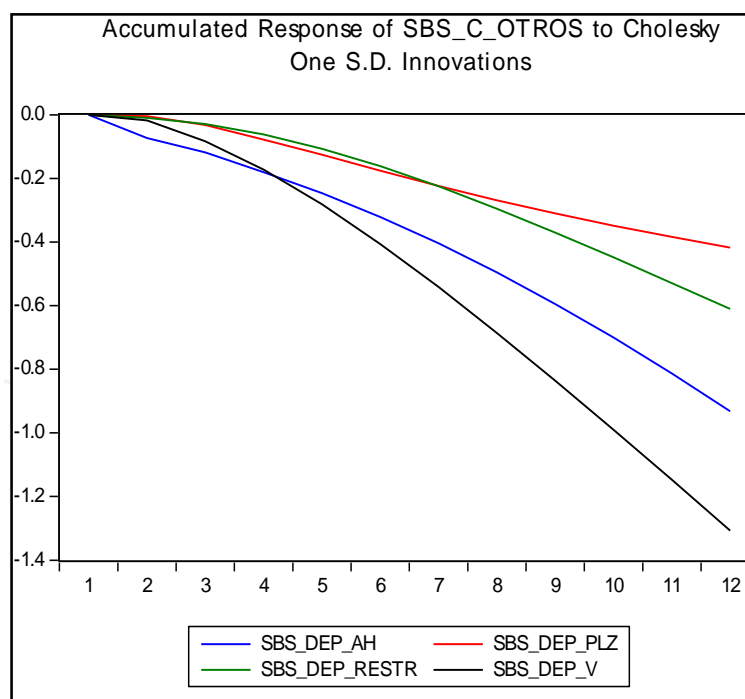

Accumulated Response of SBS_C_OTROS to Cholesky One S.D. Innovations

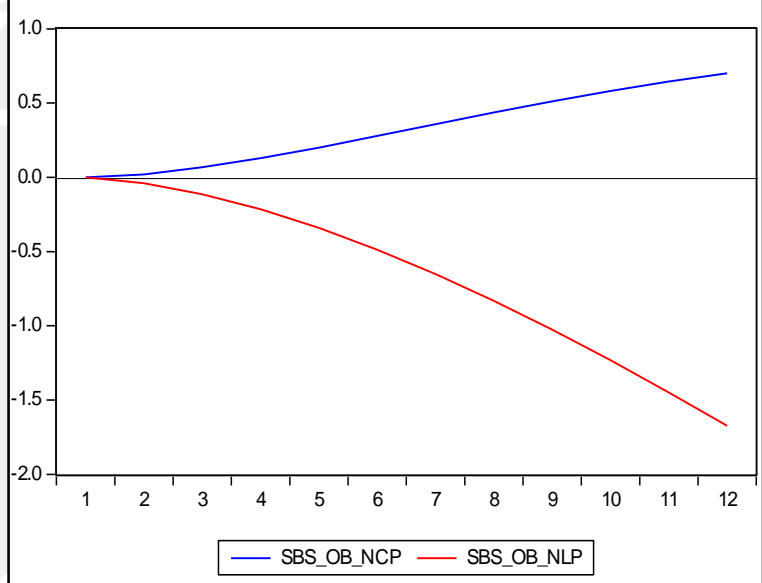

Accumulated Response of SBS_C_OTROS to Cholesky One S.D. Innovations

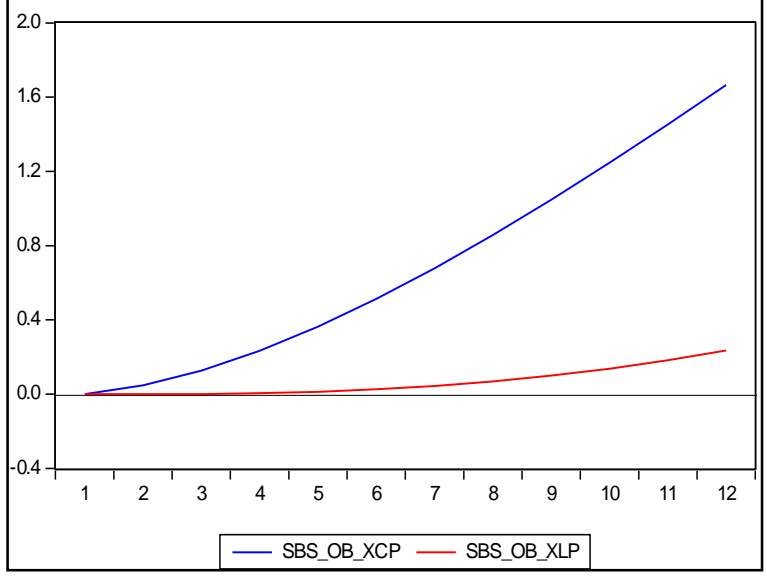


Figura 3.3.3. IR Hipotecarios

\section{para Vivienda}

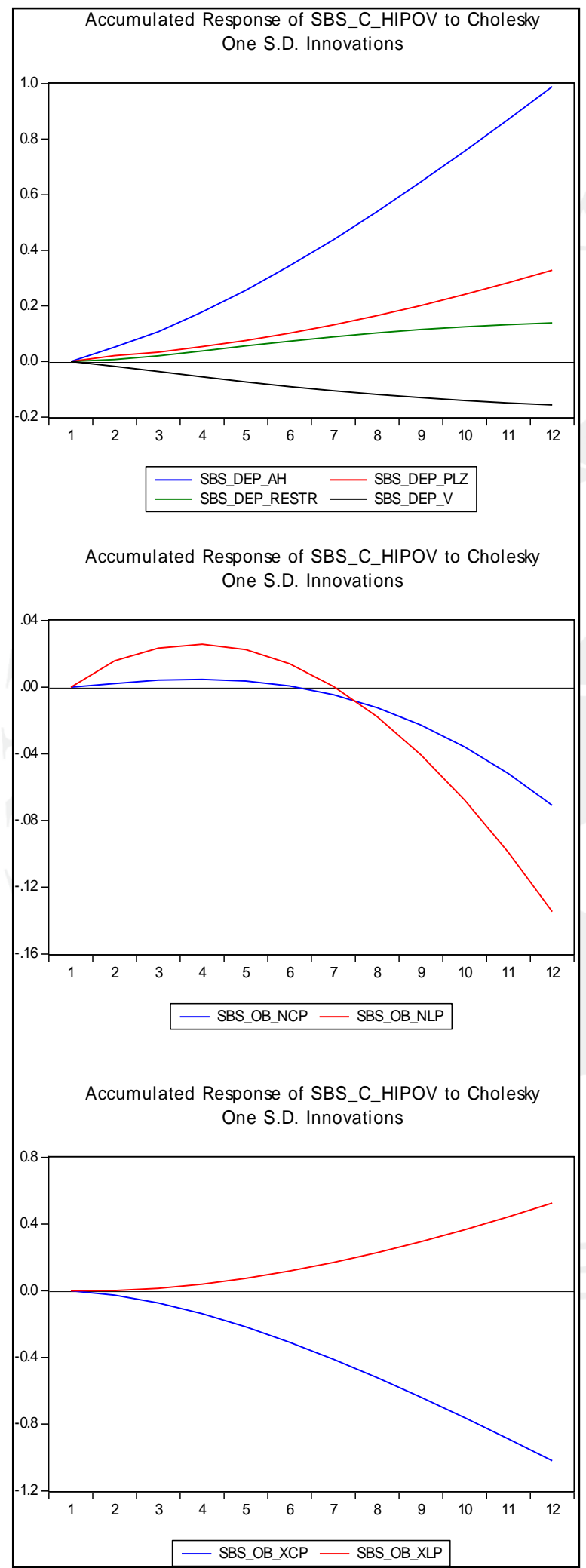

Figura 3.3.4. I R Descuentos

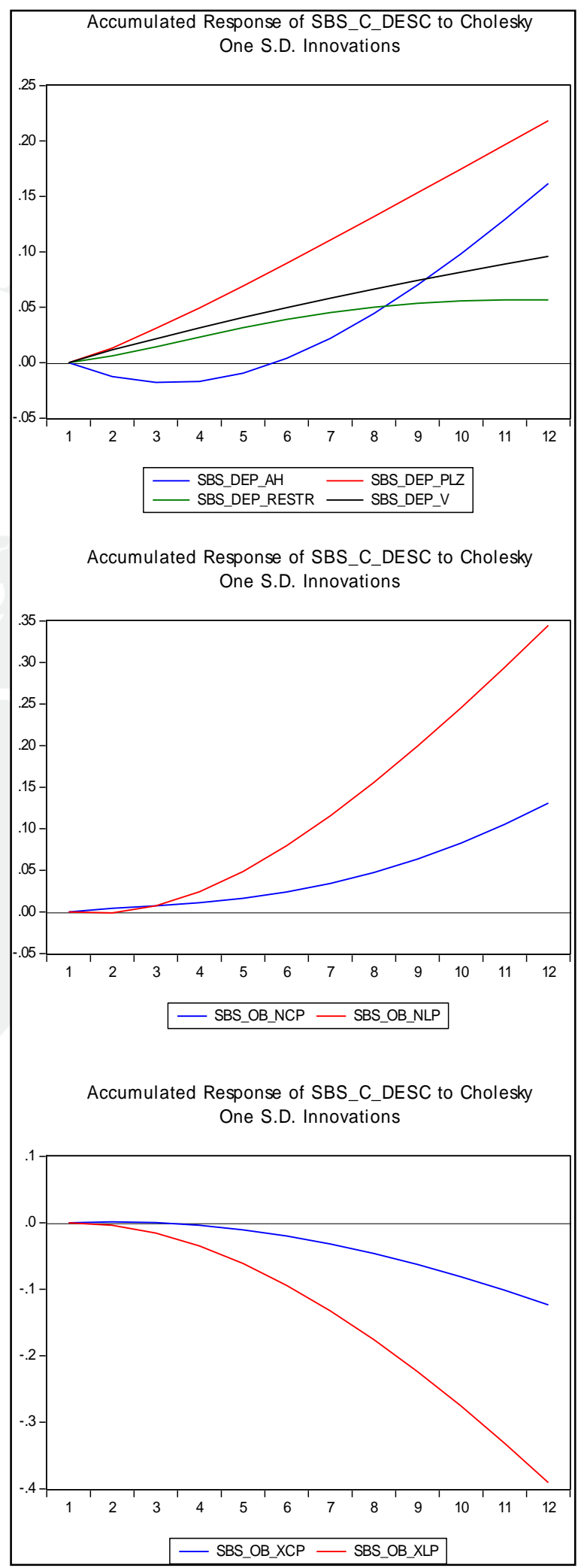


En el Figura 3.3.5 se observa el impacto sobre el Arrendamiento Financiero. En este caso, puede observarse que la variable que afecta positivamente los créditos por arrendamiento financiero, son los depósitos a plazo fijo. Esto se explica debido a que este depósito tiene un mayor umbral de tiempo retenido. En otras palabras, asumiendo que todo lo demás se mantiene constante, es posible afirmar que un incremento en los depósitos a plazo podría generar que los bancos se especialicen en arrendamiento financiero, dado que el porcentaje de estos sobre el total de la cartera podría incrementarse hasta en 40\%. Los demás tipos de depósito y el financiamiento mediante obligaciones nacionales de corto y largo plazo presentan un impacto negativo en los arrendamientos financieros. No obstante, las obligaciones externas parecen tener un impacto positivo y creciente sobre el otorgamiento de arrendamientos financieros, sobre todo las obligaciones de corto plazo. Esto se debe a que el arrendamiento financiero sirve para financiar activos productivos para las empresas que usualmente son exportados de notros países, por ello la necesidad del fondeo específico en una moneda distinta a la nacional.

En el caso de las Cuenta Corrientes en el Figura 3.3.6, los shocks positivos en los depósitos no afectan a este tipo de cuentas de crédito, salvo en el caso de los depósitos a la vista, con un efecto mixto: Negativo en los dos primeros meses y luego positivo el siguiente mes. Únicamente si aumentarán los depósitos a la vista se podría observar un incremento estable de las cuentas corrientes. Esto podría reflejar el interés de los bancos en calzar los periodos de vencimiento de obligaciones y acreencias. Cabe precisar que los depósitos de ahorro tienen un impacto positivo muy leve y no sostenible sobre las cuentas corrientes; por el contrario, los depósitos restringidos presentan un impacto inicialmente negativo hasta el cuarto mes, pero luego la dinámica se invierte. Las cuentas corrientes reducirían su participación en $16 \%$ menos si es que existiera un incremento de los depósitos a plazo u obligaciones nacionales de 
corto plazo. Se observa que si existe una relación positiva con el fondeo por obligaciones extranjeras en corto plazo, esto responde a que las operaciones puntuales se fondearían con moneda extranjera.

Vemos en el Figura 3.3.7 el impacto sobre las Tarjetas de Crédito. Se observa q existe un fuerte relación negativa con los Depósitos a plazo y obligaciones a largo plazo. Es interesante revisar que en el caso de las obligaciones con entidades del extranjero a largo plazo la relación resulta ser positiva.

En el Figura 3.3.8 se registra el impacto en el Factoring. A comparación a otros productos, no existen impactos significativos con las fuentes de Fondeo. Dentro de todo, el mayor impulso que pude recibir sería por fondeo con obligaciones de entidades nacionales a largo plazo. 
Figura 3.3.5. IR Arrendamiento

Financiero

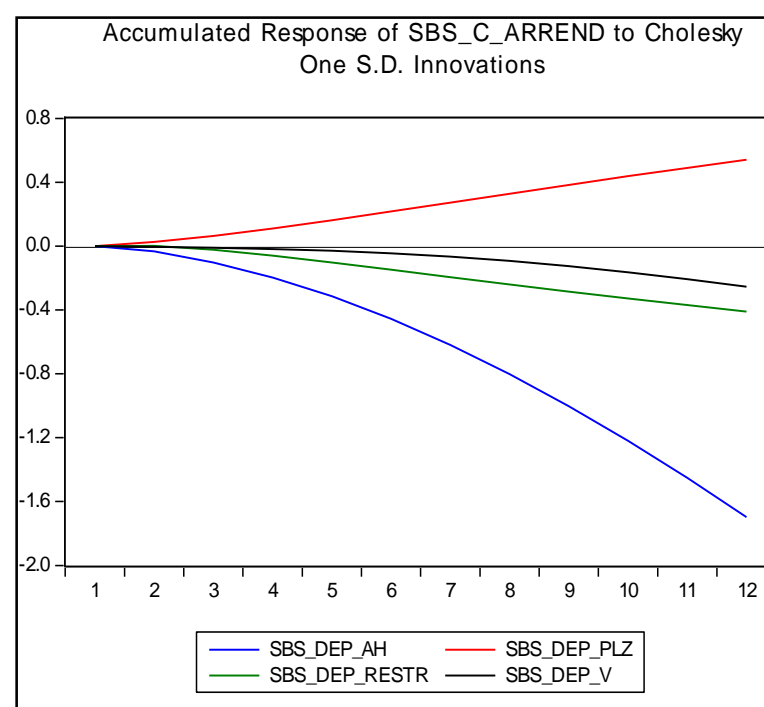

Accumulated Response of SBS_C_ARREND to Cholesky One S.D. Innovations

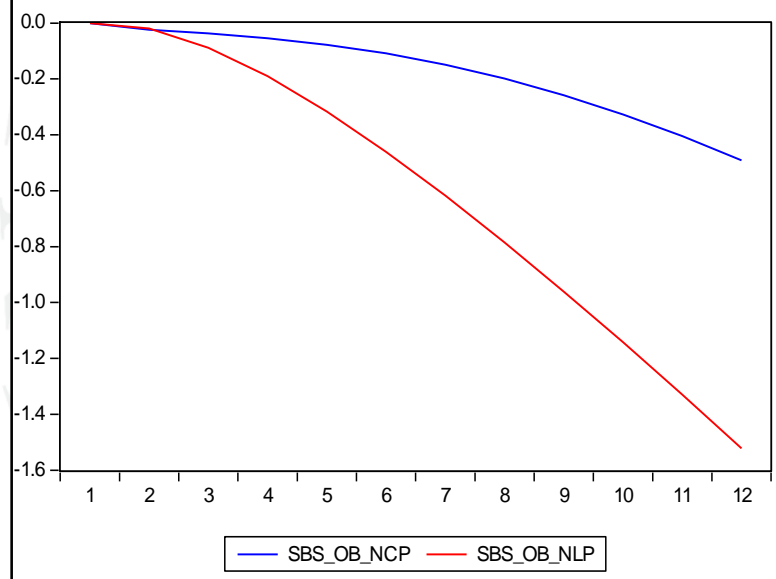

Accumulated Response of SBS_C_ARREND to Cholesky One S.D. Innovations

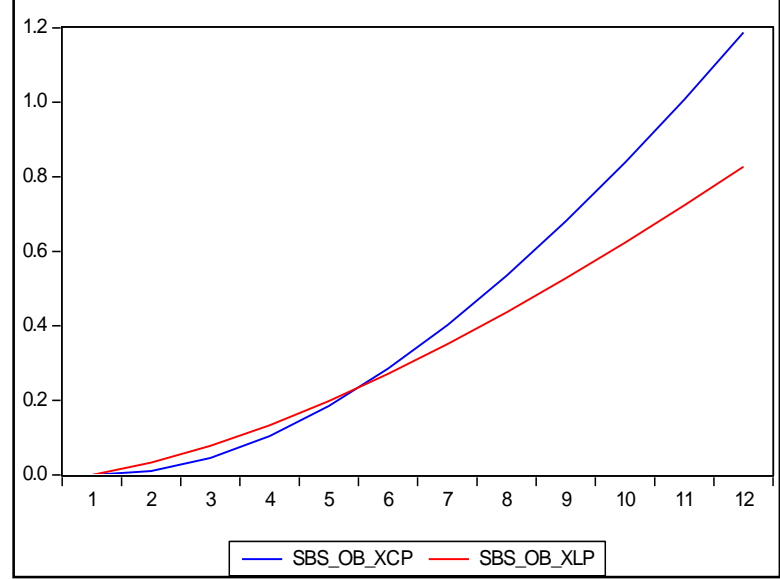

\subsubsection{R Cuentas Corrientes}

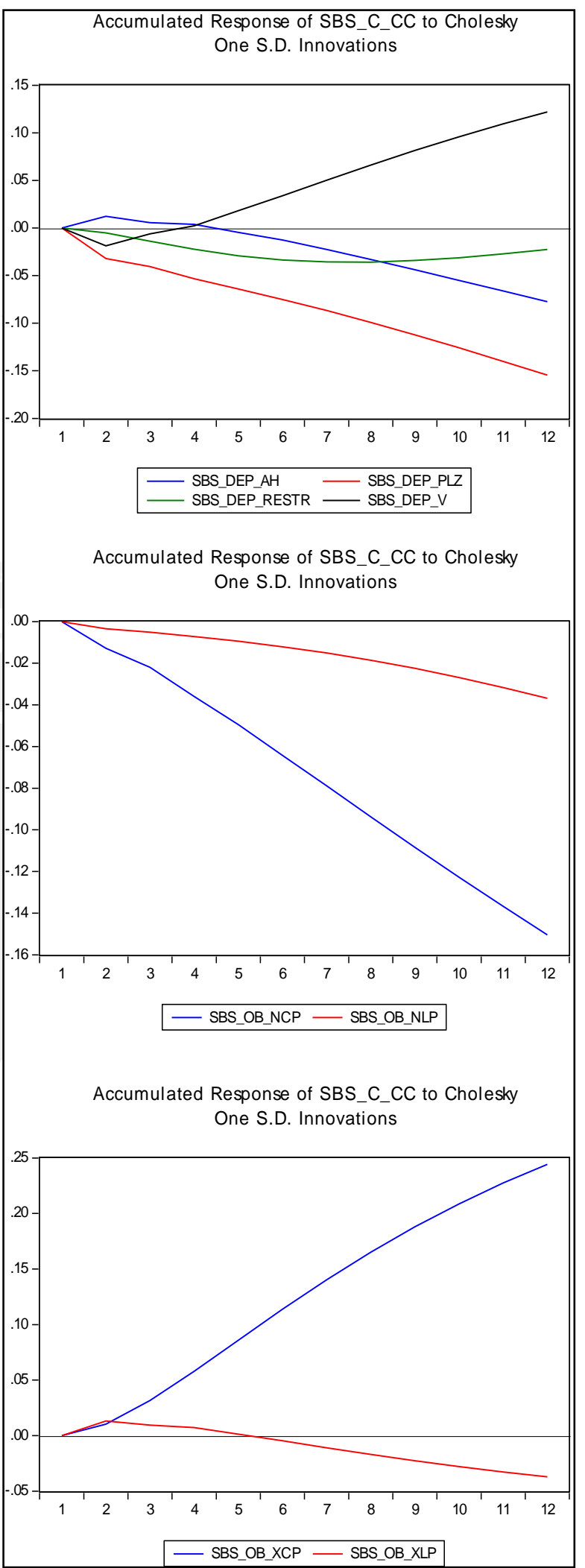


Figura 3.3.7. IR Tarjetas de

\section{Crédito}

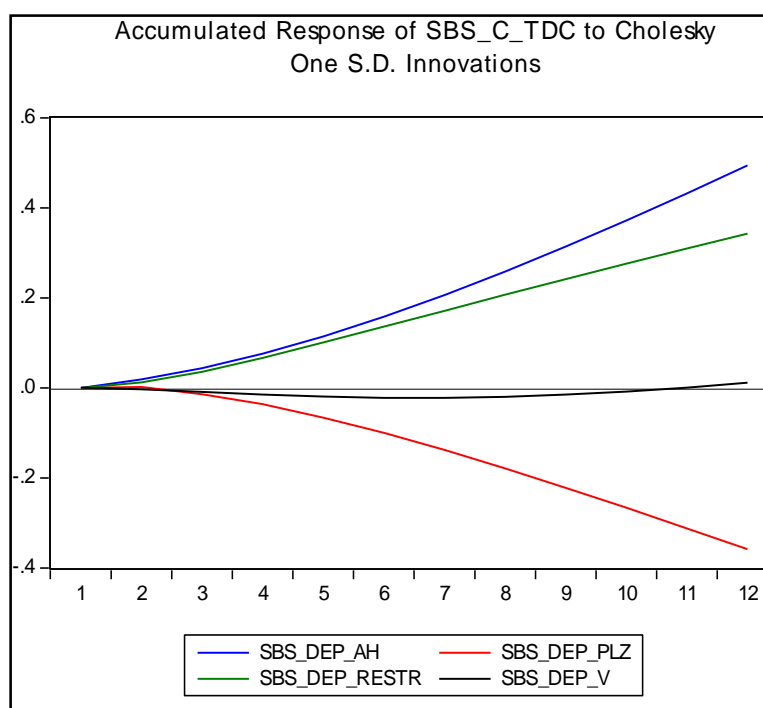

Accumulated Response of SBS_C_TDC to Cholesky One S.D. Innovations

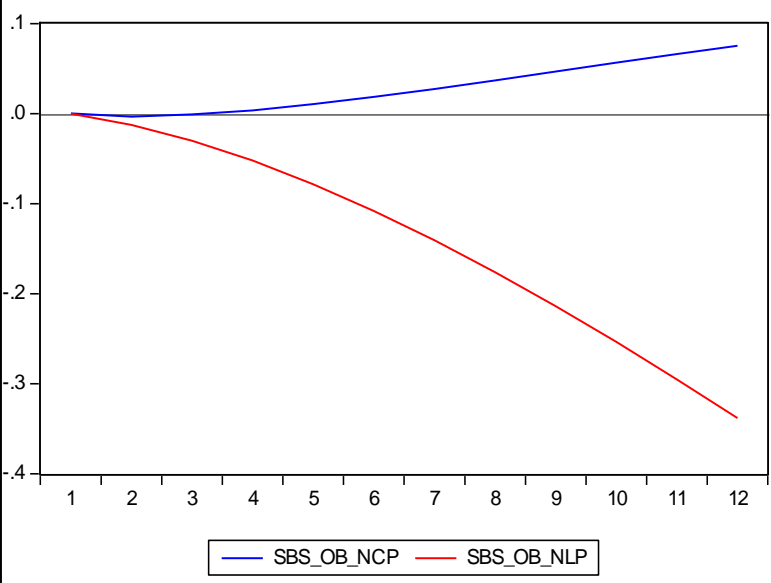

Accumulated Response of SBS_C_TDC to Cholesky One S.D. Innovations

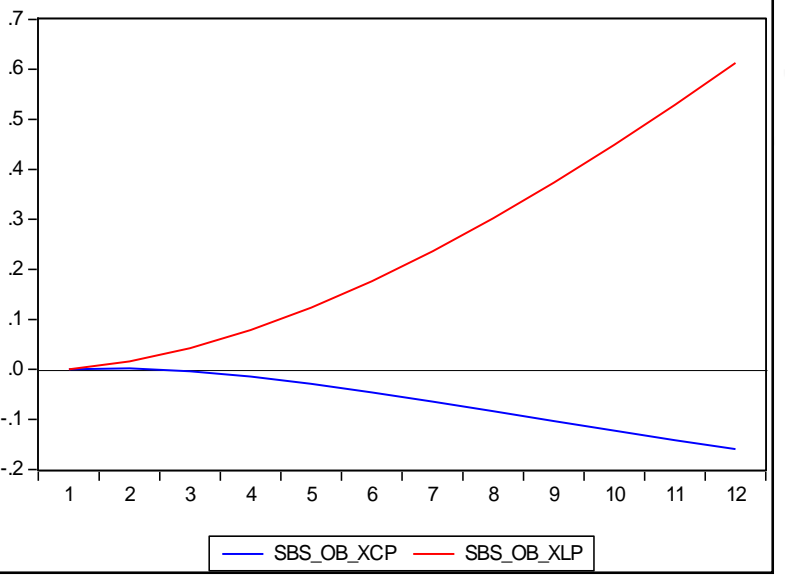

\subsubsection{R Factoring}

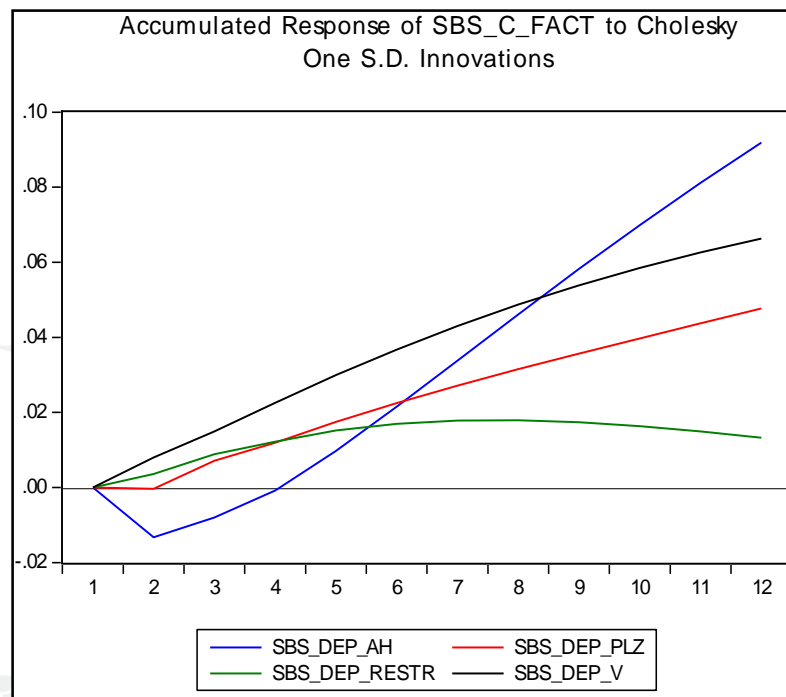

Accumulated Response of SBS_C_FACT to Cholesky One S.D. Innovations

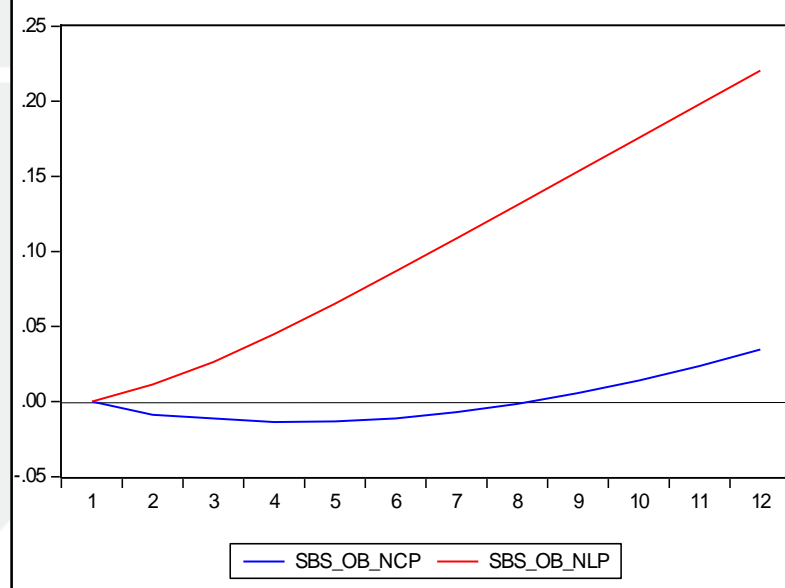

Accumulated Response of SBS_C_FACT to Cholesky One S.D. Innovations

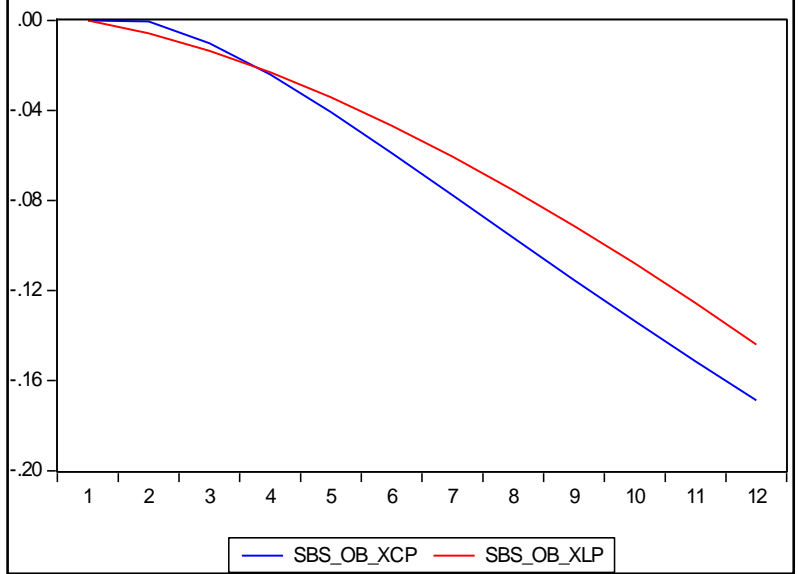


Tabla 3.3.3

Resultados medidos en desviaciones acumuladas. Resultados del stress a 12 meses según impulso-respuesta- medido en desviaciones acumuladas en Valores Absolutos

\begin{tabular}{|c|c|c|c|c|c|c|c|c|}
\hline & $\begin{array}{l}\text { STRESS } \\
\text { Dep. } \\
\text { Ahorros }\end{array}$ & $\begin{array}{l}\text { STRESS } \\
\text { Dep. } \\
\text { Plazo }\end{array}$ & $\begin{array}{l}\text { STRESS } \\
\text { Dep. } \\
\text { Restringidos }\end{array}$ & STRESS & $\begin{array}{l}\text { STRESS } \\
\text { Inst. del } \\
\text { País } \\
\text { Corto } \\
\text { Plazo }\end{array}$ & $\begin{array}{l}\text { STRESS } \\
\text { Inst. del } \\
\text { País } \\
\text { Largo } \\
\text { Plazo }\end{array}$ & $\begin{array}{l}\text { STRESS } \\
\text { Inst. del } \\
\text { Exterior } \\
\text { Corto } \\
\text { Plazo }\end{array}$ & $\begin{array}{l}\text { STRESS } \\
\text { Inst. del } \\
\text { Exterior } \\
\text { Largo } \\
\text { Plazo }\end{array}$ \\
\hline Préstamos & 0.70 & 0.09 & -0.20 & 0.54 & 1.36 & 1.64 & -2.16 & -1.09 \\
\hline Otros & -0.93 & -0.42 & -0.61 & -1.31 & 0.70 & -1.67 & 1.67 & 0.23 \\
\hline Hipotecarios & 0.99 & 0.33 & 0.14 & -0.16 & -0.07 & -0.13 & -1.02 & 0.53 \\
\hline Descuentos & 0.16 & 0.22 & 0.06 & 0.10 & 0.13 & 0.34 & -0.12 & -0.39 \\
\hline Arrend. Financiero & -1.70 & 0.54 & -0.41 & -0.25 & -0.49 & -1.52 & 1.19 & 0.83 \\
\hline Cuentas Corrientes & -0.08 & -0.15 & -0.02 & 0.12 & -0.15 & -0.04 & 0.24 & -0.04 \\
\hline Tarjetas de Crédito & 0.49 & -0.36 & 0.34 & 0.01 & 0.08 & -0.34 & -0.16 & 0.61 \\
\hline Fáctoring & 0.09 & 0.05 & 0.01 & 0.07 & 0.03 & 0.22 & -0.17 & -0.14 \\
\hline Agregado & -0.27 & 0.29 & -0.69 & -0.88 & 1.59 & -1.50 & -0.54 & 0.54 \\
\hline
\end{tabular}

Al momento de resumir los impactos acumulados revisamos que a partir de cada tipo de préstamos existen distintas respuestas antes las variaciones en las clases de pasivos. Hay que tomar en consideración que existen más variables que entran en juego al momento de decidir la composición del portafolio en la práctica, como puede ser la demanda por dinero o la estrategia de colocación de créditos del negocio.

Observamos en la vista agregada que el impacto acumulado por instituciones de exterior de corto plazo contrarresta a la variación por largo plazo. Esto obedece al hecho de que el fondeo con el exterior se utiliza en situaciones específicas para calzar la hoja de balance del banco, mientras que el endeudamiento con el exterior a largo plazo en los últimos años ha servido para satisfacer la demanda e incrementar el volumen de los portafolios de créditos. En relación a los adeudos de corto y largo plazo con las instituciones del país, el impacto neto es positivo y nos indica que ante una variación de las obligaciones con estas instituciones, los portafolios de créditos aumentan. Por lo tanto, se comprueba la hipótesis de que el impacto por una variación de los adeudos y 
obligaciones con las instituciones del país es mayor que con las instituciones del exterior.

En la primera prueba de estrés de riesgo crédito se buscó verificar si ante un escenario de estrés, existe mayor dependencia por impacto por variables endógenas o exógenas a la economía local. Se reveló que el impacto por el estrés en la variable PBI es de mayor dimensión que el del spread de tasas y las tasas de largo plazo. Esto se vislumbra en los gráficos de Impulso Respuesta acumulado (Figura 3.1.12 Impulso Respuesta) y en la distribución de probabilidades (Figura 3.1.17 Detalle del Impacto en la distribución para la Tasa Deterioro). Se interpreta que existe un mayor impacto en la tasa de deterioro de la banca múltiple por la variación de las variables endógenas a la economía local; corroborándose la hipótesis planteada. Sin embargo cuando se analizó el caso para las provisiones, se verificó que el mayor impacto proviene por las variaciones en la tasa de largo plazo (RL), lo que significó que se desestima la hipótesis para este caso debido a que se comprueba que una variable exógena a la economía posee un mayor impacto. El resumen de los impactos absolutos por variable se muestra en la Tabla 3.1.15 Resultados medidos en desviaciones acumuladas.

Para la segunda prueba de estrés de riego mercado se buscó determinar si el margen financiero de la banca múltiple es sensible a variaciones del PBI y de las tasas de interés activas e interbancarias en moneda nacional y extranjera. Se halló que el mayor impacto lo provoca una fluctuación del PBI con lo que se comprueba la Hipótesis de que las ganancias por los préstamos están más relacionadas al contexto económico local. Los resultados del análisis impulso respuesta se resumen por variable estresada en la Tabla 3.2.7. Resultados medidos en desviaciones acumuladas 
En la tercera prueba de estrés de riesgo de liquidez se analizó si ante una contracción del canal de financiamiento en la banca múltiple; existe un mayor impacto por la falta de fondeo proveniente de adeudos y obligaciones con instituciones de origen nacional que de instituciones de origen externo. Se determinó a través la creación de funciones impulso respuesta, donde los impulso son las fuentes de financiamiento y las respuesta son los créditos, el impacto en las composición del portafolio de créditos de la banca múltiple por la variación de los adeudos y obligaciones financieras con instituciones del país es mayor a las intuiciones del exterior. Con esto se verifica la hipótesis planteada para la prueba de estrés de riesgo de liquidez. Esto se muestra en la Tabla 3.3.3 Resultados medidos en desviaciones acumuladas. Resultados del stress a 12 meses -según impulso-respuesta- medido en desviaciones acumuladas en Valores Absolutos 


\section{CONCLUSIONES}

Las conclusiones son individuales e independientes entre sí ya que apuntan al estudio y análisis de distintos clases de riesgo.

- Prueba de Estrés de Riesgo de Crédito:

Como objetivo se buscó modelar la interacción de los indicadores de riesgo crédito como la tasa de deterioro y la tasa de provisiones en relación a variables endógenas y exógenas de la economía local. A partir de ello, se formuló la hipótesis de que el impacto de las variables endógenas de la economía del país era el más significativo. En este caso, se aplicó un modelo impulso respuesta para determinar si el PBI, el spread de tasas y la tasa de largo plazo impactaban en los indicadores de la tasa de deterioro y la tasa de provisiones. Para el ejercicio, el PBI representa a las variables endógenas de la economía local; mientras que el spread de tasas y la tasa de largo plazo son variables exógenas las cuales son el resultado de las transacciones en el mercado financiero internacional.

A partir del resultado agregado del modelo impulso respuesta medido en desviaciones acumuladas a doce meses se afirma lo siguiente:

El impacto en la tasa de deterioro por una variación del PBI es mayor al de una variación del spread o de la tasa de largo plazo; por lo tanto la evolución de la cartera deteriorada (alto riesgo) depende más de factores internos que factores externos. Esto implica que se corrobora la hipótesis de la prueba de riesgo crédito. Se concluye que el deterioro de los portafolios de créditos 
directos en el Perú está más ligado a la evolución de la economía y no a variaciones de las tasas que encarecerían el valor de los préstamos.

Para el caso de la tasas de provisiones, las variables exógenas juegan un papel mayor ya que su impacto es más significativo. Esto quiere decir que el nivel de provisiones asignado para los portafolios de crédito obedece o se ve influenciado en mayor proporción por una variable exógena. Por lo tanto, se rechaza la hipótesis en este caso. Ya que la metodología exacta de aprovisionamiento en la práctica pertenece a cada banco de manera interna, sería lógico que esta se vea afectada por más variables que las recogidas por el modelo. Esto debido a que en la práctica los bancos aprovisionan por encima del nivel regulatorio; por lo que sus medidas de respaldo adicional deben de responder al contexto del mercado financiero.

- Prueba de Estrés de Riesgo de Mercado

Se buscó determinar si existe un riesgo significativo de impacto por variación de las tasas de interés en la evolución de las ganancias de los bancos. Dado que la fluctuación de las tasas obedece al contexto económico global, es importante calcular escenarios de estrés sobe estas variables. A razón de ello, se modeló la interacción del margen financiero con variables endógenas y exógenas a la economía del país. Se formuló la hipótesis de que el margen financiero de la banca múltiple no es sensible a variaciones en las tasas, sino a la evolución del PBI.

Para la prueba de riesgo mercado analizamos si existía un mayor impacto por una variación del PBI que de las tasas. Registramos el caso de que la tasa interbancaria en moneda nacional si repercute de manera negativa en el resultado del Margen Financiero, pero en menor dimensión que el PBI. Por lo tanto, acorde con la hipótesis, se concluye que la variación de las tasas no genera una variación brusca en el margen financiero. Se debe de tomar en consideración los movimientos de la Tasa de Referencia del Banco Central 
debido a que repercuten en la tasa interbancaria, la cual si demostró poseer una relación negativa con las ganancias de los bancos.

- Prueba de Estrés de Riesgo de Liquidez

Se estudió si ante la variación en los adeudos y obligaciones con las instituciones del exterior del país existe el riesgo de impacto en la composición y volumen de los créditos. Se planteó la hipótesis de que los adeudos y obligaciones con las entidades del país poseen un mayor impacto a comparación de los adeudos y obligaciones con entidades del exterior. También se incluyó en el modelo la relación con los depósitos.

Se concluyó, en concordancia con la hipótesis, que el mayor impacto lo registrarían las instituciones del país. Lo que explica que a pesar de la apertura internacional de los últimos años y de la expansión de las obligaciones con entidades del exterior, el mayor impacto ocurriría con una contracción de los flujos de fondos con instituciones nacionales.

- Conclusión a partir de los resultados agregados de las Pruebas de Estrés

Siendo así, ante un escenario adverso en la banca de operaciones múltiples del Perú con horizonte de 12 meses, no existiría un efecto o impacto significativo de las variables exógenas a la economía del país sobre la tasa de deterioro, el margen financiero y en los portafolios de Créditos Directos. Sin embargo, no se puede afirmar lo mismo para el caso de la tasa de provisiones. Finalmente, en un escenario de estrés, las variables exógenas a la economía del país no desestabilizaría la tendencia que ya registran los indicadores de riesgo en la banca de operaciones múltiples del Perú. 


\section{RECOMENDACIONES}

A continuación detallaremos las recomendaciones:

A partir de los resultados de las pruebas, se rescata la importancia de la variable PBI para la construcción de modelos y escenarios dentro del esquema de regulación de los Bancos. Por lo tanto, se recomienda la incorporación de indicadores macroeconómicos locales para la identificación y cuantificación del riesgo de crédito. Ejemplo de ello son las alertas tempranas ante fluctuaciones en los indicadores o esquemas de seguimiento continuo. La incorporación de estos indicadores debe impactar en todos los procesos y decisiones de la organización. Esto repercutiría en un apetito de riesgo condicionado a la evolución de los indicadores económicos locales y en estrategias más acordes a los ciclos económicos. Esto con la finalidad de que los Bancos pueden anticiparse y adaptarse mejor a los escenarios adversos y puedan reajustar sus estrategias de manera más eficiente. No olvidemos que las instituciones bancarias cumplen un rol crucial en el desarrollo de la economía y los mercados como intermediarios entre los diversos agentes.

Para que los modelos de pruebas de estrés no se hallen limitados a su interpretación de la realidad, se recomienda en futuros ejercicios incluir distintas variables para la estimación y reproducción de más escenarios. Debido a que solo se está utilizando el PBI como variable endógena de la economía en este trabajo, se recomienda el uso de variables índice que expliquen mejor el desarrollo local y no limiten al modelo. Para la construcción de futuros modelos hay que considerar lo señalado en el punto 1.3 Literatura correspondiente a las pruebas de estrés; donde se mencionan modelos con variables como dolarización, calidad de información disponible, niveles de deuda promedio y cobertura garantías. Aparte, para explicar determinados impactos aislados se 
puede utilizar indicadores como inclusión financiera, cantidad de bancos, volúmenes de transacción o nivel de empleo e inflación.

En el caso de la prueba de estrés de riesgo de mercado, sería aconsejable determinar el efecto aislado de la tasa de referencia del Banco Central sobre las ganancias de los Bancos de operaciones múltiples ya que esta tasa determina la evolución de los préstamos interbancarios en el mercado.

Para la prueba de estrés de riesgo de liquidez, se recomienda hacer un modelo VAR en niveles parra que no exista el problema de matrices singulares y con dichos datos hacer un modelo econométrico para poder realizar las interpretaciones respectivas.

En el Perú, se necesita que las entidades reguladores realicen Programas de Pruebas de Estrés a todo el sistema financiero y publiquen sus resultados. No solo se deben limitar a las instituciones bancarias, sino también incluir a los demás intermediarios del sistema financiero. Ello debido a que en el Perú existe un sector importante conformado por micro y pequeñas empresas que son atendidas por las cajas rurales, municipales y financieras. Las pruebas de estrés deben de adaptarse al contexto económico real para brindar resultados fehacientes a la coyuntura. Sin embargo, el primer paso lo deben dar las mismas entidades financieras. Por ello, como se mencionó en la introducción del presente trabajo, la regulación no es un trabajo que solo compete a las entidades públicas sino es deber de todos los participantes y debe ser interiorizado en la gestión administrativa.

Se demostró que ante un escenario adverso por variación de variables exógenas a la economía local no se generaría un impacto mayor al producido por variables endógenas a la economía local; sin embargo esto no restringe el hecho de que se pueden producir pérdidas económicas en ambos escenarios. En respuesta, igual es necesario afinar y expandir las metodologías de gestión del 
riesgo en todas las direcciones posibles ya que la evolución de la banca múltiple en la última década ha sido acelerada. A su vez, hay que señalar que, a comparación de otras economías, el Perú recién se está insertando en el mercado financiero global; por lo que su exposición en relación al exterior se extenderá más e implicará la aparición de nuevas clases de riesgos. 


\section{REFERENCIAS}

Aguilar, Camargo \& Morales (2004). Análisis de la Morosidad en el Sistema Bancario Peruano Informe final de investigación. Instituto de Estudios peruanos.

ASBANC (2011). BASILEA III: principales cambios. ASBANC Año 1 N 11

Banco Central de Reserva del Perú (2011). Glosario de términos Económicos.

Banco Central de Reserva del Perú (2009). Folleto institucional.

Barrera, Jorge (2009). La percepción del riesgo y su relación con la actual crisis financiera global. Universidad Nacional Mayor de San Marcos.

Pensamiento Crítico N. ${ }^{\circ}$, pp. 11-26.

Basel Committee on Banking Supervision (2004). International Convergence of Capital Measurement and Capital Standards: A Revised Framework. Bank of international settlements.

Basel committee on Banking Supervision (2013). Liquidity stress testing: a survey of theory, empirics and current industry and supervisory practices. Working paper N4.

Basel Committee on Banking Supervision (2009) Principles for stress testing practices and supervision. Bank for International Settlements.

Bazerque (2011). Probabilidad de Default de los Créditos Bancarios en una Economía Dolarizada. Universidad de Montevideo

Bearing Point (2011). Liquidity Risk stress testing. White Paper .Bearign Point $\mathrm{GmbH}$.

Bikhchandani, Sushil \& Sharma, Sunil (2001). Herd Behavior in Financial Markets. IMF Staff Papers Vol. 47, No. 3.

Board of governors of the Federal Reserve System (2014). Dodd-Frank Act stress test 2014: supervisory stress test methodology and results. Marzo 2014.

Calvo, Guillermo (2012). Creación y destrucción de liquidez: Claves de la coyuntura y las crisis financieras en general. Perspectivas del sistema financiero N 104.

Céspedes, Nikita (2014). Competencia de intermediarios financieros en Perú. Banco Central de Reserva del Perú Serie de Documentos de Trabajo.

Cosimano, Thomas \& Hakura, Dalia (2011). Bank Behavior in Response to BASEL III: A Cross Country Analysis. IMF Institute, IMF Working Paper. 
Dancourt, Oscar (2013).Reglas de política monetaria y choques externos en una economía semidolarizada". Economía Vol XXXVI No 72.

Dell'Ariccia, Marquez. (2008). Credit Booms and Lending Standards: Evidence from the Subprime Mortgage Market. IMF Working Paper Research Department

De Haan, van den End \& Vermeulen (2015). Lenders on the storm of wholesale funding shocks: Saved by the central bank? De Nederlandsche Bank, Economics and Research Division.

European Banking Authority (2014). Methodology EU Wide stress test. Ver 1.8.

Deloitte (2012). Stresstesting de Riesgo de Crédito: Escenarios de riesgo de la banca chilena.Financial Advisory Services.

Fernández (2011). Credit growth, problem loans and credit risk provisioning in Spain.

Gonzales, Efraín (2007). La economía política peruana de la era neoliberal 19902006. Pontificia Universidad Católica del Perú

Hoggarth, Glenn; Sorensen, Steffen \& Zicchino, Lea (2005). Stress tests of UK banks using a VAR approach. Bank of England. Working Paper no. 282

Hwang, Soosung \& Salmon, Mark (2014). Market Stress and Herding. Sungkyunkwan University \& University of Cambridge. CEPR Discussion Paper No. 4340.

IMF Monetary and Capital Markets Department (2013). Technical notes on stress testing banks. Washington D.C.: IMF Publication of financial sector Assessment Program Documentation.

IMF (2013). Brazil: Technical Note on Stress Testing the Banking Sector.Washington D.C.: IMF Publication of financial sector Assessment Program Documentation. Country Report No. 13/147.

Jara, Luna \& Oda (2007). Prueba de tensión de la banca en Chile.

Jobst, Andres, Ong, Li Lian \& Schmieder, Christian (2013). A framework for macro prudential bank solvency stress testing: applications to s-25 and other g-20 Country FSAP'S. IMF Monetary and Capital Markets Department, IMF Working Paper.

Pérez, Daniel \& Trucharte, Carlos (2012). Los ejercicios de estrés test: una experiencia reciente y reflexiones sobre su futuro. España: Departamento de estabilidad financiera del banco de España.

Sanahuja (2012). La Unión Europea y las finanzas globales. Madrid 
Sarkar Asani (2009). Liquidity Risk, Credit Risk, and the Federal Reserve's response to crisis. FEDERAL bank ok New York Staff Reports. Working paper06/2009.

Sims (1980). Econometrica. Vol 48

SBS (2011). Glosario.

Van den End (2006). Credit and liquidity risk of Banks in stress conditions. Analyses from a macro perspective.

Van den End, J.; Hoeberichts, M. \& Tabbae, M (2006). Modelling Scenario Analysis and Macro stress-testing.Netherlands: De Nederlandsche Bank NV.

Varotto, Simone (2011). Liquidity Risk, Credit Risk, market Risk and Bank Capital.ICMA Centre Discussion Papers on Finance DP2011-02.

Velarde, Julio (2001). Efectos de la crisis financiera internacional en la economía peruana 1997-1998: lecciones e implicancias de política económica. Ícono Comunicadores

Wong Eric Cho Hoi Hui (2009). A liquidity risk stress-testing framework with interaction between market and credit risks. Hong Kong Monetary Authority 


\section{BIBLIOGRAFÍA}

Bellod, José (2010). La crisis imposible: tragedia en tres actos. Contribuciones a la Economía EUMED.

Demirguc-Kunt, Detragiache (1998). The Determinants of Banking Crises in Developing and Developed Countries. Volume 45, Number 1

Freixas, X., B. Parigi, \& J.C. Rochet (2004). Systemic Risk, Interbank Relations, and Liquidity Provision by the Central Bank. Journal of Money Credit and Banking.

Heider,Florian; Hoerova, Marie; Holthausen, Cornelia (2009). Liquidity Hoarding and interbank market spreads. The role of counterparty risk. European Central Bank.

Kennedy (1981). Estimation with correctly interpreted dummy variables in semi logarithmic equations. American EcOnomic Review, 71.

Kovacs, Tunde (2004). The Pecking Order Theory and Time-Varying Adverse Selection Costs. Virginia Tech, Pamplin College of Business, Department of Finance.

Maddala (1983). Limited-Dependent and Qualitative Variables in Econometrics

Vennet, De jonghe y Baele (2004). Bank Risks and the Business Cycle. University of Ghent Working Paper No. 04/264

Webb, R., L. Conger y P. Inga (2009). El árbol de la mostaza, historia de las microfinanzas en el Perú. Universidad Particular San Martín de Porres, Instituto del Perú. 


\section{FUENTES}

- Banco Central de Reserva del Perú

Página Web: http://www.bcrp.gob.pe/ (revisado el 1 de mayo del 2015)

- Instituto Nacional de Estadística e Informática del Perú

Página Web: https://www.inei.gob.pe/estadisticas/indice-

tematico/economia/ (revisado el 1 de mayo del 2015)

- Superintendencia de Banca y Seguros

Página web: http://www.sbs.gob.pe/ (revisado el 1 de mayo del 2015)

- Board of Governors of the Federal Reserve System

Página Web: http://www.federalreserve.gov/ (revisado el 1 de mayo del 2015) 